Alberto Douglas Silva Cavalcante

MODELAGEM NUMÉRICA DE ESCAVAÇÕES DE TÚNEIS EM MACIÇOS EVAPORÍTICOS

VERSÃO CORRIGIDA

São Carlos

2012 



\section{MODELAGEM NUMÉRICA DE ESCAVAÇÕES DE TÚNEIS EM MACIÇOS EVAPORÍTICOS}

Dissertação apresentada à Escola de Engenharia de São Carlos, Universidade de São Paulo, como parte dos requisitos para obtenção do título de mestre em Geotecnia.

Área de concentração: Geotecnia

Orientador: Prof. Dr. Tarcísio Barreto Celestino

VERSÃO CORRIGIDA

São Carlos

2012 
AUTORIZO A REPRODUÇÃO TOTAL OU PARCIAL DESTE TRABALHO, POR QUALQUER MEIO CONVENCIONAL OU ELETRÔNICO, PARA FINS DE ESTUDO E PESQUISA, DESDE QUE CITADA A FONTE.

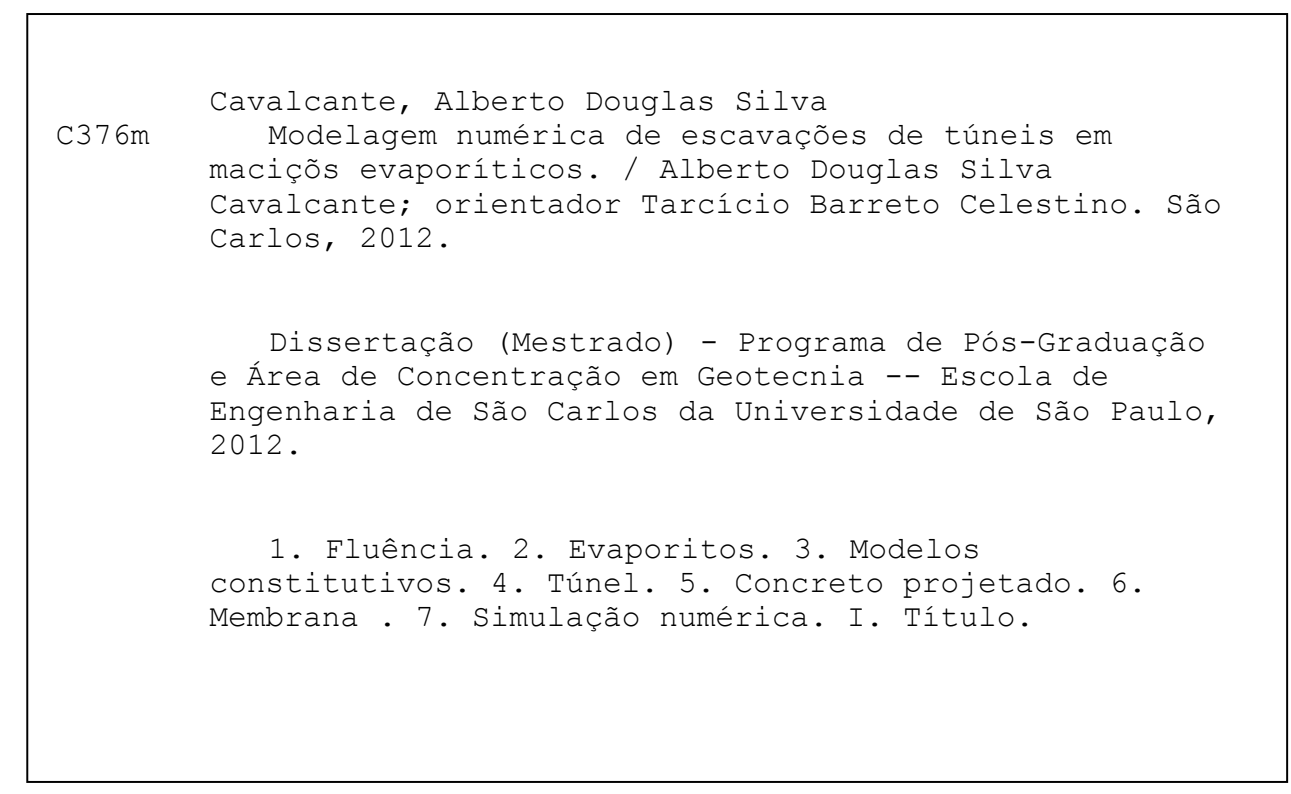


FOLHA DE JULGAMENTO

Candidato: Engenheiro ALBERTO DOUGLAS SILVA CAVALCANTE.

Título da dissertação: "Modelagem numérica de escavações de túneis em maciços evaporíticos".

Data da defesa: 28/09/2012

\section{Comissão Julgadora:}

\section{Resultado:}

Prof. Dr. Tarcísio Barreto Celestino (Orientador)

(Escola de Engenharia de São Carlos/EESC)

Prof. Dr. Antonio Airton Bortolucci

(Escola de Engenharia de São Carlos/EESC)

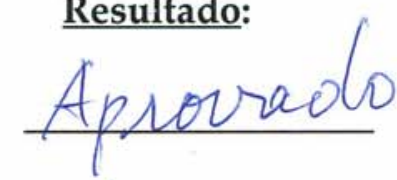

Prof. Dr. Osvaldo Luís Manzoli

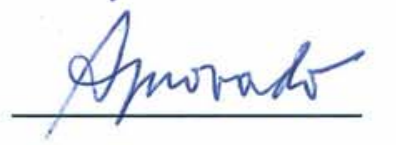

(Universidade Estadual Paulista "Júlio de Mesquita Filho"/UNESP-Bauru)

Coordenador do Programa de Pós-Graduação em Geotecnia:

Prof. Titular Osni José Pejon

Presidente da Comissão de Pós-Graduação:

Prof. Titular Denis Vinicius Coury 

Dedico este trabalho a minha família, pelo apoio e incentivo em todos os momentos da minha vida. Amo vocês! 


\section{AGRADECIMENTOS}

Ao Prof. Dr. Tarcísio Barreto Celestino, pela orientação, compreensão, incentivo e apoio durante toda a elaboração deste trabalho.

Ao Prof. Dr. Antônio Airton Bortolucci, pela ajuda com as pesquisas de artigos e teses durante todo o curso de pós-graduação.

A minha amiga Irene Maria Chaves Pimentel pela ajuda e sugestões para a melhoria do trabalho durante todo o mestrado.

Aos meus pais, Alberto e Edilma, e a minha irmã, Poliana pelo incentivo para que sempre chegasse aos meus objetivos. Lembrando ainda do amor, educação e carinho fundamentais para o fortalecimento da minha perseverança.

A minha namorada Lisdielly Melo por ter sido minha companheira. Mesmo longe estes dois anos, sempre esteve próxima com suas palavras de incentivo, carinho e amor.

Ao amigo Davyd Henrique agradeço pela relação durante o tempo que dividimos apartamento, problemas e conquistas. Sei que ganhei um grande amigo, na verdade o fortalecimento de uma amizade antiga desde os tempos de faculdade.

Aos primos, primas, tios e tias agradeço a força que me têm dado, força esta que me incentiva a voar cada vez mais alto.

Ao amigo Edson Falcão pela hospitalidade e hospedagem em minha chegada ao Rio.

A todos os amigos alagoanos, tanto no Rio quanto em São Carlos, por todos os momentos de descontração e alegrias.

Aos amigos que fiz no departamento (SGS), que já fazem parte da história da minha vida e com certeza nunca serão esquecidos.

A todos os professores, técnicos e demais funcionários do departamento de Geotecnia por ter contribuído direta ou indiretamente com este trabalho.

A SMARTTECH pela oportunidade e confiança durante este primeiro ano de empresa. Agradeço também a liberação da licença do Abaqus ${ }^{\circledR}$ para fins acadêmicos. 
A CAPES pela bolsa de estudos concedida durante 24 meses de mestrado.

Por fim, a Deus, minha maior fonte de força. 


\section{RESUMO}

CAVAlCANTE, A. D. S. (2011), Modelagem Numérica de Escavações de Túneis em Maciços Evaporíticos. São Carlos, 2011. Dissertação (Mestrado) - Escola de Engenharia de São Carlos, Universidade de São Paulo.

A precaução com a ruína em um material geológico submetido a altas tensões é um problema bastante comum na Geotecnia. Em um túnel, por exemplo, durante a escavação, é possível gerar uma perda de equilíbrio que pode levar à ruptura, fechamento e perda do mesmo. Quando a perfuração é feita em um maciço com características de deformabilidade dependentes do tempo, a redistribuição de tensões pode levar à ocorrência de grandes deformações em longo prazo. Esse fato se deve ao comportamento de fluência (Creep) do mesmo, que se caracteriza por uma deformação lenta e contínua sobtensão e temperaturas constantes. Tendo como fundamento a modelagem para melhor compreensão e controle desses problemas, este trabalho teve inicialmente por objetivo realizar simulações da interação de maciços evaporíticos com a estrutura de suporte, durante e após a escavação de um túnel. Ao longo do trabalho, vislumbrou-se a oportunidade de ampliar seu escopo para problemas mais gerais de interação maciço-suporte, detalhando-se também a interação entre camadas primária e secundária da estrutura de concreto. Assim, incorporaram-se resultados de análises com atrito limitado entre estruturas de suporte e o maciço, e de interação através da interface de uma membrana para impermeabilização aderente às duas camadas. Essas simulações foram realizadas utilizando o programa de elementos finitos Abaqus ${ }^{\circledR}$ e, em alguns casos, levou em conta a utilização de elementos de suporte no contorno do túnel.

Palavras-chave: Fluência, Evaporitos, Modelos Constitutivos, Túnel, Concreto Projetado, Membrana, Simulação Numérica. 


\section{ABSTRACT}

CAVAlCANTE, A. D. S. (2011), Numerical Modeling of Tunnel Excavation in Solid evaporite. MS.c. Thesis - São Carlos Engineering School, University of São Paulo, São Carlos.

Geotechnical engineers have been faced with difficult problems due to failure of geological materials caused by stresses exceeding the strength. The strain around a circular tunnel during and after excavation, for example, may lead to failure due to stresses redistribution. Particularly in rock masses with time-dependent deformation properties, the new stress field can lead to large strains in the long term or even to the closure of the tunnel due to creep behavior under constant stress and temperature. This work aimed originally at simulating the interaction of concrete support structures with evaporites identifying the effects of creep phenomenon in underground excavations. During the development of the work, it was decided to extend the scope to include other phenomena related to the interaction between the first and second layers of tunnel support structures. These include partial friction or the mechanical interface of a waterproofing sprayed membrane. For the development of the present study, numerical simulation of the time-dependent interaction between support and rock masses, during and after excavation of a tunnel were carried out with the commercial FEM software Abaqus ${ }^{\circledR}$, chosen due to its versatility for the solution of non-linear problems.

Keywords: Creep, Evaporites, Constitutive Models, Tunnel, Shotcrete, Membrane, Numerical Simulation. 


\section{LISTA DE SÍMBOLOS}

$\begin{array}{ll}A_{s} & \text { Área da seção transversal do suporte } \\ \alpha & \text { Fator de alívio } \\ a_{0}^{*}, a_{2}^{*}, a_{2}^{*}, b_{2}^{*} \mathrm{e} \hat{b} & \text { Parâmetros de Einstein e Schwartz (1979) }\end{array}$

$A, B, C$ e $D \quad$ Constantes empíricas

$A_{1}$

Constante

$A_{l}, n_{l}$ e $m_{l}$

Parâmetros da equação de fluência primária

$A_{2,} n_{2}$ e $m_{2}$

Parâmetros da equação de fluência secundária

$B_{1}, B_{2}$ e $q$

Constantes

$C^{*}$

Coeficiente de compressibilidade

$c_{m}$

Coesão do maciço

$\Delta \sigma$

Acréscimo de tensão

$\Delta \delta$

Acréscimo de deslocamento vertical

$\mathrm{D}$

Diâmetro escavado

$\varepsilon$

Deformação

$\dot{\varepsilon}$

Taxa de deformação ou fluência

$d \varepsilon$

Variação da deformação no intervalo de tempo

$d t$

Intervalo de tempo

$\dot{\varepsilon}_{0}$

Taxa de deformação de referência

$\varepsilon^{v}$

Deformação do elemento viscoso

$\dot{\varepsilon}^{v}$

Taxa de deformação do elemento viscoso

$\varepsilon^{e}$

Deformação do elemento elástico

$\varepsilon_{\infty}$

Deformação infinita

$\varepsilon_{p}$

Deformação do conjunto em paralelo

$\varepsilon_{s}$

Deformação do conjunto em série

$E_{\text {erro }}$

Somatório dos erros absolutos

$\varepsilon_{e}$

Deformação elástica

$\varepsilon_{f_{1}}$

Fluência primária ou transiente 


\begin{tabular}{|c|c|}
\hline$\varepsilon_{f_{2}}$ & Fluência secundária ou permanente \\
\hline$\ddot{\varepsilon}$ & Derivada segunda da deformação \\
\hline$E_{s}$ & Módulo de elasticidade do suporte \\
\hline$E_{m}$ & Módulo de elasticidade do maciço \\
\hline$E_{c}$ & Módulo de elasticidade do concreto \\
\hline$e$ & Espessura da membrana \\
\hline $\mathrm{E}$ & Módulo de elasticidade \\
\hline $\mathrm{E}_{1}$ & Módulo de elasticidade do elemento 1 \\
\hline $\mathrm{E}_{2}$ & Módulo de elasticidade do elemento 2 \\
\hline$F^{*}$ & Coeficiente de flexibilidade \\
\hline$\phi$ & Ângulo de atrito \\
\hline$\phi_{m}$ & Atrito do maciço \\
\hline$\varphi_{m}$ & Dilatância do maciço \\
\hline$g$ & Aceleração da gravidade \\
\hline$G_{m}$ & Módulo de cisalhamento do maciço \\
\hline$\gamma_{w}$ & Peso específico da água \\
\hline$\gamma$ & Peso específico \\
\hline$G$ & Módulo de cisalhamento \\
\hline$h$ & Profundidade (partindo do topo) \\
\hline $\mathrm{H}$ & Função degrau de Heaviside \\
\hline$I_{s}$ & Momento de inércia da seção transversal do suporte \\
\hline JRC & "Joint roughness coefficient" \\
\hline$K_{0}$ & Coeficiente de empuxo \\
\hline$k_{n}$ & Rigidez normal \\
\hline$k_{t}$ & Rigidez cisalhante \\
\hline$K, a, b, c e j$ & Constantes empíricas \\
\hline M & Momento fletor \\
\hline$m, n, p$ & Constantes empíricas \\
\hline$\mu$ & Coeficiente de atrito \\
\hline$\eta$ & Constante de viscosidade \\
\hline
\end{tabular}




\begin{tabular}{|c|c|}
\hline$\eta_{1}$ & Constante de viscosidade do elemento 1 \\
\hline$\eta_{2}$ & Constante de viscosidade do elemento 2 \\
\hline $\mathrm{P}$ e KP & Tensão inicial na direção vertical e horizontal \\
\hline$Q$ & Energia de ativação \\
\hline$\rho$ & Densidade do material \\
\hline$R$ & Raio do poço \\
\hline$r$ & Distância a partir do eixo do poço \\
\hline$\rho_{m}$ & Densidade do maciço \\
\hline$\rho_{c}$ & Densidade do concreto \\
\hline$R^{\prime}$ & Constante universal dos gases \\
\hline RMR & "Rock mass rating” \\
\hline$\sigma$ & Tensão desviadora \\
\hline$\sigma_{0}$ & Tensão desviadora de referência \\
\hline$\sigma^{y}$ & Tensão de escoamento \\
\hline$\sigma_{R}$ & Tensão radial no perímetro escavado \\
\hline$\sigma_{r}$ & Tensão radial no maciço \\
\hline$\sigma_{\theta}$ & Tensão tangencial no maciço \\
\hline$\sigma_{h}$ & Tensão horizontal \\
\hline$\sigma_{v}$ & Tensão vertical \\
\hline$\sigma^{v}$ & Tensão do elemento viscoso \\
\hline$\sigma^{e}$ & Tensão do elemento elástico \\
\hline$\sigma_{p}$ & Tensão do conjunto em paralelo \\
\hline$\sigma_{s}$ & Tensão do conjunto em série \\
\hline$\ddot{\sigma}$ & Derivada segunda da tensão \\
\hline$\sigma_{r}$ & Tensão normal efetiva na direção radial \\
\hline$\sigma_{\theta}$ & Tensão normal efetiva na direção tangencial \\
\hline$\sigma_{e f}$ & Tensão desviadora efetiva \\
\hline$\sigma_{c}$ & Tensão confinante \\
\hline
\end{tabular}




\begin{tabular}{|c|c|}
\hline$\sigma_{x}, \sigma_{y} \mathrm{e}^{\sigma_{z}}$ & Tensão nas direções $\mathrm{x}, \mathrm{y}$ e z \\
\hline$\sigma_{1}, \sigma_{2} \mathrm{e}^{\sigma_{3}}$ & Tensão na direção vertical e horizontal \\
\hline$\theta$ & Ângulo medido no sentido anti-horário do plano $x y$ a partir do eixo $x$ \\
\hline$\tau_{r \theta}$ & Tensão cisalhante no maciço \\
\hline$\tau_{\theta r}$ & Tensão cisalhante no plano $r \theta$ \\
\hline$\tau_{R \theta}$ & Tensão cisalhante no perímetro escavado \\
\hline$T_{0}$ & Temperatura inicial \\
\hline$\tau_{x y}, \tau_{x z} \mathrm{e}^{\tau_{y z}}$ & Tensões de cisalhamento nos planos xy, xz e yz \\
\hline$T$ & Temperatura absoluta \\
\hline$t$ & Tempo \\
\hline $\mathrm{T}$ & Esforço normal \\
\hline$t_{1}$ & Tempo de fluência primária \\
\hline$t_{2}$ & Tempo de fluência secundária \\
\hline$t_{\text {total }}$ & Tempo total de fluência \\
\hline$u_{\theta}$ & Deslocamento tangencial \\
\hline$u_{r}$ & Deslocamento radial \\
\hline$u_{s}$ & Deslocamento radial no suporte \\
\hline$u_{R}$ & Deslocamento radial no perímetro escavado \\
\hline$u_{w}$ & Pressão neutra da água \\
\hline$u$ & Deslocamento radial \\
\hline $\mathrm{U}$ & Deslocamentos \\
\hline$v_{R}$ & Deslocamento transversal no perímetro escavado \\
\hline$v_{s}$ & Coeficiente de Poisson do suporte \\
\hline$v_{m}$ & Coeficiente de Poisson do maciço \\
\hline$v_{c}$ & Coeficiente de Poisson do concreto \\
\hline$v$ & Coeficiente de Poisson \\
\hline $\mathrm{v}$ & Deslocamento transversal \\
\hline $\mathrm{V}_{\mathrm{s}}$ & Deslocamento transversal no suporte \\
\hline
\end{tabular}


$y_{i}$

$\bar{y}_{i}$

Valor de deformação do ensaio

Valor estimado no ajuste 


\section{LISTA DE ABREVIATURAS}

2D - Bidimensional

3D - Tridimensional

AC YIELD - Fator de plastificação

B21 - Elemento de viga de formulação linear bidimensional

B22 - Elementos de viga de formulação quadrática bidimensional

BEAM_STRESS, Mises - Tensão de Von Mises no suporte secundário

C3D10 - Elemento contínuo, tetraédrico-quadrático, com 10 nós

C3D8R - Elemento contínuo, tridimensional-linear, com 8 nós e integração reduzida

CAX4 - Elemento contínuo assimétrico, quadrilateral-linear, com 4 nós

COH2D4 - Elementos coesivos, bidimensional, com 4 nós

CPE3 - Elemento contínuo, plano deformado, triangular-linear, com 3 nós

CPE4 - Elementos contínuo, plano deformado, quadrilateral-linear, com 4 nós

CPE6 - Elemento contínuo, plano deformado, triangular- quadrático, com 6 nós

CPE8 - Elemento contínuo, plano deformado, quadrilateral-quadrático, com 8 nós

CSL - "Composite shell lining"

$\varepsilon_{p}$ - Deformação principal

E - Elástico

EP - Elastoplástico

$\mathrm{H}$ - Profundidade

LE, Max. Principal - Deformação máxima principal

NA - Nível d'água

PE, PE11 - Deformação plástica horizontal

PE, PE22 - Deformação plástica vertical

PEEQ - Deformação plástica equivalente

$\sigma_{\text {Mises }}-$ Tensão de Von Mises

S, Mises - Tensão de Von Mises

S, S11 - Tensão horizontal

S, S22 - Tensão vertical

S4R - Elemento "shell”, tridimensional, com 4 nós e integração reduzida

SF, SF1 - Esforço normal

SF, SF2 - Esforço cortante 
SM, SM1 - Momento fletor

SSL - "Single shell lining"

$t_{w}$ - Espessura do suporte

U - Deslocamento

U, Magnitude - Deslocamento resultante

U, U1 - Deslocamento horizontal

U, U2 - Deslocamento vertical

$\mathrm{V}-\mathrm{Viscoso}$

VE - Viscoelástico

VP - Viscoplástico 


\section{LISTA DE FIGURAS}

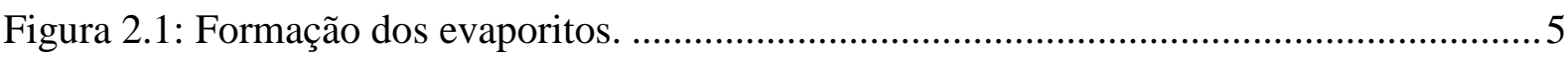

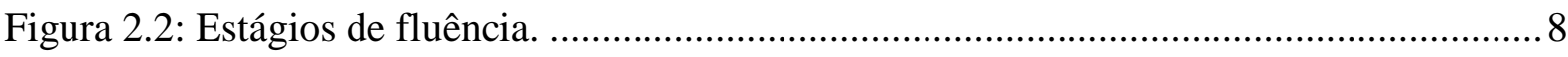

Figura 2.3: (a) Modelo Hookeano, (b) Modelo Newtoniano, (c) Modelo de Saint Venant. .... 16

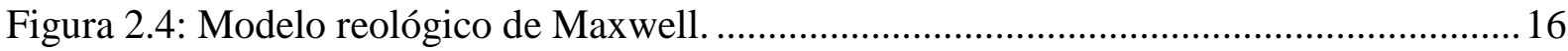

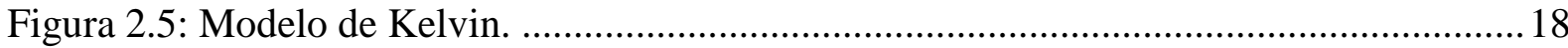

Figura 2.6: (a) Modelo de Maxwell generalizado, (b) Modelo de Kelvin generalizado.......... 19

Figura 2.7: Representação esquemáticas do modelo de Burgers..............................................20

Figura 2.8: Ensaio de fluência representado pelo modelo de Burgers. ......................................21

Figura 2.9: Comportamento geral de um modelo reológico elaborado de rochas salinas........ 22

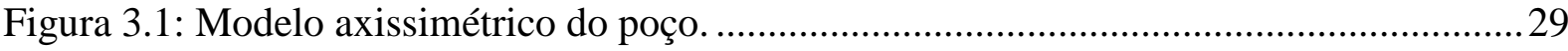

Figura 3.2: Deslocamento radial em cinco diferentes profundidades. .................................... 30

Figura 3.3: Tensões tangenciais em cinco diferentes profundidades. ...................................... 30

Figura 3.4: Tensões radiais em cinco diferentes profundidades.............................................. 31

Figura 3.5: Modelo plano de deformação do poço..................................................................... 31

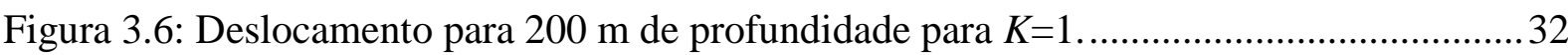

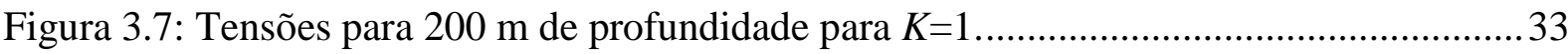

Figura 4.1: Notação para a solução de rigidez relativa de Einstein e Schwartz (1979). .......... 36

Figura 4.2:Convenção de sinais positivos para o esforço normal e momento fletor na seção do

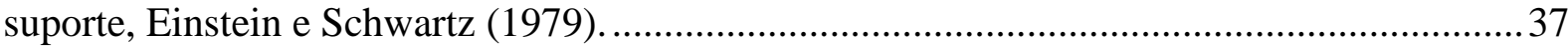

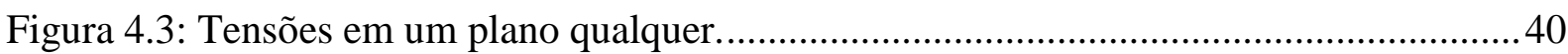

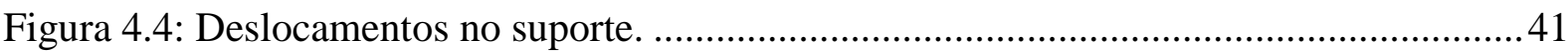

Figura 4.5: Malha do modelo (interação maciço-suporte). .................................................. 42

Figura 4.6: Tensão radial entre o maciço e o suporte ( "no slip")............................................. 43

Figura 4.7: Tensão cisalhante entre o maciço e o suporte ( "no slip"))....................................44

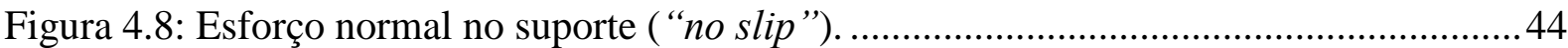

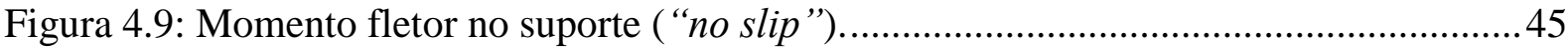

Figura 4.10: Deslocamento radial do suporte ("no slip ") …...................................................... 45

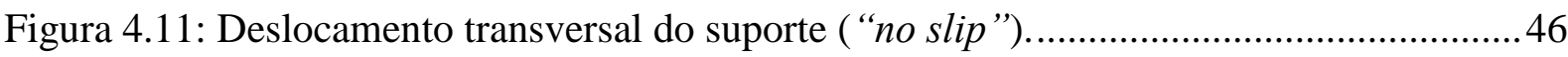

Figura 4.12: Tensão radial entre o maciço e o suporte ( "full slip")........................................47

Figura 4.13: Tensão radial entre o maciço e o suporte com elementos CPE4 ("full slip").....48

Figura 4.14: Tensão cisalhante entre o maciço e o suporte ("full slip ")................................. 48 


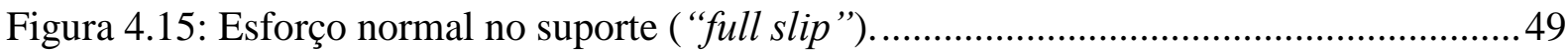

Figura 4.16: Momento fletor no suporte ("full slip") . .......................................................... 49

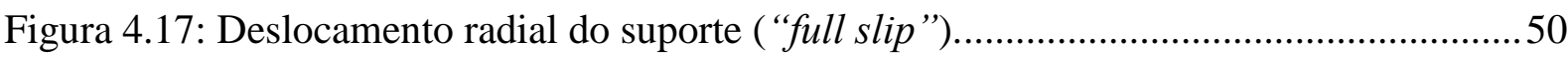

Figura 4.18: Deslocamento transversal do suporte ("full slip"). ..........................................50

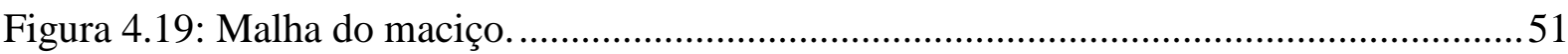

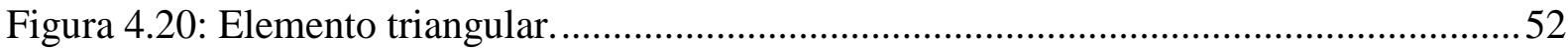

Figura 4.21: Tensão radial entre o maciço e o suporte (malha triangular)...............................53

Figura 4.22: Tensão cisalhante entre o maciço e o suporte (malha triangular).......................53

Figura 4.23: Deslocamento transversal do suporte ("full slip"). ...........................................54

Figura 4.24: Tensão radial do entre o maciço e o suporte (malha quadrilateral). ....................55

Figura 4.25: Tensão cisalhante entre maciço e o suporte (malha quadrilateral). .....................55

Figura 4.26: Tensão radial entre o maciço e o suporte para diferentes atritos. .........................58

Figura 4.27: Tensão cisalhante entre o maciço e o suporte para diferentes atritos. .................59

Figura 4.28: Esforço normal no suporte para diferentes atritos. ...........................................59

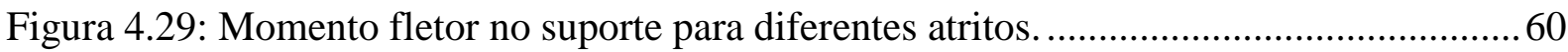

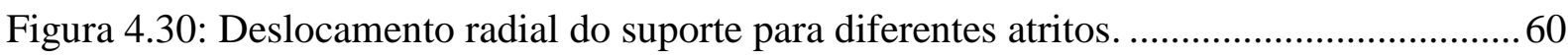

Figura 4.31: Deslocamento transversal do suporte para diferentes atritos. ...............................61

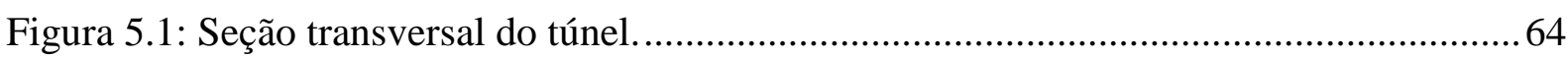

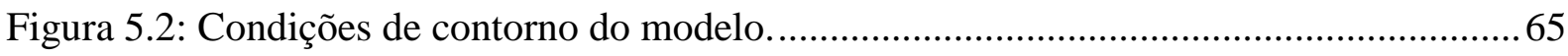

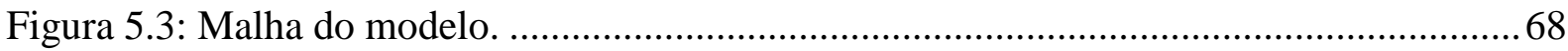

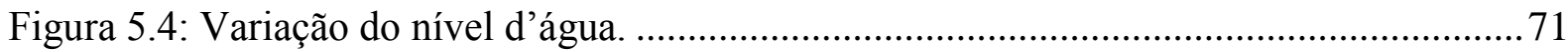

Figura 5.5: Orientação para leitura dos dados. ........................................................................ 71

Figura 5.6: Tensões Von Mises, horizontais e verticais, estado inicial.................................... 72

Figura 5.7: Deslocamentos resultantes, horizontais e verticais no maciço nas etapas

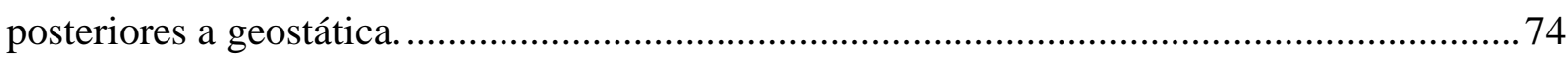

Figura 5.8: Esforços na seção do suporte nas etapas posteriores a escavação. ......................... 77

Figura 5.9: Esforço normal na seção do suporte secundário. ................................................. 78

Figura 5.10: Momento fletor na seção do suporte secundário................................................. 79

Figura 5.11: Tensões na seção do suporte primário e secundário nas etapas posteriores a escavação.

Figura 5.12: Deslocamentos na seção do suporte secundário nas etapas posteriores a etapa de suporte primário. 84

Figura 5.13: Deslocamentos resultantes na seção do suporte secundário. 85

Figura 5.14: Deslocamento no contato. 


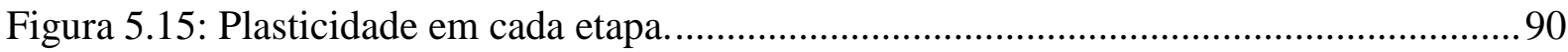

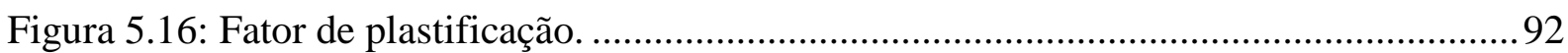

Figura 6.1: Ajuste da deformação ao longo do tempo para os diferentes níveis de tensões desviadora

Figura 6.2: Comparação com outros parâmetros..................................................................... 101

Figura 6.3: Comparação com o modelo de Costa et al. (2005)).............................................. 102

Figura 6.4: Perfil geológico analisado, fora de escala......................................................... 103

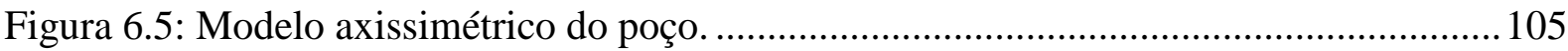

Figura 6.6: Modelo plano de deformação do poço................................................................ 106

Figura 6.7: Curva de fechamento do poço para 6 diferentes profundidades .......................... 107

Figura 6.8: Curva de fechamento do poço, profundidade de $4020 \mathrm{~m}$ abaixo do nível do mar. 108

Figura 7.1:Comportamento primário e secundário de fluência........................................... 110

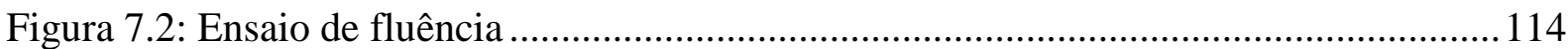

Figura 7.3: Condições de contorno do ensaio de fluência.................................................... 117

Figura 7.4:Comparação dos resultados da simulação numérica e ensaio de fluência de Costa et al. (2005) com os resultados da simulação pelo Abaqus®.

Figura 7.5: Resultados da simulação numérica com os parâmetros de Starfield e Mcclain (1973), Hansen e Mellegard (1980), e Costa (1984) em comparação com os resultados de Costa et al. (2005).

Figura 7.6:Curva tempo x tensão para obtenção do tempo limite da fluência primária, início da fluência secundária.

Figura 7.7:Deformações ao longo do tempo para as tensões de 12, 14, 16-17 MPa. 123

Figura 7.8: Deformações ao longo do tempo para as tensões de 6, 8 e $10 \mathrm{MPa}$..................... 124

Figura 7.9: Galeria subterrânea da mina Taquari-Vassoura................................................. 126

Figura 7.10: Seção da galeria para a simulação.................................................................... 127

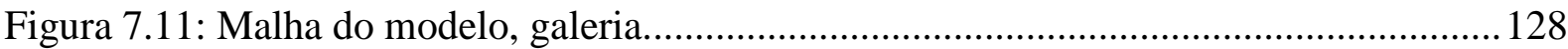

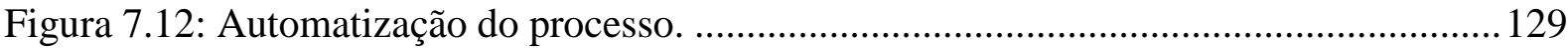

Figura 7.13: Deslocamentos horizontais ao longo do tempo para $h=100,200,300$ e $400 \mathrm{~m} .132$ Figura 7.14: Deslocamentos horizontais ao longo do tempo para $h=500,600,700,800,900$ e $1000 \mathrm{~m}$

Figura 7.15: Deslocamentos verticais ao longo do tempo para $h=100,200,300$ e 400 m..... 133 Figura 7.16: Deslocamentos vertical ao longo do tempo para $h=500,600,700,800,900$ e $1000 \mathrm{~m}$. 
Figura 7.17: Tempo até que os deslocamentos máximos sejam obtidos. 135

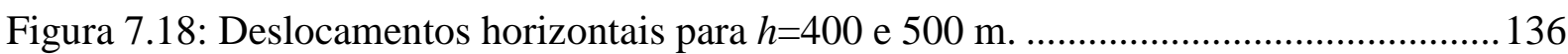

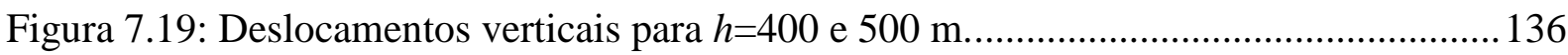

Figura 7.20: Resultados no término da simulação para $h=100 \mathrm{~m}$. ...................................... 137

Figura 7.21: Resultados no término da simulação para $h=200$ m. ........................................ 137

Figura 7.22: Resultados no término da simulação para $h=300$ m....................................... 137

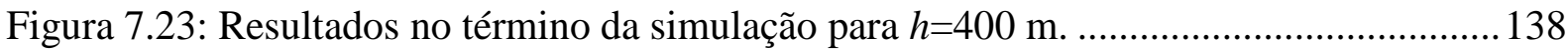

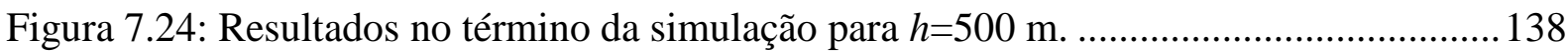

Figura 7.25: Resultados no término da simulação para $h=600 \mathrm{~m}$. ...................................... 138

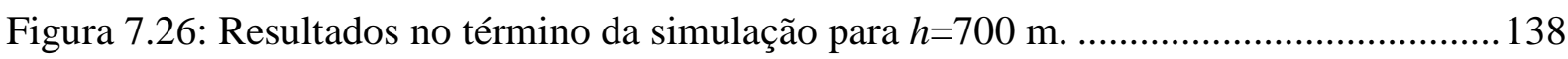

Figura 7.27: Resultados no término da simulação para $h=800$ m. ....................................... 139

Figura 7.28: Resultados no término da simulação para $h=900$ m. ........................................ 139

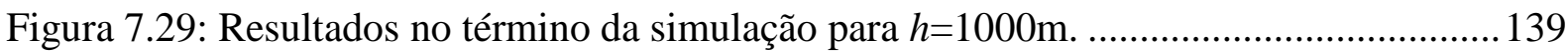

Figura A.1: Modelo plano de deformação para análise do atrito. ........................................ 150

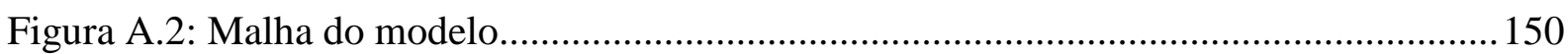

Figura A.3: Deslocamentos ao longo da superfície do suporte para diferentes coeficientes de

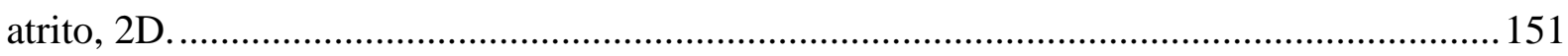

Figura A.4: Modelo cúbico para análise do atrito. ........................................................... 152

Figura A.5: Malha do modelo; (a) elementos sólidos, (b) elementos de casca. ...................... 153

Figura A.6: Deslocamentos ao longo da superfície do suporte para diferentes atritos, 2D e 3D.

Figura A.7: Geometria do modelo para análise dos elementos de suporte de um túnel......... 156

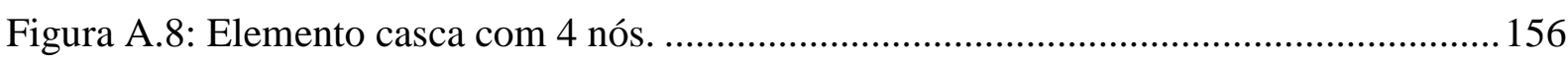

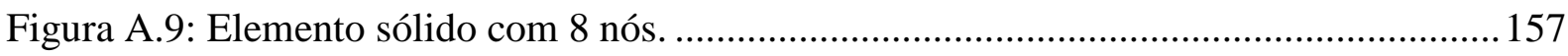

Figura A.10: Malha para o maciço - (a) utilizando elementos de casca, (b) utilizando elementos sólidos.

Figura A.11: Malha do suporte - (a) utilizando elementos de casca, (b) utilizando elementos sólidos. 158

Figura A.12: Tensões de Von Mises - (a) utilizando elementos de casca, (b) utilizando elementos sólidos.

Figura A.13: Verificação das tensões atuantes no maciço. ................................................. 160

Figura A.14: Eixos de referências para utilizados na interpretação dos resultados. ...............161

Figura A.15: Deslocamentos ao longo do eixo Z adimensionalizados pelo diâmetro. 161 


\section{LISTA DE TABELAS}

Tabela 2.1: Propriedade elástica de evaporitos (Poiate et al., 2006)......................................6

Tabela 2.2: Modelos empíricos de Farmer (1983). ............................................................... 14

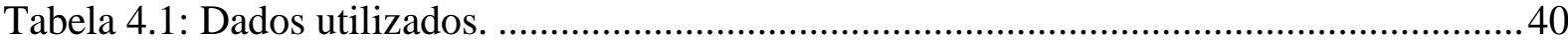

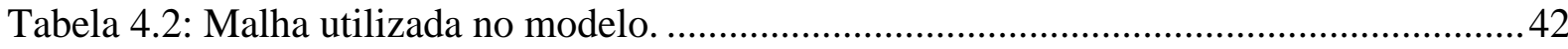

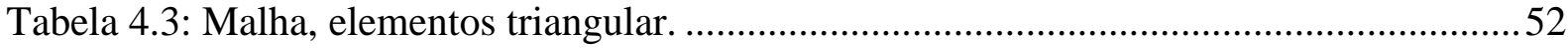

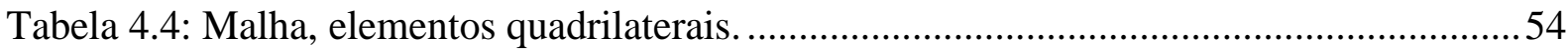

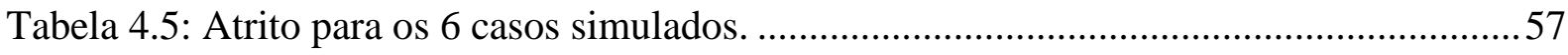

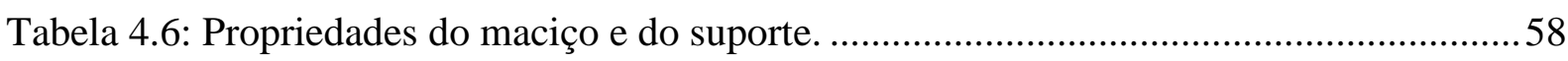

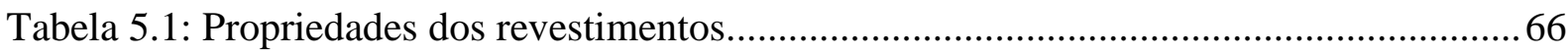

Tabela 5.2: Ensaio de cisalhamento direto do "Institute for Rock Mechanics and Tunnelling" (2008). 67

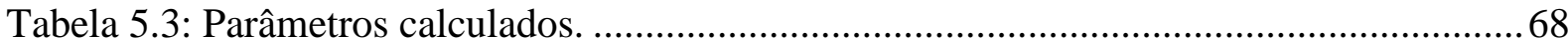

Tabela 6.1: Taxa de deformação para as diferentes tensões diferenciais, Cella (2003)..........98

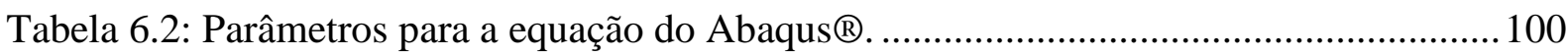

Tabela 6.3: Cálculo das tensões até $4000 \mathrm{~m}$ abaixo do novel do mar. ................................... 104

Tabela 7.1: Propriedade elástica de evaporitos (Costa, 1995 apud Cella, 2003). ..................111

Tabela 7.2: Parâmetros obtidos por Costa (1984) para a equação potencial de Lomenick.... 112

Tabela 7.3: Parâmetros de fluência estacionária de evaporitos obtidos por retroanálise de medidas de convergência em abertura experimental da Mina Taquari-Vassouras, Sergipe (Costa, 1995 apud Cella, 2003).

Tabela 7.4: Parâmetros para a equação do Abaqus ${ }^{\circledR}$ para fluência primária......................... 116

Tabela 7.5: Parâmetros para a equação do Abaqus ${ }^{\circledR}$ para fluência secundária. .................... 116

Tabela 7.6: Parâmetros de fluência secundária, Costa et al. (2005)......................................... 123

Tabela 7.7: Resultados máximos obtidos para deformação, tensão e deslocamento. ............. 140

Tabela A.1: Propriedades dos materiais. 


\section{SUMÁRIO}

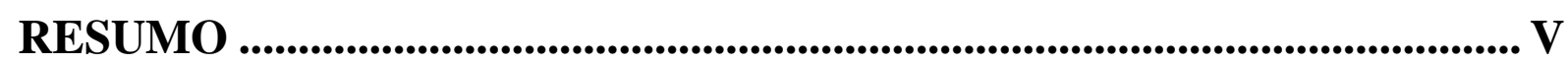

ABSTRACT ........................................................................................................ VII

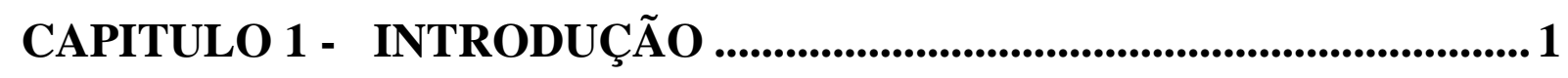

CONTEXTO DO PROBLEMA.................................................................................1

JUSTIFICATIVA ......................................................................................................................

OBJETIVOS.....................................................................................................................2

CAPITULO 2 - REVISÃO BIBLIOGRÁFICA ............................................ 3

2.1 MACIÇO DE EVAPORITOS...................................................................

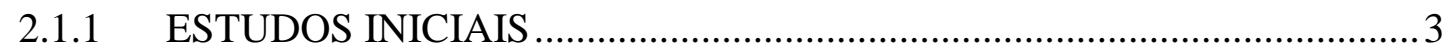

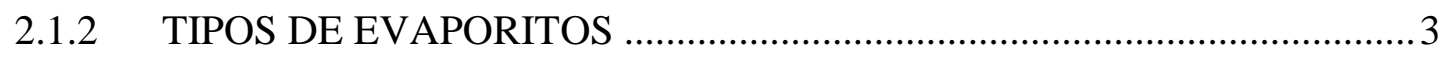

2.1.3 FONTES DE EVAPORITOS ………………………………………….. 4

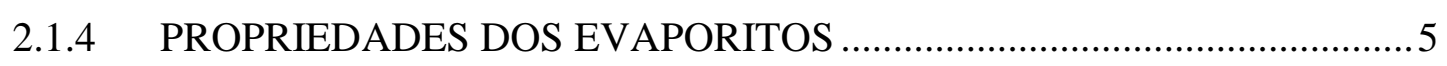

2.1.5 PRINCIPAIS CARACTERÍSTICAS.........................................................

2.1.6 IMPORTÂNCIA DOS EVAPORITOS ......................................................

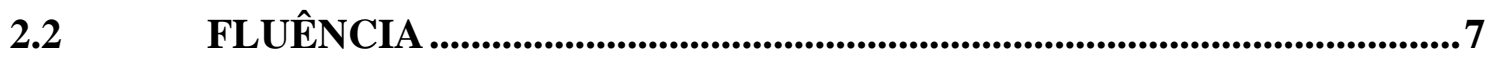

2.2.1 FLUÊNCIA PRIMARIA OU TRANSIENTE ……………………………....

2.2.2 FLUÊNCIA SECUNDÁRIA OU ESTACIONÁRIA.....................................9

2.2.3 FLUÊNCIA TERCIÁRIA....................................................................

2.3 MODELOS CONSTITUTIVOS DE FLUÊNCIA.......................................9

2.3.1 MODELOS BASEADOS EM LEIS FÍSICAS …………………………..... 10

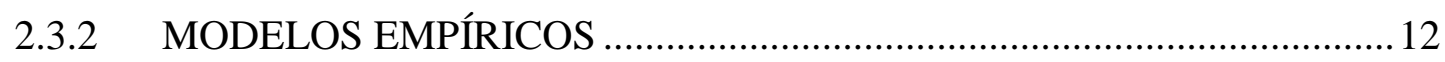

2.3.3 MODELOS BASEADOS EM LEIS REOLÓGICAS..................................... 14

2.4 ESCOLHA DO MODELO CONSTITUTIVO..........................................22

2.5 MODELAGEM DE UM TÚNEL ........................................................24

2.5.1 ESCAVAÇÃO DO TÚNEL ......................................................................24

2.5.2 CONSIDERAÇÕES PARA O MACIÇO EVAPORÍTICO ..........................24

2.5.3 NECESSIDADE DE SUPORTE ……………………………………....... 24

2.5.4 AVALIAÇÃO DA SEGURANÇA............................................................ 25 
CAPITULO 3 - VALIDAÇÃO DO PROGRAMA ABAQUS® 27

3.1 SOLUÇÃO DE KIRSCH................................................................27

3.2 MODELO AXISSIMÉTRICO........................................................28

3.3 MODELO PLANO DE DEFORMAÇÃO ....................................................31

CAPITULO 4 - ESTUDO PRELIMINAR NA MODELAGEM

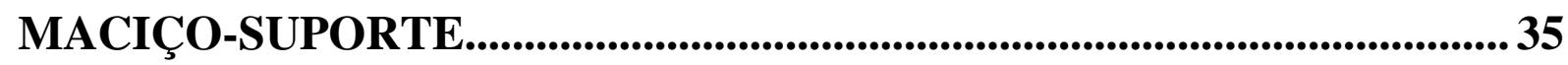

4.1 MODELO DE EINSTEIN E SCHWARTZ …...........................................35

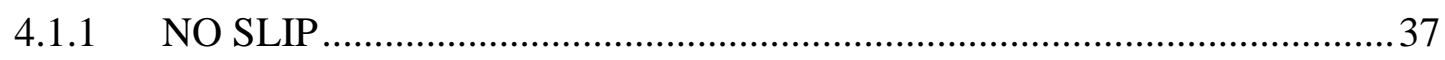

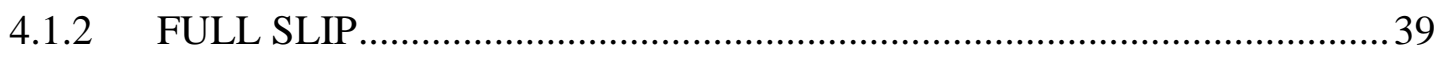

4.2 DADOS DE ENTRADA _.............................................................................40

4.3 RESULTADOS...............................................................................................40

4.3.1 TENSÕES …………………………………………………………ㄴ... 40

4.3.2 DESLOCAMENTOS ............................................................................ 41

4.4 EFEITO DO ATRITO NA INTERAÇÃO MACIÇO-SUPORTE ......... 41

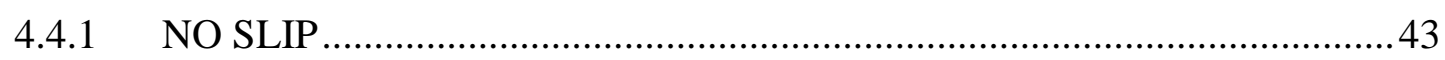

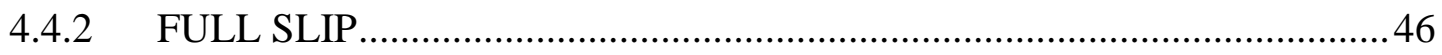

4.5 EFEITO DA MALHA NOS RESULTADOS ..........................................51

4.5.1 MALHA TRIANGULAR …………………………………………......52

4.5.2 MALHA QUADRILATERAL ……………………………………….....54

4.6 VARIAÇÃO DO ATRITO NA INTERAÇÃO MACIÇO-SUPORTE .56

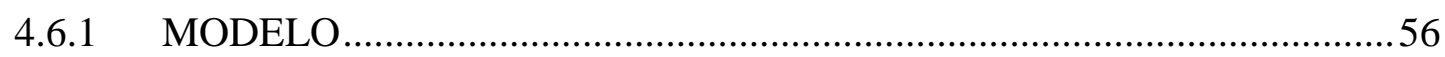

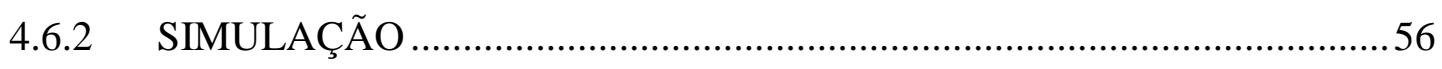

4.6.3 INTERAÇÃO MACIÇO-SUPORTE............................................................57

4.6.4 DEFINIÇÕES DE MATERIAIS ................................................................57

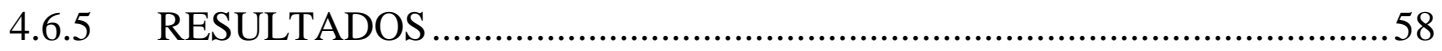

CAPITULO 5 - INTRODUÇÃO AO ESTUdO DE INTERAÇÃO DO SUPORTE COM MEMBRANAS DE IMPERMEABILIZAÇÃO EM TÚNEIS $\quad$..............................................................................63

$5.1 \quad$ MODELO EM ESTUDO.........................................................................64

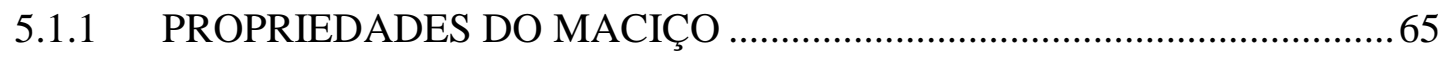

5.1.2 PROPRIEDADES DO REVESTIMENTO...................................................66

5.1.3 PROPRIEDADES DA MEMBRANA DE IMPERMEABILIZAÇÃO........66 
5.2 CARACTERÍSTICAS DA SIMULAÇÃO 68

5.3 RESULTADOS E DISCUSSÕES . .71

CAPITULO 6 - SIMULAÇÃO DE FLUÊNCIA EM EVAPORITOS........93

6.1 EQUAÇÕES CONSTITUTIVAS DE FLUÊNCIA DO ABAQUS® .....93

6.1.1 LEI POTENCIAL - "POWER-LAW MODEL"...........................................94

6.1.2 LEI SENO-HIPERBÓLICA - “HYPERBOLIC-SINE LAW MODEL”........95

6.2 AJUSTE DE PARÂMETROS PARA FLUÊNCIA ……...........................96

6.2.1 LEI CONSTITUTIVA DE FLUÊNCIA PARA AJUSTE .............................96

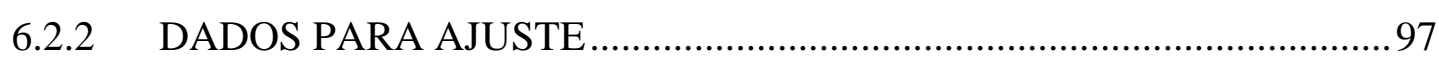

6.2.3 MÉTODO DE AJUSTE........................................................................ 98

6.2.4 APRESENTAÇÃO DOS RESULTADOS DO AJUSTE ..............................99

6.3 MODELAGEM NUMÉRICA DE UM POÇO .........................................103

6.3.1 MODELO AXISSIMÉTRICO DO POÇO .................................................. 105

6.3.2 MODELO PLANO DE DEFORMAÇÃO DO POÇO.................................... 106

6.3.3 RESULTADOS DA SIMULAÇÃO DO POÇO..........................................107

CAPITULO 7 - CONSIDERAÇÃO DA FLUÊNCIA PRIMÁRIA E SECUNDÁRIA NA SIMULAÇÃO DE EVAPORITOS .............................. 109

7.1 PARÂMETROS ELÁSTICOS DE EVAPORITOS ...............................110

7.2 PARÂMETROS PARA A FLUÊNCIA PRIMÁRIA E SECUNDÁRIA DO ABAQUS® ......................................................................................................111

7.2.1 PARÂMETROS PARA A FLUÊNCIA PRIMÁRIA …………………........111

7.2.2 PARÂMETROS PARA A FLUÊNCIA SECUNDÁRIA .............................112

7.3 VALIDAÇÃO DA METODOLOGIA A PARTIR DE ENSAIOS FLUÊNCIAS..................................................................................................113

7.3.1 CARACTERÍSTICAS DA SIMULAÇÃO................................................114

7.3.2 PROPRIEDADES DO MATERIAL ........................................................... 115

7.3.3 CONDIÇÕES DE CONTORNO ……………………………………...... 117

7.3.4 MALHA DO MODELO ……………………………………………......

7.3.5 RESULTADOS E DISCUSSÕES ........................................................... 118

7.4 EQUAÇÃO PARA OBTENÇÃO DO TEMPO DE INÍCIO DA FLUÊNCIA SECUNDÁRIA ...................................................................................120 
7.5 SIMULAÇÃO DE FLUÊNCIA UTILIZANDO A EQUAÇÃO TEMPO

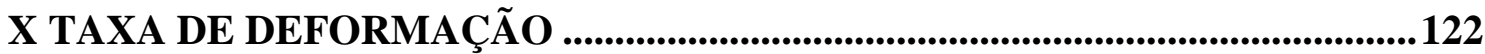

7.6 SIMULAÇÃO DE UMA GALERIA ESCAVADA EM MACIÇO

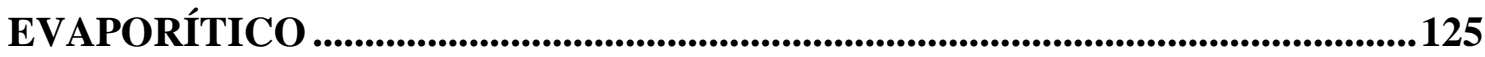

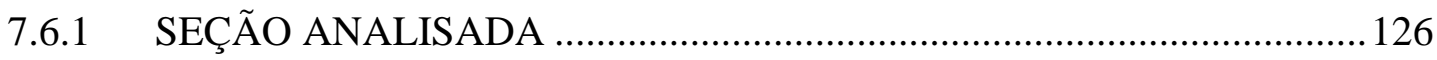

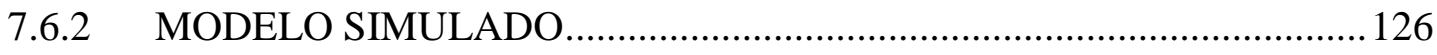

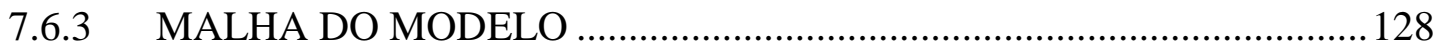

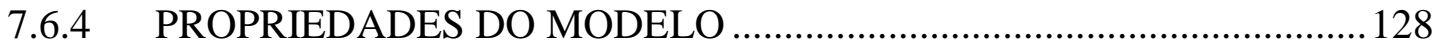

7.6.5 AUTOMATIZAÇÃO DAS SIMULAÇÕES .......................................... 128

7.6.6 RESULTADOS E DISCUSSÕES ...................................................... 131

CAPITULO 8 - CONCLUSÕES E RECOMENDAÇÕES ....................... 141

REFERÊNCIAS BIBLIOGRÁFICAS ........................................................... 145

APENDICE A - ESTUDO PRELIMINAR NA MODELAGEM MACIÇO/SUPORTE...................................................................................... 149

A.1 EFEITO DO ATRITO NA INTERAÇÃO MACIÇO/SUPORTE ..............149

A.1.1 ANÁLISE EM DUAS DIMENSÕES .................................................. 149

A.1.2 ANÁLISE EM TRÊS DIMENSÕES .................................................. 152

A.2 ESCOLHA DO ELEMENTO FINITO PARA O SUPORTE ...................154

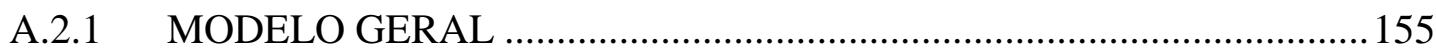

A.2.2 SUPORTE COM ELEMENTOS DE CASCA ….................................... 156

A.2.3 SUPORTE COM ELEMENTOS SÓLIDOS …...................................... 157

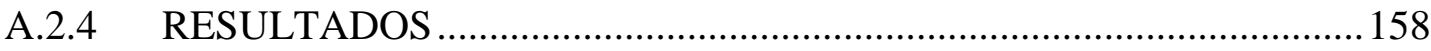




\section{CAPITULO 1 - INTRODUÇÃO}

\section{CONTEXTO DO PROBLEMA}

Durante muitos anos buscaram-se alternativas de cálculo para os diferentes tipos de problemas de Geotecnia. Muitos dos métodos de cálculos utilizados até hoje foram obtidos de maneira empírica, com base na experiência de engenheiros. Nas obras de escavações subterrâneas essa prática foi e ainda continua sendo bastante utilizada. O emprego da mesma serve para prever o comportamento do maciço (como os recalques da superfície, e.g. Peck, 1969 Celestino e Ruiz, 1998) e definir a metodologia construtiva e o sistema de suporte a ser adotado (e.g. Schwartz e Einstein, 1980). Atualmente, já existem alguns modelos constitutivos baseados, não só em métodos empíricos, como em métodos teóricos. Para a fluência, por exemplo, já existem modelos que podem representar o comportamento da mesma em diferentes materiais.

O fenômeno fluência (creep) é responsável pela deformação lenta e contínua nos materiais, sobtensão e temperatura constantes. Essa deformação pode ocorrer de forma irreversível e causar danos a uma estrutura. Na maioria dos casos a fluência se manifesta em materiais, sujeitos a altas temperaturas ou não, por longo tempo. As propriedades dos materiais, as tensões de sobrecarga aplicadas, o tempo e a temperatura de exposição são fatores que podem interferir na ocorrência da mesma. Em maciços de evaporitos a fluência vem despertando o interesse geotécnico devido ao crescente número de escavações de túneis e perfuração de poços de petróleo, em grandes profundidades (sob altas temperaturas e pressões). Em túneis esse fato traz importantes complicações para a engenharia, mesmo depois de alguns anos da construção do mesmo. Em geral, a remoção da coluna de material sólido gera uma redistribuição de tensões que, por consequência, leva o entorno a se deformar durante toda a vida. Quando estas deformações ocorrem de maneira excessiva pode haver o colapso na estrutura e até mesmo a perda total do túnel.

\section{JUSTIFICATIVA}

O estudo de escavações em evaporitos é de fundamental importância pelo grande volume de exploração destas rochas e pelas acentuadas deformações que podem ocorrer em longo prazo, levando eventualmente à ocorrência de instabilidade. A perda da estabilidade 
pode ser causada pelo comportamento de fluência presente nas mesmas. A fluência se caracteriza por uma deformação lenta a uma tensão constante, onde a taxa de deformação (deformação por fluência no tempo) é uma função dependente da tensão e temperatura. Tal comportamento pode causar alguns problemas de instabilidade e gerar o fechamento ou ruptura de um túnel, por exemplo.

\section{OBJETIVOS}

\section{Gerais}

Identificar e quantificar fenômenos que regem a interação de maciços e estruturas de suporte de túneis, com ênfase para os efeitos do fenômeno de fluência em maciços de evaporitos; aplicações a tuneis, galerias e poços de modo a minimizar os problemas ocasionados e manter a qualidade e a integridade dos mesmos durante sua vida útil. Para isto, utilizar modelagem numérica com elementos finitos para simular o processo de escavação dos maciços, submetidos à fluência de curto e médio prazo, utilizando o programa computacional Abaqus ${ }^{\circledR}$, analisando os deslocamentos, as deformações e as tensões no maciço.

\section{Específicos}

- Estudar o comportamento viscoelástico das rochas evaporíticas;

- Estudar modelos constitutivos que permitam simular e analisar o fenômeno de fluência (creep) em evaporitos;

- Ajustar parâmetros para as equações viscoelásticas de fluência em diferentes níveis de tensão;

- Adaptar modelos constitutivos para simular numericamente os diferentes estágios de fluência;

- Estudar a interação Maciço-Suporte;

- Estudar a interação das duas camadas da estrutura de suporte de um túnel;

- Estudar o efeito de uma membrana na interação Maciço-Suporte. 


\section{CAPITULO 2 - REVISÃO BIBLIOGRÁFICA}

\subsection{MACIÇO DE EVAPORITOS}

Maciços de Rochas Evaporíticas ou Salinas são compostos por rochas sedimentares que geralmente se formam em locais de clima seco e com alta taxa de evaporação. Esta evaporação permite a sedimentação de baixo aporte de terrígenos (areia e cascalho), daí o nome, que por sua vez leva a formação dos minerais evaporíticos. Este tipo de maciço se destaca por seu comportamento mecânico e, devido a isto, tem uma grande importância para engenharia de estruturas geológicas, como: repositório de resíduos nucleares, cavernas de armazenamento e minas subterrâneas de sal.

\subsubsection{ESTUDOS INICIAIS}

Os estudos sobre Maciço Evaporíticos surgiram há mais de um século e até os anos de 1960 se fundamentaram na análise química dos minérios. Em seguida este estudo se tornou sedimentológico com uma visão mais atual, onde os ambientes modernos passaram a ser utilizados como modelos para o entendimento de paleoambientes deposicionais. Segundo Curtis et al. (1963), a principal razão para esta mudança é a descoberta de faciologias evaporíticas costeiras na Costa Trucial do Golfo da Pérsia.

Com a descoberta da propriedade de fluência dos evaporitos, os estudos passaram a se fundamentar no comportamento mecânico dos mesmos. A partir de então se identificou a capacidade de auto cicatrização deste tipo de rocha. Esta descoberta, motivada pela necessidade de armazenamento de resíduos nucleares e de produtos com valores agregados, como o petróleo, deu um grande impulso ao estudo da mecânica das rochas. As primeiras tentativas teóricas para estimar as deformações de Maciços Evaporíticos foram feitas por Dreyer (1972) com extrapolações de modelos experimentais de medições in situ.

\subsubsection{TIPOS DE EVAPORITOS}

A halita $(\mathrm{NaCl})$, mais conhecida como sal, é o evaporito mais comum devido ao seu grande consumo diário. Seu uso é grande na indústria para a fabricação de soda cáustica, conservantes, inseticidas, entre outros. Os evaporitos são formados por alguns grupos de 
minerais, dentre eles se destacam: cloretos, sulfatos (de sódio, de potássio, de cálcio e de magnésio) e nitratos (de sódio e de potássio). A silvita $(\mathrm{KCl})$, também tem sua importância para a indústria na fabricação de fertilizantes, vidros cerâmicos, sabão e explosivos. Além destes evaporitos, a gipsita $\left(\mathrm{CaSO}_{4} \cdot 2 \mathrm{H}_{2} \mathrm{O}\right)$, a anidrita $\left(\mathrm{CaSO}_{4}\right)$, a carnalita $\left(\mathrm{KCl} \cdot \mathrm{MgCl}_{2} \cdot 6 \mathrm{H}_{2} \mathrm{O}\right)$, taquidrita $\left(2 \mathrm{MgCl}_{2} \cdot 12 \mathrm{H}_{2} \mathrm{O}\right)$ e a dolomita $\left(\mathrm{CaMg} .2 \mathrm{CO}_{4}\right)$ também têm valor econômico e são bem conhecidas.

\subsubsection{FONTES DE EVAPORITOS}

Conforme Da Silva et al. (2000), os ambientes de formação dos evaporitos ocorrem tanto em situações de caráter continental como marinho e três fatores críticos controlam esta formação e o acúmulo de sedimentos: a baixa umidade relativa do ar, a temperatura, o conteúdo iônico inicial e suas relações.

Como se sabe a maioria dos evaporitos é de origem marinha e pode ser encontrada em quase toda parte do globo, em locais onde a evaporação da água é superior à precipitação. De acordo com Gravina (1997), as diferenças nas condições ambientais durante o processo de precipitação dos diversos componente da água do mar ajudam a explicar as variações encontradas na composição dos evaporitos. No Brasil sua ocorrência é bastante significativa nas bacias Amazonas, Paraíba com sedimentos formados no Paleozoico, e na bacia SergipeAlagoas (Cretáceo). Além dessas bacias, os evaporitos são encontrados em todas as bacias costeiras.

Botelho (2008) afirma que a precipitação do sal acontece quando o soluto atinge o ponto de saturação salina daquele componente. Desta maneira a deposição de camadas salinas ocorre em uma sequência ou sucessão de salinização progressiva da bacia de deposição, dos sais menos solúveis para os mais solúveis; por exemplo, gipsita $\left(\mathrm{CaSO}_{4} \cdot 2 \mathrm{H}_{2} \mathrm{O}\right)$ e anidrita $\left(\mathrm{CaSO}_{4}\right)$ nas camadas inferiores, halita ("sal de cozinha", $\left.\mathrm{NaCl}\right)$, silvita $(\mathrm{KCl})$, carnalita $\left(\mathrm{KCl} \cdot \mathrm{MgCl}_{2} \cdot 6 \mathrm{H}_{2} \mathrm{O}\right)$ e taquidrita $\left(2 \mathrm{MgCl}_{2} \cdot 12 \mathrm{H}_{2} \mathrm{O}\right)$ nas camadas superiores. A Figura 2.1 esquematiza o processo de formação dos evaporitos. 


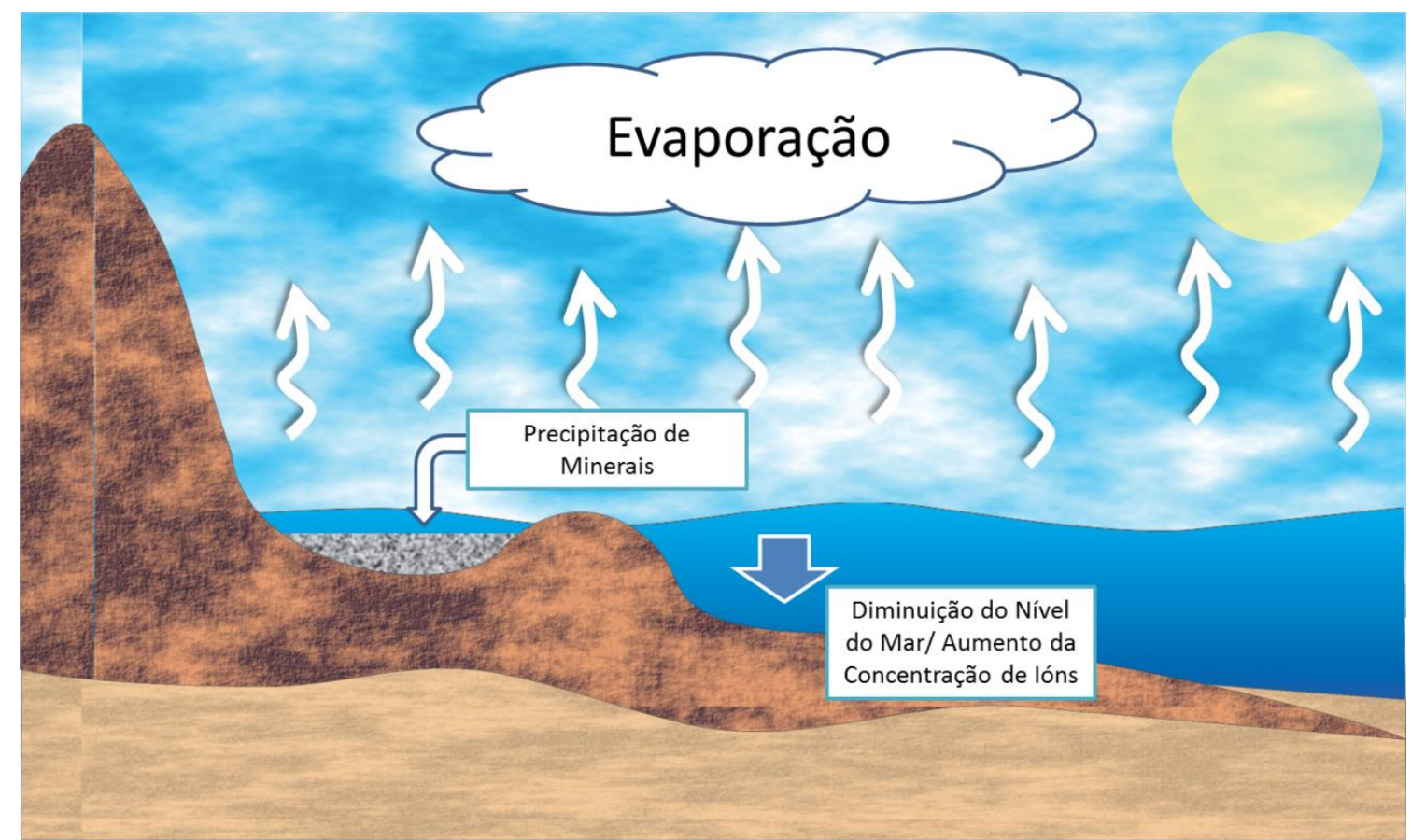

Figura 2.1: Formação dos evaporitos.

A química da água do mar moderna é dominada pelos íons $\mathrm{Na}+\mathrm{e} \mathrm{Cl-}$, e quantidades

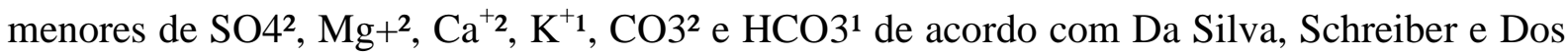
Santos (2000). Ainda segundo os autores, acima referenciados, quando a água do mar é evaporada, uma suíte de minerais é precipitada em ordem previsível: primeiro é um carbonato, comumente aragonita ou calcita; a seguir ocorre a precipitação de sulfato, geralmente na forma de gipsita ou anidrita; em concentrações de onze a doze vezes a da água do mar, a halita precipita; e após essa precipitação, sais complexos de potássio e magnésio (exemplo, silvinita), entre outros, podem precipitar em concentrações superiores a sessenta vezes à original.

\subsubsection{PROPRIEDADES DOS EVAPORITOS}

O comportamento mecânico dos maciços rochosos é comumente analisado pelo princípio da elasticidade ou inelasticidade. Na maioria dos casos o princípio da elasticidade é adotado, pela facilidade nas aplicações práticas. Para alguns maciços de rochas, a hipótese de comportamento inelástico é a mais adequada, especialmente em maciços de pouca competência. Os Maciços Evaporíticos são exemplos de maciços pouco competentes e apresentam muitas características distintas em comparação com outros tipos. A ductilidade, por exemplo, é um destas características e, de acordo com Boulianne et al. (2004), deve ser considerada na análise de aberturas subterrâneas. 
Conforme Boulianne et al. (2004), o comportamento mecânico dos evaporitos é principalmente controlado pelas deformações inelásticas e as análises de estruturas, neste tipo de maciço, devem levar em conta esta dependência. No entanto, a modelagem para a obtenção desta resposta é uma tarefa difícil, pois os diferentes estágios de deformação do maciço incluem a resposta instantânea (elástica e/ou plástica), a resposta no estado transitório e a resposta no estado estacionário. Poiate et al. (2006) apresentam as propriedades elásticas para alguns tipos de evaporitos, Tabela 2.1.

Tabela 2.1: Propriedade elástica de evaporitos (Poiate et al., 2006).

\begin{tabular}{|c|c|c|}
\hline Material & $\boldsymbol{E}(\mathbf{G P a})$ & $\boldsymbol{v}$ \\
\hline Halita & 20,4 & 0,36 \\
\hline Carnalita & 4,20 & 0,36 \\
\hline Taquidrita & 4,92 & 0,33 \\
\hline
\end{tabular}

\subsubsection{PRINCIPAIS CARACTERÍSTICAS}

Mackay et al. (2008) apontam como características principais dos evaporitos a alta solubilidade, a ativação geoquímica, o comportamento contínuo de fluência e a ativação térmica. No mesmo trabalho os autores acima citados ainda apontam como características do extrato de sal as pequenas camadas insolúveis e as estruturas complexas ao redor do diapiro ${ }^{1}$. Por ser rochas com grande complexidade geotécnica, os evaporitos devem receber uma atenção especial em cada tipo de situação estudada.

\subsubsection{IMPORTÂNCIA DOS EVAPORITOS}

A importância dos Maciços Evaporíticos está ligada diretamente a capacidade de cicatrização e selagem no armazenamento de lixo radioativo e em reservatórios de petróleo. Chan et al. (1994) afirmam que este fato se deve a algumas características mecânicas neles presentes, como a fluência, que impossibilita o vazamento e garante o bom isolamento do material. Segundo Warren (1989), cerca de 70\% dos campos de petróleo gigantes em rochas carbonáticas estão relacionados a depósitos evaporíticos. Tais características, comuns em rochas salinas, aumentam as chances de sucesso na exploração do petróleo, além de as diferenciarem do restante.

\footnotetext{
${ }^{1}$ Um diapiro em geologia, é uma intrusão de material rochoso menos denso que a rocha encaixante, um processo conhecido como diapirismo.
} 


\subsection{FLUÊNCIA}

O fenômeno responsável pela deformação lenta e contínua nos materiais, a uma tensão e temperatura constante, é conhecido como fluência ou "creep". As propriedades dos materiais, as tensões de sobrecarga aplicadas, o tempo e a temperatura de exposição são fatores que podem interferir na ocorrência da fluência. Em maciços evaporíticos, a fluência vem despertando o interesse geotécnico devido ao crescente número de construções de túneis (para acesso a minas), cavernas subterrâneas (para estocagem e eliminação de lixo) e perfurações de poços de petróleo.

O comportamento de fluência marcante nos maciços evaporíticos os torna diferentes dos demais tipos de maciços de rochas sedimentares. De acordo com Poiate et al. (2006), os evaporitos são materiais geológicos não usuais em que, sob tensões constantes, significativas deformações são esperadas em função do tempo, das condições de carregamento e das propriedades físicas.

Em geral, os maciços de rochas sofrem fluência quando estão submetidas a carregamento e a mesma tende a parar em pouco tempo. Na maioria dos casos, as rochas deformam-se em regime de fluência a uma temperatura e tensão além dos limites usuais da engenharia. Os maciços de evaporitos são exceções e sofrem fluência em temperaturas e tensões bastante comuns na prática da engenharia de rochas. Devido a isso, existe um crescente aprofundamento nos estudos desse comportamento nestes materiais.

A fluência é uma propriedade complexa e que merece bastante atenção da engenharia. Seu estudo, geralmente feito em laboratórios, é de fundamental importância para a prevenção de danos e obtenção dos parâmetros fundamentais para os projetos estruturais. De maneira direta, a fluência é descrita em termos da velocidade de deformação, ou taxa de deformação, pela Equação (2.1):

$$
\dot{\varepsilon}=\frac{d \varepsilon}{d t}
$$

onde $\dot{\varepsilon}$ é a taxa de deformação ou fluência e $d \varepsilon$ é a variação da deformação no intervalo de tempo $d t$ na condição de tensão desviadora e temperatura constantes. 
Segundo Botelho (2008), nos evaporitos, a fluência é influenciada sensivelmente pela espessura da camada de sal, pela temperatura de formação, pela composição mineralógica, pelo teor de água, pela presença de impurezas e pela extensão em que a tensão diferencial é aplicada no corpo salino. Em laboratório a deformação para o fenômeno é caracterizada por três estágios de comportamento (Figura 2.2): primário ou transiente, secundário ou estacionário e terciário, todos relacionados diretamente com a taxa de deformação.

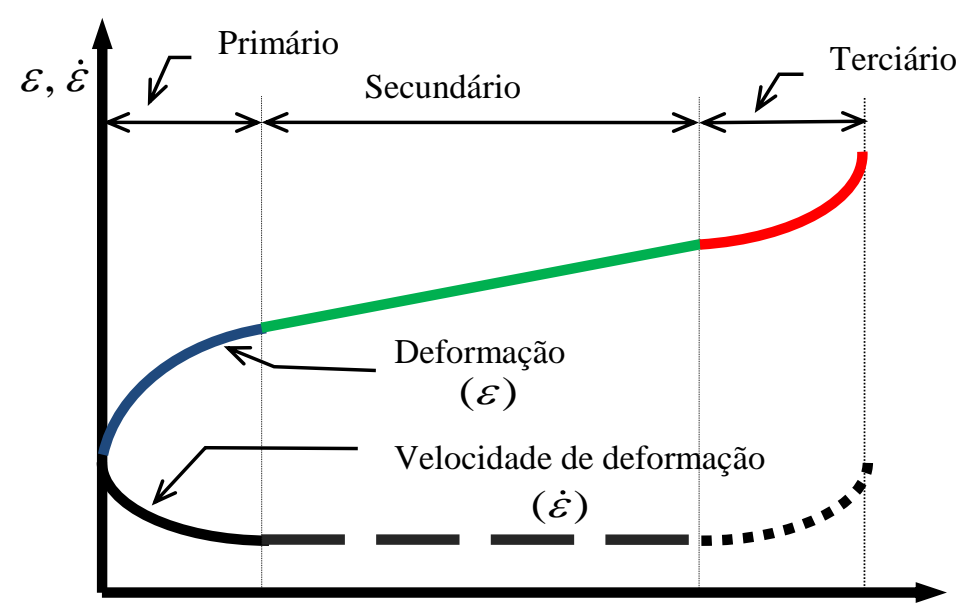

Figura 2.2: Estágios de fluência.

\subsubsection{FLUÊNCIA PRIMARIA OU TRANSIENTE}

A Fluência Primária ocorre depois da aplicação de um nível constante de tensão, após a deformação elástica instantânea, e se caracteriza pela diminuição da velocidade de deformação. Nessa fase o corpo ainda pode voltar a sua configuração original, quando a tensão aplicada é reduzida a zero. Gravina (1997), Cella (2003), Botelho (2008), entre outros afirmam que neste estágio, logo que a tensão desviadora é aplicada, a taxa de deformação é muito alta, ou seja, possui uma elevada velocidade de fluência, e que diminui até uma taxa constante de deformação. Segundo Botelho (2008), em rochas evaporíticas raramente a deformação é reversível, mas existem exceções como a halita $(\mathrm{NaCl})$ e a gipsita $\left(\mathrm{CaSO}_{4} 2 \mathrm{H}_{2} \mathrm{O}\right)$ que em temperaturas muito elevadas podem reverter sua deformação sem causar danos à sua textura. 


\subsubsection{FLUÊNCIA SECUNDÁRIA OU ESTACIONÁRIA}

A Fluência Secundária ocorre quando a velocidade de deformação permanece aproximadamente constante, logo após a fluência primaria. Neste estágio, quando a tensão é repentinamente reduzida a zero, ocorre inicialmente uma recuperação elástica, em seguida o corpo restaura lentamente sua configuração inicial. Depois de certo tempo a deformação evolui assintoticamente para um valor permanente. A deformação lenta e contínua que caracteriza o regime de fluência estacionária é responsável por uma distribuição uniforme das pressões em todo corpo, impedindo a concentração de pressões que poderia gerar fraturas e consequentemente a ruptura, em pouco tempo, do corpo. Esses aspectos são bastante favoráveis desde que se tenha uma preocupação especial, pois a deformação lenta e contínua pode durar algum tempo (de meses a anos) e levar o maciço a ruptura.

\subsubsection{FLUÊNCIA TERCIÁRIA}

A Fluência Terciária ocorre logo após a fluência secundária, neste estágio há um aumento crescente da velocidade de deformação, aceleração da taxa de fluência, até a ruptura do corpo sólido.

A recuperação das deformações, também é um fenômeno característico de materiais em regime de fluência. Em maciços evaporíticos essa recuperação pode ser total, se a tensão for reduzida a zero na fase primária. Na fase secundária, essa recuperação pode não ser completa e na fase terciária essa recuperação não é total. Isso se deve a propriedade elástica presente nas mesmas, que tende a ser perdida à medida que a rocha se deforma.

\subsection{MODELOS CONSTITUTIVOS DE FLUÊNCIA}

Para descrever a fluência das rochas, muitos modelos matemáticos têm sido desenvolvidos e correlacionam estado de tensão, deformação e tempo. O agrupamento destes em categorias, de acordo com os mecanismos que regem o processo, é bastante comum. Yu (1998), por exemplo, quando estudou a fluência em rochas fez essa separação em três categorias: modelos viscoelásticos, modelos viscoelastoplásticos e, baseados nos experimentos de laboratório, modelos empíricos. Neste trabalho os modelos serão agrupados de outra maneira, visto que a temperatura e a microestrutura formadora da rocha evaporítica 
têm uma importante contribuição no processo. Dessa forma, assim como fizeram Cella (2003) e Botelho (2008), os modelos serão agrupados em: modelos físicos, modelos empíricos e modelos reológicos, detalhados a seguir.

\subsubsection{MODELOS BASEADOS EM LEIS FÍSICAS}

Os modelos baseados em processos físicos, que em geral se associam às leis de fluência estacionária, surgiram com objetivo de representar o comportamento dos evaporitos baseados em mecanismos de interação por meio de certos intervalos de tensões, de estado de deformação, de taxa de deformação, de temperatura e de microestrutura formadora da rocha.

Conforme Cella (2003), os diferentes mecanismos físicos correlacionados com a estrutura interna dos agregados policristalinos e com as variações de temperatura e pressão são os fatores responsáveis pela fluência dos corpos. Ainda de acordo com o autor, existem alguns mecanismos de deformação que controlam a taxa de fluência, entre eles pode-se destacar: deformação a partir da propagação de distorções originais no retículo cristalino a exemplo, "dislocation climb" ou "dislocation glide"; difusão de massa liquida ou sólida; dissolução sob pressão ou "pressure solution"; deslizamento ou superplasticidade de interfaces granulares; catáclase e suas variações com e sem cicatrização dinâmica.

Pehovaz-Alvarez (2009) constatou, por meio de ensaios monitorados por emissão acústica, que a fluência de alguns evaporitos está diretamente ligada ao processo de microfissuramento.

Basicamente os estudos, com base em processos físicos, se fundamentam nos três mecanismos predominantes no comportamento de fluência dos materiais: "dislocation climb", "dislocation glide" e um mecanismo indefinido.

\section{Mecanismo "Dislocation Climb"}

Controlado por um fenômeno chamado ativação térmica, oscilação de átomos em torno de uma posição de equilíbrio devido ao aumento da temperatura de um corpo sólido, o “dislocation climb" é responsável pela redistribuição molecular da estrutura do material. Esta redistribuição provoca o aumento da capacidade de fluência, ou seja, velocidade de fluência é diretamente dependente da temperatura. Munson e Devries (1991) afirmam que nas situações 
em que a temperatura está no intervalo de moderada a alta e o material está sujeito a um baixo regime de tensão desviadora, a fluência é controlada pelo "dislocation climb" e pode ser expressa pela Equação (2.2).

$$
\dot{\varepsilon}=A_{1}\left(\frac{\sigma}{G}\right)^{n_{1}} \exp \left(-\frac{Q}{R^{\prime} T}\right)
$$

onde $\dot{\varepsilon}$ é a taxa de deformação de fluência na condição de regime permanente, $A_{l}$ é uma constante, $\sigma$ é a tensão desviadora, $G$ é o módulo de cisalhamento, $Q$ é a energia de ativação, $R$ ' é a constante universal dos gases, $T$ é a temperatura absoluta e $n_{l}$ é o expoente de tensão.

\section{Mecanismo "Dislocation Glide"}

Caracterizado pela superposição de vários mecanismos de deslizamento durante o processo de fluência, o "dislocation glide" se relaciona à fluência estacionária quando o corpo está submetido a elevados níveis de tensões. Segundo Munson e Devries (1991), o mecanismo pode ser representado por uma função seno-hiperbólica do nível de tensão desviadora aliada a fatores de ativação térmica, de acordo com a Equação (2.3):

$$
\dot{\varepsilon}=H\left(B_{1} e^{-\frac{Q}{R^{\prime} T}}+B_{2} e^{-\frac{Q}{R^{\prime} T}}\right)^{n_{1}} \sinh \left(\frac{q\left(\sigma-\sigma_{0}\right)}{G}\right),
$$

onde $\dot{\varepsilon}$ é a taxa de deformação de fluência, H é a função degrau de Heaviside, $\sigma$ é a tensão desviadora, $\sigma_{0}$ é a tensão desviadora de referência, $G$ é o módulo de cisalhamento, $Q$ é a energia de ativação, $R$ ' é a constante universal dos gases, $T$ é a temperatura absoluta e, $B_{1}, B_{2}$ e $q$ são constantes.

\section{Mecanismo Indefinido}

$\mathrm{Na}$ maioria das vezes o mecanismo físico de fluência é definido empiricamente em ensaios de laboratórios e o resultado apresentado se relaciona ao obtido pelo mecanismo “dislocation climb". Por esta razão a Equação (2.2) pode representar este mecanismo indefinido, que recebe este nome por não se associar a nenhum modelo micromecânico. Geralmente, quando a rocha evaporítica está sujeita à baixa temperatura e a baixo regime de tensão, a fluência não sofre os efeitos da temperatura e da tensão, logo ela é controlada por um mecanismo indefinido. 


\section{Mecanismo Duplo de Deformação}

A equação de deformação de mecanismo duplo, Equação (2.4), proposta por Dusseault, M. B. et al. (1987) é uma simplificação da equação constitutiva da lei de fluência de Munson e Devries (1991), que considera a possibilidade de três mecanismos baseados nas condições de temperatura e tensão. Neste caso apenas se considerou o "dislocation glide" e o mecanismo indefinido.

$$
\dot{\varepsilon}=\dot{\varepsilon}_{0}\left(\frac{\sigma}{\sigma_{0}}\right)^{n} \exp \left(\frac{Q}{R^{\prime} T_{0}}-\frac{Q}{R^{\prime} T}\right)
$$

onde $\dot{\varepsilon}$ é a taxa de deformação de fluência na condição de regime permanente, $\dot{\varepsilon}_{0}$ é a taxa de deformação de referência no regime permanente, $\sigma$ é a tensão desviadora de fluência, $\sigma_{0}$ é a tensão desviadora de referência e Q é a energia de ativação.

\subsubsection{MODELOS EMPÍRICOS}

Os modelos empíricos, nada mais são que equações matemáticas deduzidas de observações e ajustes entre o comportamento de uma curva típica de fluência e o seu resultado experimental. De acordo com a função matemática dominante a equação empírica de fluência pode ser subdividida em: potencial, logarítmica e exponencial.

\section{Lei Potencial}

A lei empírica potencial, geralmente a mais utilizada pela maioria dos autores, é o modelo que melhor representa o comportamento no primeiro estágio de fluência. Um exemplo é a Equação (2.5), desenvolvida por Lomenick e Bradshaw (1969), que utiliza três constantes empíricas e relaciona a deformação com a tensão, temperatura e tempo.

$$
\varepsilon=K \sigma^{c} t^{b} T^{a}
$$

onde $\varepsilon$ é a deformação transiente de fluência, $\sigma$ é a tensão desviadora, $t$ é o tempo, $T$ é a temperatura, e $K, a, b$ e $c$ são constantes empíricas.

Devido ao comportamento desse tipo de curva a lei potencial vem sendo aplicada no estágio transiente de fluência. Alguns trabalhos sugerem outros tipos de equações para 
descrever o fenômeno, mas não se entrará em detalhes aqui, visto que existem dezenas de equações potenciais e nem todas se aplicam às rochas evaporíticas.

II. Lei Logarítmica

As leis empíricas para fluência começaram a surgir no início do século XX. A primeira delas, Equação (2.6), foi proposta por Phillips (1905) apud Dusseault e Fordham (1994) e se baseia na lei logarítmica:

$$
\dot{\varepsilon}=B t^{-1}
$$

onde $\dot{\varepsilon}$ é a taxa de deformação, $B$ é uma constante, obtidas experimentalmente e $t$ é o tempo.

Da mesma forma que a lei potencial de fluência, a lei logarítmica descreve bem a fluência primária e geralmente é utilizada em curto prazo de tempo. Nesse tipo de modelo a variável de tempo é expressa com uma função logarítmica. A Equação (2.7) mostra uma lei geral para esse tipo de modelo.

$$
\varepsilon=K \sigma^{c} \ln (t) T^{a}
$$

Em valores de tempo tendendo a zero, para o caso onde se considera a tensão e temperatura constantes, a taxa de fluência torna-se infinita (Equação (2.7)), o que permite o surgimento de uma alternativa para esse problema, Equação (2.8) apresentada em Botelho (2008).

$$
\varepsilon=K \ln (1+B t)
$$

\section{Lei Exponencial}

A Lei Exponencial, assim como os outros modelos empíricos apresentados, descreve bem a deformação transiente de fluência. Esse tipo de equação se assemelha bastante aos outros modelos empíricos e pode ser descrita pela Equação (2.9).

$$
\varepsilon=K \sigma^{c} t^{b} e^{\frac{j}{T}}
$$

onde $\varepsilon$ é a deformação transiente de fluência, $\sigma$ é a tensão desviadora, $t$ é o tempo, $T$ é a temperatura e $K, b, c$ e $j$ são constantes empíricas. 
Como se observa, os Modelos Empíricos podem assumir formas matemáticas muito complexas com um grande número de parâmetros. A Tabela 2.2 mostra alguns modelos encontrados em Farmer (1983).

Tabela 2.2: Modelos empíricos de Farmer (1983).

\begin{tabular}{|c|c|}
\hline 1 & $\varepsilon=A t^{m}$ \\
\hline 2 & $\varepsilon=A+B t^{m}$ \\
\hline 3 & $\varepsilon=A+B t+C t^{n}$ \\
\hline 4 & $\varepsilon=A+B t^{m}+C t^{n}+D t^{p}+\ldots$ \\
\hline 5 & $\varepsilon=A \log (t)$ \\
\hline 6 & $\varepsilon=A+B \log (t)$ \\
\hline 7 & $\varepsilon=A \log (B+t)$ \\
\hline 8 & $\varepsilon=A \log (B+C t)$ \\
\hline 9 & $\varepsilon=A+B \log (C+t)$ \\
\hline 10 & $\varepsilon=A+B \log (C+t)$ \\
\hline 11 & $\varepsilon=A+B \log (t+D t)$ \\
\hline 12 & $\varepsilon=A \cdot t / 1+B t$ \\
\hline 13 & $\varepsilon=A+B \sinh \left(C t^{n}\right)$ \\
\hline 14 & $\varepsilon=A+B t-C \exp (-D t)$ \\
\hline 15 & $\varepsilon=A t+B[1-\exp (-C t)]$ \\
\hline 16 & $\varepsilon=A[1-\exp (-B t)]+C[1-\exp (-D t)]$ \\
\hline 17 & $\varepsilon=A+B \log (t)+C t^{n}$ \\
\hline 18 & $\varepsilon=A+B \log (t)+C t$ \\
\hline 19 & $\varepsilon=\log (t)+B t^{n}+C t$ \\
\hline 20 & $\varepsilon=A \log [1+(t / B)]$ \\
\hline 21 & $\varepsilon=A\left[1-\exp \left(B-C t^{n}\right)\right]$ \\
\hline 22 & $\varepsilon=A[1-\exp (-B t)]$ \\
\hline 23 & $\varepsilon=A \exp (B t)$ \\
\hline
\end{tabular}

onde $\varepsilon$ é a deformação de fluência, $t$ é o tempo, e $A, B, C, D, m, n$ e $p$ são constantes empíricas que pode ter relação com temperatura, com a tensão desviadora e/ou com outras variáveis, o que torna estes sem base física (como mostrou Senseny (1983) em seus experimentos).

\subsubsection{MODELOS BASEADOS EM LEIS REOLÓGICAS}

Os modelos reológicos são modelos que representam de forma macroscópica o comportamento mecânico dos corpos sólidos em termos de tensão, deformação e tempo. Tais 
modelos utilizam representações simbólicas dos aspectos básicos do comportamento do material.

\section{Modelo Básicos}

Os modelos reológicos básicos não são aplicados para fluência de matérias, pois são modelos simples que descrevem um dos fenômenos de deformação: elástico, plástico ou viscoso. O Modelo de Hooke, por exemplo, simula a deformação elástica descrita por um módulo de elasticidade constante e tem como símbolo uma mola. Ao aplicar uma tensão à mola, ela se deforma e caso a tensão seja removida, ela retornará a sua configuração inicial. Esse modelo, proposto por Hooke, é representado pela Equação (2.10).

$$
\sigma(t)=\varepsilon(t) \cdot E
$$

onde $E$ é o módulo de elasticidade (constante elástica da mola). A Figura 2.3(a) é uma esquematização do modelo.

Outro modelo é o de Newton cujo elemento representativo é um amortecedor e descreve um comportamento perfeitamente viscoso. Neste caso, quando uma tensão é aplicada, o elemento deforma-se gradualmente com o tempo sob taxa de deformação constante. Quando ela é retirada, o corpo não retorna a sua configuração inicial, ou seja, ele sofre uma deformação irreversível. A Equação (2.11) é a expressão proposta por Newton para esta situação.

$$
\sigma(t)=\eta \dot{\varepsilon}(t)
$$

onde $\eta$ é a constante de viscosidade (constante do amortecedor) e $\dot{\varepsilon}(\mathrm{t})$ é a taxa de deformação (ou velocidade de deformação). A Figura 2.3(b) mostra o comportamento perfeitamente viscoso que rege o modelo.

O modelo de Saint Venant é mais um dos modelos básicos e representa a deformação plástica, simbolizada por um elemento deslizante (Figura 2.3(c)). Na simulação da deformação plástica é necessário que uma tensão, no mínimo equivalente à tensão de ativação (necessária para que ocorra o deslizamento) seja aplicada, do contrário a tensão de escoamento $\sigma^{y}$ não será atingida $\left(\sigma<\sigma^{y}\right)$, portanto não haverá deformação. Caso essa tensão 
seja atingida a deformação sofrida pelo corpo será irreversível e o comportamento tensãodeformação terá resposta independente do tempo.
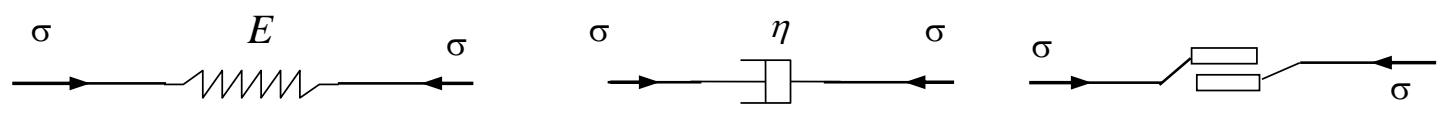

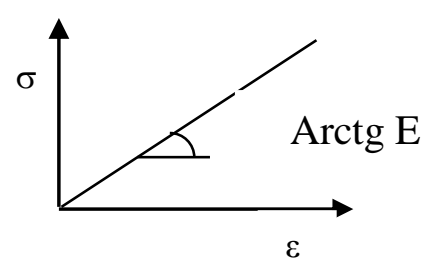

(a)

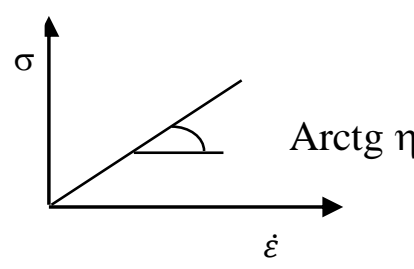

(b)

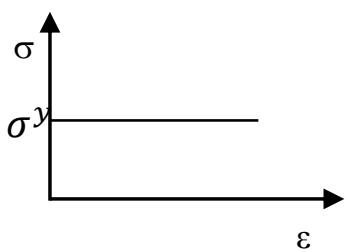

(c)

Figura 2.3: (a) Modelo Hookeano, (b) Modelo Newtoniano, (c) Modelo de Saint Venant.

A partir da combinação desses elementos em paralelo, em série ou em combinações múltiplas é possível desenvolver modelos mais complexos, como o de Burgers, que permite a modelação de uma ampla faixa de regimes e comportamentos.

\section{Modelo de Maxwell}

No modelo de Maxwell, a combinação em série de um elemento de Hooke com um elemento de Newton determina um comportamento viscoelástico de fluência estacionária. Este modelo pode determinar as deformações elásticas imediatas e o estágio de fluência secundária. A Figura 2.4 mostra o elemento que simboliza o modelo e os gráficos tensãodeformação $(\sigma \times \varepsilon)$ e deformação-tempo $(\varepsilon \times t)$.
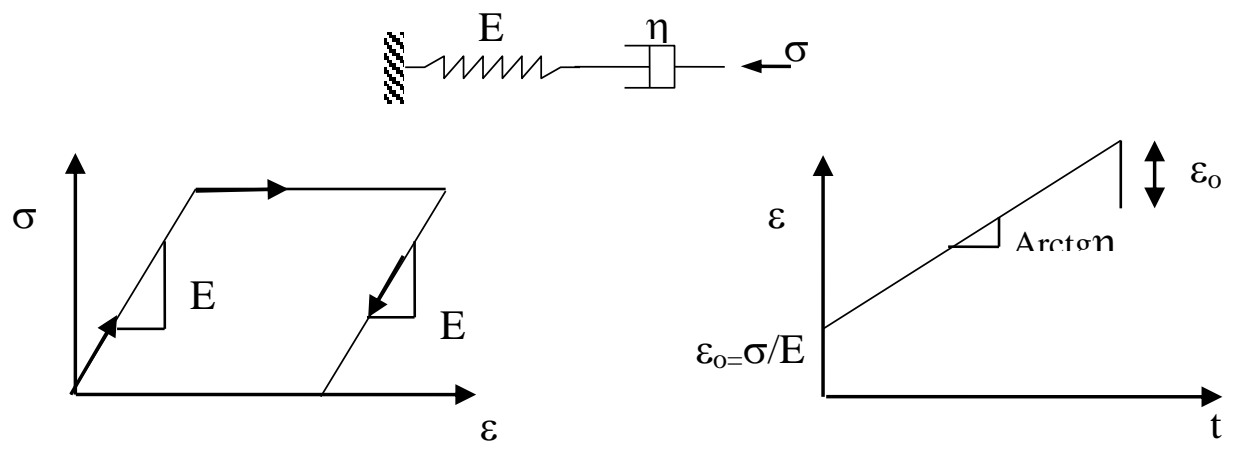

Figura 2.4: Modelo reológico de Maxwell.

As equações a seguir são deduzidas a partir do comportamento e combinação dos elementos, sabendo que neste caso a deformação total é a soma das deformações em cada elemento e tensão é a mesma em ambos: 
1) Equação de equilíbrio: $\sigma^{\mathrm{e}}=\sigma^{\mathrm{v}}=\sigma$

2) Equação de compatibilidade: $\varepsilon=\varepsilon^{\mathrm{e}}+\varepsilon^{\mathrm{v}}$

3) Equação constitutiva para elemento elástico: $\sigma^{\mathrm{e}}=\mathrm{E} \varepsilon^{\mathrm{e}}$

4) Equação constitutiva para elemento viscoso: $\sigma^{\mathrm{v}}=\eta \dot{\varepsilon}^{\mathrm{v}}$

Com o rearranjado das equações acima é possível chegar à equação diferencial (2.13), para o modelo de Maxwell.

$$
\dot{\varepsilon}=\frac{\dot{\sigma}}{E}+\frac{\sigma}{\eta}
$$

Resolvendo esta equação para $\sigma(t)=\sigma_{o}$, tensão constante ao longo do tempo, obtémse:

$$
\varepsilon(t)=\frac{\sigma_{o}}{E}+\frac{\sigma_{o}}{\eta} t
$$

No caso de se ter $\sigma_{o}=$ constante, a relação deformação-tempo é linear e cresce indefinidamente com o tempo devido à introdução do elemento viscoso, Figura 2.4. Neste caso se o tempo tende para infinito, as deformações também tendem o que não é verdade no comportamento de alguns materiais. Existem ainda algumas limitações deste modelo na simulação do comportamento viscoelástico de materiais. Uma delas é a falta de capacidade de representar a taxa de deformação decrescente sob um nível de tensão constante para o estágio primário de fluência.

\section{Modelo de Kelvin}

A combinação do elemento de Hooke com o de Newton, em paralelo, dá origem ao modelo de Kelvin (Figura 2.5). O modelo de Kelvin representa bem a fluência primária, mas não prevê a deformação elástica inicial. A Figura 2.5 mostra o elemento que simboliza o modelo, o gráfico tensão-deformação $(\sigma \times \varepsilon)$ e o gráfico deformação-tempo $(\varepsilon \times t)$. 

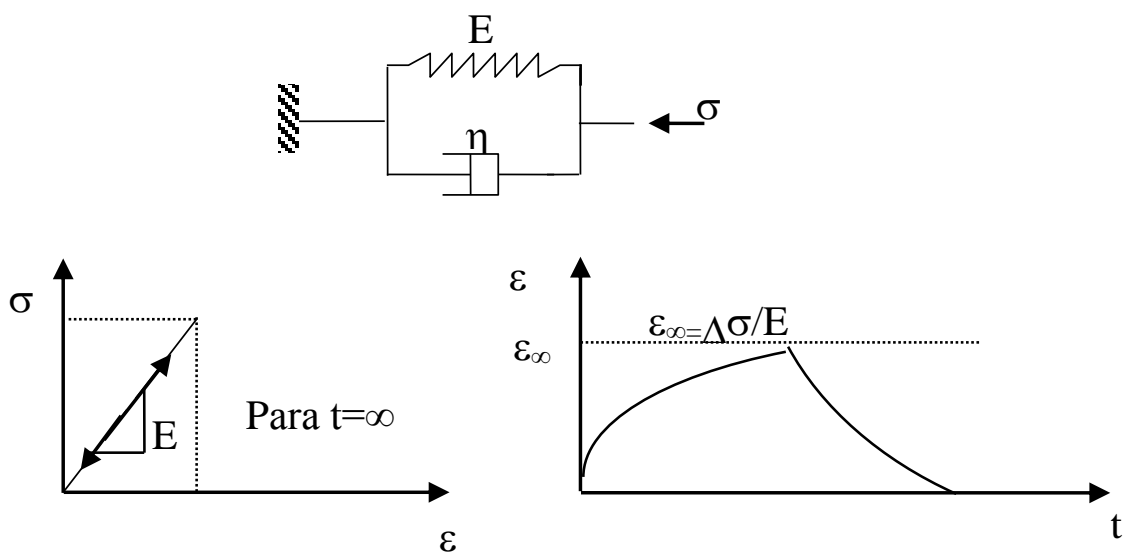

Figura 2.5: Modelo de Kelvin.

As equações a seguir são deduzidas a partir do comportamento e combinação dos elementos, sabendo que neste caso a tensão total é a soma das tensões em cada elemento e deformação é a mesma em ambos os elementos:

1) Equação de equilíbrio: $\sigma=\sigma^{\mathrm{e}}+\sigma^{\mathrm{v}}$

2) Equação de compatibilidade: $\varepsilon=\varepsilon^{\mathrm{e}}=\varepsilon^{\mathrm{v}}$

3) Equação constitutiva para elemento elástico: $\sigma^{\mathrm{e}}=\mathrm{E} \varepsilon^{\mathrm{e}}$

4) Equação constitutiva para elemento viscoso: $\sigma^{v}=\eta \dot{\varepsilon}^{v}$

Com a combinação das equações acima, chega-se à:

$$
\dot{\varepsilon}=\frac{\sigma}{\eta}-\frac{E}{\eta} \varepsilon
$$

Como condição inicial $\sigma(t)=\sigma_{o}$ para Equação(2.16) tem-se:

$$
\varepsilon(t)=\frac{\sigma_{o}}{E}\left[1-\exp \left(-\frac{E}{\eta} t\right)\right]
$$

Da mesma forma que o modelo de Maxwell, o modelo de Kelvin também possui algumas limitações na simulação do comportamento de materiais viscoelásticos. Uma delas é a não representação da deformação permanente após a fluência primária, estágio de fluência secundário (ou estacionário). 


\section{Modelos Generalizados}

Na simulação do comportamento ideal dos materiais, vários modelos são utilizados e podem determinar os mais variados tipos de deformações (elastoplástica, viscoelástica, elastoviscoplástica, entre outras). Por exemplo, a combinação do modelo de Kelvin e Hooke em series dá origem um Modelo de Kelvin Generalizado (Figura 2.6(b)). É evidente que a generalização de modelos torna a descrição do comportamento de fluência mais próxima da realidade, desde que se tenha uma base física forte para tanto. Outro modelo generalizado pode ser formado pela associação de um elemento de Hooke com um elemento de Maxwell, Figura 2.6(a), mas não é usado para rochas evaporíticas, pois não permite a descrição da resposta elástica instantânea.

$\mathrm{E}_{1}$
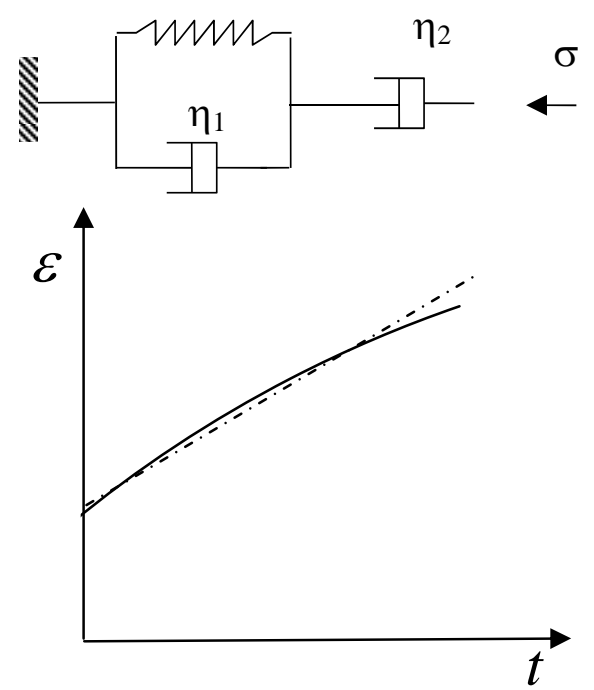

(a)
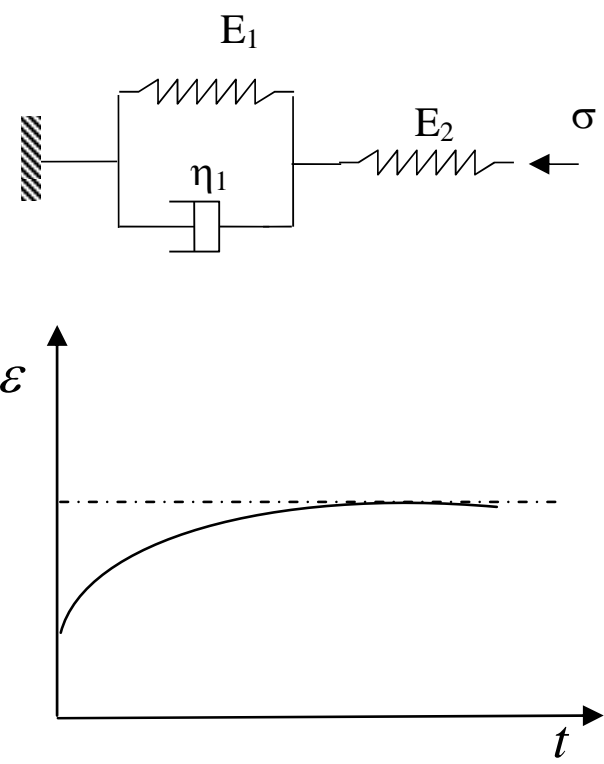

(b)

Figura 2.6: (a) Modelo de Maxwell generalizado, (b) Modelo de Kelvin generalizado.

Utilizando o mesmo raciocínio dos itens anteriores e admitindo que a tensão seja constante no tempo $\left(\sigma(t)=\sigma_{o}\right)$ é possível encontrar a Equação (2.18) para o Modelo de Maxwell Generalizado e a Equação (2.19) para o Modelo de Kelvin Generalizado.

$$
\begin{gathered}
\varepsilon(t)=\frac{\sigma_{o}}{E_{1}}\left[1-\exp \left(-\frac{E_{1}}{\eta_{1}} t\right)\right]+\frac{\sigma_{o} \cdot t}{\eta_{2}} \\
\varepsilon(t)=\frac{\sigma_{o}}{E_{2}}+\frac{\sigma_{o}}{E_{1}}\left[1-\exp \left(-\frac{E_{1}}{\eta_{1}} t\right)\right]
\end{gathered}
$$


Yu (1998) depois de ter estudado alguns modelos de fluência observou que a maioria dos modelos satisfaz a determinadas situações. Por exemplo, o Modelo de Kelvin e Kelvin Generalizado pertencem aos corpos sólidos, por isso simulam apenas a fluência primária. Os modelos de Maxwell e de Maxwell Generalizado se aplicam aos corpos líquidos e só descrevem a fluência secundária da rocha.

\section{Modelo de Burgers}

Formado pela associação em série dos modelos de Maxwell e de Kelvin, o modelo de Burgers é um modelo composto de quatro elementos que, devido ao arranjo feito, permite um melhor ajuste na representação do comportamento de fluência. A acoplagem dos elementos de Maxwell e de Kelvin em série permite que a deformação total do sistema seja obtida pela soma das deformações destes dois elementos (Equação (2.20)), apresentados na Figura 2.7:

$$
\varepsilon=\varepsilon_{p}+\varepsilon_{s}
$$

Para a tensão atuante, sabe-se que é igual em cada um dos elementos:

$$
\sigma=\sigma_{p}=\sigma_{s}
$$

Com isso é possível substituir as equações constitutivas de Maxwell (2.13) e de Kelvin (2.16), na Equação (2.20) junto a Equação (2.21) e chegar à equação de equilíbrio:

$$
\eta_{1} \ddot{\varepsilon}+E_{1} \dot{\varepsilon}=\left(\frac{\eta_{1}}{E_{2}}\right) \ddot{\sigma}+\left(1+\frac{E_{1}}{E_{2}}+\frac{\eta_{1}}{\eta_{2}}\right) \dot{\sigma}+\left(\frac{E_{1}}{\eta_{2}}\right) \sigma
$$

onde $\eta_{1}$ e $E_{1}$ são constantes referentes aos elementos do modelo de Kelvin, $\eta_{2}$ e $E_{2}$ são constantes referentes aos elementos do modelo de Maxwell (ver Figura 2.7).

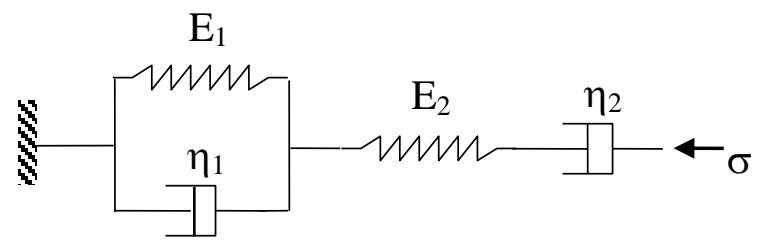

Figura 2.7: Representação esquemáticas do modelo de Burgers. 
Aplicando a condição de tensão constante no tempo $\left(\sigma(t)=\sigma_{0}\right)$ e resolvendo a equação diferencial, pode-se chegar à Equação (2.23).

$$
\varepsilon(t)=\left(\frac{\sigma_{0}}{E_{2}}\right)+\left(\frac{\sigma_{0}}{E_{1}}\right)\left(1-e^{\frac{-E_{1} t}{\eta_{1}}}\right)+\left(\frac{\sigma_{0}}{\eta_{2}}\right) t
$$

A Figura 2.8 representa o comportamento de fluência de um material utilizando o modelo de Burgers. Como se vê na representação gráfica, o modelo consegue reproduzir a deformação inicial elástica instantânea $\left(\varepsilon_{0}=\sigma_{0} / E_{2}\right)$, a deformação na fase de fluência transiente e a deformação na fase secundária (velocidade de deformação constante $\left(\sigma_{0} / \eta_{2}\right)$.

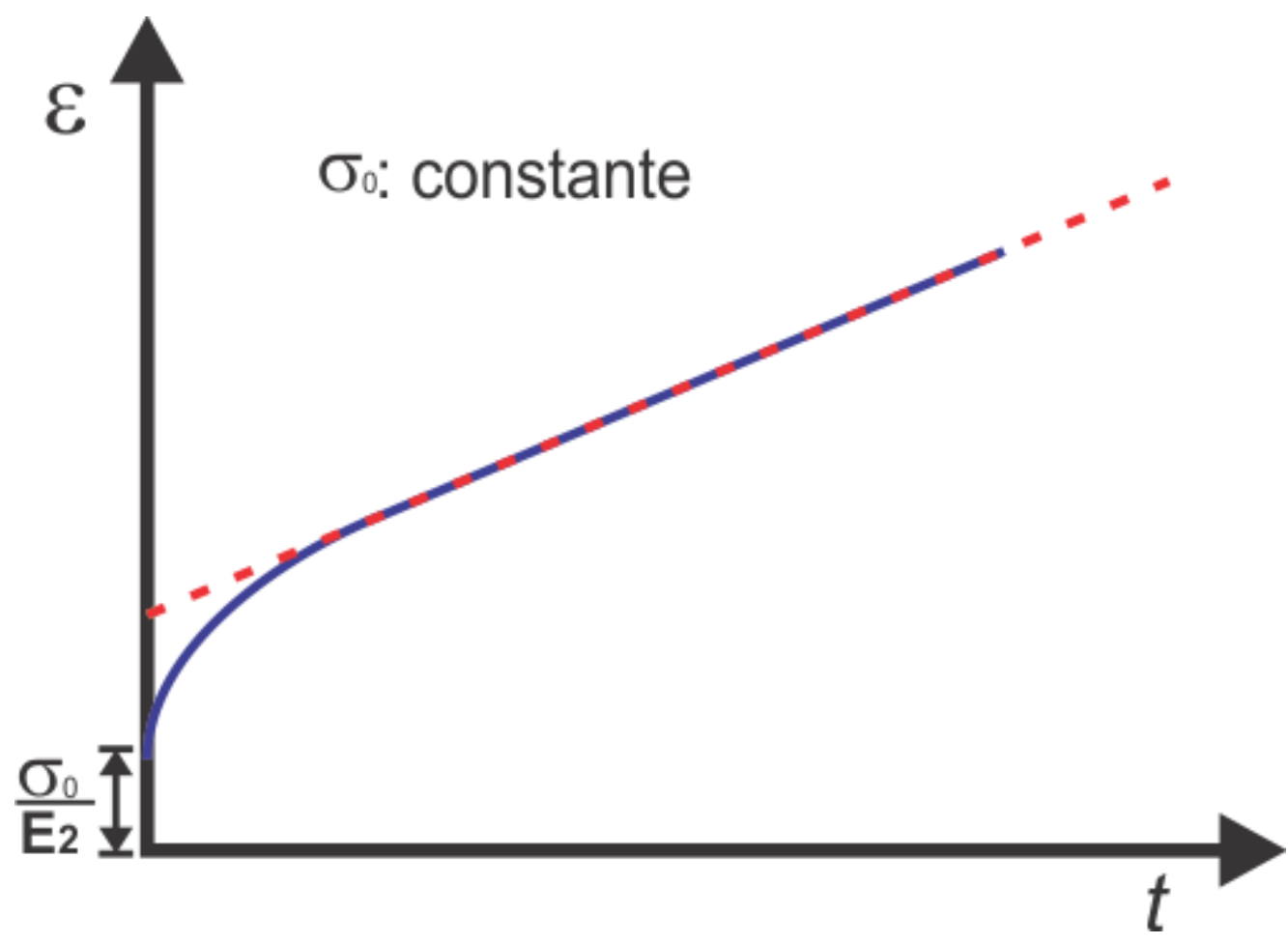

Figura 2.8: Ensaio de fluência representado pelo modelo de Burgers.

Conforme Goodman (1989), Yu (1998), Costa (1984), Cella (2003) e Jaeger et al. (2007), o modelo de Burgers representa muito bem as deformações de fluência a uma taxa decrescente e as deformações permanentes, o que o torna o modelo reológico mais representativo em relação às curvas experimentais obtidas em ensaios de laboratórios.

\section{Outros Modelos}

As leis constitutivas baseadas em modelos reológicos recebem varias críticas devido as suas limitações. Segundo Cella (2003), elas são válidas para períodos curtos de tempo ou 
intervalo limitado de tensões, não devendo ser extrapoladas além do domínio valido por dados experimentais.

A Figura 2.9, apresentada por Dusseault, M.B. et al. (1987), é um modelo reológico utilizado para representar o comportamento geral de fluência em rochas evaporíticas. Este modelo inclui as fases de deformação elástica instantânea, fluência primária, fluência estacionaria e recuperação, e retomada com ciclos de descargas e recarga.

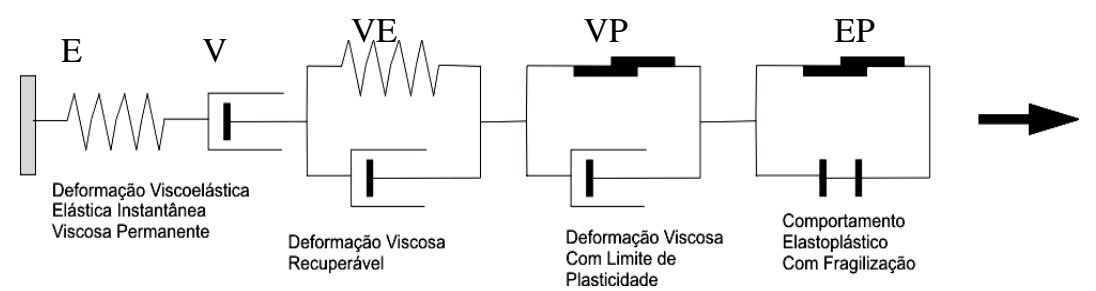

(a) Associação de elementos para formação do modelo

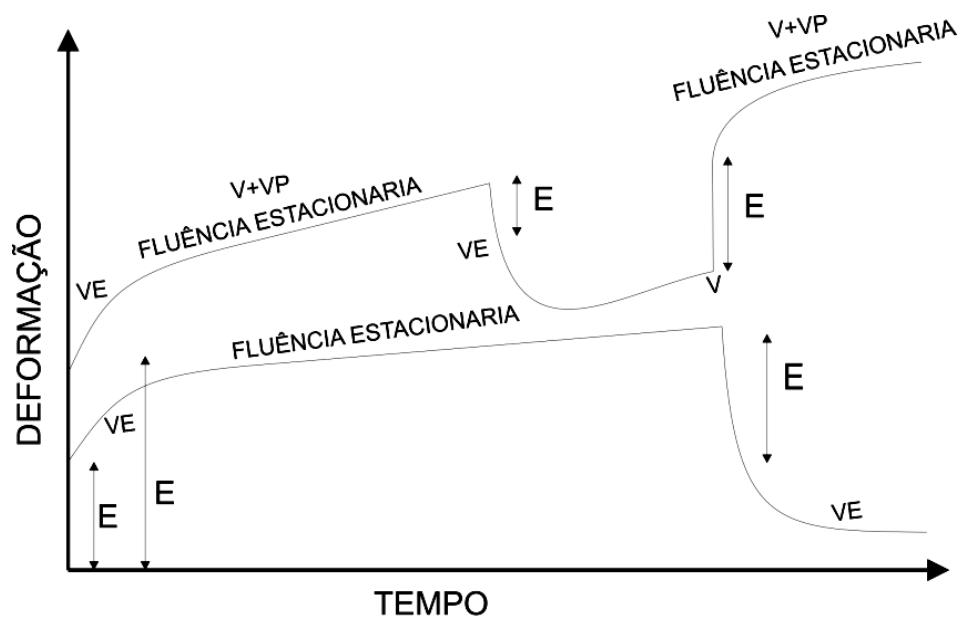

(b) Comportamento de fluência de uma rocha salina

Figura 2.9: Comportamento geral de um modelo reológico elaborado de rochas salinas.

É fácil perceber que à medida que as combinações de modelos se tornam mais complexas, a quantidade de parâmetros aumenta de modo a dificultar o estudo. Este fato pode tornar obscuro o significado físico e comprometer as aplicações práticas. Para tanto, Goodman (1989) concluiu que, para muitos propósitos práticos, o modelo de fluência de Burgers é preferível e suficiente para descrever o comportamento de uma rocha com tal característica, desde que se utilizem parâmetros adequados para cada tipo de situação.

\subsection{ESCOLHA DO MODELO CONSTITUTIVO}

Segundo Cristescu (1988), a deformação de fluência em rochas, em torno de túneis escavados em alguns evaporitos, leva a um fechamento lento com o tempo e, portanto, um 
modelo reológico pode ser apropriado para descrever o comportamento da mesma. Esta formulação matemática (ou modelo constitutivo) geralmente tem uma grande influência sobre os resultados calculados analiticamente e/ou numericamente. Bérest et al. (2005), trabalharam com interpretação de testes de estanqueidade em cavernas em evaporitos, estudaram os fenômenos gerados pela queda de pressão devido ao vazamento de líquido. Este estudo foi baseado em equações de fluência, dependente da temperatura, capaz de descrever o regime transiente do maciço a uma profundidade entre 500m e 2000m. Nesta situação o efeito da temperatura sobre a fluência teve uma grande relevância e caso não tivesse sido considerada os resultados poderiam ficar longe do esperado.

Como se percebe a diversidade de modelos constitutivos de fluência é enorme. $\mathrm{O}$ fato é que a fluência dos evaporitos é muito complexa e o número de evaporitos é grande, o que pode explicar esta diversidade. Boulianne et al. (2004), por exemplo, utilizaram três modelos constitutivos para caracterizar a resposta de fluência da rocha evaporítica. Os resultados mostraram que cada modelo utilizado tem uma grande influência sobre os resultados numéricos obtidos.

$\mathrm{Na}$ escolha de um modelo ideal é preciso levar em conta as características marcantes do tipo de evaporito em estudo. Além disto, é necessário levar em consideração o tipo de análise que será feita, por exemplo, numa analise de uma escavação profunda se faz necessário considerar o efeito geotérmico. De acordo com Yu (1998), não existe um modelo simples que possa descrever o comportamento de fluência de forma satisfatória. Ainda, conforme Yu (1998), um modelo adequado deve satisfazer os seguintes requisitos:

$\checkmark$ Ser capaz de simular o comportamento de deformação da rocha nos diferentes níveis de tensão, tais como a resposta elástica instantânea, fluência primária, fluência secundária e até mesmo a fluência terciária;

$\checkmark$ Ter significado físico;

$\checkmark$ Os parâmetros do modelo devem ser determinados em ensaios de laboratório ou de campo. 


\subsection{MODELAGEM DE UM TÚNEL}

\subsubsection{ESCAVAÇÃO DO TÚNEL}

O processo de escavação de um túnel leva a um alivio de tensões nas paredes do mesmo. Segundo Panet (1979) e Panet e Guenot (1982), o alívio provoca deformações e à medida que a frente de escavação avança, as deformações tendem a aumentar nas seções anteriores. Este fato pode levar a convergência do túnel e causar a perda total do mesmo. Segundo Goodman (1989), em túneis escavados em maciços evaporíticos, a convergência da seção pode ocorrer durante toda vida, devido ao comportamento de fluência das mesmas. Dessa forma se faz necessário ter atenção às escavações em regiões com este tipo de maciço.

\subsubsection{CONSIDERAÇÕES PARA O MACIÇO EVAPORÍTICO}

Segundo Yu (1998), para túneis escavados em maciços pouco competentes ou pobres, as deformações podem aumentar com o tempo mesmo depois da frente de escavação ter passado. O maciço evaporítico se enquadra neste grupo e merece destaque por ter uma característica viscoelástica bem definida. A viscoelasticidade tende a provocar deformações quando um carregamento é aplicado e mesmo se mantendo constante as deformações não param, de modo a provocar instabilidades de blocos e fechamento do túnel. Segundo o autor acima referenciado, neste tipo de caso a convergência do túnel deve ser considerada e a seção deve ser analisada como um estado plano de deformação.

Dusseault et al. (2004) afirmam que o detalhamento da escavação de um maciço evaporítico exige que as propriedades particulares da rocha (comportamento de fluência e alta solubilidade) sejam reconhecidas e incorporadas no plano de escavação. Segundo Cristescu (1985) em certas regiões em torno do túnel a rocha está em um estado dilatante, em outras em um estado compressível ou em um estado elástico. Para tanto o mesmo apresentou critérios matemáticos para delinear os tais limites e ainda levou em consideração que os limites podem variar com o tempo, sabido que o estado de tensão varia lentamente.

\subsubsection{NECESSIDADE DE SUPORTE}

A convergência do túnel escavado em um maciço evaporítico, que começa logo após o início da escavação, ocorre lentamente no tempo e pode ser bastante falha. Geralmente 
quando se escava um túnel neste tipo de maciço, um suporte é instalado a fim de limitar o fechamento do túnel e garantir segurança da abertura. $\mathrm{Na}$ análise da interação maciço-suporte é importante pensar na redistribuição de tensões no suporte, devido à pressão exercida pela rocha, e na influência do suporte sobre o processo de fluência. Schwartz e Einstein (1980) analisaram a importância do suporte, em maciços de pouca competência, em modelos numéricos em duas dimensões. Naquele estudo, os autores acima citados mostraram a relação existente entre o atraso na instalação do suporte, a espessura do suporte, o raio do túnel, e as propriedades do maciço e do suporte com o efeito de convergência do túnel. Mais tarde, Gomes (2006) mostrou que as três dimensões devem ser levadas em conta, numa análise dependente do tempo, na interação maciço suporte. Segundo Cristescu et al. (1987), para um longo período de tempo a análise da interação maciço-suporte tem que ser baseada nas propriedades reológicas do maciço e nas propriedades mecânicas do suporte. Ainda segundo os autores acima referenciados, para a concepção do suporte adequado é preciso escolher o melhor "layout" e a melhor sequência de escavação.

\subsubsection{AVALIAÇÃO DA SEGURANÇA}

A segurança de um túnel tem relação direta com a forma da seção transversal, com a sequência de escavação e logicamente, com a instalação e tipo de suporte. Cristescu (1985), Cristescu et al. (1987), Cristescu (1988) já diziam isso e afirmavam que em rochas com características viscoelásticas a análise teórica da interação maciço-suporte pode ser significativa. Em rochas pouco competentes a ausência de suporte pode provocar muitas falhas e levar o aumento das deformações, por consequência à convergência do túnel.

Em alguns casos, mesmo na presença de suporte, perda de estabilidade pode ocorrer como resultado do aumento das deformações. Isto se deve à fluência dos evaporitos, que mesmo submetidos a tensões de confinamento constante, provoca deformações permanentes. Por outro lado, conforme Schwartz e Einstein (1980) e Gomes (2006), é sabido que a sequência de escavação e instalação do suporte pode afetar o desempenho do túnel e sua forma final. Em condições como esta, o revestimento secundário pode ser utilizado para suportar a sobrecarga do maciço e estabilizar o movimento do túnel. Portanto, o desenvolvimento de um método racional para calcular as tensões no revestimento secundário de túneis deve ser levado em conta. 


\section{CAPITULO 3 - VALIDAÇÃO DO PROGRAMA ABAQUS®}

O programa Abaqus® é consagrado e já foi validado para muitas condições mais complexas que as apresentadas aqui. A validação abaixo apresentada tem a finalidade de verificar as técnicas de modelagem a serem adotadas nos problemas reais a serem analisados nos capítulos seguintes.

Para a validação do uso do Abaqus® é utilizado, como exemplo, um poço com $0.36 \mathrm{~m}$ de raio, aproximadamente 14". Nele são verificados os deslocamentos radiais, as tensões radiais e as tensões tangenciais em dois modelos. O primeiro modelo corresponde a um modelo Plano de Deformação e o segundo a um modelo Axissimétrico. No modelo Plano de Deformação é analisada uma situação a $200 \mathrm{~m}$ da superfície, em uma região de maciço evaporítico. Para o modelo Axissimétrico a verificação dos deslocamentos radiais, das tensões radiais e das tensões tangenciais é feita em diferentes profundidades neste mesmo maciço.

Na determinação das tensões in situ é idealizado que as tensões horizontais iniciais são iguais nas duas direções. Além disso, o módulo de elasticidade $(E$ ) é constante em toda camada do material, ou seja, o meio é homogêneo e também isotrópico. Os parâmetros elásticos foram adotados iguais aos de análise de um poço apresentada por Poiate et al. (2006) e têm como valor para o módulo de elasticidade e coeficiente de Poisson: $E=20.7$ GPa e $v=$ 0.36, respectivamente. Esses valores foram obtidos a partir de estudos relacionados ao comportamento mecânico do sal da mina Taquari-Vassouras no Nordeste Brasileiro.

A comparação dos resultados da resposta elástica do Abaqus ${ }^{\circledR}$ é feita com as formulações elásticas de Kirsch.

\subsection{SOLUÇÃO DE KIRSCH}

A solução de Kirsch (1898) apud Gomes (2006) para os deslocamentos radiais e o estado de tensões normais e cisalhantes resultantes da retirada de material, na forma de uma circunferência de raio $R$, de um meio elástico infinito regido por um estado de deformações planas e submetido a um estado de tensões principais iniciais $\sigma_{x}$ e $\sigma_{y}$, pode ser representada pelas seguintes equações: 


$$
\begin{gathered}
\sigma_{r}=\left(\frac{\sigma_{x}+\sigma_{y}}{2}\right)\left(1-\frac{R^{2}}{r^{2}}\right)+\left(\frac{\sigma_{x}-\sigma_{y}}{2}\right)\left(1+\frac{3 R^{4}}{r^{4}}-\frac{4 R^{2}}{r^{2}}\right) \cos (2 \theta), \\
\tau_{\theta r}=-\frac{1}{2}\left(\sigma_{x}-\sigma_{y}\right)\left(1+\frac{2 R^{2}}{r^{2}}-\frac{3 R^{4}}{r^{4}}\right) \sin (2 \theta), \\
\sigma_{\theta}=\left(\frac{\sigma_{x}+\sigma_{y}}{2}\right)\left(1+\frac{R^{2}}{r^{2}}\right)-\left(\frac{\sigma_{x}-\sigma_{y}}{2}\right)\left(1+\frac{3 R^{4}}{r^{4}}\right) \cos (2 \theta), \\
u_{r}=\frac{1}{4}\left(\frac{\sigma_{x}+\sigma_{y}}{G}\right)\left(\frac{R^{2}}{r}\right)+\frac{1}{4}\left(\frac{\sigma_{x}-\sigma_{y}}{G}\right)\left(\frac{R^{2}}{r}\right)\left(\frac{\sigma_{x}-\sigma_{y}}{G}\right)\left(\frac{R^{2}}{r}\right)\left(2(1-2 v)+\frac{R^{2}}{r^{2}}\right) \sin (2 \theta), \\
\left.u_{\theta}=-\frac{R^{2}}{r^{2}}\right) \cos (2 \theta),
\end{gathered}
$$

onde $\sigma_{r}$ é a tensão normal efetiva na direção radial, $\sigma_{\theta}$ é a tensão normal efetiva na direção tangencial, $\tau_{\theta r}$ é a tensão cisalhante no plano $\mathrm{r} \theta, \sigma_{x}$ é a tensão inicial na direção $\mathrm{x}, \sigma_{y}$ é a tensão inicial na direção y, $u_{\theta}$ é o deslocamento tangencial, $u_{r}$ é o deslocamento radial, $G$ é o módulo de cisalhamento do maciço $R$ é o raio do poço, $r$ é à distância a partir do eixo do poço, $\theta$ é o ângulo medido no sentido anti-horário do plano $x y$ a partir do eixo $x$.

\subsection{MODELO AXISSIMÉTRICO}

O modelo axissimétrico corresponde a um plano de $7.2 \mathrm{~m}$ x $200 \mathrm{~m}$, como mostra a Figura 3.1. Nessa situação considera-se apoio de primeiro gênero na parte inferior e lateral, de modo a impedir os deslocamentos nas direções vertical e horizontal, respectivamente. $\mathrm{Na}$ Figura 3.1 é possível observar o eixo de revolução na lateral esquerda, onde são colocados os apoios laterais, o que caracteriza o modelo. 


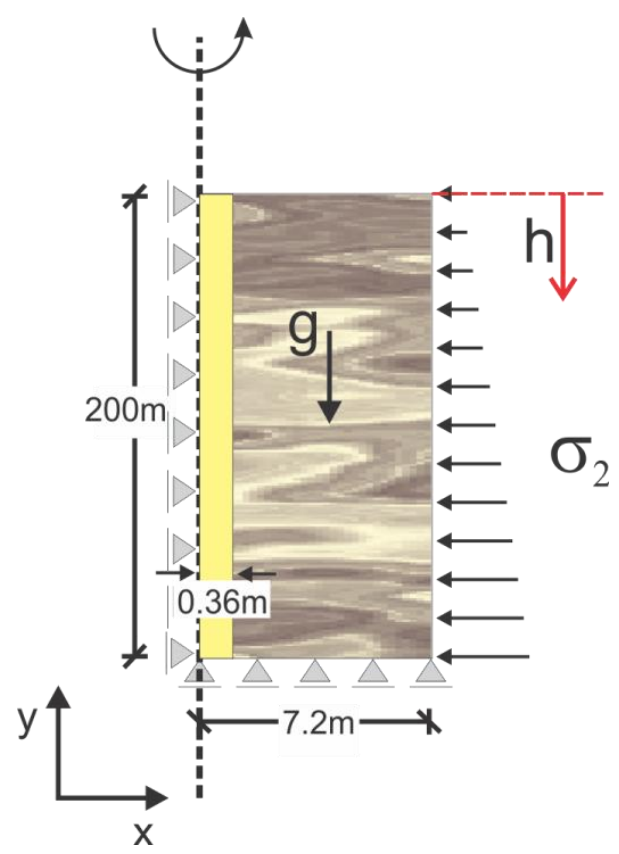

Figura 3.1: Modelo axissimétrico do poço.

Observa-se ainda a aplicação de um carregamento gravitacional g, Figura 3.1, onde $\mathrm{g}=10 \mathrm{~m} / \mathrm{s}^{2}$. Desta forma, as tensões verticais são obtidas a partir da equação:

$$
\sigma_{1}=\rho \cdot g \cdot h
$$

onde $\rho=2160 \mathrm{~kg} / \mathrm{m}^{3}$ e $0 \mathrm{~m} \leq h \leq 200 \mathrm{~m}$, correspondendo respectivamente à massa específica do evaporito e $h$ a profundidade de interesse. Considerando o equilíbrio elástico, as tensões horizontais são:

$$
\sigma_{2}=\left(\frac{v}{1-v}\right) \sigma_{1}
$$

A simulação do modelo Axissimétrico é dividida em 2 etapas (steps) como no modelo Plano de Deformação. Os resultados numéricos, tanto de deslocamentos, quanto de tensões, se encontram bem próximos dos resultados obtidos pela solução analítica de Kirsch. Nas Figuras 2.2 a 2.4 podem ser vistas as comparações entre os resultados da solução clássica de Kirsch e os obtidos com a modelagem no Abaqus®. Observa-se que são comparados resultados para $h$ igual a $0 \mathrm{~m}$, a $50 \mathrm{~m}$, a $100 \mathrm{~m}$, a $150 \mathrm{~m}$ e a $200 \mathrm{~m}$, tanto para os deslocamentos radiais quanto para as tensões tangenciais e radiais, ou seja, para as tensões perpendiculares e paralelas 
(horizontalmente) ao plano do modelo. Em relação ao erro máximo entre os resultados de deslocamentos, o mesmo foi de $46 \%$ para $r=7,2 \mathrm{~m}$ e próximo de $0 \%$ para $r=0,36 \mathrm{~m}$.

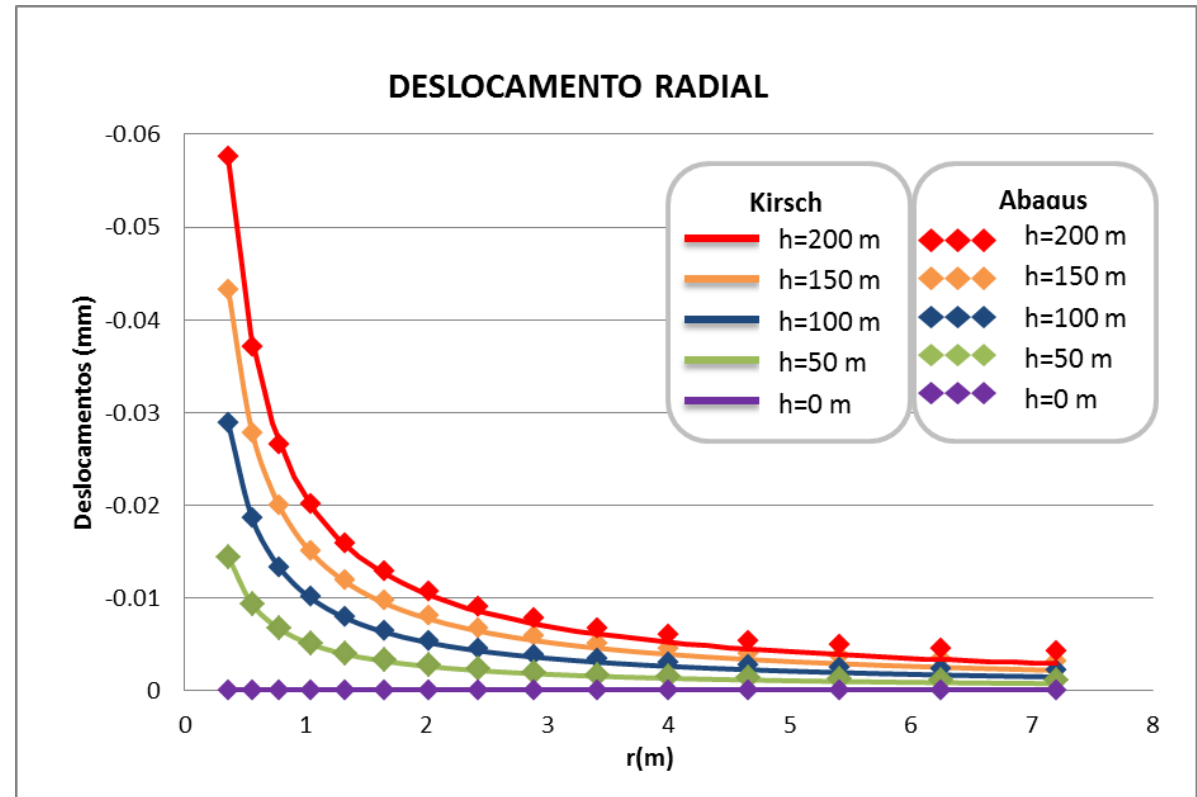

Figura 3.2: Deslocamento radial em cinco diferentes profundidades.

Na Figura 3.2 é possível verificar a boa aderência entre as curvas de Kirsch e os dados obtidos com a simulação no Abaqus ${ }^{\circledR}$. Esse fato é confirmado nos gráficos de tensões tangenciais e radiais da Figura 3.3 e da Figura 3.4. Em relação ao erro máximo entre os resultados de tensões tangencias, o mesmo foi de até $4 \%$ para $r \leq 1 \mathrm{~m}$ e próximo de $0 \%$ para $r$ $>1 \mathrm{~m}$. Para as tensões radiais, o erro máximo foi de até $3 \%$ para $r \leq 1 \mathrm{~m}$ e próximo de $0 \%$ para $r>1 \mathrm{~m}$.

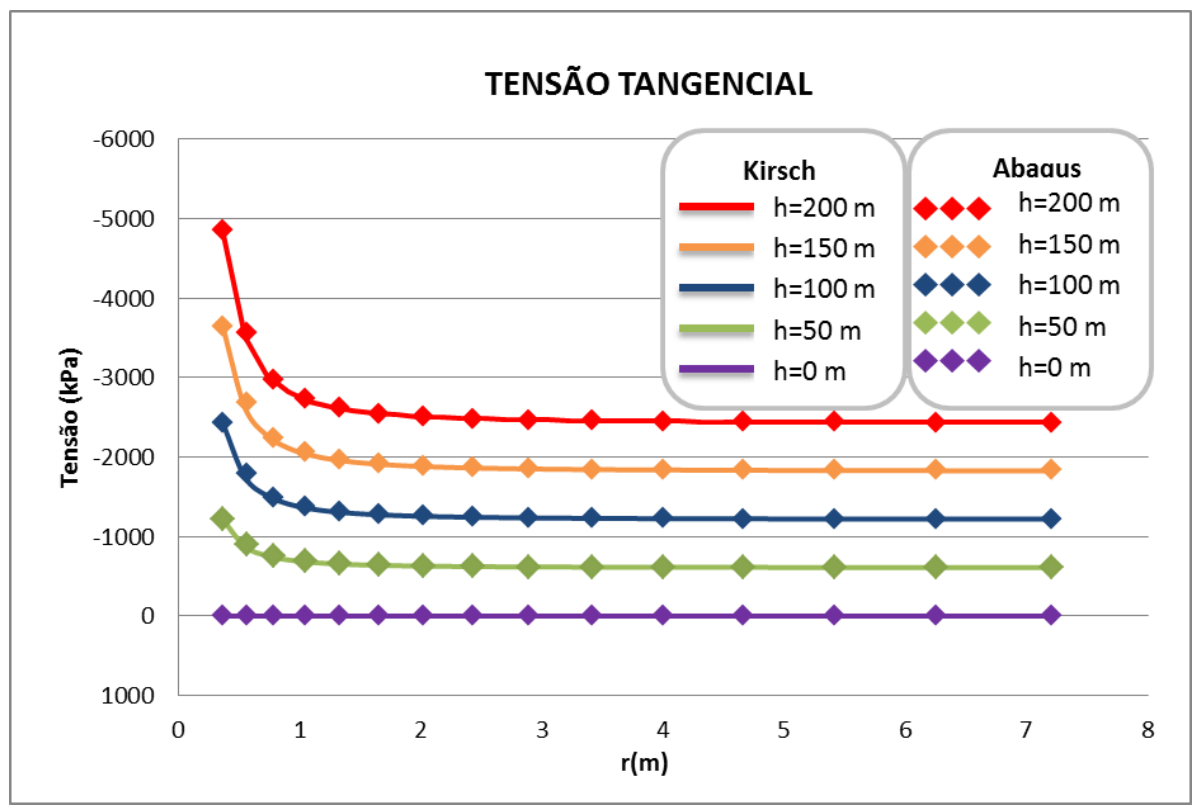

Figura 3.3: Tensões tangenciais em cinco diferentes profundidades. 


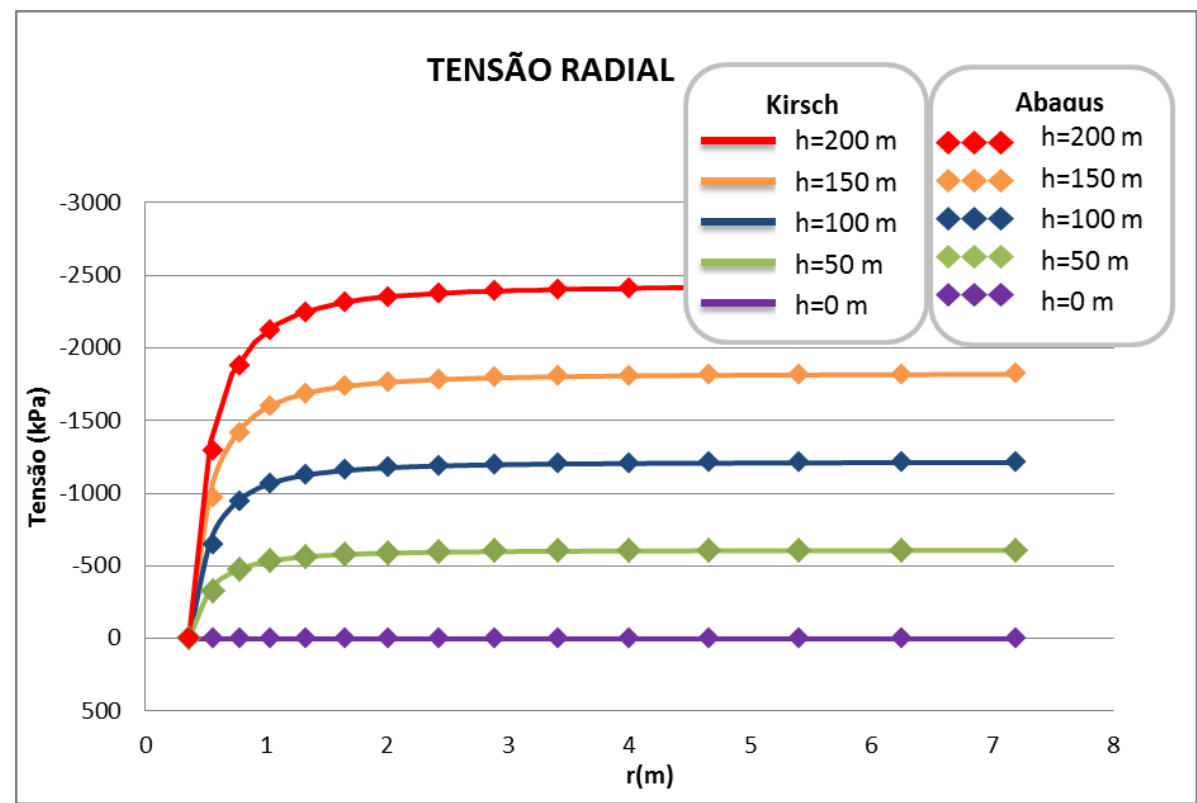

Figura 3.4: Tensões radiais em cinco diferentes profundidades.

\subsection{MODELO PLANO DE DEFORMAÇÃO}

O modelo Plano de Deformação correspondeu a um plano de $7.2 \mathrm{~m}$ x $7.2 \mathrm{~m}$ como mostra a Figura 3.5. Na parte inferior e lateral esquerda são considerados apoios do primeiro gênero de modo a impedir os deslocamentos nas direções x e $y$, respectivamente. $\mathrm{Na}$ superfície do modelo e na lateral direita são admitidas tensões de compressão nas direções 1 e 2, calculadas para uma profundidade de $200 \mathrm{~m}$ abaixo da superfície e correspondentes a $\sigma_{1}=\sigma_{2}=4320 \mathrm{kPa}$, por ser considerado um meio isotrópico com peso especifico para maciço de $21,6 \mathrm{kN} / \mathrm{m}^{3}$.

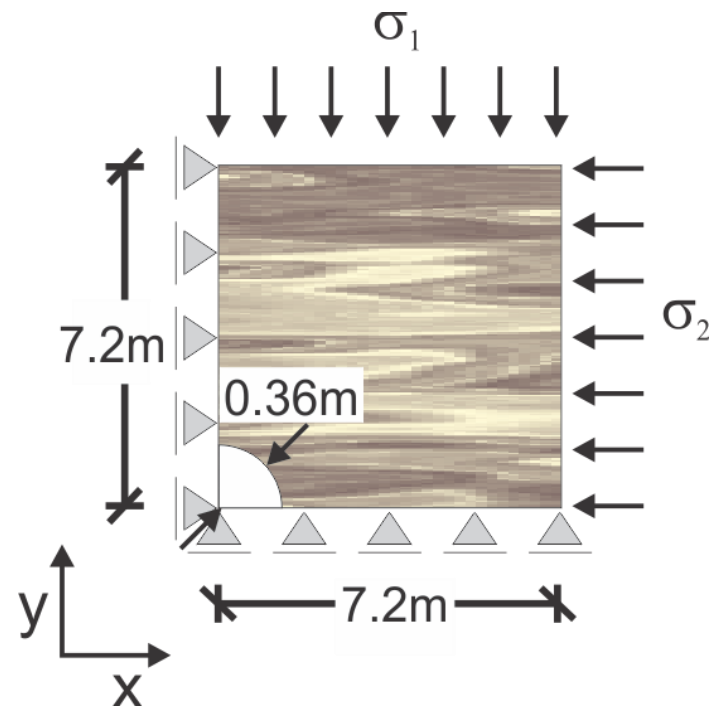

Figura 3.5: Modelo plano de deformação do poço. 
Esta situação não necessita de um carregamento gravitacional, pois as deformações são analisadas em uma dada profundidade. A simulação do modelo Plano de Deformação é dividida em 2 etapas (steps) que correspondem a cada passo da simulação. Na primeira etapa (step) é feito o uso da função geostática do Abaqus® e na segunda é feita a simulação da resposta elástica. Os resultados da simulação, em comparação com a solução de Kirsch (1898), são apresentado nas Figuras 2.6 e 2.7.

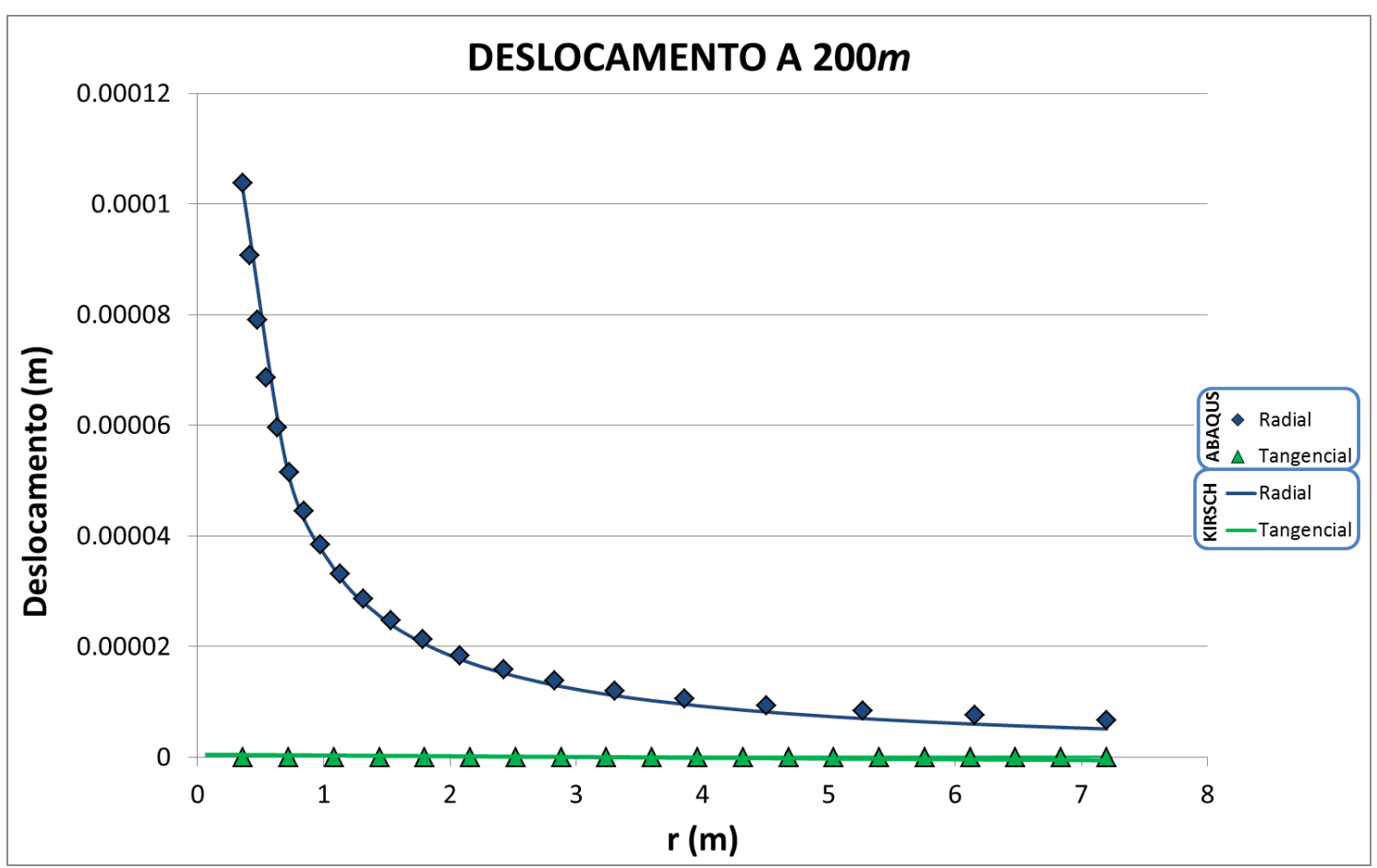

Figura 3.6: Deslocamento para $200 \mathrm{~m}$ de profundidade para $K=1$.

Observa-se que os deslocamentos tangenciais foram constantes e iguais à zero ao longo de todo eixo horizontal. Também é visto que os deslocamentos radiais próximos à parede do poço são maiores e tendem a zero à medida que se afasta do poço. Em relação ao erro máximo entre os resultados de deslocamentos, o mesmo foi de $32 \%$ para $r=7,2 \mathrm{~m}$ e próximo de $0 \%$ para $r=0,36 \mathrm{~m}$.

As tensões tangenciais e a radial para $h=200 \mathrm{~m}$ são mostradas na Figura 3.7, onde se observa que as que as tensões tangenciais são maiores próximo ao poço e tendem a um valor que corresponde ao da tensão inicial em posições remotas ao poço. Por outro lado, as tensões radiais são nulas próximas ao poço e tendem a um valor que corresponde ao da tensão inicial em posições remotas ao poço Em relação ao erro máximo entre os resultados de tensões tangencias, o mesmo foi de até $3 \%$ para $r \leq 1 \mathrm{~m}$ e de $0 \%$ para $r>1 \mathrm{~m}$. Para as tensões radiais, o erro máximo foi de até $4 \%$ para $r \leq 1 \mathrm{~m}$ e próximo de $0 \%$ para $r>1 \mathrm{~m}$. 


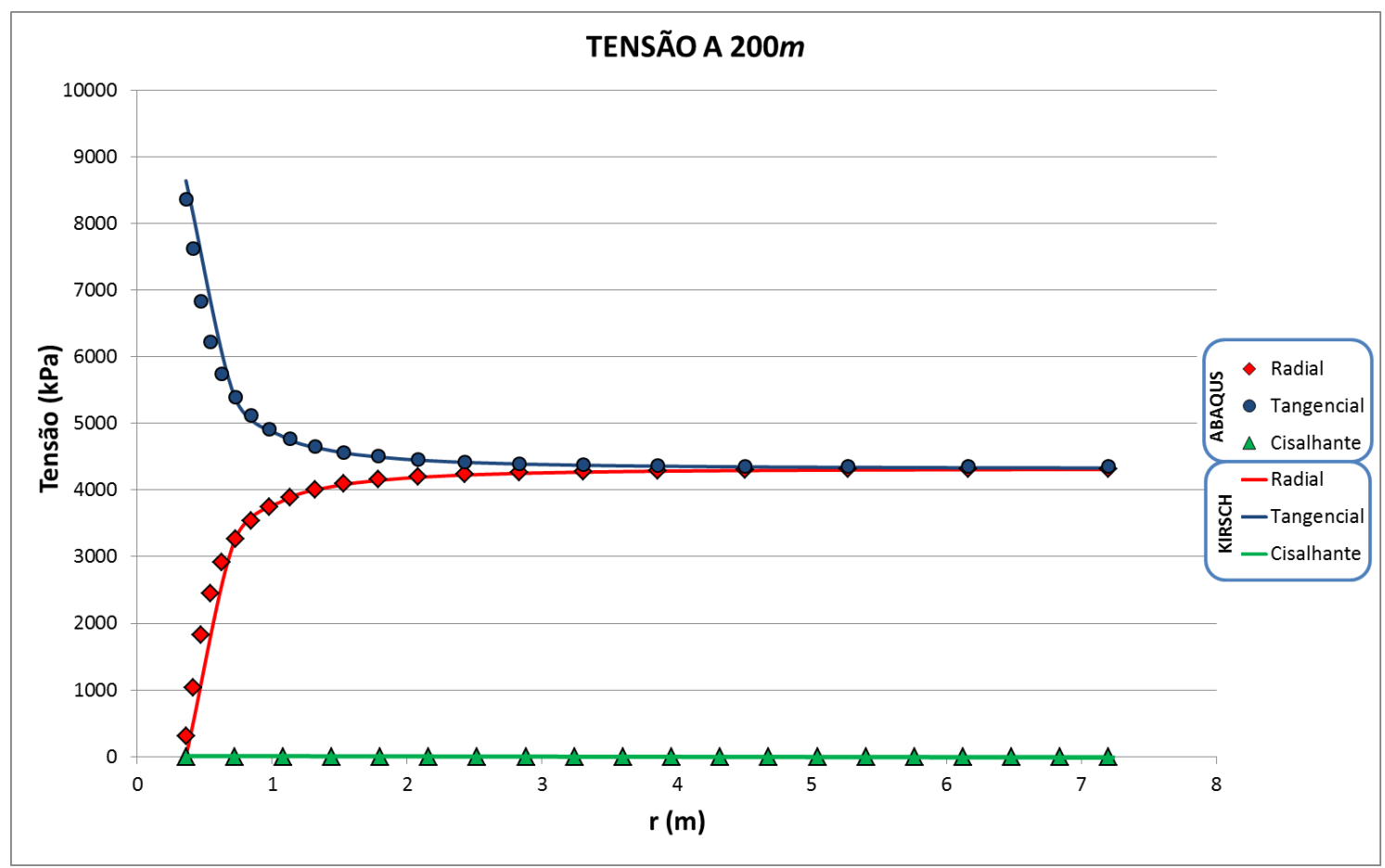

Figura 3.7: Tensões para $200 \mathrm{~m}$ de profundidade para $K=1$. 


\section{CAPITULO 4 - ESTUDO PRELIMINAR NA MODELAGEM MACIÇO- SUPORTE}

Os estudos preliminares, realizados com o Abaqus ${ }^{\circledR}$, possibilitaram a escolha dos elementos finitos e das considerações para a interação maciço-suporte. Para tanto, os resultados da simulação foram comparados com a solução de Einstein e Schwartz (1979), casos "no slip" e "full slip" (com e sem atrito entre maciço e suporte). Inicialmente foi realizado um estudo da interação maciço-suporte e devido aos resultados obtidos observou-se a necessidade do estudo da melhor malha.

\subsection{MODELO DE EINSTEIN E SCHWARTZ}

O comportamento do suporte de um túnel em um maciço depende da interação maciço-suporte. A presença de um suporte no maciço modifica as tensões afetando o comportamento do mesmo, principalmente quando o suporte se deforma excessivamente.

Peck et al. (1972) já haviam citado o efeito da rigidez relativa, maciço-suporte, em dois casos: o primeiro de um suporte ideal flexível, sem momento fletor; e o segundo de um suporte ideal rígido, onde o momento fletor pode existir. Posteriormente, Einstein e Schwartz (1979) mostraram que a tensão cisalhante existente na interface maciço-suporte também influenciava no comportamento do maciço.

Burns e Richard (1964) formularam pela primeira vez a solução da rigidez relativa, desenvolvida para bueiros com carregamento unidimensional. Esta solução é aplicada para aberturas circulares em um plano de deformação de um material elástico linear e uma das hipóteses mais restritivas é assumir que a face de escavação está afastada do plano de deformação analisado. Além disto, a solução admite que a abertura do túnel seja escavada e suportada antes que o campo de tensões seja aplicado.

Einstein e Schwartz (1979), seguindo a mesma lógica de Burns e Richard (1964), propuseram uma solução que incluía a escavação. Para tanto Einstein e Schwartz (1979) postularam que o maciço seria semi-infinito, elástico, homogêneo, isotrópico com uma tensão vertical inicial $P$ e uma tensão horizontal igual à $K P$ (ver, Figura 4.1). Além disto, o suporte 
do túnel foi idealizado como elástico de parede espessa, em que a flexão e as deformações circunferenciais são consideradas.

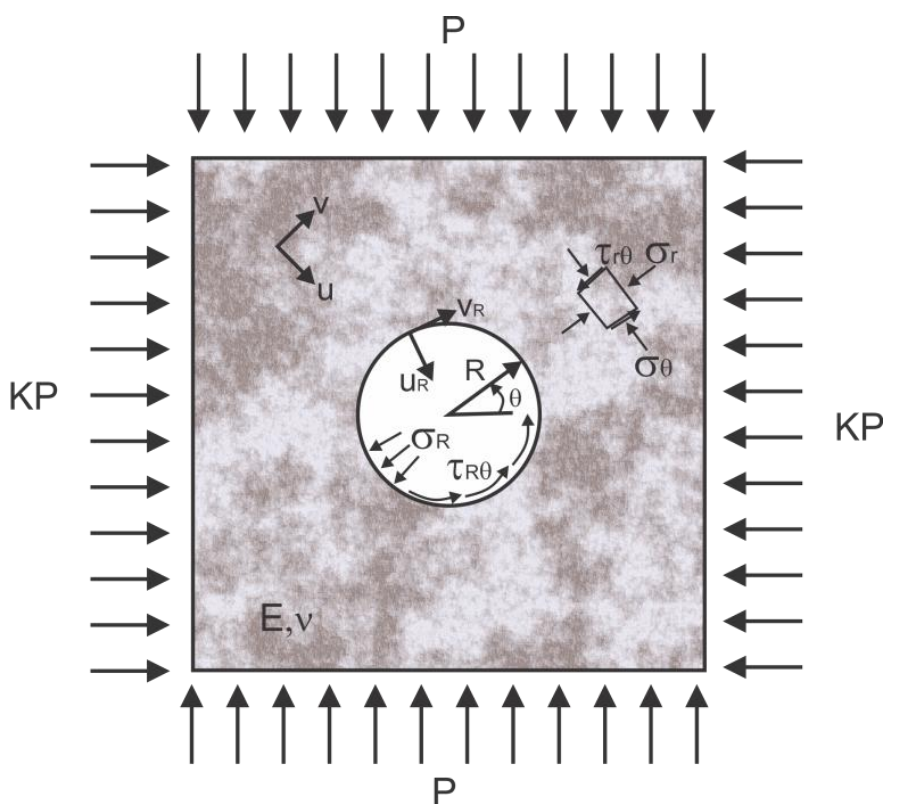

(a) Maciço

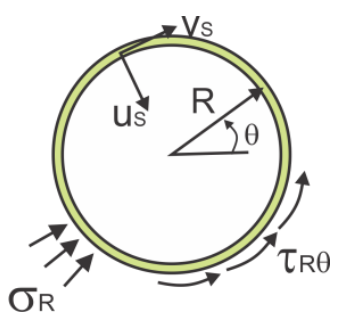

(b) Suporte

Figura 4.1: Notação para a solução de rigidez relativa de Einstein e Schwartz (1979).

Na metodologia de Einstein e Schwartz (1979), a obtenção da solução revisada da rigidez relativa segue três etapas: a primeira obtém o campo de deslocamento no maciço devido às tensões in situ; a segunda etapa obtém os deslocamentos no suporte e as tensões no maciço depois da escavação, na interface maciço-suporte; e a terceira etapa computa os esforços solicitantes no suporte induzidos pelas tensões de contato na interface maciço suporte. Para as etapas 2 e 3 Einstein e Schwartz (1979) consideram as condições "full-slip" (sem atrito) e "no-slip" (contato fixo), porém, com o campo de tensão lateral livre restrito por uma função de tensão vertical, como exemplo: $\sigma_{h}=(v / 1-v) \sigma_{v}$, onde $\sigma_{h}, \sigma_{v}$ e $v$ são tensão horizontal, tensão vertical e coeficiente de Poisson, respectivamente.

Por se tratar de um estudo que leva em conta a importância do atrito no comportamento maciço-suporte, optou-se em utilizar a "Etapa 2" da solução de rigidez relativa de Einstein e Schwartz (1979). A seguir, as formulações para obtenção das tensões radias e cisalhantes do maciço na interface maciço suporte, e os deslocamentos radiais e tranversais do suporte são apresentadas. 


\subsubsection{NO SLIP}

As tensões radiais e cisalhantes na interface maciço-suporte para o caso "no slip" são expressas pelas Equações (4.1) e (4.2), respectivamente (ver, Figura 4.1).

$$
\begin{gathered}
\sigma_{R}=\frac{P}{2}\left[\left(1+K_{0}\right)\left(1-a_{0}^{*}\right)-\left(1-K_{0}\right)\left(1-6 a_{2}^{*}+4 b_{2}^{*}\right) \cos (2 \theta)\right], \\
\tau_{R \theta}=\frac{P}{2}\left[\left(1-K_{0}\right)\left(1+6 a_{2}^{*}-2 b_{2}^{*}\right) \sin (2 \theta)\right],
\end{gathered}
$$

O esforço normal e o momento fletor no suporte para o caso "no slip" são expressos pelas Equações (4.3) e (4.4), respectivamente. A Figura 4.2 mostra a convenção de sinais adotada para o esforço normal $T$ e momento fletor $M$ na seção do suporte.

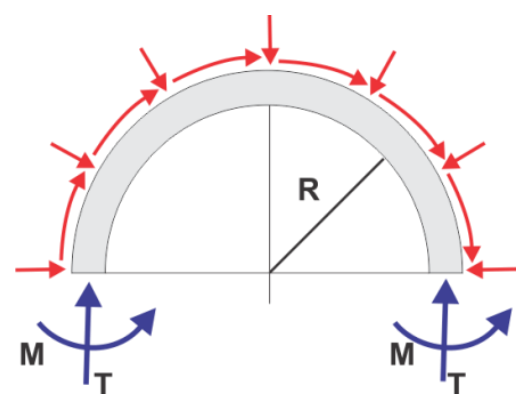

Figura 4.2:Convenção de sinais positivos para o esforço normal e momento fletor na seção do suporte, Einstein e Schwartz (1979).

$$
\begin{gathered}
T=\frac{P \cdot R}{2}\left(1+K_{0}\right)\left(1-a_{0}^{*}\right)+\frac{1}{2}\left(1-K_{0}\right)\left(1+2 a_{2}^{*}\right) \cos (2 \theta) \\
M=\frac{P \cdot R^{2}}{4}\left(1-K_{0}\right)\left(1-2 a_{2}^{*}+2 b_{2}^{*}\right) \cos (2 \theta)
\end{gathered}
$$

Os deslocamentos radiais e transversais no suporte para o caso "no slip" são expressos pelas Equações (4.5) e (4.6), respectivamente (ver, Figura 4.1).

$$
\begin{gathered}
u_{s}=\frac{P \cdot R \cdot(1+v)}{2 E}\left\{\left(1+K_{0}\right) a_{0}^{*}+\left(1-K_{0}\right)\left[4(1-v) b_{2}^{*}-2 a_{2}^{*}\right] \cos (2 \theta)\right\} \\
v_{s}=-\frac{P \cdot R \cdot(1+v)\left(1-K_{0}\right)}{E}\left[a_{2}^{*}+(1-2 v) b_{2}^{*}\right] \sin (2 \theta),
\end{gathered}
$$


onde:

$a_{0}^{*}=\frac{C^{*} F^{*}(1-v)}{C^{*}+F^{*}+C^{*} F^{*}(1-v)} ;$

$a_{2}^{*}=\hat{b} b_{2}^{*}$;

$b_{2}^{*}=\frac{C^{*}(1-v)}{2\left[C^{*}(1-v)+4 v-6 \hat{b}-3 \hat{b} C^{*}(1-v)\right]} ;$

$\hat{b}=\frac{\left(6+F^{*}\right) C^{*}(1-v)+2 F^{*} v}{3 F^{*}+3 C^{*}+2 C^{*} F^{*}(1-v)} ;$

A rigidez relativa maciço-suporte, incorporada à solução, leva em conta dois parâmetros adimensionais: coeficiente de compressibilidade, Equação (4.7), e coeficiente de flexibilidade, Equação (4.8). O coeficiente de compressibilidade mede a rigidez relativa do sistema maciço-suporte em uma condição de carregamento uniforme ou simétrico (tensão horizontal igual à tensão vertical) e o coeficiente de flexibilidade mede a rigidez relativa do sistema em uma condição de flexão sob carregamento não simétrico (tensão horizontal do maciço diferente da tensão vertical)

$$
\begin{gathered}
C^{*}=\frac{E R\left(1-v_{s}^{2}\right)}{E_{s} A_{s}\left(1-v^{2}\right)} \\
F^{*}=\frac{E R^{3}\left(1-v_{s}^{2}\right)}{E_{s} I_{s}\left(1-v^{2}\right)}
\end{gathered}
$$

onde: $E, \quad v$ são o módulo de elasticidade e o coeficiente de Poisson do maciço, respectivamente; $E_{s}, v_{s}$ são o módulo de elasticidade e coeficiente de Poisson do suporte, respectivamente; $A_{s}$ é a área da seção transversal do suporte; $I_{s}$ é o momento de inércia da mesma seção; e $R$ é o raio da escavação. 


\subsubsection{FULL SLIP}

As tensões radiais e cisalhantes na interface maciço suporte para o caso "full slip" são expressas pelas Equações (4.9) e (4.10), respectivamente (ver, Figura 4.1).

$$
\begin{gathered}
\sigma_{R}=\frac{P}{2}\left[\left(1+K_{0}\right)\left(1-a_{0}^{*}\right)-\left(1-K_{0}\right)\left(3-6 a_{2}^{\prime *}\right) \cos (2 \theta)\right], \\
\tau_{R \theta}=0
\end{gathered}
$$

O esforço normal e o momento fletor no suporte para o caso "full slip" são expressos pelas Equações (4.11) e (4.12), respectivamente. A convenção de sinais pode ser vista na Figura 4.2, a mesma adotada para o caso "no slip".

$$
\begin{gathered}
T=\frac{P \cdot R}{2}\left[\left(1+K_{0}\right)\left(1-a_{0}^{*}\right)+\left(1+K_{0}\right)\left(1-2 a_{2}^{\prime *}\right) \cos (2 \theta)\right] \\
M=\frac{P \cdot R^{2}}{2}\left(1-K_{0}\right)\left(1-2 a_{2}^{\prime *}\right) \cos (2 \theta)
\end{gathered}
$$

Os deslocamentos radiais e transversais no suporte para o caso "full slip" são expressos pelas Equações (4.13) e (4.14), respectivamente (ver, Figura 4.1).

$$
\begin{gathered}
u_{s}=\frac{P \cdot R \cdot(1+v)}{E}\left\{\frac{1}{2}\left(1+K_{0}\right) a_{0}^{*}-\left(1-K_{0}\right)\left[(5-6 v) a_{2}^{*^{*}}-(1-v)\right] \cos (2 \theta)\right\}, \\
v_{s}=\frac{P \cdot R \cdot(1+v)\left(1-K_{0}\right)}{2 E}\left[(5-6 v) a_{2}^{\prime *}-(1-v)\right] \sin (2 \theta),
\end{gathered}
$$

onde:

$a_{0}^{*}=\frac{C^{*} F^{*}(1-v)}{C^{*}+F^{*}+C^{*} F^{*}(1-v)}$

$a_{2}^{\prime *}=\frac{\left(F^{*}+6\right)(1-v)}{2 F^{*}(1-v)+6(5-6 v)}$. 


\subsection{DADOS DE ENTRADA}

Em todas as simulações deste capítulo foram utilizados os valores relacionados na Tabela 4.1. Os mesmos valores foram adotados para a solução de Einstein e Schwartz (1979) para posterior comparação dos resultados.

Tabela 4.1: Dados utilizados.

\begin{tabular}{|c|c|c|c|c|c|c|}
\hline $\boldsymbol{P}(\mathbf{k P a})$ & $\boldsymbol{R}(\mathbf{m})$ & $\boldsymbol{A s}\left(\mathbf{m}^{\mathbf{2}}\right)$ & $\boldsymbol{v}$ & $\boldsymbol{E}(\mathbf{M P a})$ & $v_{s}$ & $\boldsymbol{E} \boldsymbol{s}(\mathbf{M P a})$ \\
\hline 80 & 5 & 0,1 & 0,3 & 10 & 0,3 & 100 \\
\hline
\end{tabular}

Para o estudo do efeito da interação maciço-suporte foram simuladas duas situações: uma para o coeficiente de empuxo $K_{0}=1$ e outra para $K_{0}=0,5$. No estudo da malha, são mostrados apenas os resultados para $K_{0}=0,5$, por serem mais discrepantes.

\subsection{RESULTADOS}

\subsubsection{TENSÕES}

Como o Abaqus® retorna apenas as tensões normais $\sigma_{x}$ e $\sigma_{y}$, e cisalhante $\tau_{x y}$ foi necessário calcular as tensões normais radiais $\sigma_{R}$ e de cisalhamento $\tau_{R \theta}$ na interação maciçosuporte. A Figura 4.3 mostra a convenção das tensões normais e cisalhantes em um plano qualquer, Farmer (1983).

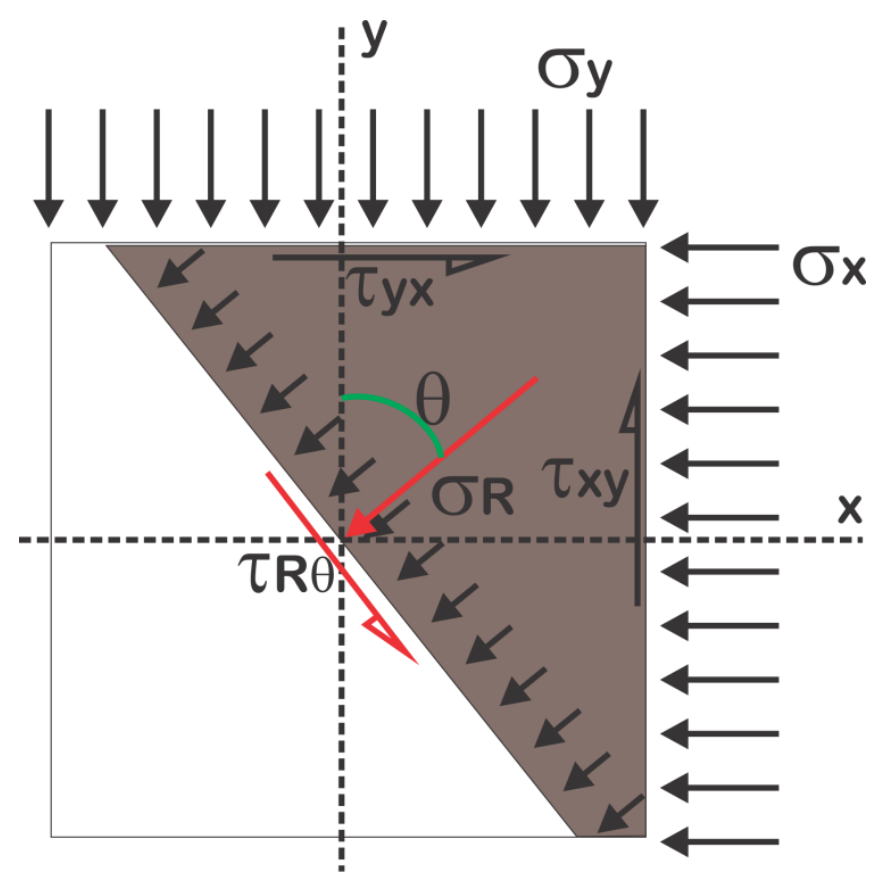

Figura 4.3: Tensões em um plano qualquer. 
Conhecidas as tensões em dois planos perpendiculares é possível calcular as tensões em qualquer outro plano com base nas Equações (4.15) e (4.16), admitindo $\tau_{x y}=\tau_{y x}$. As mesmas são facilmente obtidas a partir da condição de equilíbrio de forças.

$$
\begin{gathered}
\sigma_{R}=\frac{\sigma_{x}+\sigma_{y}}{2}+\frac{\sigma_{x}-\sigma_{y}}{2} \cos 2 \theta+\tau_{x y} \sin 2 \theta, \\
\tau_{R \theta}=\frac{\sigma_{x}-\sigma_{y}}{2} \sin 2 \theta-\tau_{x y} \cos 2 \theta,
\end{gathered}
$$

\subsubsection{DESLOCAMENTOS}

Para a obtenção dos deslocamentos radiais $u_{\mathrm{s}}$ e transversais $v_{\mathrm{s}}$ no suporte, é necessário representar os deslocamentos horizontais $u$ e verticais $v$ em um novo sistema de referência, Figura 4.4.

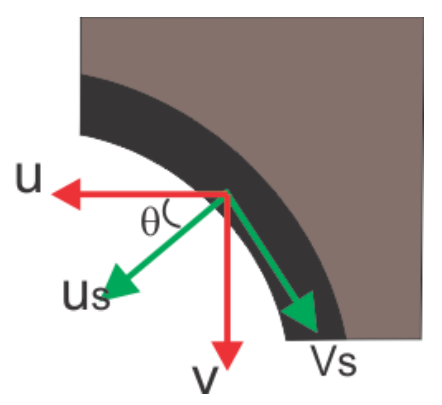

Figura 4.4: Deslocamentos no suporte.

Conhecidos os deslocamentos horizontais e verticais fornecido pelo Abaqus®, é possível calcular os deslocamentos radias e transversais, Equações (4.17) e (4.18).

$$
\begin{aligned}
& u_{s}=u \cos \theta+v \sin \theta \\
& v_{s}=v \cos \theta-u \sin \theta
\end{aligned}
$$

\subsection{EFEITO DO ATRITO NA INTERAÇÃO MACIÇO-SUPORTE}

Para a simulação da interação maciço-suporte foi utilizado um quarto de simetria de um túnel circular, Figura 4.5. Nas bordas inferior e lateral esquerda do modelo são 
consideradas condições de simetria em y e em $\mathrm{x}$, respectivamente. Nas bordas superior e lateral direita do modelo são aplicadas as tensões de compressão nas direções y e x, respectivamente.

A malha dos modelos utilizou três tipos de elementos: elementos de vigas quadráticos (B22) para o suporte, triangulares lineares (CPE3) região interna ao perímetro de escavação (túnel); e quadrilaterais quadráticos (CPE8) para o restante do maciço. Um resumo com o número de nós e elementos é mostrado na Tabela 4.2; maiores detalhes dos elementos encontram-se no Item 4.5.

Tabela 4.2: Malha utilizada no modelo.

\begin{tabular}{|c|c|c|c|}
\cline { 2 - 4 } \multicolumn{1}{c|}{} & Tipos & Nós & Elementos \\
\hline \multirow{3}{*}{ "No Slip" } & CPE8 & 7217 & 2322 \\
\cline { 2 - 4 } & CPE3 & 55 & 54 \\
\cline { 2 - 4 } & B22 & 55 & 54 \\
\hline \multirow{3}{*}{ "Full Slip" } & CPE8 & 7217 & 2322 \\
\cline { 2 - 4 } & CPE3 & 55 & 54 \\
\cline { 2 - 4 } & B22 & 201 & 200 \\
\hline
\end{tabular}

Estes elementos permitem capturar concentrações de tensão e modelar geometrias complexas com superfície curva, sem a necessidade de uma malha muito refinada. Além disto, são eficazes em problemas com domínio de flexão, Abaqus-6.11 (2011). A Figura 4.5 mostra a malha utilizada no modelo.

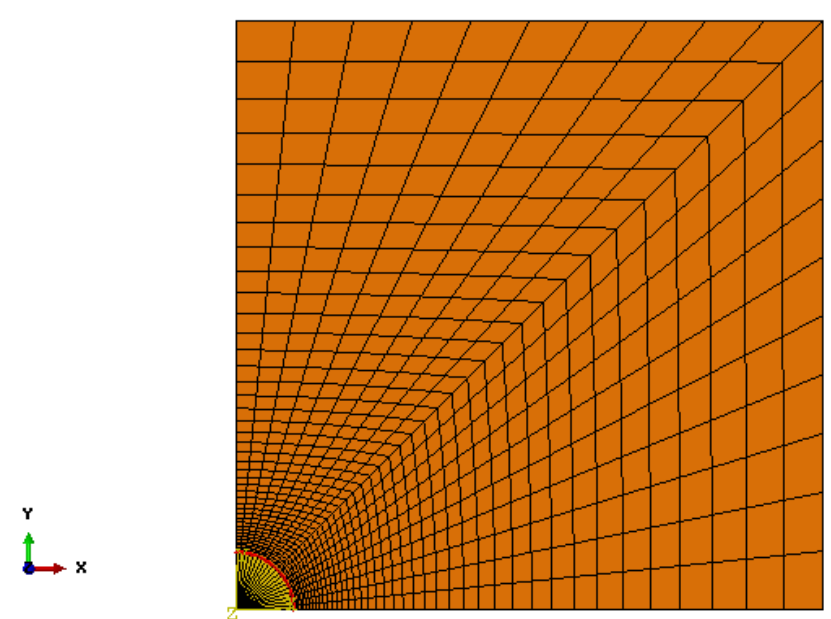

Figura 4.5: Malha do modelo (interação maciço-suporte).

Observa-se que, para o modelo "no slip" utilizaram-se 54 elementos B22 e para o modelo "full slip" 200 elementos B22. Isto se deve à necessidade da condição "full slip" de utilizar a função “*Surface Interaction” do Abaqus®, ou seja, o contato se dá entre 
superfícies, e assim, quanto maior o número de elementos em contato mais preciso é o resultado.

\subsubsection{NO SLIP}

A simulação "no slip" foi divida em duas fases, que correspondem a cada etapa de análise. A primeira etapa é geostática, onde se faz o uso da função geostática do Abaqus®. Nesta etapa, as tensões são colocadas no modelo e a condição de deformação nula antes da escavação é garantida. A segunda etapa é Elástica, onde é simulada a resposta elástica devido à remoção dos elementos do túnel com a colocação do suporte. Nesta etapa, o suporte é colocado no mesmo instante da escavação, idealização estabelecida na formulação de Einstein e Schwartz (1979).

Para garantir a condição de "no slip" utilizou-se a ferramenta "Create Stringer" do Abaqus®. Esta ferramenta permite a criação dos elementos do suporte, elementos B22, com os mesmos nós da superfície escavada do maciço. Mesmo tendo os mesmos nós o Abaqus® calcula dois resultados, um para o suporte e outro para o maciço. Esta estratégia garante a condição de "no slip", ou seja, fixa uma superfície a outra.

Na Figura 4.6 podem-se observar os resultados para as tensões radiais na interação maciço-suporte, obtidos para o caso "no slip".

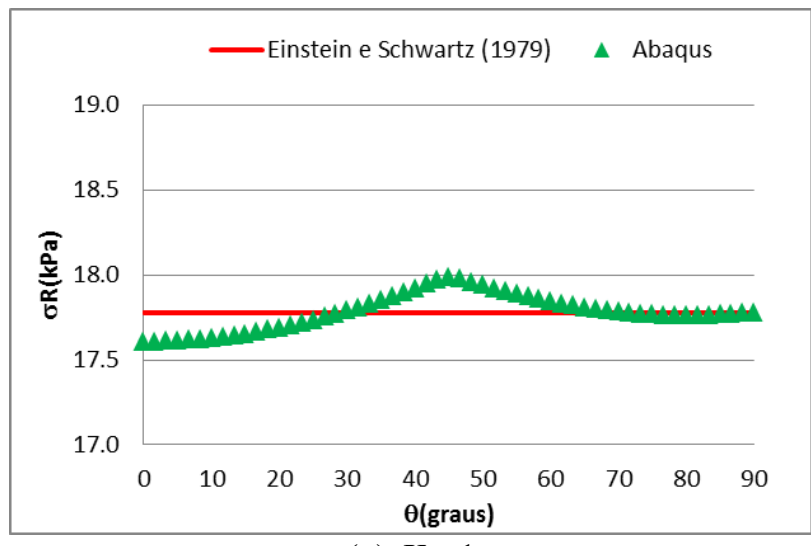

(a) $K_{0}=1$

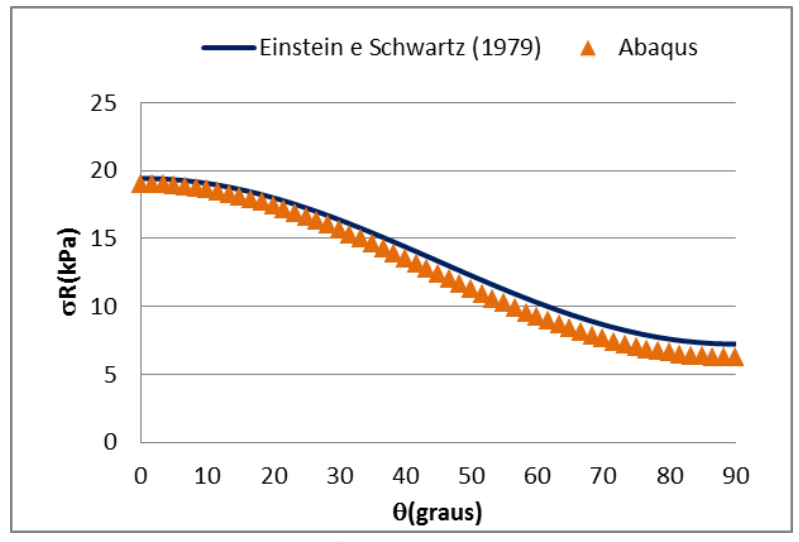

(b) $K_{0}=0,5$

Figura 4.6: Tensão radial entre o maciço e o suporte ("no slip").

Observa-se que houve uma pequena variação nas tensões radiais entre a solução de Einstein e Schwartz (1979) e a solução numérica do Abaqus® tanto para $K_{0}=1$ como para $K_{0}=0,5$, com um erro máximo absoluto próximo de $5 \%$. Desta forma, verificou-se a 
necessidade do estudo da melhor malha e melhor elemento finito para a simulação deste tipo de problema, Item 4.5 .

A Figura 4.7 apresenta os resultados para as tensões cisalhantes na interação maciçosuporte obtidos para o caso "no slip".

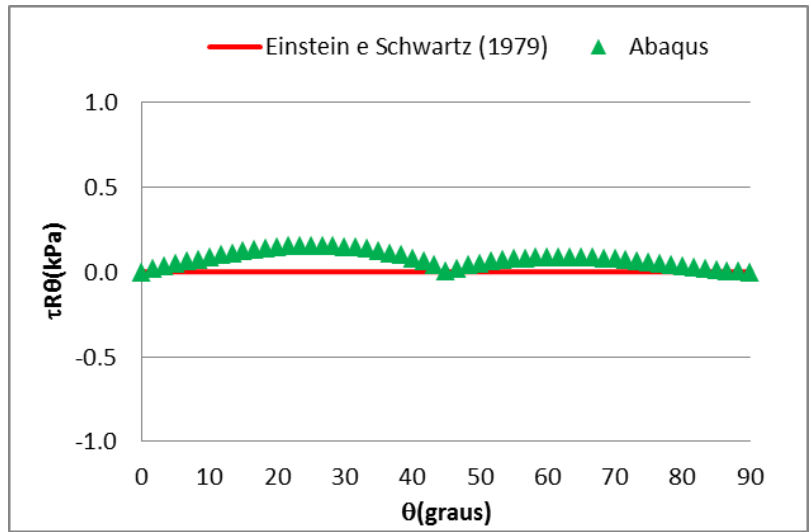

(a) $K_{0}=1$

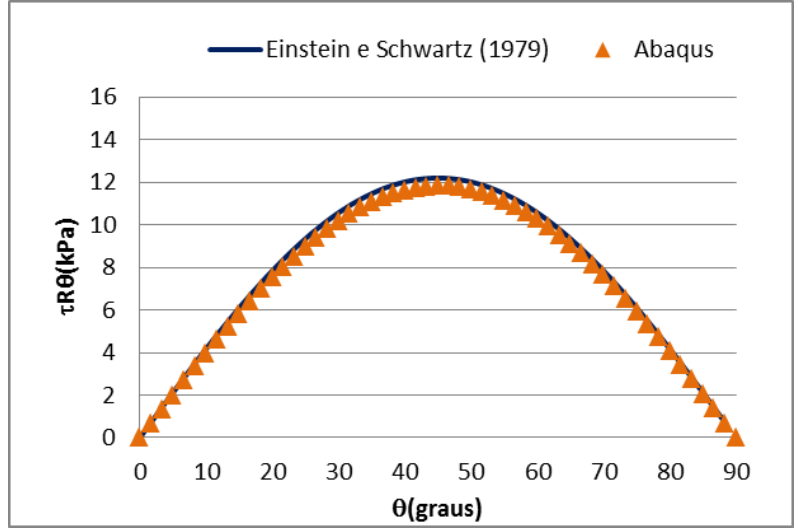

(b) $K_{0}=0,5$

Figura 4.7: Tensão cisalhante entre o maciço e o suporte ("no slip").

Nesta situação a discrepância das tensões cisalhantes, entre a solução de Einstein e Schwartz (1979) e a solução numérica do Abaqus ${ }^{\circledR}$, foi menor que no caso anterior. No caso de $K_{0}=1$ o erro máximo absoluto foi menor que $1 \%$ e para $K_{0}=0,5$ o mesmo foi chegou próximo de $2 \%$ próximo de $\theta=45^{\circ}$. Por ser um modelo simétrico as tensões cisalhantes em $\theta=0^{\circ}$ e $\theta=90^{\circ}$ são nulas, como pode ser observado nos resultados.

O esforço normal na seção do suporte, caso "no-slip", é mostrado na Figura 4.8.

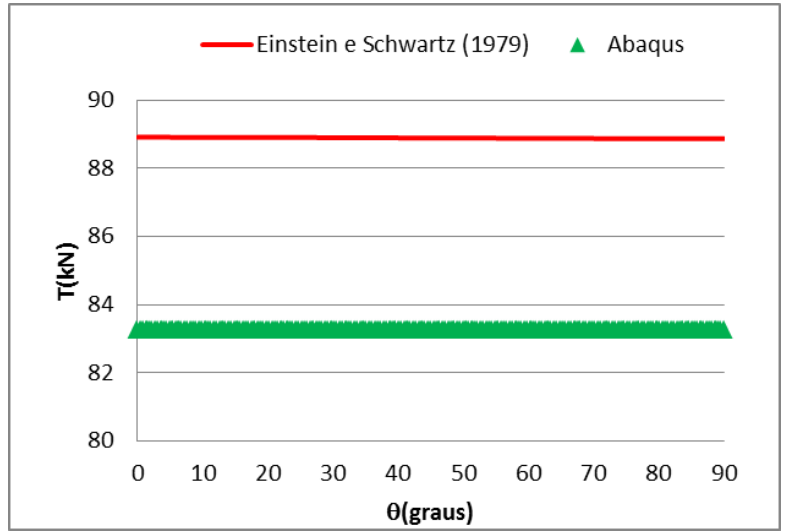

(a) $K_{0}=1$

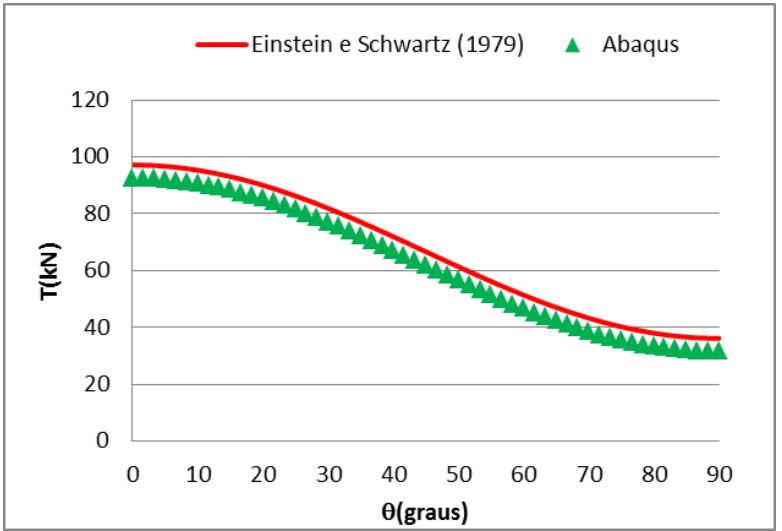

(b) $K_{0}=0,5$

Figura 4.8: Esforço normal no suporte ("no slip”).

Nesta situação o erro absoluto para o esforço normal no suporte foi próximo a 5\%, tanto para $K_{0}=1$ quanto para $K_{0}=0,5$. No caso de $K_{0}=1$ os esforços normais ficaram próximos 
de $80 \mathrm{kN}$ e para $K_{0}=0,5$ os mesmos variaram de entre $93 \mathrm{kN}\left(\theta=0^{\circ}\right)$ e $32 \mathrm{kN}\left(\theta=90^{\circ}\right)$. O resultado mostra a confiabilidade da simulação numérica do Abaqus® nesta simulação.

O momento fletor da seção do suporte, caso "no-slip", são mostrados na Figura 4.9.

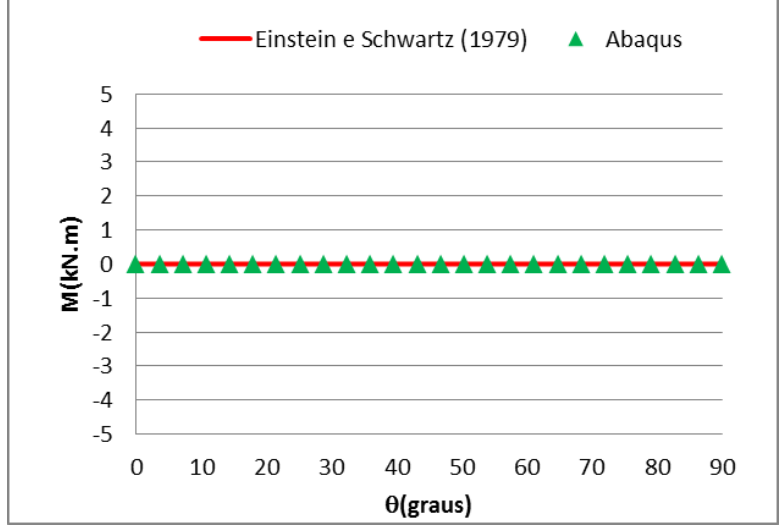

(a) $K_{0}=1$

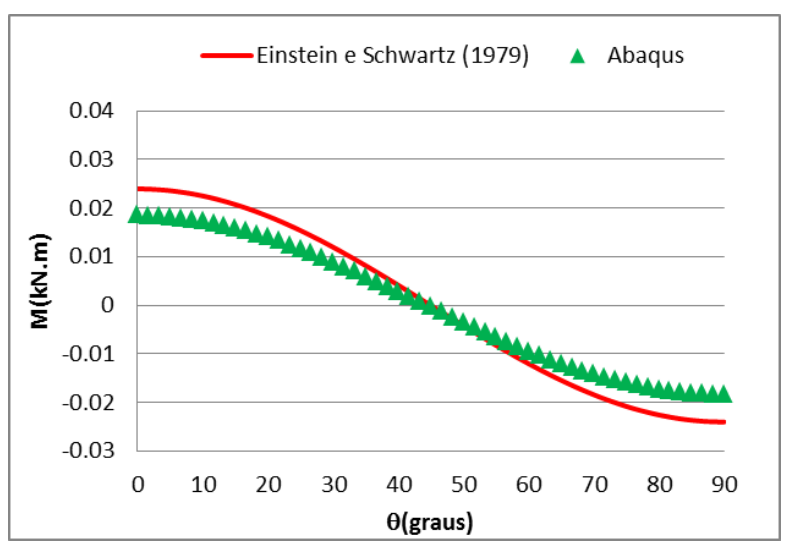

(b) $K_{0}=0,5$

Figura 4.9: Momento fletor no suporte ("no slip”).

Nesta situação o momento fletor para $K_{0}=1$ foi nulo e para $K_{0}=0,5$ o momento variou entre 0.025 kN.m e -0.025 kN.m, ao longo da seção do suporte com $\theta$ variando de $0^{\circ}$ a $90^{\circ}$. Como se vê o erro absoluto foi quase nulo para a situação de $K_{0}=1$ e de aproximadamente $25 \%$ para $K_{0}=0,5$. Este último é devido ao tipo de elemento finito utilizado na simulação. O Item 4.5 trará alguns tipos de elementos testados para este tipo de simulação.

Para o deslocamento radial do suporte no caso "no slip", a Figura 4.10 mostra os resultados obtidos para $K_{0}=1$ (a) e para $K_{0}=0,5$ (b).

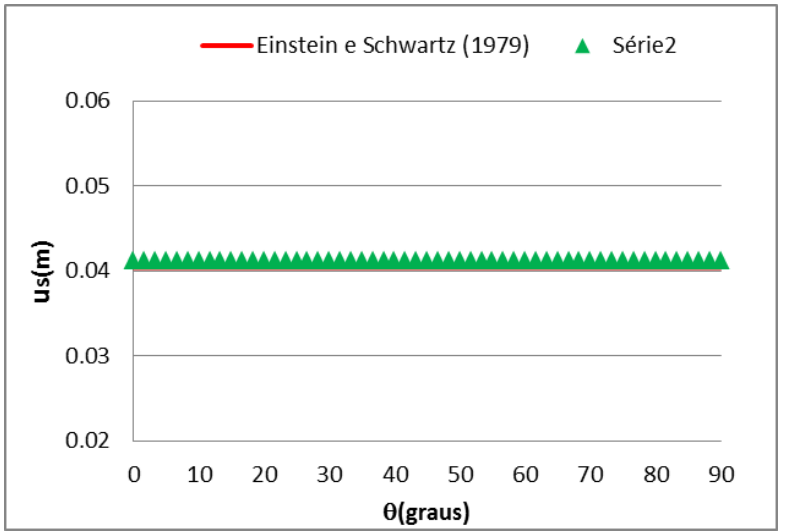

(a) $K_{0}=1$

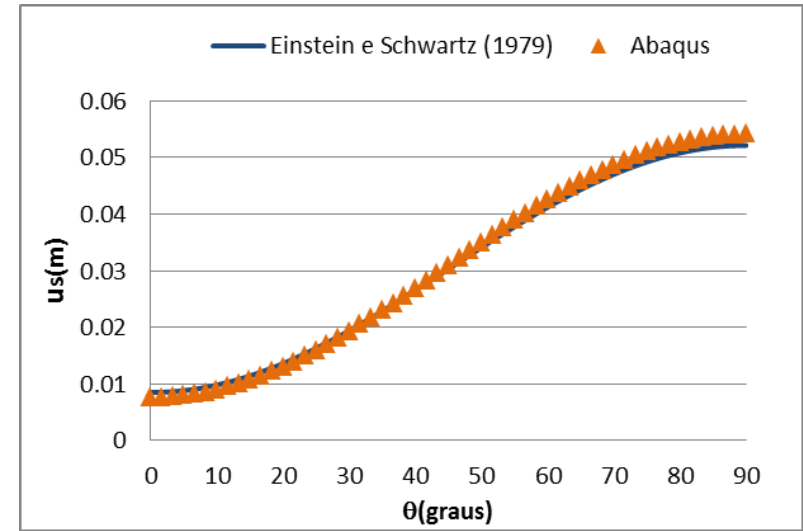

(b) $K_{0}=0,5$

Figura 4.10: Deslocamento radial do suporte ("no slip").

Observa-se que, tanto para $K_{0}=1$ como para $K_{0}=0,5$ o erro absoluto obtido para o deslocamento radial do suporte não ultrapassou $2 \%$, resultado bem significativo que se torna 
desprezível do pondo de vista da engenharia e aceitáveis em modelos numéricos de elementos finitos.

Já para o deslocamento transversal do suporte no caso "no slip", são apresentados na Figura 4.11, resultados obtidos para $K_{0}=1$ (a) e para $K_{0}=0,5$ (b).

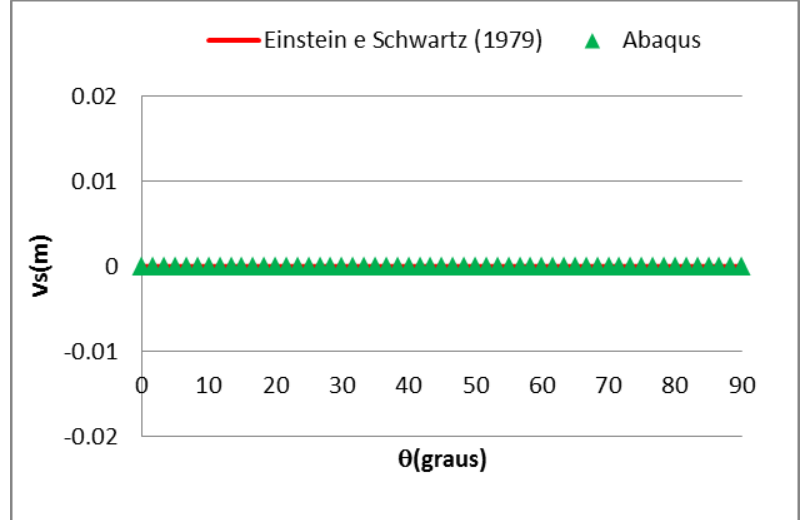

(a) $K_{0}=1$

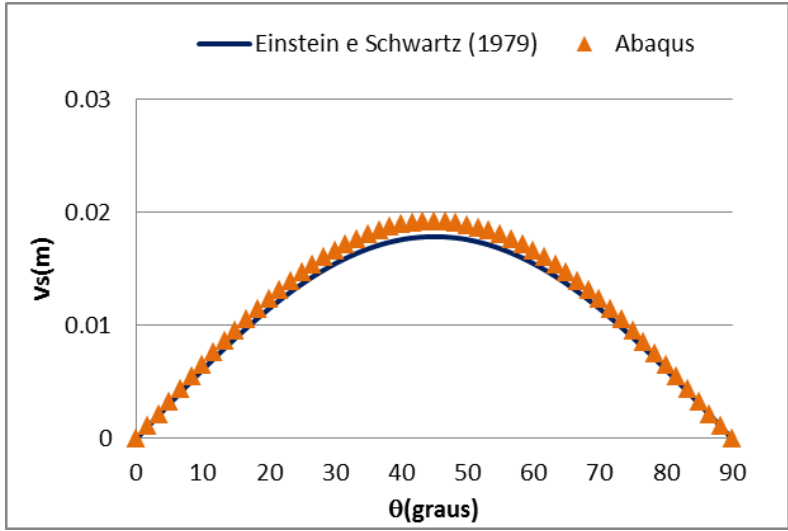

(b) $K_{0}=0,5$

Figura 4.11: Deslocamento transversal do suporte ("no slip").

Da mesma forma que para o deslocamento radial, o deslocamento transversal teve erros menores que $2 \%$, na comparação entre o resultado numérico do Abaqus ${ }^{\circledR}$ e a solução de Einstein e Schwartz (1979). Com isto, já é possível verificar que o elemento B22 (elemento tipo "beam") representa de maneira satisfatória os deslocamentos ocorridos no suporte em situação "no slip".

\subsubsection{FULL SLIP}

A simulação "full slip" considerou um estágio inicial de tensões geostática e duas fases, um geostático e o outro estático geral. Esta simulação inicia com as tensões geostáticas, o que já garante a situação de deformações iniciais nulas.

Por ser um caso em que foi necessário o uso da função *Contact Pair o primeiro "step" já iniciou escavado, mas com engaste no contorno da escavação, ou seja, as tensões iniciais foram aplicadas e as deformações nulas foram verificadas no primeiro "step" (geostático). Esta estratégia possibilitou gerar a interação entre o maciço e o suporte, fato que não é garantido quando a escavação é feita no mesmo "step" que o suporte é colocado. O terceiro "step" simulou a retirada da vinculação da parede do túnel e a colocação do suporte. Esta etapa foi marcada pela obtenção da resposta elástica do maciço e suporte. 
No contato utilizaram-se os comandos:

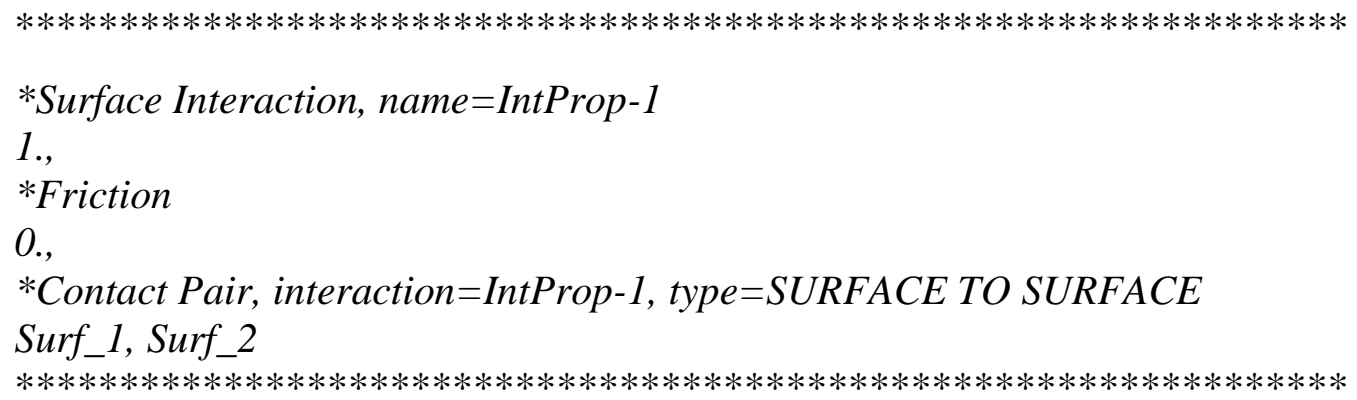

ou seja: *Surface Interaction - para determinar a espessura de interação maciço-suporte, por ser um plano de deformação o valor passado foi $1 \mathrm{~m}$; *Friction - para determinar o atrito entre o maciço e o suporte, para "full slip" o valor passado foi 0; *Contact Pair, interaction=IntProp -1 , type $=S U R F A C E$ TO SURFACE - para associar as superfícies de contato Surf_1 (suporte) e Surf_2 (maciço) e definir o atrito nulo entre elas.

A Figura 4.12 mostra os gráficos de tensão radial no contato maciço-suporte para a condição "full slip".

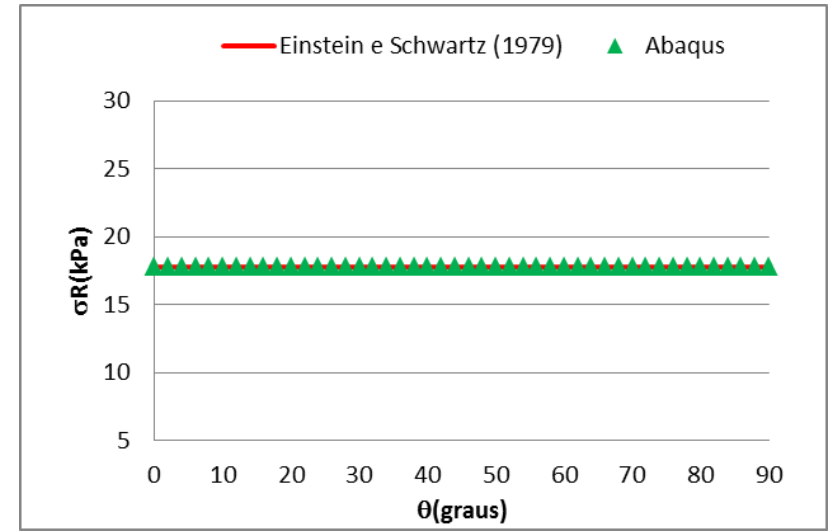

(a) $K_{0}=1$

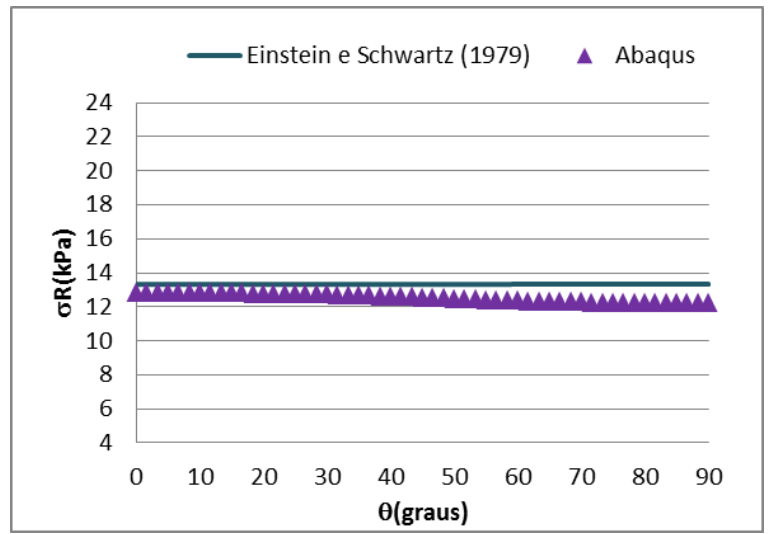

(b) $K_{0}=0,5$

Figura 4.12: Tensão radial entre o maciço e o suporte ("full slip").

Na situação para $K_{0}=1$, para a solução de Einstein e Schwartz (1979) e para a solução numérica do Abaqus ${ }^{\circledR}$, os resultados são semelhantes. Já para $K_{0}=0,5$ os resultados não foram tão bons, quando comparados. Observa-se que, neste caso, a solução de Einstein e Schwartz (1979) teve $\sigma_{R}$ constante em toda superfície e a solução numérica do Abaqus® variou um pouco, com erros absolutos próximos de $-10 \%$. Este fato aumentou a necessidade de se estudar os melhores elementos para este tipo de simulação. Por exemplo, utilizando-se 
elementos CPE4 (com 4 nós) para modelar o maciço, os resultados para $K_{0}=0,5$ praticamente coincidem com os analíticos, Figura 4.13.

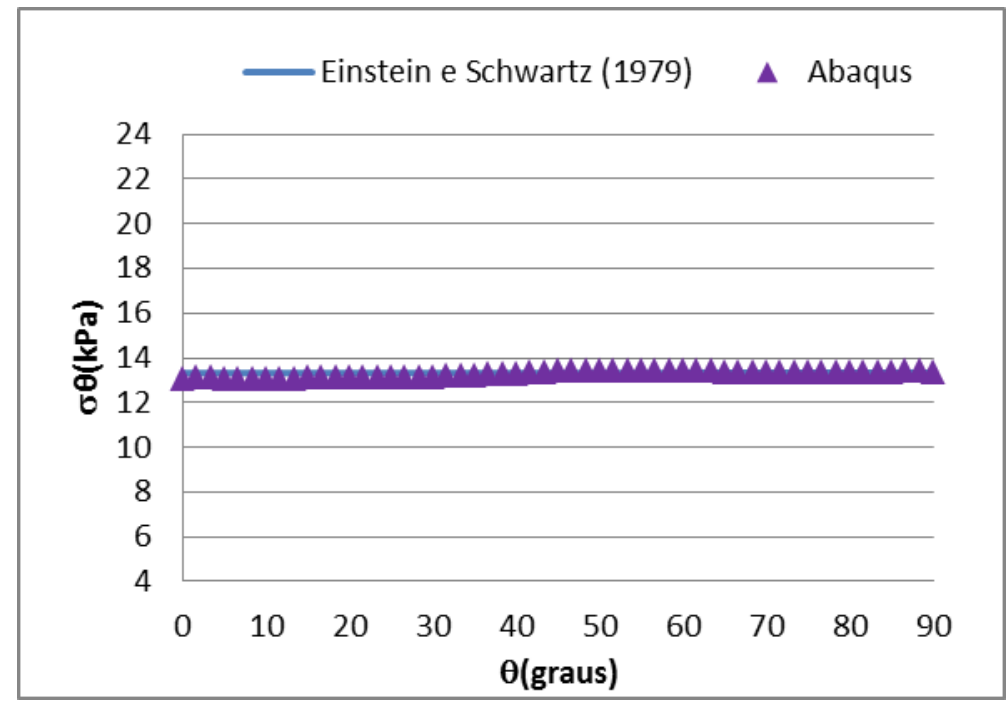

Figura 4.13: Tensão radial entre o maciço e o suporte com elementos CPE4 (“full slip”).

Os resultados obtidos para a tensão cisalhante na interação maciço-suporte, caso "full slip", são apresentados na Figura 4.14.

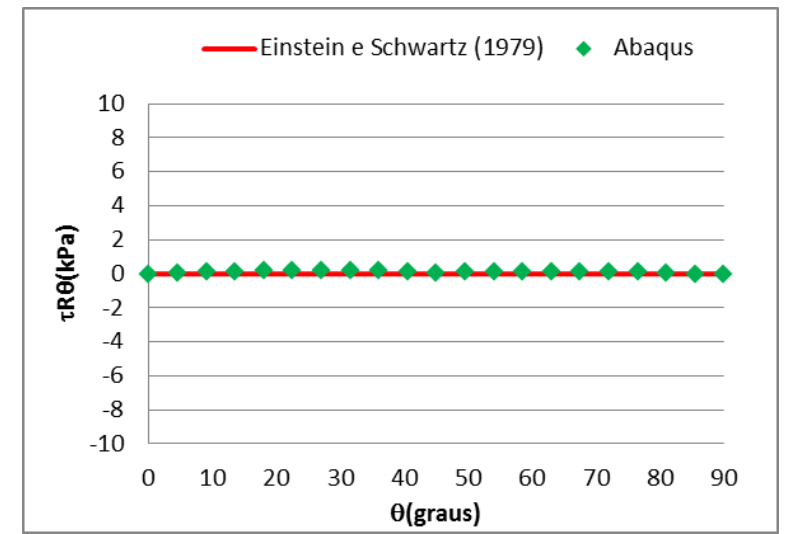

(a) $K_{0}=1$

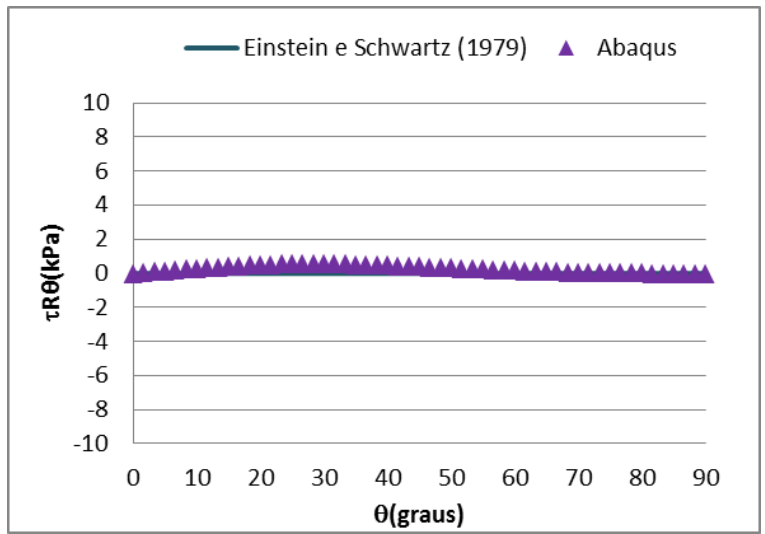

(b) $K_{0}=0,5$

Figura 4.14: Tensão cisalhante entre o maciço e o suporte ("full slip").

Observa-se que a tensão cisalhante foi nula tanto para $K_{0}=1$ como para $K_{0}=0,5$, o que confirma a ausência de atrito. Neste caso, resultados da solução Einstein e Schwartz (1979) e da solução numérica do Abaqus® foram relativamente próximos, com erros absolutos quase nulos.

Os esforços normais na seção do suporte, caso "no-slip", são mostrados na Figura 4.15 . 


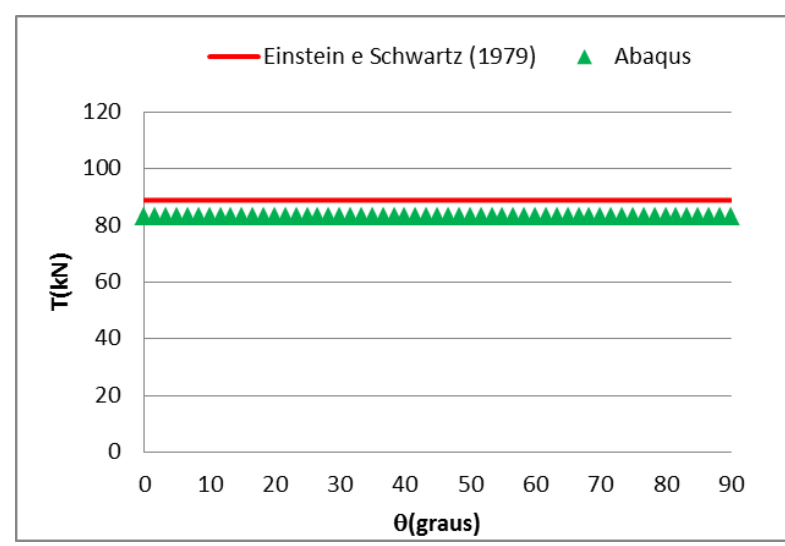

(a) $K_{0}=1$

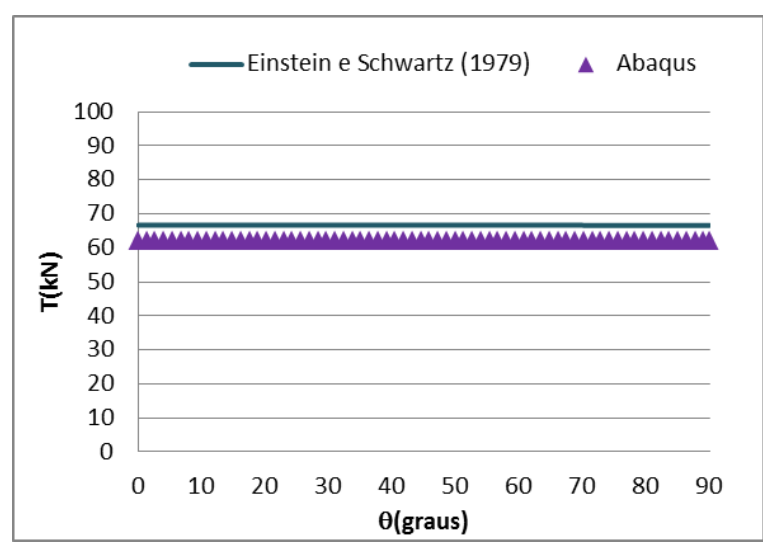

(b) $K_{0}=0,5$

Figura 4.15: Esforço normal no suporte ("full slip").

Nesta situação os esforços normais se mostram constantes ao longo de toda seção do suporte. No caso de $K_{0}=1$ os esforços normais mostram erros absolutos menores que $5 \%$ e para $K_{0}=0,5$ os erros também estiveram nesta faixa.

O momento fletor da seção do suporte, caso "full-slip", são mostrados na Figura 4.16.

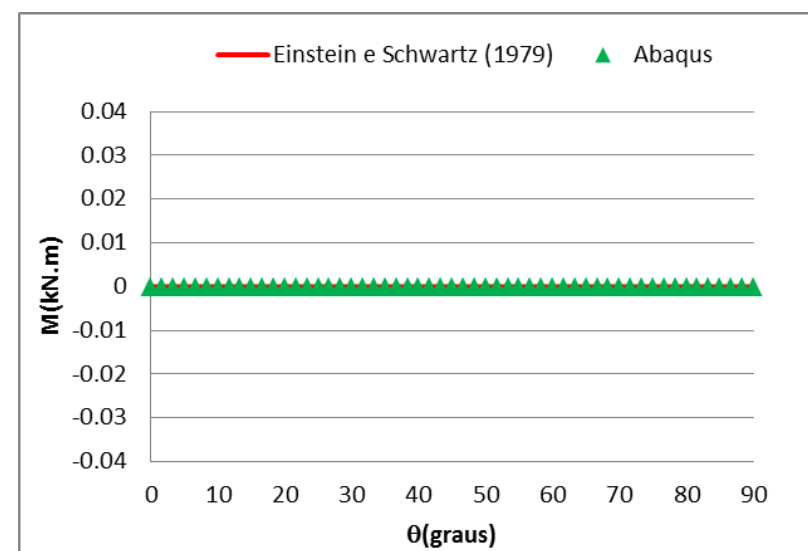

(a) $K_{0}=1$

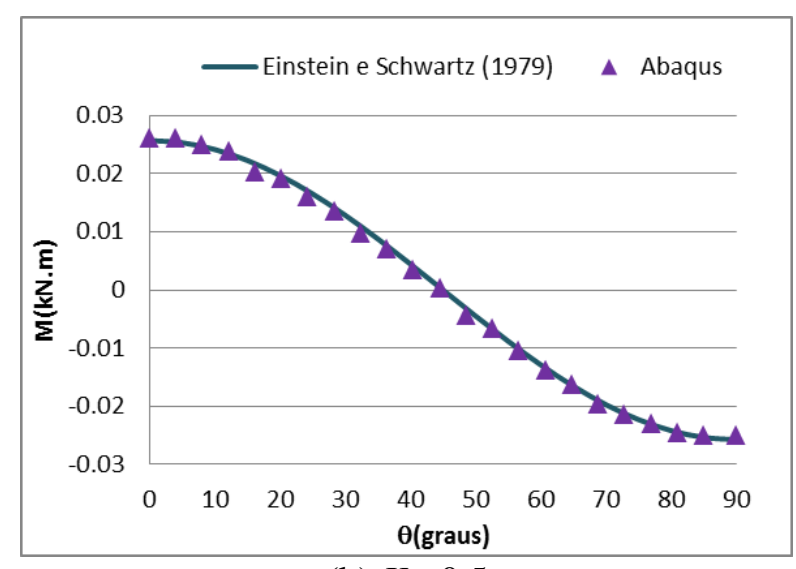

(b) $K_{0}=0,5$

Figura 4.16: Momento fletor no suporte ("full slip").

Nesta situação a discrepância de valores do momento fletor da solução de Einstein e Schwartz (1979) e da solução numérica do Abaqus ${ }^{\circledR}$ foi quase nula. Este resultado garante a confiabilidade da modelagem numérica para este tipo de aplicação de engenharia.

Na Figura 4.17 podem ser observados os resultados para o deslocamento radial do suporte, caso "full slip". 


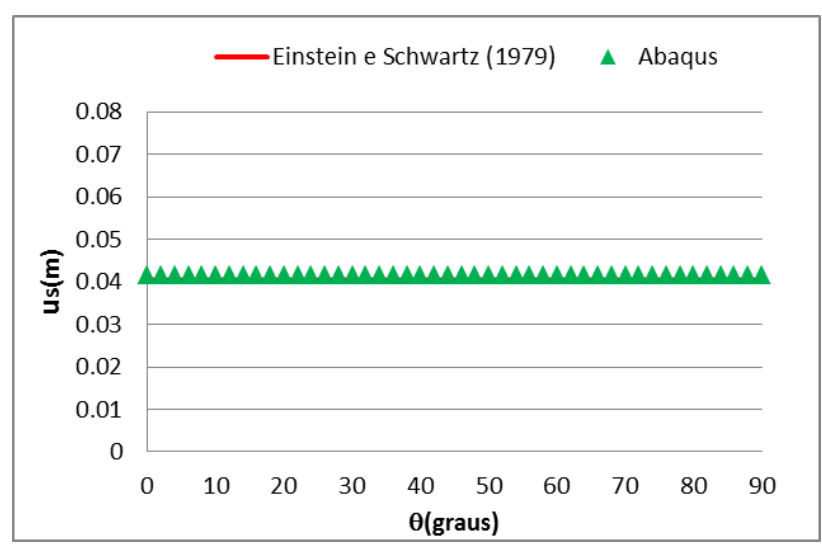

(a) $K_{0}=1$

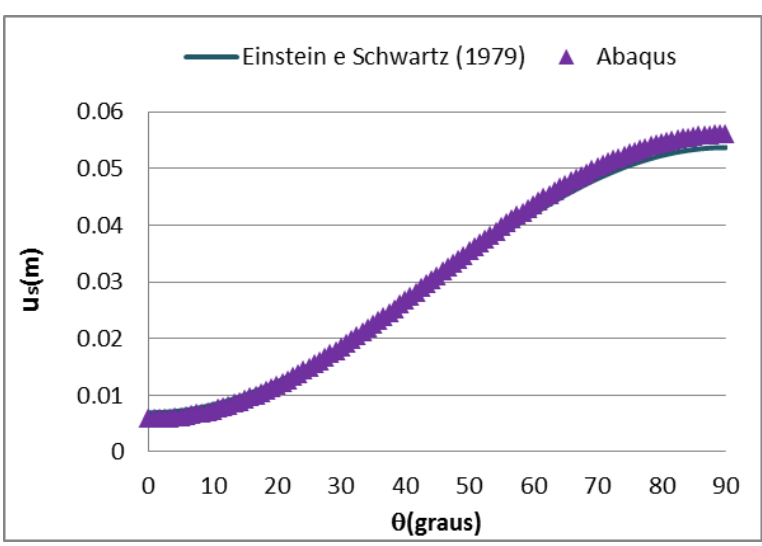

(b) $K_{0}=0,5$

Figura 4.17: Deslocamento radial do suporte ("full slip").

Tem-se que para $K_{0}=1$ o deslocamento radial foi constante e igual nas duas soluções, com erros absolutos próximos a $0 \%$. Para o $K_{0}=0,5$ verifica-se que os resultados apresentaram o mesmo comportamento, mais uma vez comprovando a boa qualidade dos resultados do elemento B22.

Os resultados para o deslocamento transversal do suporte, caso "full slip" encontramse na Figura 4.18.

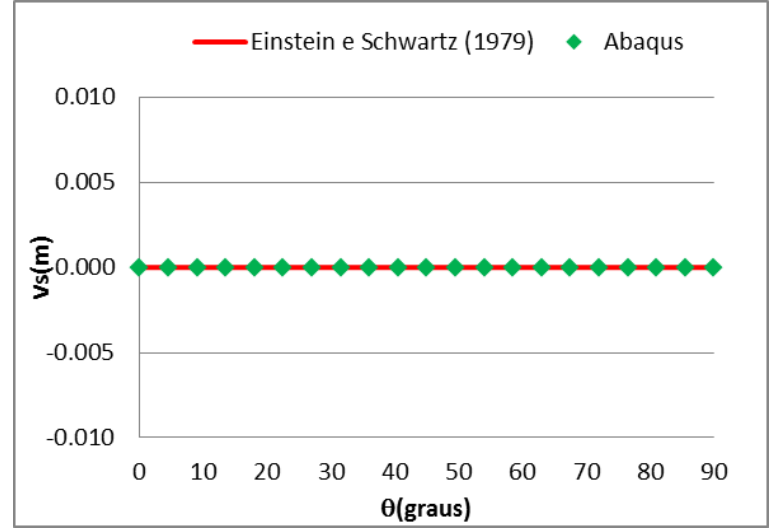

(a) $K_{0}=1$

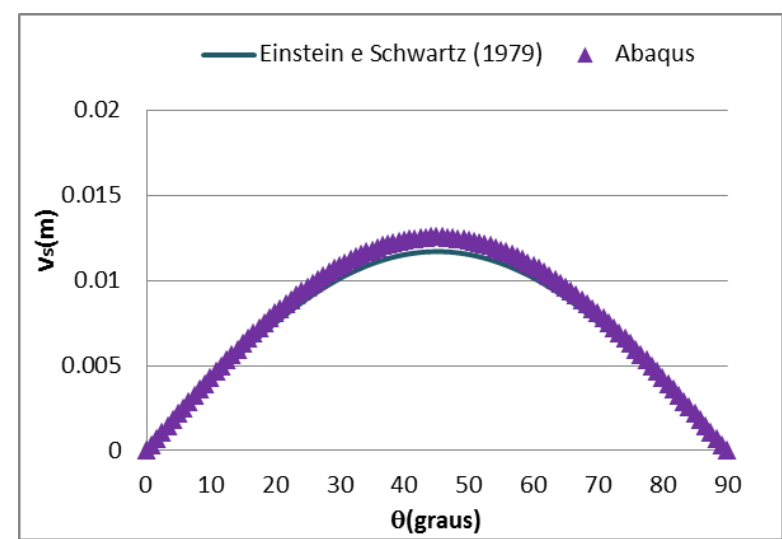

(b) $K_{0}=0,5$

Figura 4.18: Deslocamento transversal do suporte ("full slip").

Observa-se que para $K_{0}=1$ os deslocamentos foram nulos e iguais nas duas soluções com erros absolutos próximos de $0 \%$. Para $K_{0}=0,5$ verifica-se que os resultados também foram bem semelhantes, com erro máximo absolutos não chegando a 5\%.

Como é observado, a solução numérica do Abaqus® mostrou resultados, se não iguais, bem semelhantes à solução de Einstein e Schwartz (1979). Além disto, já é possivel concluir que os deslocamentos radiais e transversais do suporte são iguais tanto para a o caso "no-slip" como para o caso "full slip", ou seja, o atrito não interfere no deslocamento do suporte. 


\subsection{EFEITO DA MALHA NOS RESULTADOS}

Devido à pequena imprecisão que houve nos resultados das tensões radiais, Item 4.3.1, viu-se a necessidade de realizar um estudo em diferentes tipos de malha. A ideia é verificar a relação existente dos elementos com os resultados de tensões obtidos. Neste estudo optou-se por utilizar a interação maciço-suporte com atrito total, "no slip", suporte com elementos B22 (elementos lineares tipo "Beam") e $K_{0}=0,5$. Os dados de entrada do modelo foram os mesmo apresentados na Tabela 4.1 e as condições de contorno foram às mesmas utilizadas no Item 4.4 .

Para a malha do maciço utilizaram-se elementos triangulares e quadrilaterais, Figura 4.19, e para cada elemento verificaram-se duas situações: uma utilizando formulação de primeira ordem ou linear e a outra e utilizando formulação de segunda ordem ou quadrática. Os elementos de primeira ordem, ou lineares, fornecem tensão volumétrica constante ao longo do elemento. Os elementos de segunda ordem, ou quadráticos, fornecem uma maior precisão que os elementos de primeira ordem, principalmente em problemas com grande suavidade e que não envolvem condições de contato complexas, impacto, ou graves distorções (Abaqus$6.11,2011)$.

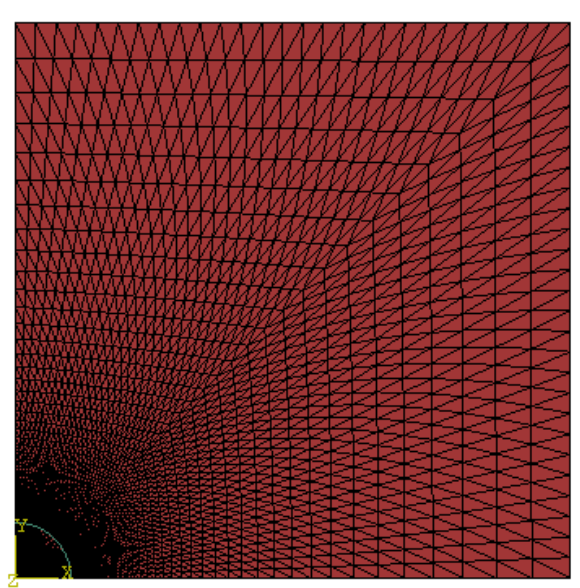

(a) Triangular

Figura 4.19: Malha do maciço.

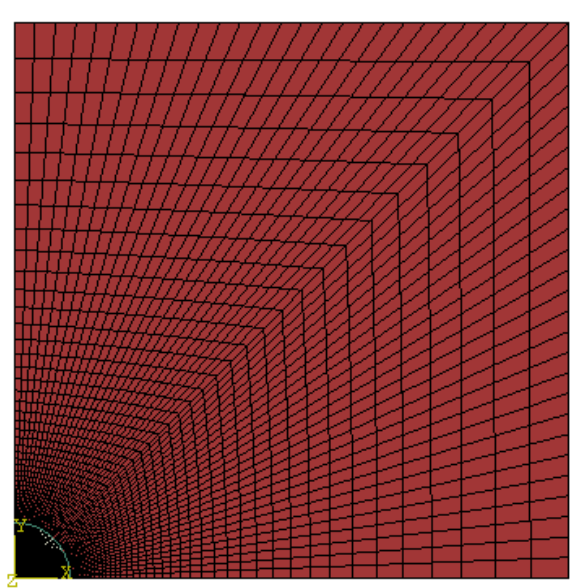

(b) Quadrilateral

O tipo de elemento considerado foi sólido (ou contínuo), disponível no Abaqus $® / S t a n d a r d$. Estes elementos podem ser compostos de um único material homogêneo ou de várias camadas de diferentes materiais, podendo ser usados em análises lineares e não lineares, análises complexas envolvendo contato, plasticidade e grandes deformações (Abaqus-6.11, 2011). 


\subsubsection{MALHA TRIANGULAR}

A malha triangular utilizou dois tipos de elementos: o CPE3 (elemento contínuo, plano deformado, triangular-linear, com 3 nós) e o CPE6 (elemento contínuo, plano deformado, triangular-quadrático, com 6 nós), Figura 4.20.

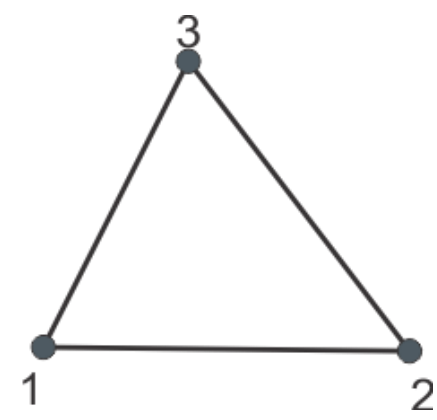

(a) Linear

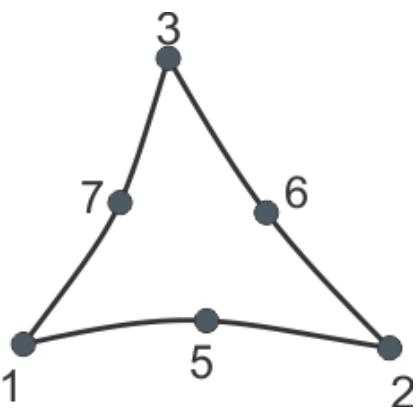

(b) Quadrático

Figura 4.20: Elemento triangular.

Nas duas simulações foi utilizada a mesma malha com a mesma quantidade de elementos, a única diferença foi o número de nós. A Tabela 4.3 mostra o tipo, número de nós e o número de elementos utilizados em cada modelo.

Tabela 4.3: Malha, elementos triangular.

\begin{tabular}{|c|c|c|c|}
\hline Modelo & Tipo de Elemento & $\mathbf{N}^{\mathbf{0}}$ de Nós & $\mathbf{N}^{\mathbf{0}}$ de Elementos \\
\hline \multirow{2}{*}{ Linear } & CPE3 & 2421 & 4698 \\
\cline { 2 - 4 } & B22 & 55 & 54 \\
\hline \multirow{2}{*}{ Quadrática } & CPE6 & 9539 & 4698 \\
\cline { 2 - 4 } & B22 & 55 & 54 \\
\hline
\end{tabular}

Por utilizar a ferramenta "stringer" para estabelecer a condição de "no slip", verificase que há 55 nós iguais para o maciço e para o suporte. Mesmo com nós iguais o Abaqus® diferencia as formulações de cada elemento e retorna os resultados para cada elemento.

A Figura 4.21 mostra os resultados das tensões radiais obtidos para as duas malhas triangulares, (a) elementos lineares e (b) elementos quadráticos. 


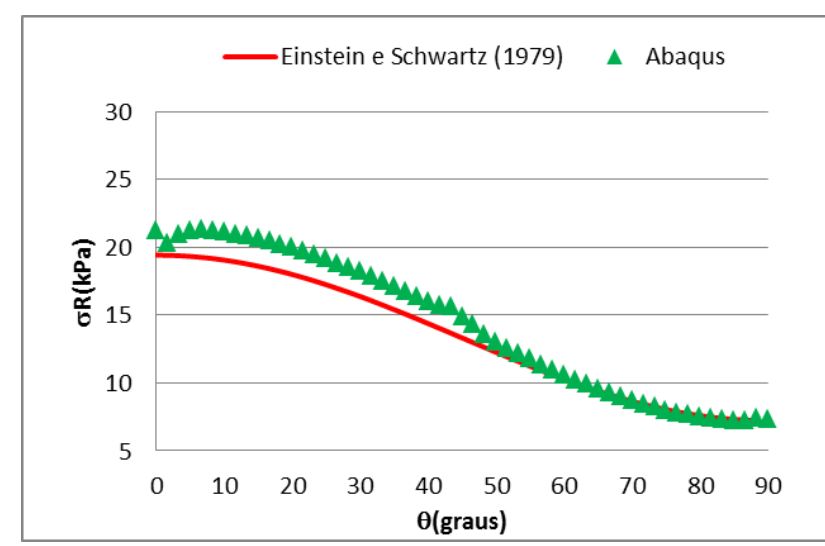

(a) Elementos CPE3

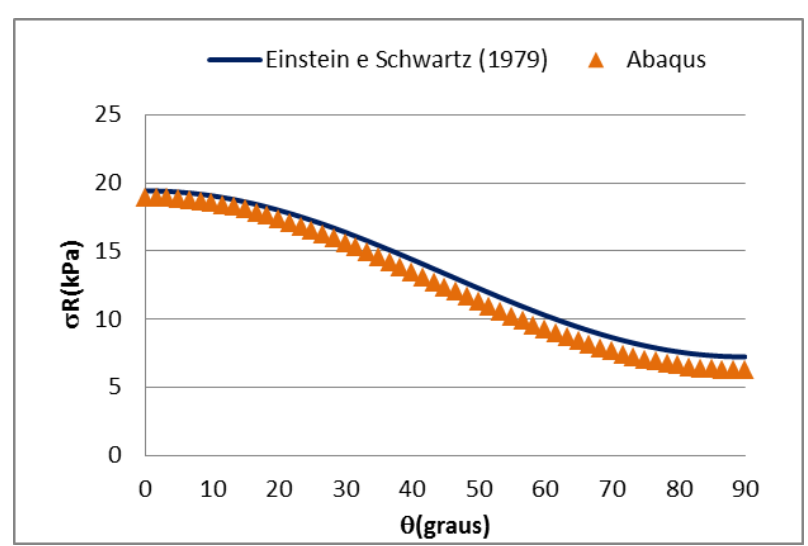

(b) Elementos CPE6

Figura 4.21: Tensão radial entre o maciço e o suporte (malha triangular).

Observa-se que para o elemento CPE3, o comportamento do gráfico $\sigma_{R} \times \theta$ apresentou bastante discrepância entre resultados numéricos e da solução de Einstein e Schwartz (1979). Para os elementos CPE6, o comportamento da curva é semelhante, entretanto há um pequeno desvio da curva quando $\theta$ se aproxima de $90^{\circ}$. Nesta situação o erro máximo absoluto foi de aproximadamente 3\% e na situação para os elementos CPE3 o mesmo chegou próximo de $10 \%$.

Na Figura 4.22 têm-se os resultados das tensões cisalhantes obtidos para as duas malhas triangulares, (a) elementos lineares e (b) elementos quadráticos.

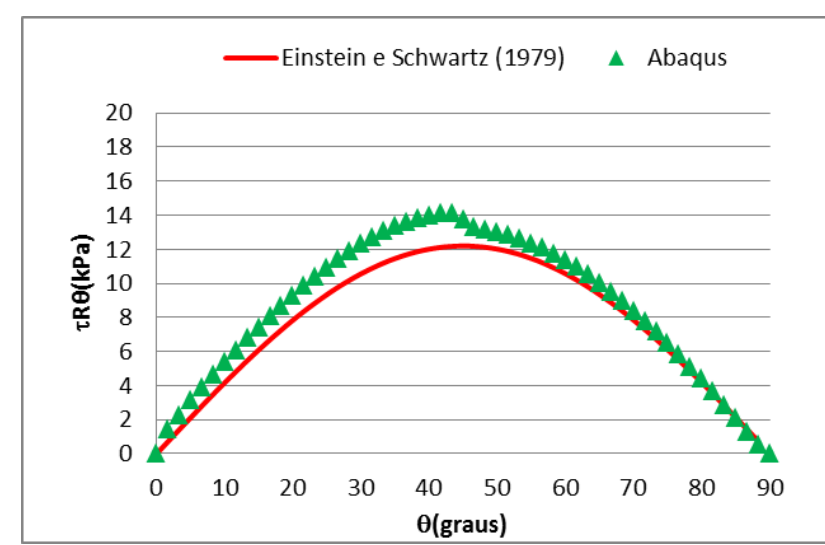

(a) Elementos CPE3

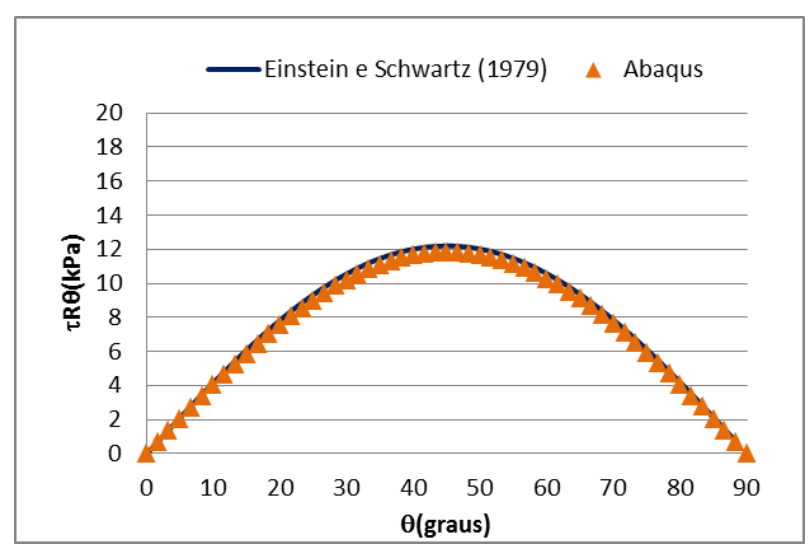

(b) Elementos CPE6

Figura 4.22: Tensão cisalhante entre o maciço e o suporte (malha triangular).

Resultados $\tau_{R \theta} \times \theta$ foram discrepantes com o elemento CPE3, quando comparados com a solução de Einstein e Schwartz (1979), de forma semelhante ao da tensão radial. Para os elementos CPE6, este comportamento foi quase idêntico e o erro máximo absoluto foi bem próximo de zero. O mesmo não aconteceu com os elementos CPE3, como se pode observar 
em $\theta=45^{\circ}$ ocorreu variação em $\tau_{R \theta}$, ou seja, houve uma diminuição no erro absoluto de aproximadamente $10 \%$.

Com base nestes resultados já é possível comprovar o manual do Abaqus-6.11 (2011). Segundo o mesmo, os elementos triangulares de primeira ordem (lineares) devem ser evitados, tanto quanto possível, pois apresentam rigidez excessiva e convergência lenta em problemas de tensão-deformação, fato que pode explicar a falta de simetria nos resultados obtidos com este elemento.

\subsubsection{MALHA QUADRILATERAL}

A malha quadrilateral utilizou dois tipos de elementos: o CPE4 (elemento contínuo, plano deformado, quadrilateral-linear, com 4 nós) e o CPE8 (elemento contínuo, plano deformado, quadrilateral-quadrático, com 8 nós), Figura 4.23.

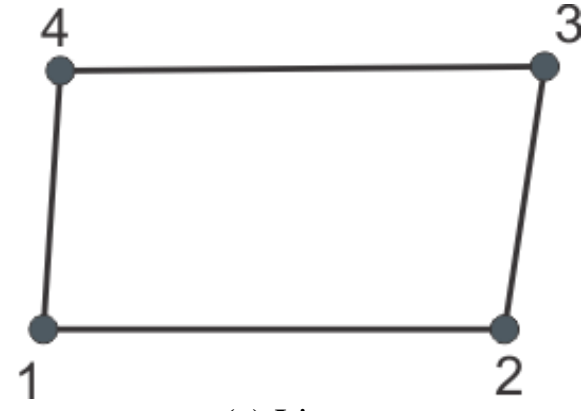

(a) Linear

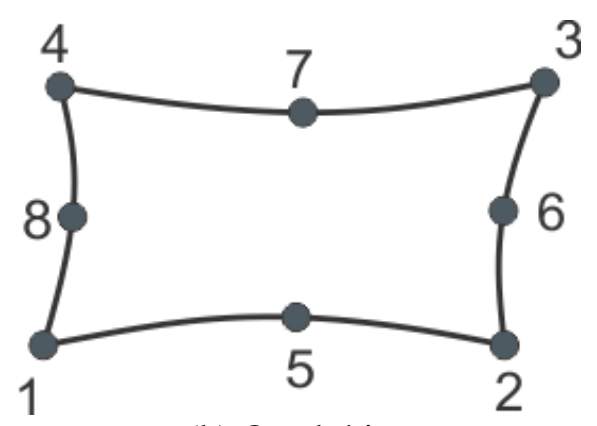

(b) Quadrático

Figura 4.23: Deslocamento transversal do suporte ("full slip").

Nas duas simulações foi utilizada a mesma malha com a mesma quantidade de elementos, a única diferença sendo o número de nós. A Tabela 4.4 mostra o tipo, o número de nós e o número de elementos utilizados em cada modelo.

Tabela 4.4: Malha, elementos quadrilaterais.

\begin{tabular}{|c|c|c|c|}
\hline Modelo & Tipo de Elemento & $\mathbf{N}^{\mathbf{0}}$ de Nós & $\mathbf{N}^{\mathbf{0}}$ de Elementos \\
\hline \multirow{3}{*}{ Linear } & CPE4 & 2421 & 2322 \\
\cline { 2 - 4 } & CPE3 & 55 & 54 \\
\cline { 2 - 4 } & B22 & 55 & 54 \\
\hline \multirow{3}{*}{ Quadrática } & CPE8 & 7217 & 2322 \\
\cline { 2 - 4 } & CPE3 & 55 & 54 \\
\cline { 2 - 4 } & B22 & 55 & 54 \\
\hline
\end{tabular}

A Figura 4.24 apresenta os resultados das tensões radiais obtidos para as duas malhas quadrilaterais, (a) elementos lineares e (b) elementos quadráticos. 


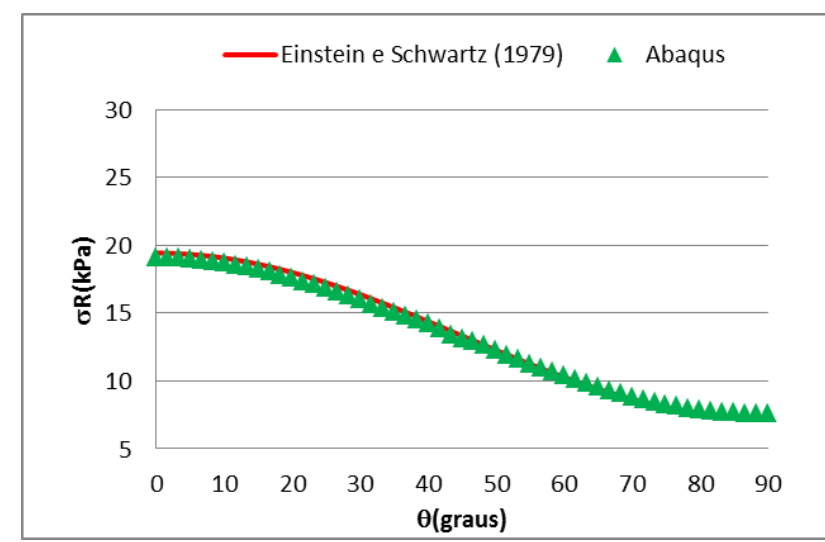

(a) Elementos CPE4

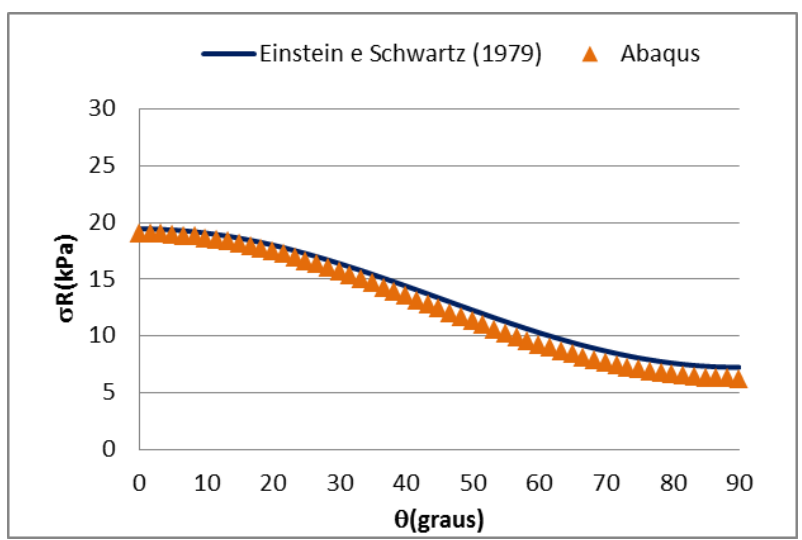

(b) Elementos CPE8

Figura 4.24: Tensão radial do entre o maciço e o suporte (malha quadrilateral).

Observa-se que com o elemento CPE4, os resultados numéricos do gráfico $\sigma_{R} \times \theta$ foram praticamente idênticos aos da solução Einstein e Schwartz (1979), com um erro máximo absoluto para $\sigma_{R}$ próximo a $0 \%$. Para o elemento CPE8 este comportamento variou um pouco quando $\theta$ se aproxima de $90^{\circ}$, mesmo assim o erro absoluto não chegou a $5 \%$. Desta forma, já é possível comprovar que o elemento quadrilateral-linear representa as tensões radias melhores que os elementos triangulares e o quadrilateral-quadrático.

Na Figura 4.25 observam-se os resultados das tensões cisalhantes obtidos para as duas malhas quadrilaterais, (a) elementos lineares e (b) elementos quadráticos.

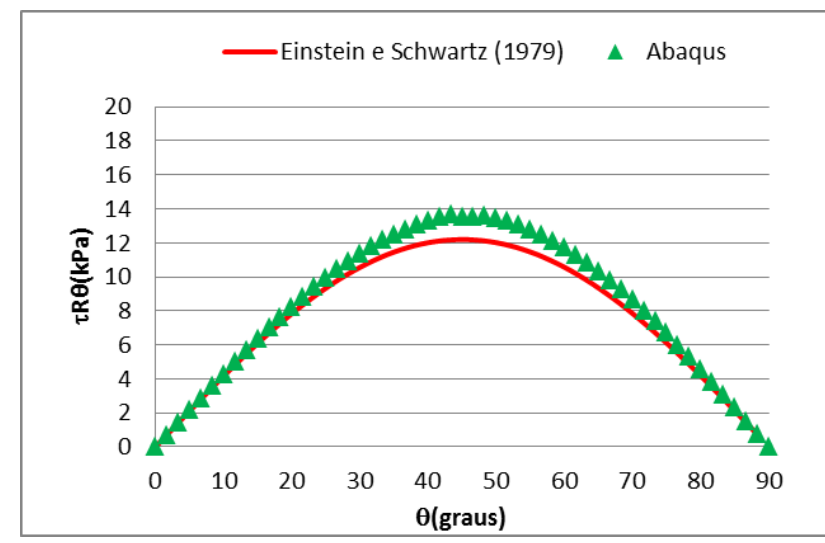

(a) Elementos CPE4

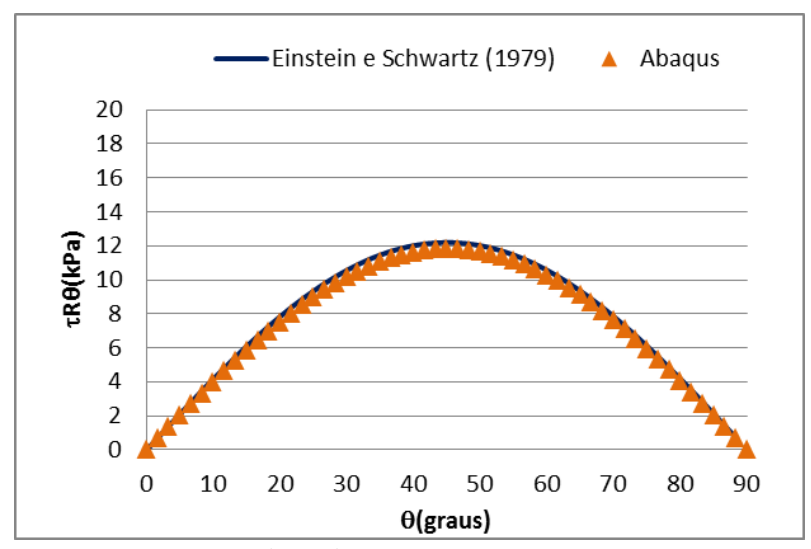

(b) Elementos CPE8

Figura 4.25: Tensão cisalhante entre maciço e o suporte (malha quadrilateral).

Observa-se que com o elemento CPE4 o comportamento do gráfico $\tau_{R \theta} \times \theta$ apresentou um maior desvio para $\tau_{R \theta}$ em $\theta$ próximo de $45^{\circ}$, quando comparado com a solução Einstein e Schwartz (1979). Neste caso, o erro máximo absoluto chegou próximo de 10\%. Por outro lado com os elementos CPE8 tem-se uma maior precisão e o mesmo foi próximo a 1\%. Desta 
forma, já é possível comprovar que o elemento quadrilateral quadrático representa as tensões cisalhantes melhor que os elementos triangulares e o quadrilateral linear.

Para o suporte também foram feitas comparações entre os elementos B21 e B22, elementos de viga linear e quadrática, respectivamente. Neste caso não houve grande discrepância entre os resultados de esforços normais e deslocamentos, mas em relação aos momentos fletores os resultados não foram observados, levando utilização do elemento B22 para modelar o suporte em todas as simulações.

\subsection{VARIAÇÃO DO ATRITO NA INTERAÇÃO MACIÇO-SUPORTE}

O modelo de Einstein e Schwartz (1979) está restrito aos dois casos extremos de atrito: "no slip" e "full slip", ou seja, suporte totalmente ligado ao maciço (atrito infinito) e suporte totalmente livre do maciço (atrito nulo), respectivamente. Esta restrição impede que o modelo seja utilizado em situações em que o atrito esteja entre estes extremos. Em situações como esta uma das soluções possível seria analisar numericamente o problema através de programas de elementos finitos. Pelo que foi visto no Item 4.4, a solução numérica obtida pelo Abaqus®, para as condições "no slip" e "full slip", apresentou uma boa aproximação com a solução teórica de Einstein e Schwartz (1979). Este fato possibilitou a simulação numérica para diversos valores de atritos, o que foi realizado e será apresentado a seguir.

\subsubsection{MODELO}

O modelo simulado é um poço de $150 \mathrm{~mm}$ de raio, escavado em um maciço de evaporito e revestido com aço de espessura $15 \mathrm{~mm}$. A utilização do aço como revestimento foi levada em consideração devido, entre outras coisas, a sua resistência ser maior que a do maciço e a necessidade que existe da colocação de um revestimento perfurado (tela) que, além de impedir o fechamento do poço, possa permitir o fluxo de óleo.

\subsubsection{SIMULAÇÃO}

Para a simulação do poço revestido com aço foi utilizado uma malha de elementos finitos com 5400 elementos do tipo CPE8 (elemento plano deformado com 8 nós) e 200 elementos tipo B22 (elemento de viga bidimensional quadrático). As condições de contornos são as mesmas apresentadas no Item 4.4, ou seja, nas bordas inferior e lateral esquerda do 
modelo são consideradas condições de simetria em y e em x, respectivamente. Neste caso o carregamento aplicado nas bordas superior e lateral direita do modelo são as tensões de compressão de $100 \mathrm{MPa}$ e $50 \mathrm{MPa}$ nas direções $y$ e $x$, respectivamente. Estas tensões foram consideradas altas devido às altas profundidades de escavação de um poço de petróleo, que muitas vezes passam dos $3000 \mathrm{~m}$ e geralmente são escavados no mar com laminas d'água superior a $1000 \mathrm{~m}$. O fato de se considerar valores diferentes para as tensões pode ser explicado pela presença de um trecho horizontal para o poço nos últimos metros de escavação, trecho de onde se retira a maior parte do óleo.

As etapas de simulação são as mesmas do Item 4.4, ou seja: a primeira para simular as condições iniciais geostática, zerando as deformações iniciais, e a segunda para simular a escavação com a colocação do suporte.

\subsubsection{INTERAÇÃO MACIÇO-SUPORTE}

A interação maciço-suporte foi simulada conforme Item 4.4. Neste caso o coeficiente de atrito $\mu$ foi variado de zero a infinito, ou seja, foram simulados alguns casos dentro desta faixa de valor. Por definição o coeficiente de atrito é dado por:

$$
\mu=\operatorname{tg} \phi
$$

onde $\phi$ corresponde o ângulo de atrito.

Foram simulados 6 casos com diferentes atritos. A Tabela 4.5 mostra os diferentes ângulos para cada caso simulado.

Tabela 4.5: Atrito para os 6 casos simulados.

\begin{tabular}{|c|c|c|c|c|c|c|}
\hline Simulação & 1 & 2 & 3 & 4 & 5 & 6 \\
\hline$\phi$ & $0,0^{\circ}$ & $4,5^{\circ}$ & $9,0^{\circ}$ & $18,0^{\circ}$ & $36,0^{\circ}$ & $90,0^{\circ}$ \\
\hline
\end{tabular}

No Abaqus® o atrito é passado em forma de coeficiente de atrito $\mu$, ou seja, há a necessidade da utilização da Equação (4.19).

\subsubsection{DEFINIÇÕES DE MATERIAIS}

A Tabela 4.6 mostra as propriedades do maciço e do suporte utilizadas na simulação. Para o maciço foi adotada uma halita com módulo de elasticidade e coeficiente de Poisson 
conforme Poiate et al. (2006). Os valores do módulo de elasticidade do aço e do coeficiente de Poisson são dados comumente encontrados na literatura.

Tabela 4.6: Propriedades do maciço e do suporte.

\begin{tabular}{|c|c|c|}
\hline \multicolumn{3}{|c|}{ Dados } \\
\hline \multirow{2}{*}{ Maciço } & $v$ & 0,36 \\
\cline { 2 - 3 } & $\mathrm{E}$ & $20,7 \mathrm{GPa}$ \\
\hline \multirow{2}{*}{ Suporte } & $v \mathrm{~s}$ & 0,3 \\
\cline { 2 - 3 } & $\mathrm{Es}$ & $210 \mathrm{GPa}$ \\
\hline
\end{tabular}

\subsubsection{RESULTADOS}

Os resultados obtidos para as diferentes simulações são mostrados a seguir. Os mesmos são comparados com a solução de Einstein e Schwartz (1979) e a verificação é apenas para garantir que os resultados da simulação estão dentro dos valores extremos daquela solução nas situações de "no slip" e full slip".

Os graficos, a seguir, apresentam os resultados para as tensões radiais e cisalhantes no suporte, e para os esforços nomais, momentos fletores e deslocamentos (radial e tranversal) no suporte. Na Figura 4.26 podem-se observar os resultados para as tensões radiais na interação maciço-suporte com a solução de Einstein e Schwartz (1979) (a) e com a modelagem numérica do Abaqus® (b).

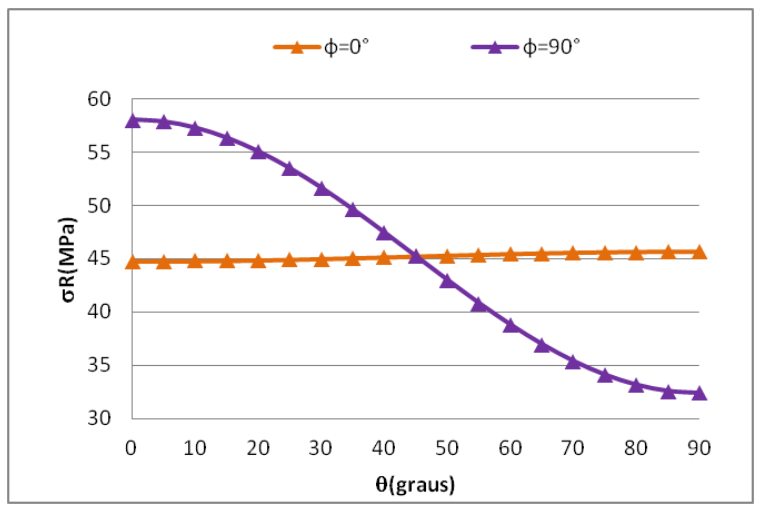

(a) Einstein e Schwartz (1979)

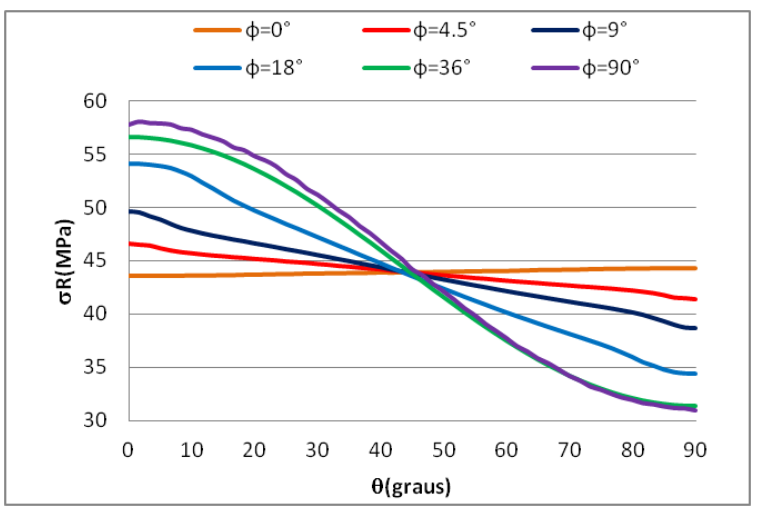

(b) Modelo numérico

Figura 4.26: Tensão radial entre o maciço e o suporte para diferentes atritos.

Observa-se que quase não houve discrepância de tensões radiais entre a solução de Einstein e Schwartz (1979) e a solução numérica do Abaqus® para $\phi=0^{\circ}$ e $\phi=90^{\circ}$. Para $0<\phi<90^{\circ}$ a solução numérica esteve dentro da solução de Einstein e Schwartz (1979), o que era esperado. 
A Figura 4.27 apresenta os resultados para as tensões cisalhantes na interação maciçosuporte com a solução de Einstein e Schwartz (1979) (a) e com a modelagem numérica do Abaqus ${ }^{\circledR}(b)$.

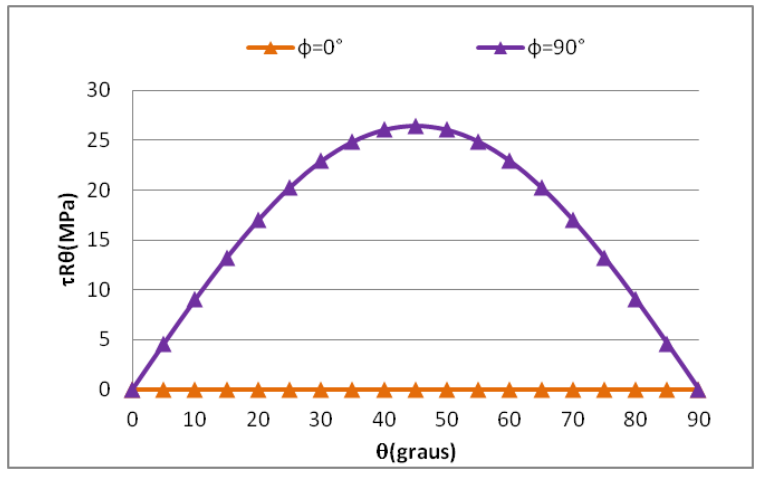

(a) Einstein e Schwartz (1979)

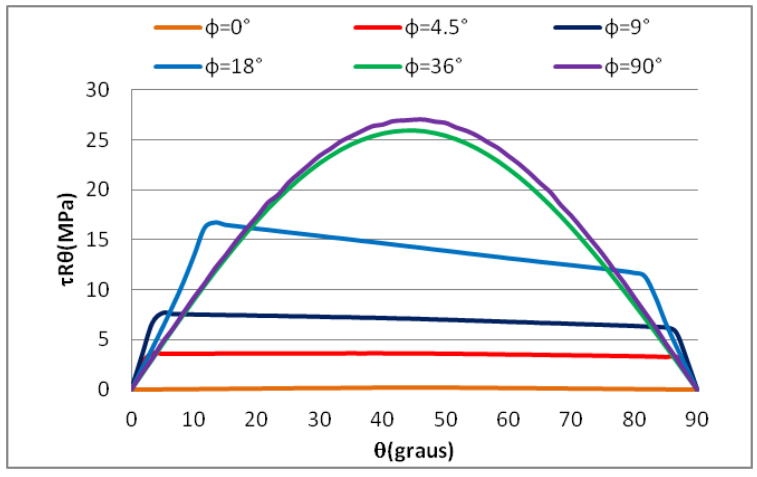

(b) Modelo numérico

Figura 4.27: Tensão cisalhante entre o maciço e o suporte para diferentes atritos.

Nesta situação as discrepâncias das tensões cisalhantes, entre a solução de Einstein e Schwartz (1979) e a solução numérica do Abaqus®, também foram semelhantes para $\phi=0^{\circ} \mathrm{e}$ $\phi=90^{\circ}$. Assim como para as tensões radiais, a solução numérica para diferentes ângulos de atrito $\left(0<\phi<90^{\circ}\right)$ esteve dentro dos limites da solução de Einstein e Schwartz (1979).

Observa-se que tanto as tensões radiais como as tensões cisalhantes do maciço não obedecem a uma relação linear com o atrito, provando que a partir de certo ângulo de atrito o coeficiente de atrito tende ao infinito e as tensões tendem a seu valor máximo.

Esforços normais na seção do suporte obtidos com a solução de Einstein e Schwartz (1979) (a) e com a modelagem numérica do Abaqus® (b) são mostrados na Figura 4.28.

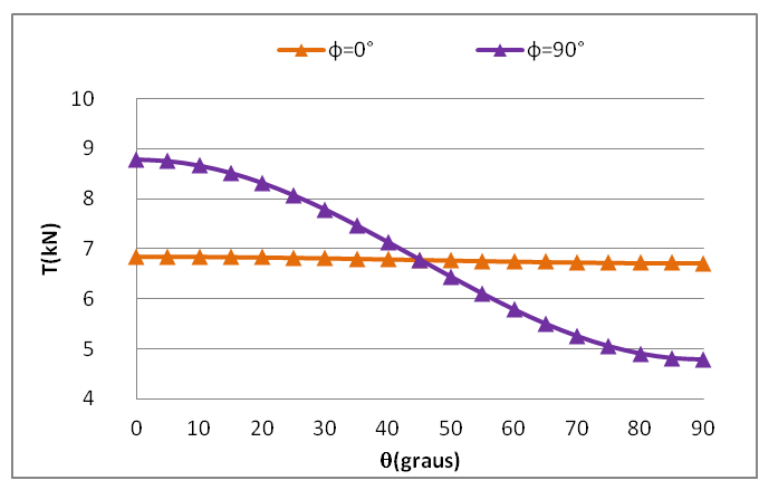

(a) Einstein e Schwartz (1979)

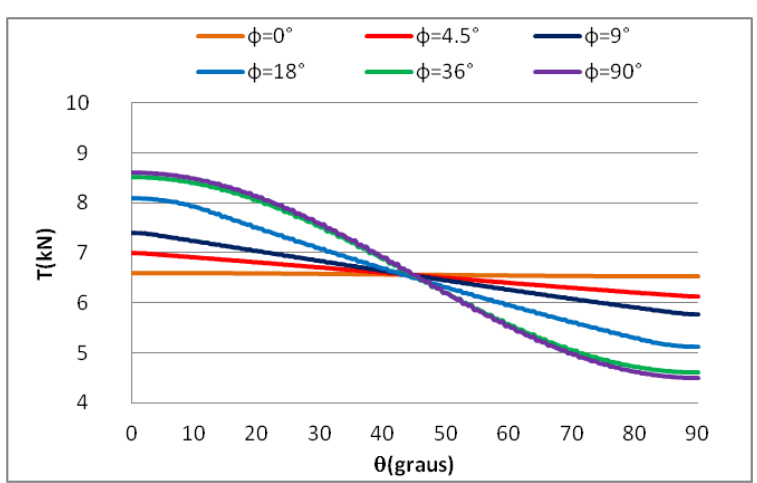

(b) Modelo numérico

Figura 4.28: Esforço normal no suporte para diferentes atritos. 
Nesta situação os esforços normais na seção do suporte, obtidos para os diferentes ângulos de atritos com a solução numérica do Abaqus®, também estiveram dentro dos limites da solução numérica de Einstein e Schwartz (1979).

A Figura 4.29 apresenta valores do momento fletor da seção do suporte obtidos através da solução de Einstein e Schwartz (1979) (a) e com a modelagem numérica do Abaqus® (b).

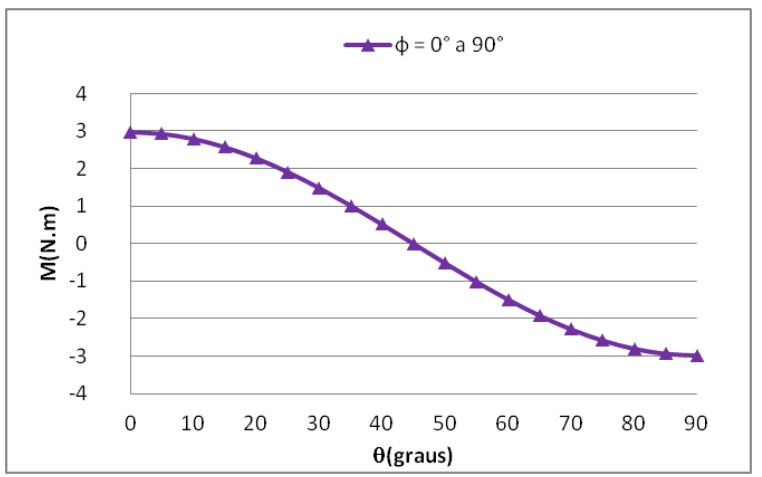

(a) Einstein e Schwartz (1979)

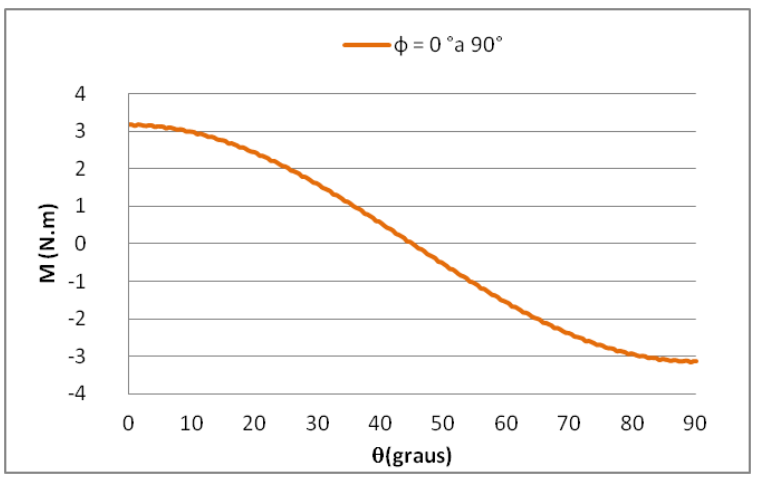

(b) Modelo numérico

Figura 4.29: Momento fletor no suporte para diferentes atritos.

Nesta situação, em todos os casos, os valores de momento fletor na seção do suporte foram os mesmos para a solução de Einstein e Schwartz (1979) e para a solução numérica do Abaqus®.

A Figura 4.30 mostra os resultados obtidos com a solução de Einstein e Schwartz (1979) (a) e com a modelagem numérica do Abaqus® (b) para os deslocamentos radiais do suporte.

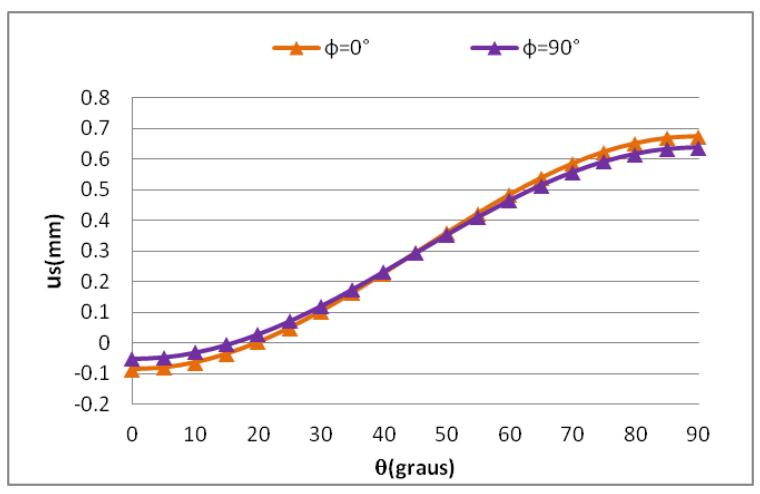

(a) Einstein e Schwartz (1979)

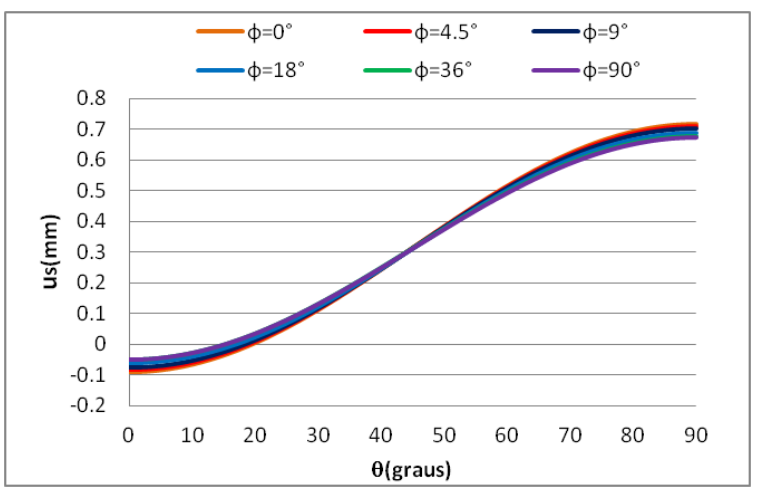

(b) Modelo numérico

Figura 4.30: Deslocamento radial do suporte para diferentes atritos.

Observa-se na Figura 4.30 que a solução numérica para os diferentes ângulos de atrito esteve dentro dos limites da solução de Einstein e Schwartz (1979). Mesmo a com uma 
variação muito pequena entre os deslocamentos (de $\phi=0^{\circ}, \phi=4,5^{\circ}, \phi=9^{\circ}, \phi=18^{\circ}, \phi=36^{\circ}$ e $\phi=90^{\circ}$ ) a solução numérica apresentou comportamento adequado.

Para o deslocamento transversal do suporte, são apresentados na Figura 4.31 os resultados da solução de Einstein e Schwartz (1979) (a) e da modelagem numérica do Abaqus® (b).

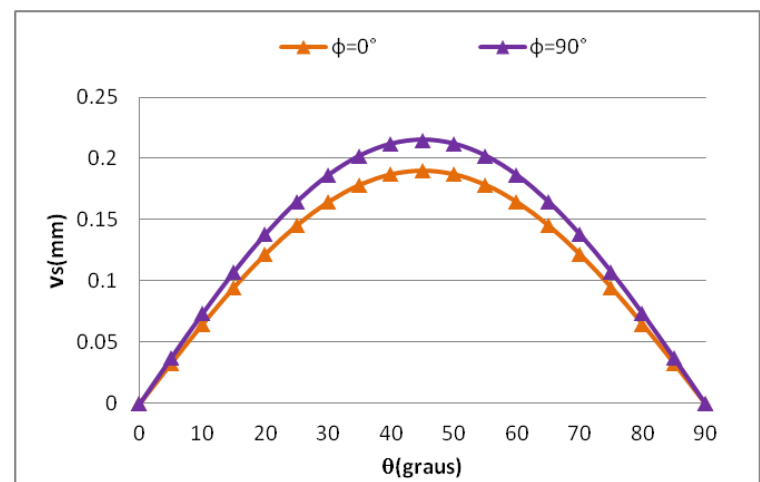

(a) Einstein e Schwartz (1979)

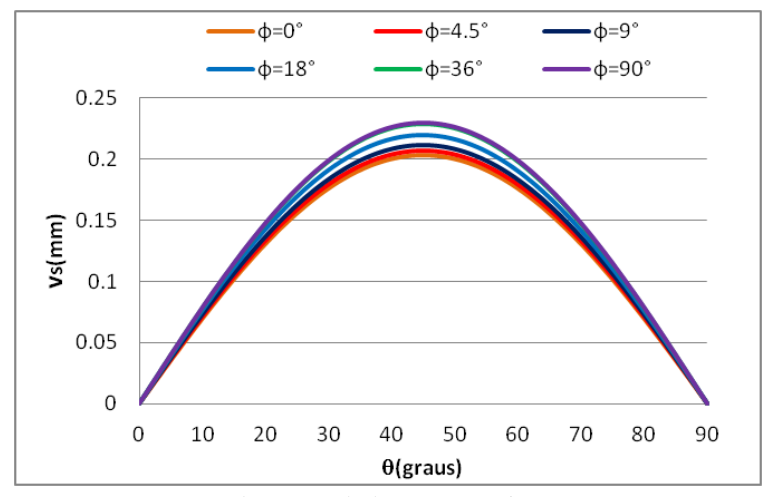

(b) Modelo numérico

Figura 4.31: Deslocamento transversal do suporte para diferentes atritos.

Da mesma forma que para o deslocamento radial, o deslocamento transversal apresentou solução numérica para diferentes ângulos de atrito dentro dos limites da solução de Einstein e Schwartz (1979). Observa-se que, mesmo para deslocamentos pequenos, a solução númerica levou a resultados muito próximos da solução teórica de Einstein e Schwartz (1979).

De fato, a falta de modelos teóricos e de ensaios para problemas de interação entre duas superfícies pode ser um dos fatores limitante na aceitação dos resultado obtidos com a solução númerica. A dificultade para deduções de formulações, bem como para a realização de ensaios deste tipo de problema torna a validação da solução númerica quase impossível. Isto não impede a utilização da mesma, visto que, este tipo de análise trouxe uma boa aproximação para o problema e os resultados obtidos estão coerentes com os resultados teóricos. 


\section{CAPITULO 5 - INTRODUÇÃO AO ESTUdO DE INTERAÇÃO DO SUPORTE COM MEMBRANAS DE IMPERMEABILIZAÇÃO EM TÚNEIS}

A utilização de membrana impermeabilizante em tuneis é uma técnica recente, quando comparada ao surgimento da escavação de túneis e galerias. A técnica consiste na utilização de um tecido impermeável, aderido ou não ao concreto, cuja função é impedir o fluxo de água entre o maciço e o revestimento. A impermeabilização é necessária em alguns casos por motivos operacionais e para evitar possível deterioração da estrutura de suporte por ação da água.

As membranas são usualmente instaladas entre o suporte primário e revestimento secundário. Existem dois tipos básicos de membranas: as mantas não aderidas e as membranas projetadas que aderem ao primário e ao secundário. As mantas não aderidas separam estruturalmente os concretos primário e secundário, quebrando seu monolitismo. Como consequência, o secundário é dimensionado para resistir ao carregamento total, desprezando, portanto a contribuição do primário. No caso de membranas projetadas e aderidas ao primário e secundário, o monolitismo é preservado e o dimensionamento pode contar com as duas camadas com o conceito de composite shell lining (CSL), como exposto por Thomas e Pickett (2011). Por outro lado, a membrana de menor rigidez que o concreto tem de ser levada em conta como elemento de ligação entre os elementos primário e secundário, limitando portanto a transferência de tensões de cisalhamento em relação ao que ocorre nos revestimentos compostos por duas camadas de concreto projetado diretamente em contato, single shell lining (SSL). A análise deste capítulo se refere a casos de CSL.

Muito se fala sobre as propriedades e a funcionalidade da utilização de membrana, algumas delas já comprovadas e outras ainda meras idealizações. Alguns autores como Ertin (2006), Šíma et al. (2011) e Brandenberger et al. (2004) já publicaram estudos sobre o tema, mas até o momento pouco se sabe sobre o que a membrana pode afetar no comportamento da estrutura do revestimento. De fato ela pode afetar a rigidez da interface e a capacidade de resistir a carregamentos externos, mas até que ponto isto será aceitável? A variação do nível d'água poderá causar algum problema à sustentação? Com base nestes questionamentos, o presente capítulo vem mostrar um exemplo prático do comportamento de um túnel com 
revestimento primário e secundário de concreto projetado, entre eles uma membrana projetada responsável pela impermeabilização do revestimento secundário.

Devido à importância que este assunto vem tomando nos últimos tempos, verificou-se a necessidade de simular este tipo de interação. A ideia é simular a escavação do túnel com a colocação do revestimento (suporte primário, membrana projetada e suporte secundário) e aplicação do carregamento decorrente da variação do nível d'água, com o objetivo de analisar o contato membrana-suporte.

\subsection{MODELO EM ESTUDO}

O modelo avaliado leva em consideração um caso geral de um túnel escavado em um maciço homogêneo, com as tensões hidrostáticas e pressões neutras variando com a profundidade. O túnel tem a forma de ferradura e é escavado a 50 metros de profundidade. A Figura 5.1 mostra as dimensões da seção do túnel em forma de ferradura adotada para a simulação.

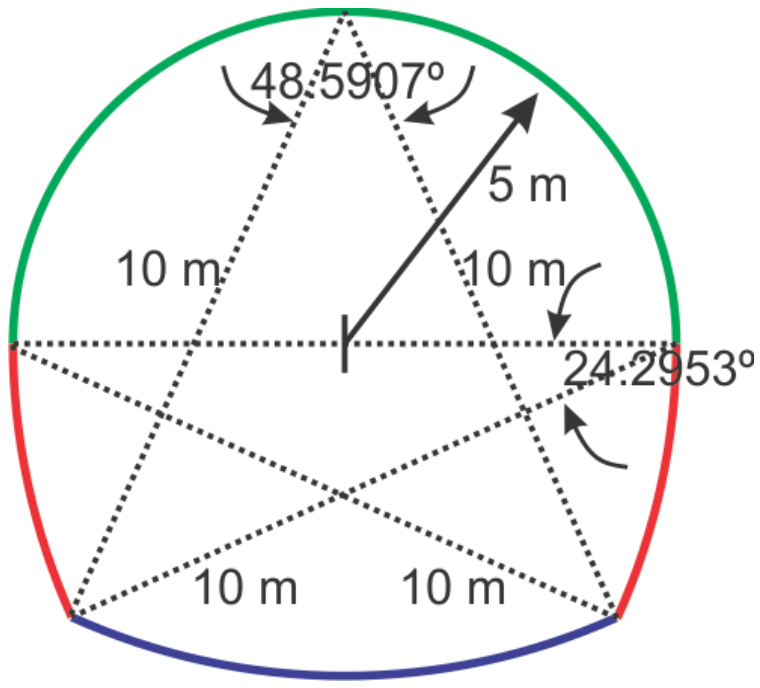

Figura 5.1: Seção transversal do túnel.

Devido à simetria a simulação é realizada com metade do modelo, como mostra a Figura 5.2. Com base nesta simetria são colocados vínculos no eixo vertical de simetria, impedindo os deslocamentos horizontais, ver Figura 5.2. Além disto, a base do modelo também é vinculada, impedindo os deslocamentos verticais. 


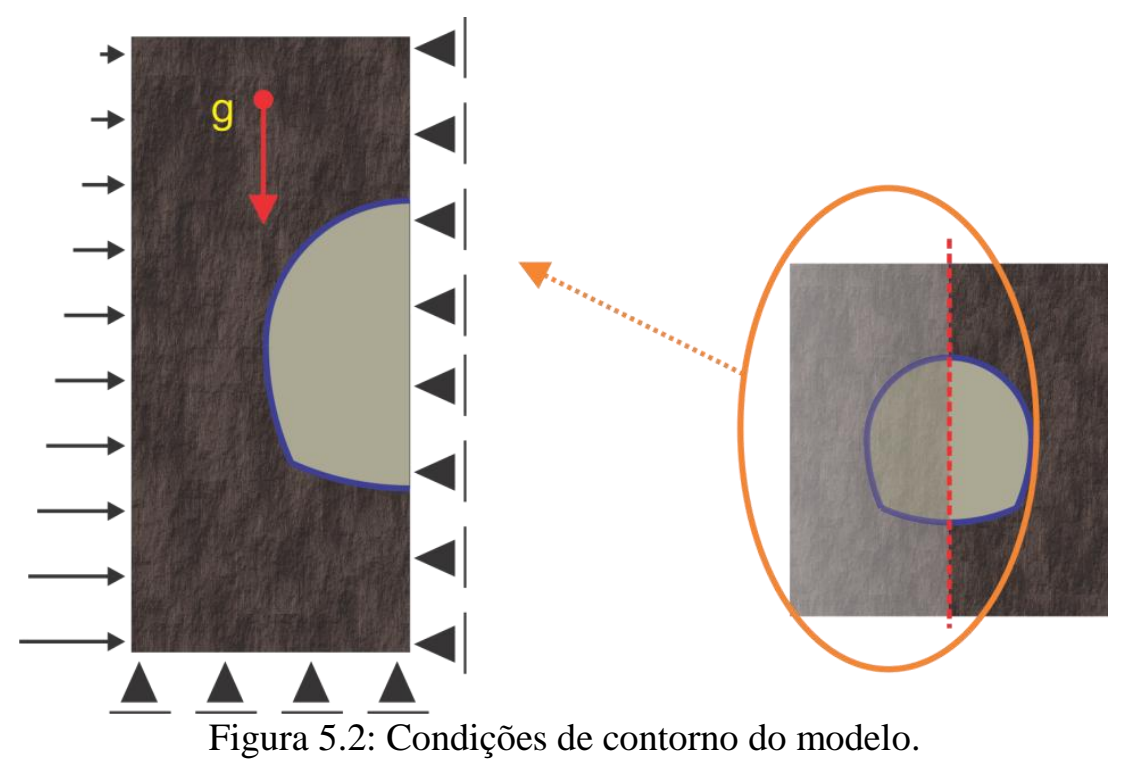

A Figura 5.2 ainda mostra a gravidade e as tensões horizontais aplicadas na etapa geostática da simulação. Nesta situação as tensões verticais iniciais $\sigma_{v}$ são calculadas pelo programa, a partir do carregamento gravitacional imposto. Para a obtenção da tensão horizontal $\sigma_{h}$ é assumida a relação $\sigma_{h}=\left(\frac{v}{1-v}\right), \sigma_{v}$, onde $v$ é o coeficiente de Poisson do maciço. O intuito é analisar uma situação de maciço com anisotropia de tensões iniciais de modo a gerar tensões de cisalhamento na membrana.

\subsubsection{PROPRIEDADES DO MACIÇO}

O maciço adotado é de classe IV, conforme classificação de Bieniawski (1984) com RMR igual a 40. Optou-se por adotar um maciço pouco competente, mais uma vez com o intuito de aumentar a solicitação mecânica da membrana. Os parâmetros adotados para o maciço são:

- Densidade

$$
\rho_{m}=2100 \mathrm{~kg} / \mathrm{m}^{3}
$$

- Coesão

$$
c_{m}=200 \mathrm{kPa} \text {, }
$$

- Atrito

$$
\phi_{m}=25^{\circ}
$$

- Dilatância

$$
\varphi_{m}=22,5^{\circ}
$$

- Parâmetros Elásticos 
O módulo de elasticidade é obtido de acordo com a Equação (5.1) proposta por Serafim e Pereira (1983).

$$
E_{m}=10^{\left(\frac{R M R-10}{40}\right)} \cdot \mathrm{GPa}
$$

Desta forma, tem-se para o módulo de elasticidade $E_{m}$ e coeficiente de Poisson $v_{m}$ do maciço:

$$
\begin{aligned}
& E_{m}=3,16 \mathrm{GPa}, \\
& v_{m}=0,3 .
\end{aligned}
$$

\subsubsection{PROPRIEDADES DO REVESTIMENTO}

Os revestimentos primário e secundário são considerados de concreto projetado e suas propriedades estão resumidas na Tabela 5.1. O concreto projetado é idealizado como homogêneo e perfeitamente elástico, ou seja, não serão avaliados os danos devido à plasticidade.

Tabela 5.1: Propriedades dos revestimentos.

\begin{tabular}{|c|c|c|}
\hline Módulo de Elasticidade $\left(\mathbf{E}_{\boldsymbol{c}}\right)$ & Coeficiente de Poisson $\left(\boldsymbol{v}_{\boldsymbol{c}}\right)$ & Densidade $\left(\boldsymbol{\rho}_{\boldsymbol{c}}\right)$ \\
\hline $21 \mathrm{GPa}$ & 0,3 & $2400 \mathrm{~kg} / \mathrm{m}^{3}$ \\
\hline
\end{tabular}

Tanto o revestimento primário como o secundário tem espessura de $15 \mathrm{~cm}$ e os mesmo são utilizados em todo perímetro do túnel. Vale ressaltar que o revestimento primário está em contato com o maciço e a membrana, e o secundário com a membrana.

\subsubsection{PROPRIEDADES DA MEMBRANA DE IMPERMEABILIZAÇÃO}

A membrana considerada é a Masterseal ${ }^{\circledR} 345$ e seus parâmetros são obtidos com base no relatório de ensaios de cisalhamento direto do "Institute for Rock Mechanics and Tunnelling" (2008). Os ensaios foram realizados em corpos de prova formados por duas camadas de concreto separadas pela membrana de impermeabilização. Cada camada possuía $20 \times 20 \times 16 \mathrm{~cm}$ de dimensões.

Foram realizados dois ensaios: o primeiro sem rugosidade e o outro com rugosidade na interface concreto/membrana/concreto. Neste estudo é considerado um caso ideal sem rugosidade, ou seja, com JRC (“Joint Roughness Coefficient”) igual à zero. Mais uma vez, 
adotou-se esta situação com limite inferior de rugosidade para resultar em limite superior da solicitação de cisalhamento sobre a membrana.

A Tabela 5.1 mostra os resultados do ensaio do "Institute for Rock Mechanics and Tunnelling" (2008) para o caso em que o a rugosidade na interface é zero, experimento 00 (Test 188.1).

Tabela 5.2: Ensaio de cisalhamento direto do "Institute for Rock Mechanics and Tunnelling" (2008).

\begin{tabular}{|l|c|}
\hline \multicolumn{1}{|c|}{ Modelo do ensaio } & $\begin{array}{c}\text { Experimento 00 } \\
\text { Teste 188.1 }\end{array}$ \\
\hline Espessura da camada de Masterseal® 345 & $2 \mathrm{~mm}$ \\
\hline JRC (“Joint Roughness Coefficient”) & 0 \\
\hline Módulo de Elasticidade Vertical (carregamento) & $32 \mathrm{MPa}$ \\
\hline Módulo de Elasticidade Vertical (descarregamento) & $40 \mathrm{MPa}$ \\
\hline Módulo de Cisalhamento & $7,2 \mathrm{MPa}$ \\
\hline Máxima Tensão Cisalhante & $1,76 \mathrm{MPa}$ \\
\hline Coesão & $1,05 \mathrm{MPa}$ \\
\hline Ângulo de Atrito & $43^{\circ}$ \\
\hline
\end{tabular}

Para consideração de contato na interface concreto/membrana/concreto se faz necessário conhecer a rigidez normal $\left(k_{n}\right)$ e a rigidez cisalhante $\left(k_{t}\right)$. Tais coeficientes são calculados a partir do modulo de elasticidade vertical $\left(E_{m}=32 \mathrm{MPa}\right)$, do modulo de cisalhamento $\left(G_{m}=7,2 \mathrm{MPa}\right)$ e da espessura da membrana ( $\left.e=2 \mathrm{~mm}\right)$. Por definição tem-se que a rigidez normal e o acréscimo de deslocamento vertical ( $\Delta \delta$ ) são, respectivamente:

$$
\begin{gathered}
k_{n}=\frac{\Delta \sigma}{\Delta \delta}, \\
\Delta \delta=\frac{\Delta \sigma \cdot e}{E_{m}},
\end{gathered}
$$

onde $\Delta \sigma$ é o acréscimo de tensão vertical.

Substituindo a Equação (5.3) na Equação (5.2) e fazendo o análogo para a rigidez cisalhante, chega-se às Equações (5.4) e (5.5) para rigidez normal e para a rigidez cisalhante, respectivamente:

$$
k_{n}=\frac{E_{m}}{e}
$$




$$
k_{t}=\frac{G_{m}}{e}
$$

A partir das Equações (5.4) e (5.5) e dos parâmetros da Tabela 5.2, pode-se obter a rigidez normal e a rigidez cisalhante (Tabela 5.3).

Tabela 5.3: Parâmetros calculados.

\begin{tabular}{|l|r|}
\hline \multicolumn{1}{|c|}{ Parâmetros } & Valor \\
\hline Rigidez Normal & $16,0 \mathrm{MPa} / \mathrm{mm}$ \\
\hline Rigidez Cisalhante & $3,6 \mathrm{MPa} / \mathrm{mm}$ \\
\hline
\end{tabular}

\subsection{CARACTERÍSTICAS DA SIMULAÇÃO}

O modelo utiliza 12740 elementos do tipo CPE4 (elemento contínuo plano deformável com 4 nós) para simular o maciço e o revestimento primário, 88 elementos B21 (elementos de viga 2D de formulação linear) para simular o revestimento secundário, como apresenta a Figura 5.3 e 88 elemento COH2D4 (elementos coesivos 2D com 4 nós) para simular a membrana. A utilização do elemento coesivo possibilita a consideração de uma interface com as características da membrana, ou seja, permite a consideração da rigidez normal e cisalhante, Abaqus-6.11 (2011).

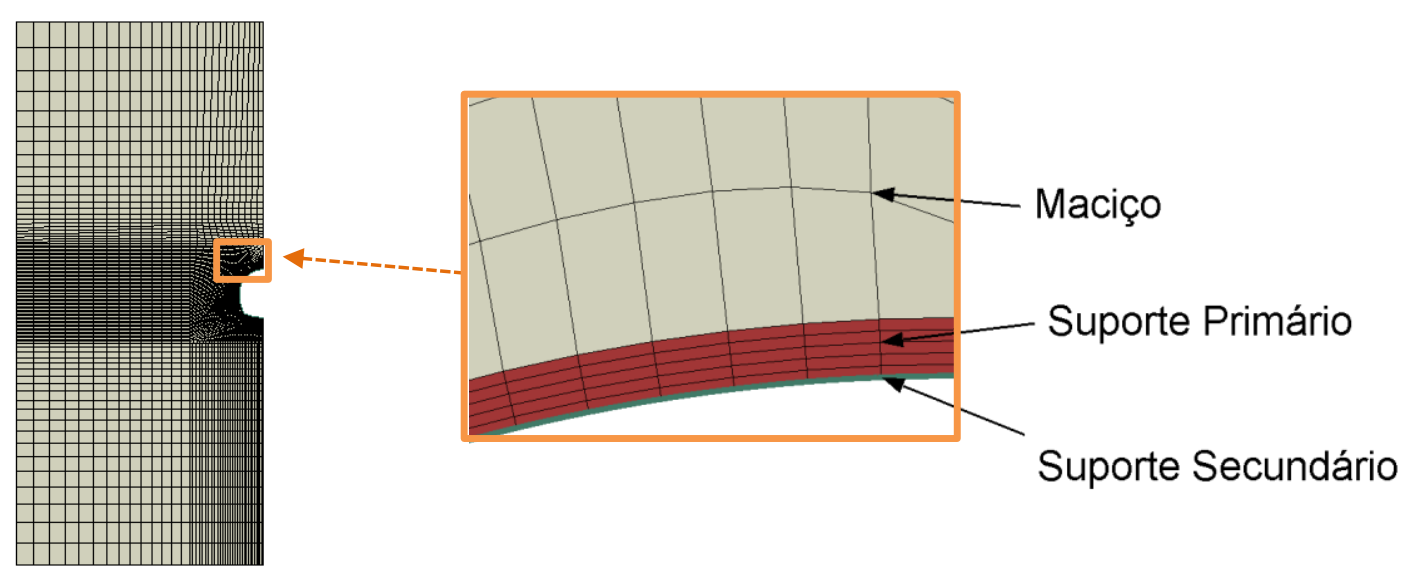

Figura 5.3: Malha do modelo.

Partindo do principio que a membrana é impermeável, opta-se por acrescentar um carregamento na membrana durante a simulação. Este corresponde à atuação das pressões neutras com a variação do nível d'água. Para o cálculo deste carregamento é estimada a pressão neutra à profundidade $h$, ou seja: 


$$
u_{w}=\gamma_{w} \cdot h
$$

onde $\gamma_{\mathrm{w}}=10 \mathrm{kN} / \mathrm{m}^{3}$ é o peso específico da água e $h$ é a profundidade medida a partir do nível d'água.

Para a simulação são consideradas 8 (oito) etapas, mostradas a seguir:

\section{Etapa Geostática}

Etapa de carregamento que serve para zerar as deformações geradas com a colocação das tensões iniciais. Nesta primeira etapa todos os elementos têm as mesmas propriedades do maciço, exceto o elemento coesivo por ser um elemento especial. Desta forma, o mesmo é impedido de se deformar com a colocação de vínculos (retirados na etapa seguinte).

\section{Etapa de Escavação}

Retirada dos elementos dentro do túnel, ou seja, os elementos dos suportes, da membrana e do maciço de modo a simular a escavação. Nesta etapa é considerada uma pressão fictícia no perímetro de escavação com um fator de alívio $\alpha=0,5$, conforme Panet (1976). A consideração do fator de alívio serve para permitir uma relaxação parcial do maciço, antes da colocação do suporte.

\section{Etapa de Suporte Primário}

Após a escavação é colocado o revestimento primário com a reativação destes elementos. Nesta etapa as pressões fictícias são retiradas e o maciço passa a ser suportado apenas pelo revestimento primário. Para a colocação do suporte também se faz a mudança de material durante a simulação, ou seja, incialmente os elementos do suporte têm as propriedades do maciço e em seguida, com a colocação do suporte, passa a ter as propriedades do concreto projetado.

\section{Etapa de Suporte Secundário}

A quarta etapa é de instalação do revestimento secundário e da membrana. Nesta etapa os elementos que constituem o revestimento secundário e a membrana são reativados com as devidas propriedades mecânicas e com tensões nulas.

\section{Etapa NA_1}


Até o momento é considerado que as pressões neutras no modelo são nulas. A partir desta etapa o nível d'água sobe até o nível NA_1, ou seja, até 5,0 m acima do túnel. Nesta e nas demais etapas é analisada a nova condição de equilíbrio do modelo com a membrana sendo solicitado também pela pressão gerada no entorno do perímetro da interface de contato, pressão esta calculada a partir peso da água e colocada interface da membrana com o revestimento secundário. A utilização desta pressão na interface entre a membrana e revestimento secundário, e não entre o revestimento primário e a membrana, é para possibilitar a simulação do efeito de desprendimento do revestimento secundário, efeito este bem mais preocupante que a simples compressão da membrana caso fosse considerado a pressão entre o revestimento primário e a membrana. Fica claro que desta maneira serão exacerbados deslocamentos relativos entre as extremidades da membrana.

\section{Etapa NA_2}

Nesta etapa o nível d'água é elevado até NA_2, ou seja, 10,0 m acima do túnel, onde também é verificada a nova situação de equilíbrio com a membrana sendo mais solicitada.

\section{Etapa NA_3}

Nesta etapa o nível d'água é elevado até NA_3, ou seja, 15,0 m acima do túnel, onde também é verificada a nova situação de equilíbrio com a membrana sendo mais solicitada.

\section{Etapa NA_4}

Por fim, o nível d'água é elevado até o NA_4, ou seja, 20,0 m acima do túnel, onde também é verificada a nova situação de equilíbrio com a membrana sendo mais solicitada.

A Figura 5.4 mostra a variação do nível d'água ocorrida durante a simulação. 


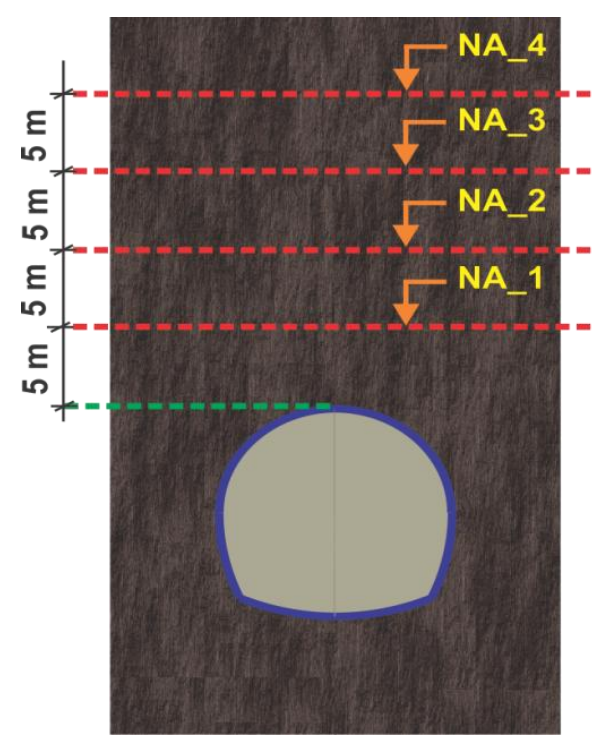

Figura 5.4: Variação do nível d'água.

\subsection{RESULTADOS E DISCUSSÕES}

Os resultados a seguir são para o maciço, revestimento primário, membrana e revestimento secundário. Em cada caso são analisados apenas os resultados mais relevantes. Para melhor visualização dos dados, apresenta-se na Figura 5.5 a orientação (no sentido antihorário) utilizada para nos resultados da Figura 5.6 a Figura 5.16.

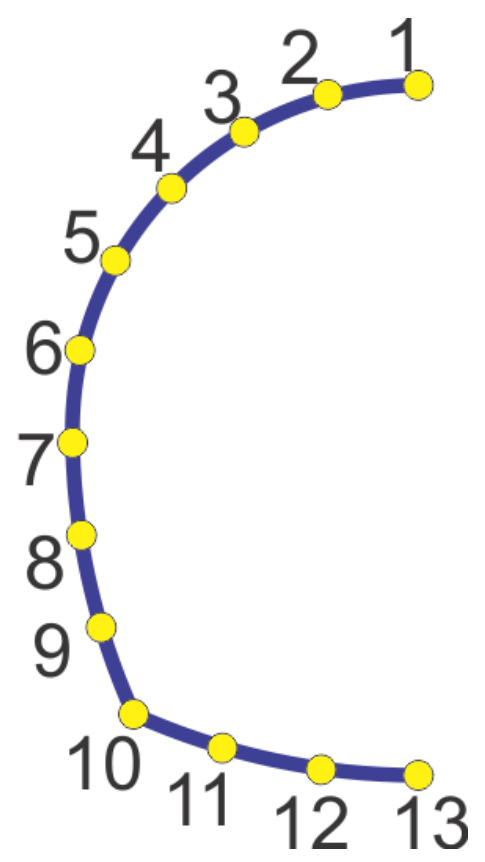

Figura 5.5: Orientação para leitura dos dados.

Após a primeira etapa de simulação foram verificadas as tensões geradas com o carregamento e se as deformações foram zeradas. A Figura 5.6 apresenta as tensões de Von 
Mises (S, Mises), tensões horizontais (S,S11) e tensões verticais (S,S22) em MPa no estado inicial (etapa geostática).
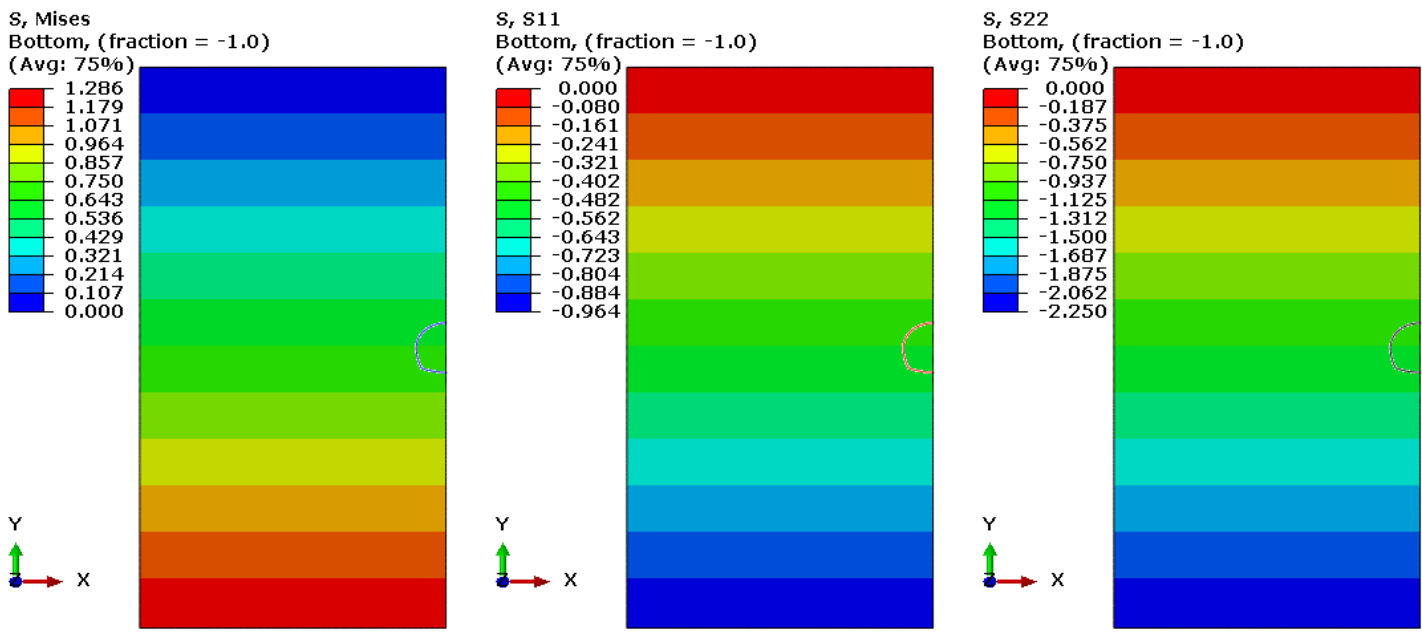

Figura 5.6: Tensões Von Mises, horizontais e verticais, estado inicial.

Observa-se na Figura 5.6 as tensões iniciais devido ao carregamento imposto. Para as tensões verticais (S,S22) iniciais tem-se uma variação de 0 a 2,250 MPa já as tensões horizontais iniciais variaram de 0 a $0,964 \mathrm{MPa}$ devido ao empuxo.

Após a etapa geostática o maciço é escavado e relaxado (etapa de escavação) até a colocação do suporte primário (etapa de suporte primário) e secundário (etapa de suporte secundário), posteriormente as pressões são aplicadas na interface de contato (etapas NA_1, NA_2, NA_3, NA_4). Na Figura 5.7 são mostrados os deslocamentos resultantes (U, Magnitude), horizontais (U,U1) e verticais (U,U2) do maciço obtidos nas etapas posteriores à geostática, unidade em mm.
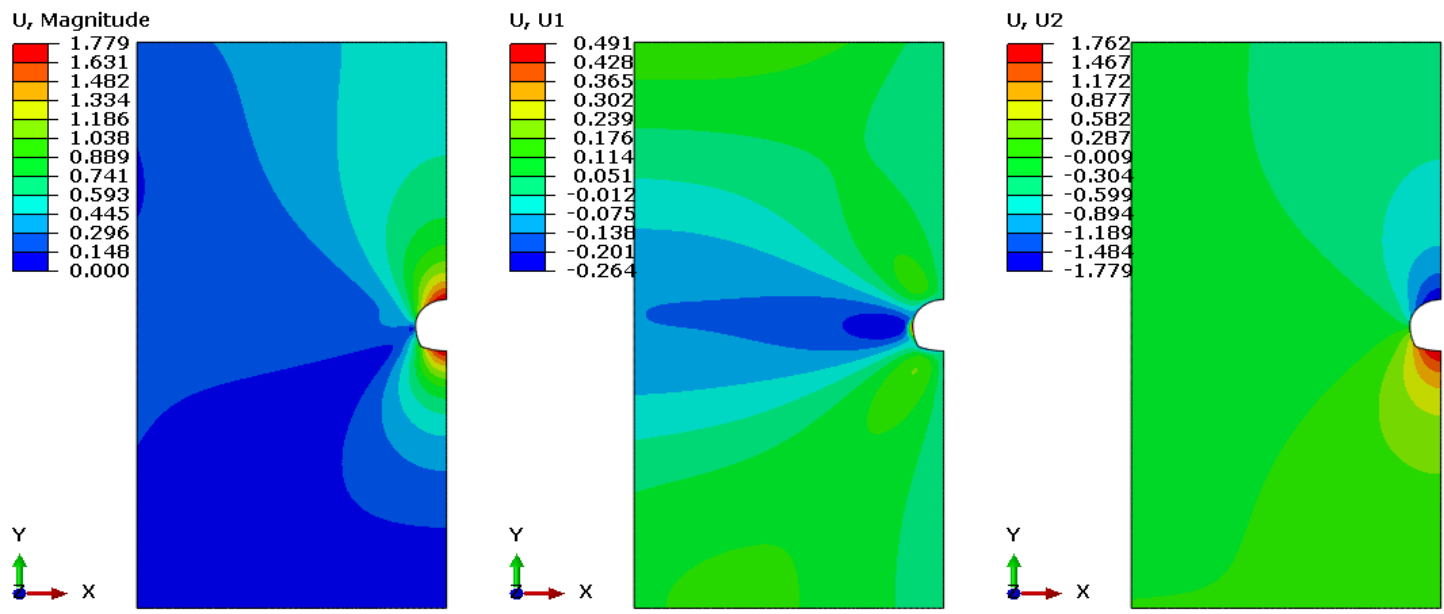

(a) Etapa de escavação 

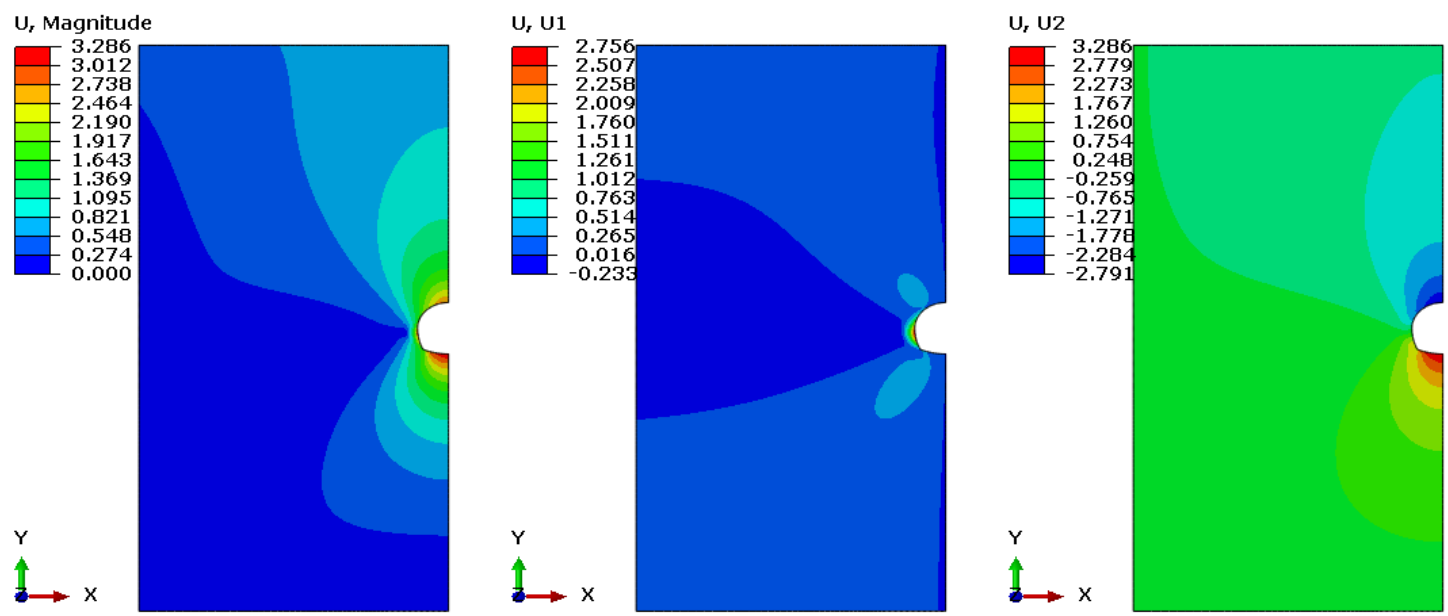

(b) Etapa de suporte primário
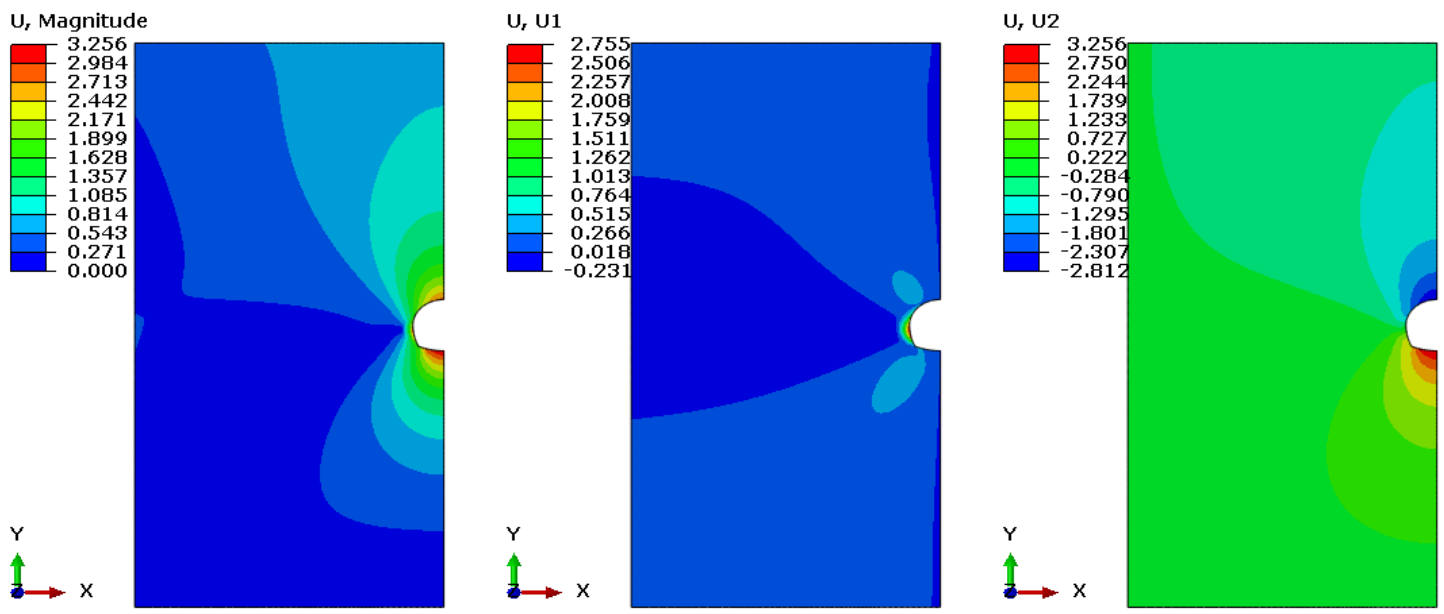

(c) Etapa de suporte secundário

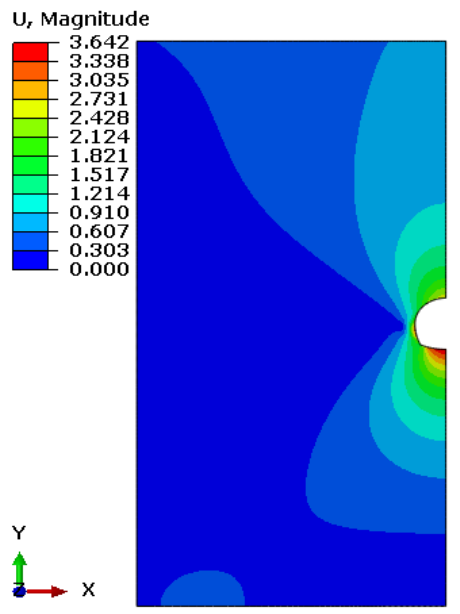

U, U1

$\mathrm{U}, \mathrm{U} 2$
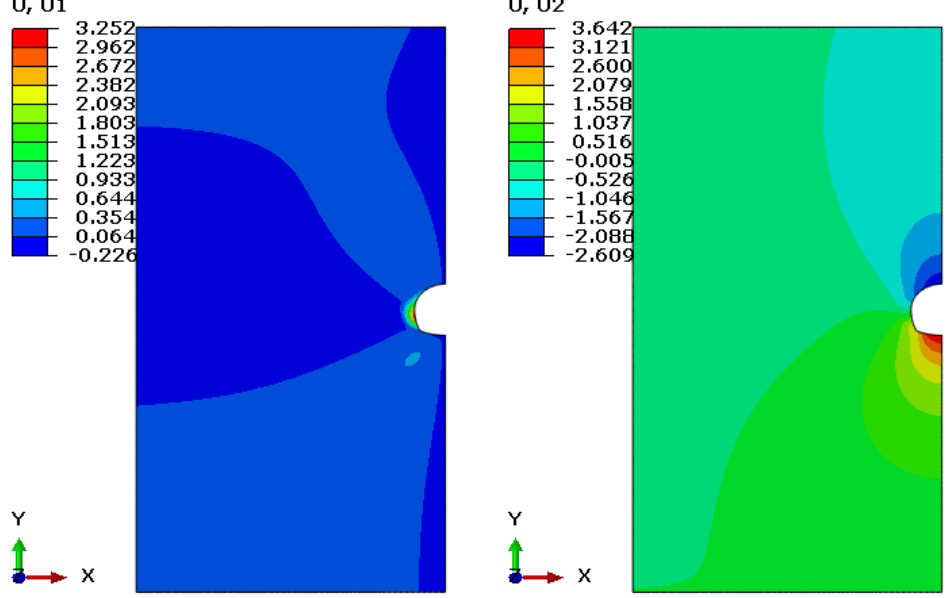

(d) Etapa NA_1 


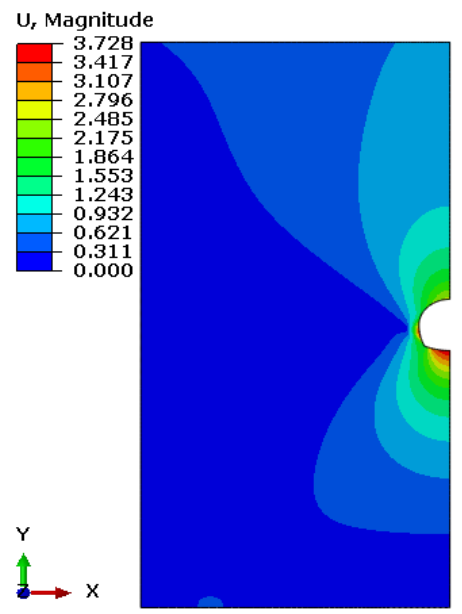

$\mathrm{U}$, Magnitude

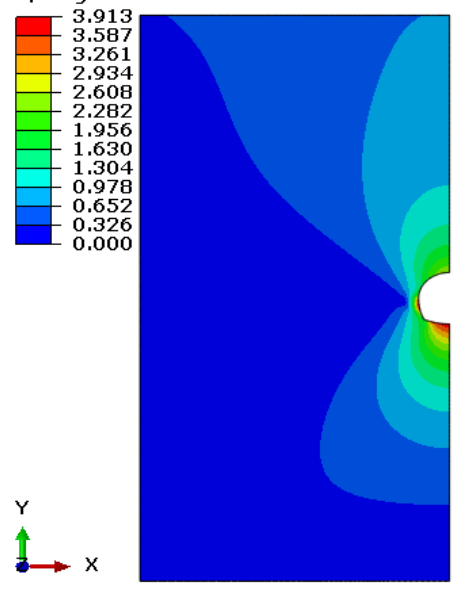

$\mathrm{U}$, Magnitude

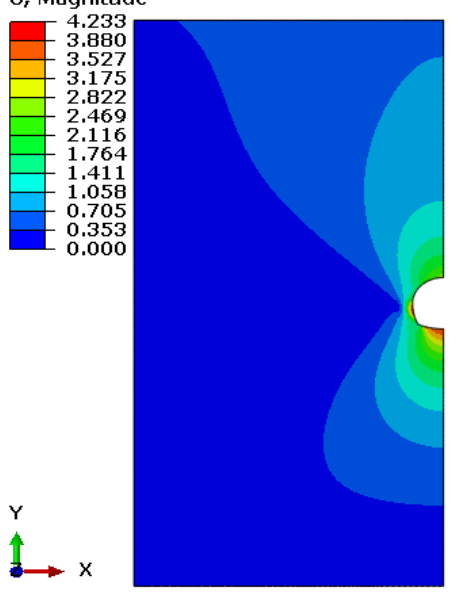

$\mathrm{U}, \mathrm{U} 1$

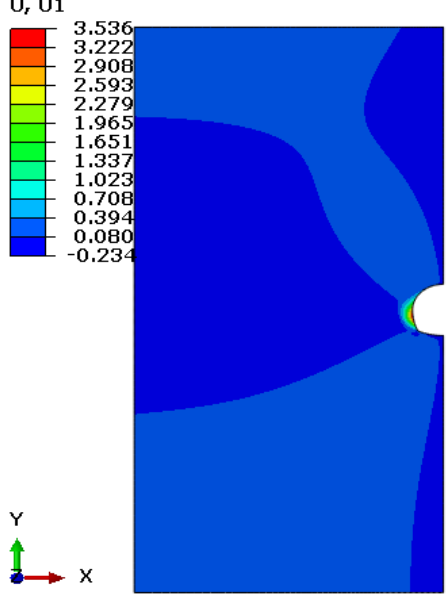

(e) Etapa NA_2

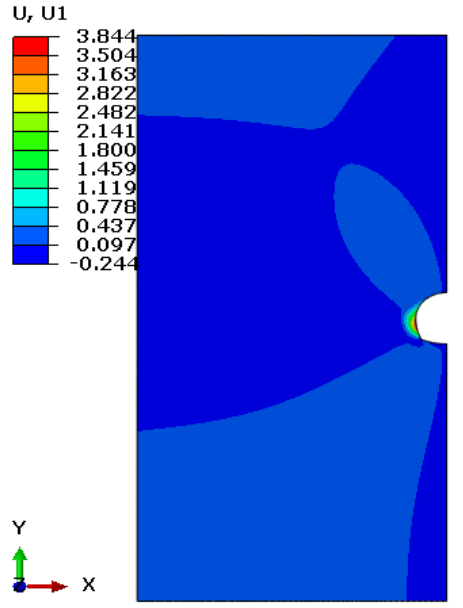

(f) Etapa NA_3

U, U1
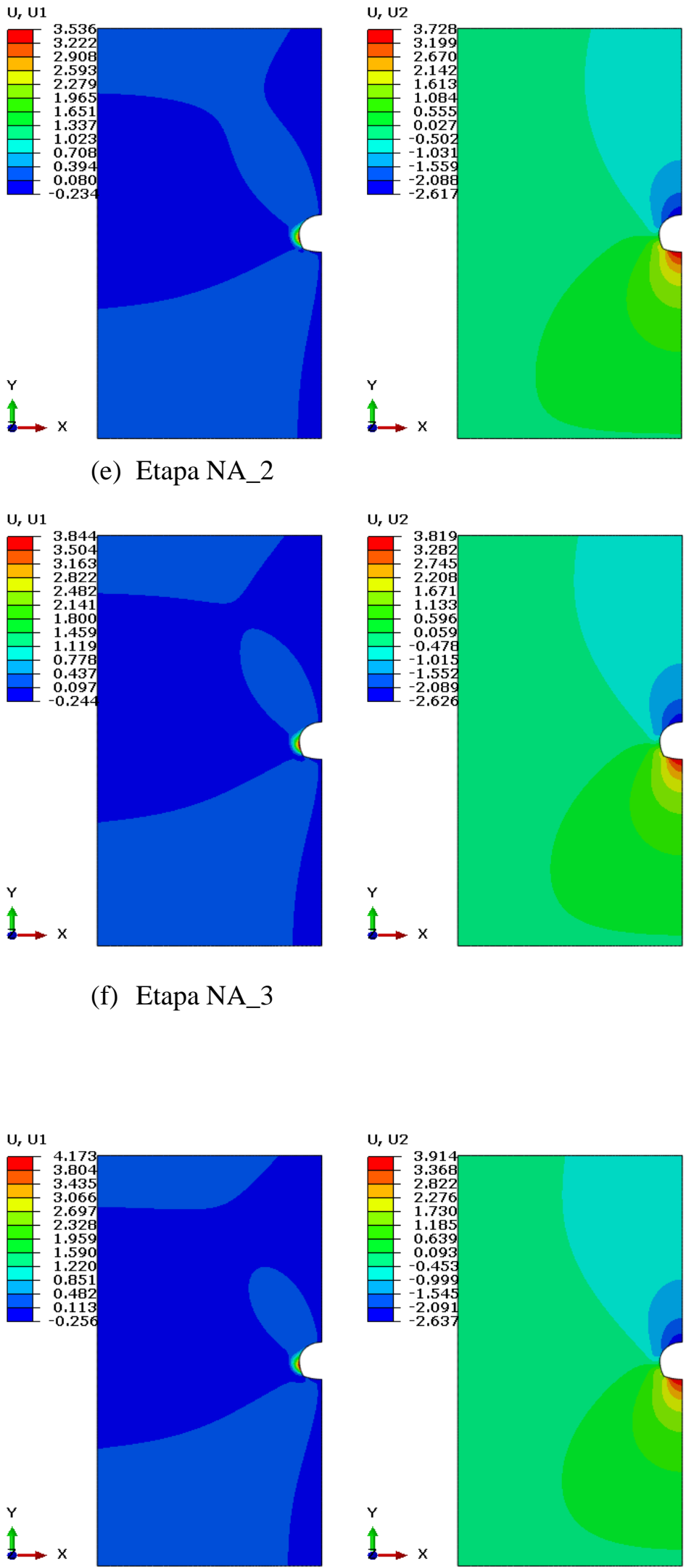

$\mathrm{U}, \mathrm{U} 2$

(g) Etapa NA_4

Figura 5.7: Deslocamentos resultantes, horizontais e verticais no maciço nas etapas posteriores a geostática. 
Observa-se na Figura 5.7 que os deslocamentos resultantes, horizontais e verticais no maciço vão aumentando a cada etapa, com exceção das etapas de colocação dos suportes (etapa 3 e 4). Nestas etapas houve uma pequena redução dos deslocamentos provocados pela instalação do suporte secundário, deslocamentos desprezíveis (cerca de 0,030 mm) e que pode ser entendida como a readaptação da malha de elementos finitos para o novo suporte. Inicialmente com a escavação os deslocamentos máximos foram de $1,779 \mathrm{~mm}$, deslocamentos estes que poderiam ser maiores se a pressão fictícia não fosse considerada. Com a colocação do suporte e a retirada da pressão fictícia o máximo deslocamento chegou a 3,286 mm, mostrando que o maciço ainda se deforma. Nas etapas NA_1, NA_2, NA_3 e NA_4 o maciço continua se deslocando e os deslocamentos máximos chegaram a 3,642 mm, 3,728 mm, 3,813 mm e 4,233 mm em cada etapa, respectivamente.

Com a colocação do suporte secundário e com o aumento da pressão na interface de contato entre o suporte primário e secundário, o suporte secundário passa a ser mais solicitado a cada aumento da pressão neutra. A Figura 5.8 mostra o esforço normal (SF, SF1) e esforço cortante (SF, SF2) em N, bem como, o momento fletor (SM, SM1) na seção do suporte secundário em N.mm em todas as etapas posteriores a colocação do suporte primário.
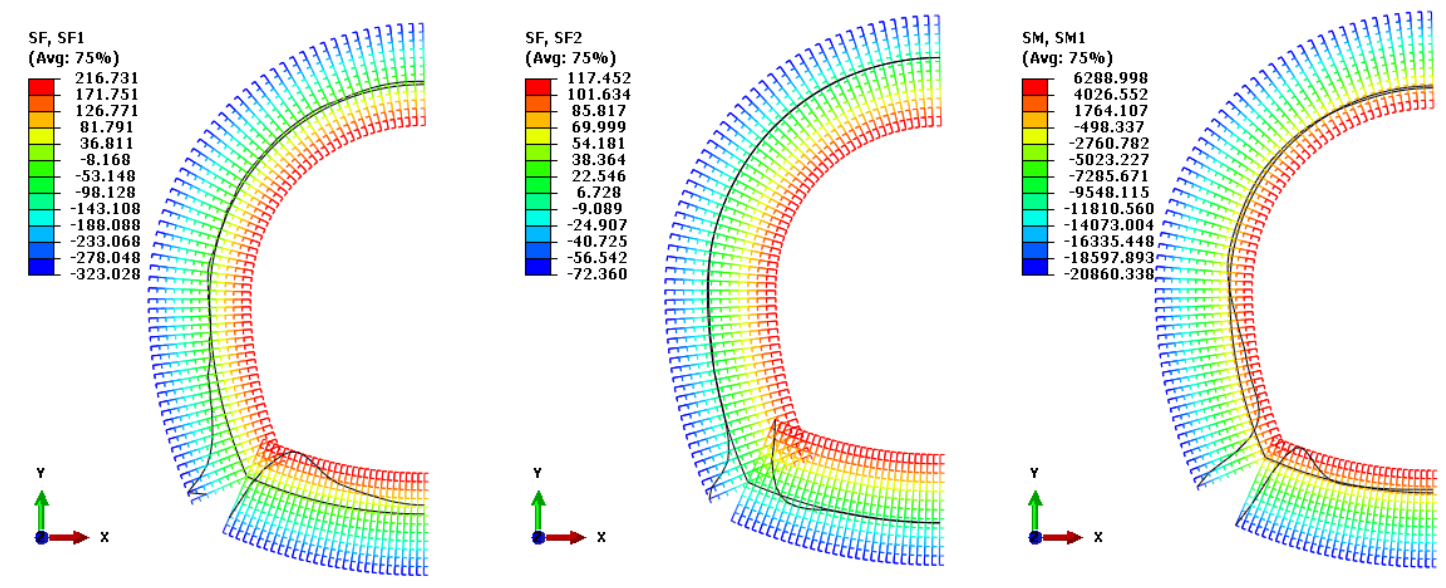

(a) Etapa de suporte ssecundário 

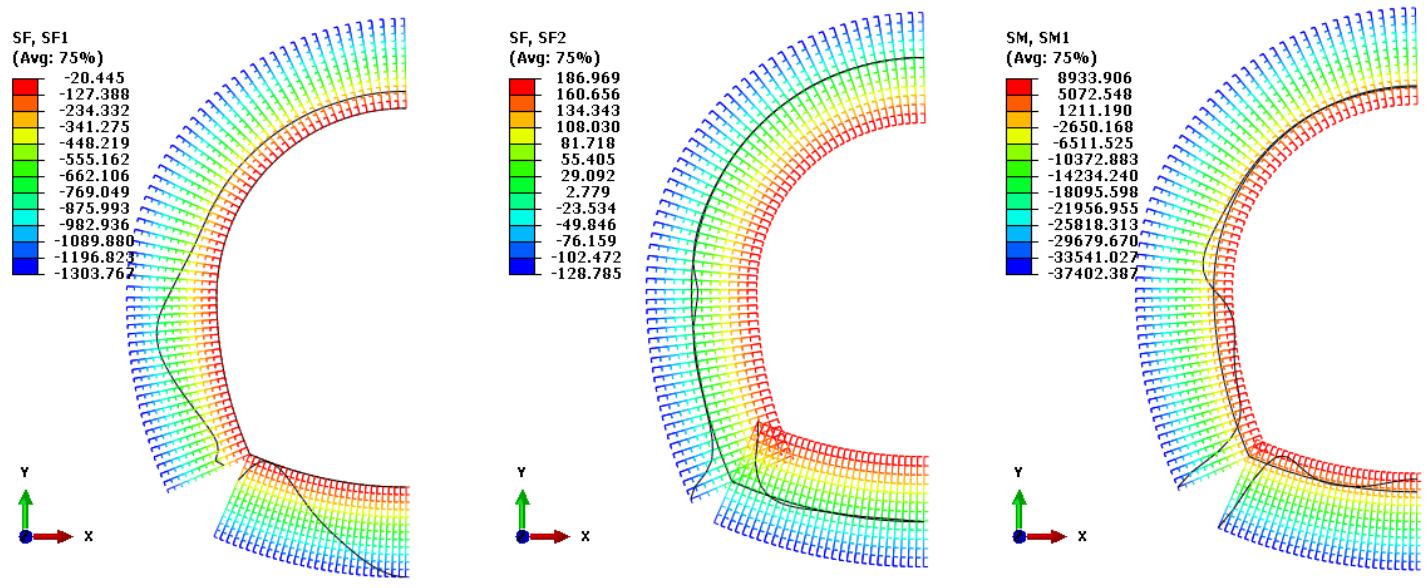

(b) Etapa NA_1
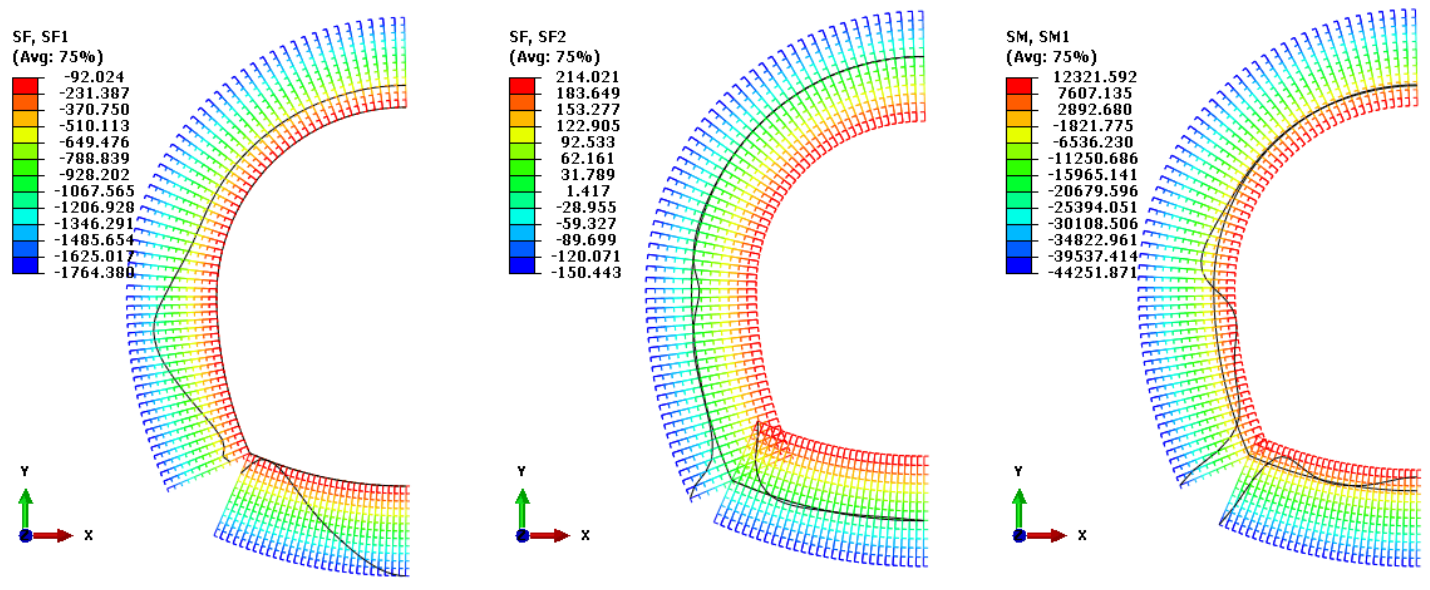

(c) Etapa NA_2
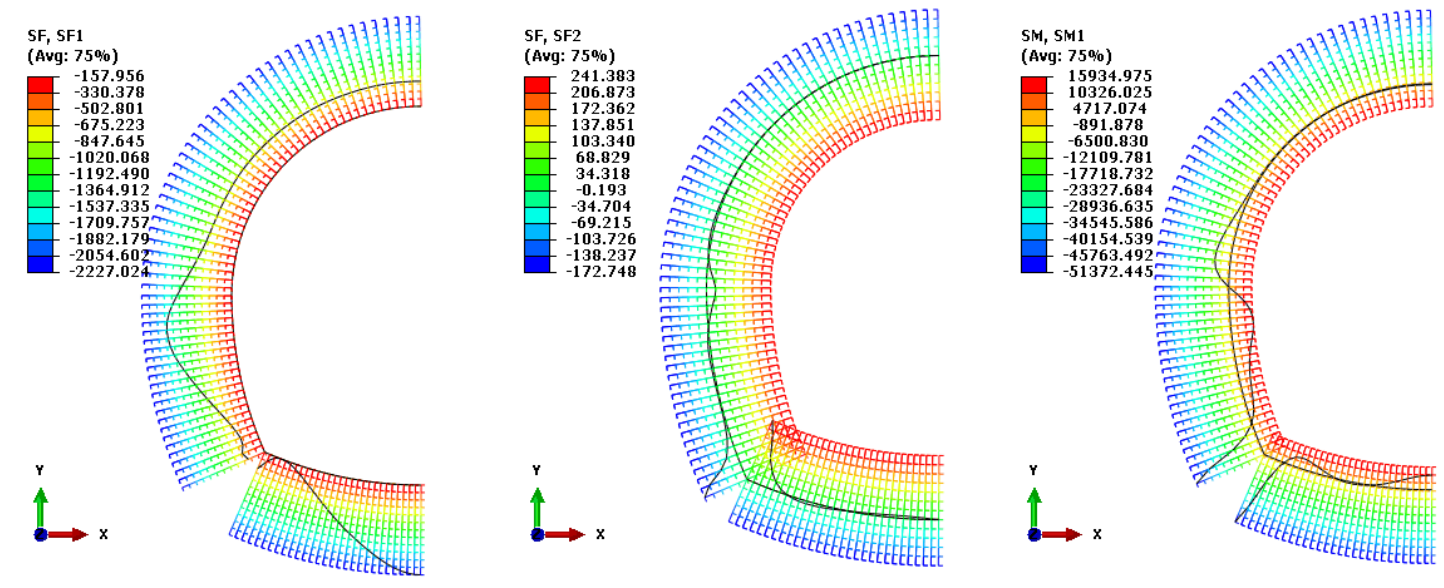

(d) Etapa NA_3 


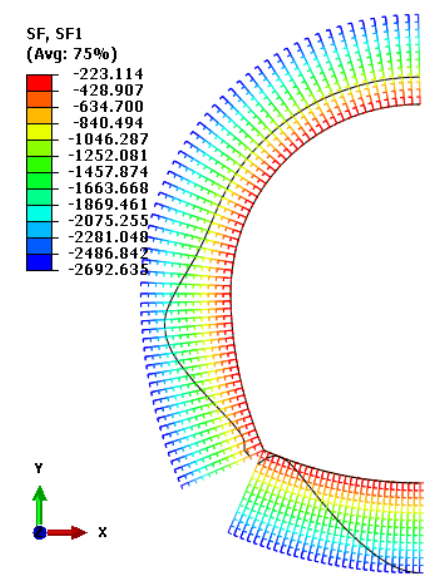

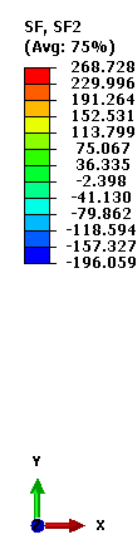
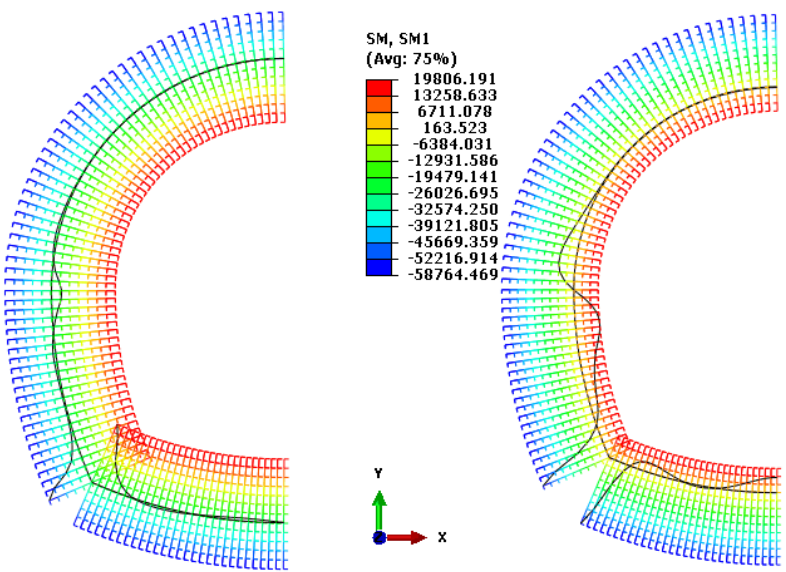

(e) Etapa NA_4

Figura 5.8: Esforços na seção do suporte nas etapas posteriores a escavação.

Observam-se na Figura 5.8 que os esforços normais são maiores negativamente do ponto 6 ao ponto 10 e menores do ponto 0 ao ponto 6 em todas as etapas (Suporte, NA_1, NA_2, NA_3, NA_4), ver Figura 5.5. Diferente do esforço normal, o esforço cortante apresentou-se nulo em quase todo suporte primário, o que era esperado. Neste caso observa-se que existe uma variação no ponto 10 , o que também era esperado devido à variação do arco neste ponto. Ainda na Figura 5.8 é observado, em todos os casos, o momento fletor negativo do ponto 0 ao 6 e no ponto 10 , sendo positivo nos demais pontos.

A Figura 5.9 apresenta graficamente os resultados dos esforços normais, no suporte secundário, em todas as etapas simuladas, onde:

- NA_Sem $\rightarrow$ sem nível d'água, ou seja, pressão neutra nula (Etapa de Suporte Secundário);

- NA_5,0 m $\rightarrow$ nível d'água 5 metros acima do túnel (Etapa NA_1);

- NA_10,0 $\rightarrow$ nível d'água 10 metros acima do túnel (Etapa NA_2);

- NA_15,0 $\rightarrow$ nível d'água 15 metros acima do túnel (Etapa NA_3);

- NA_20,0 $\rightarrow$ nível d'água 20 metros acima do túnel (Etapa NA_4). 


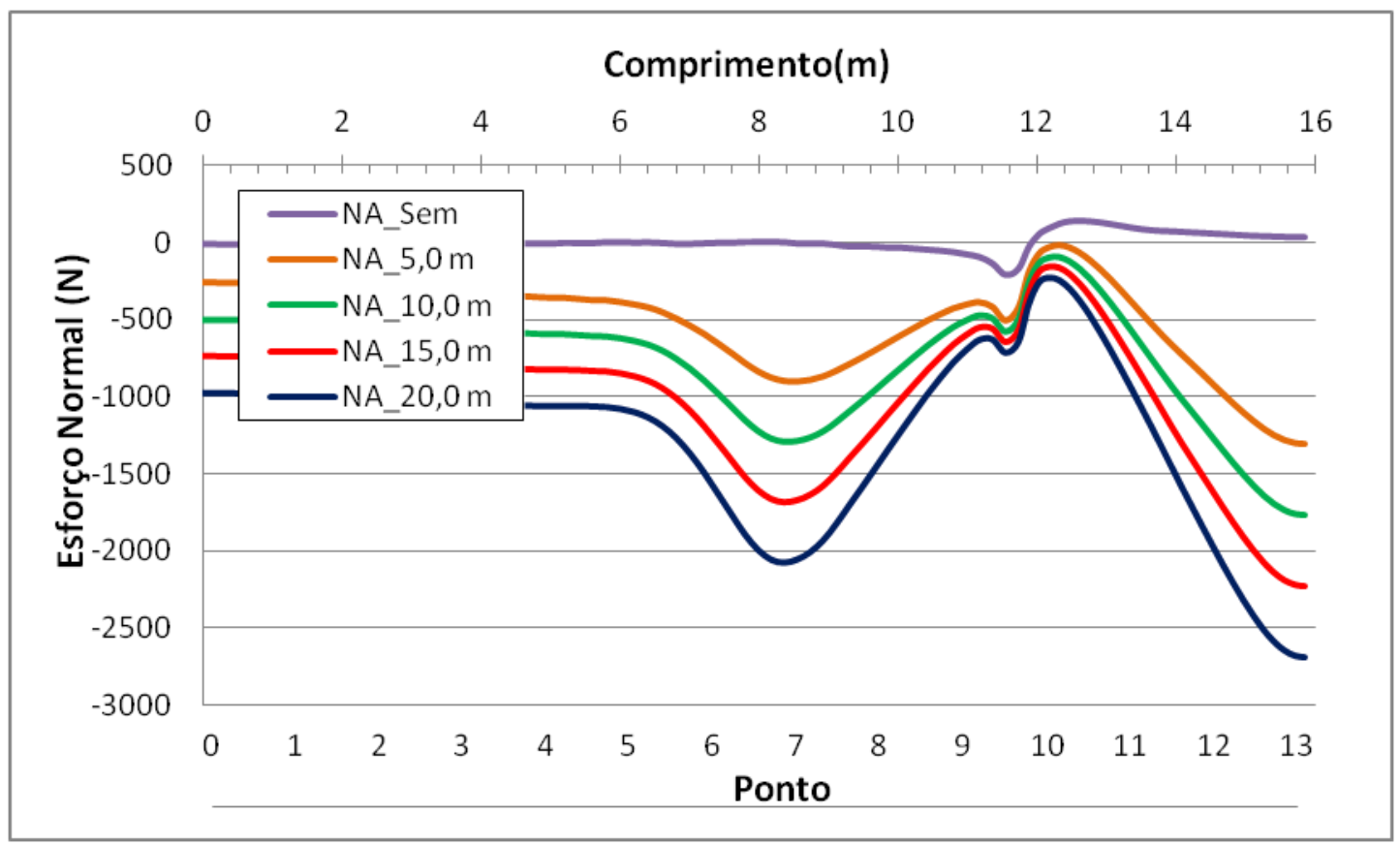

Figura 5.9: Esforço normal na seção do suporte secundário.

Tem-se pela Figura 5.9 que o esforço normal na situação NA_Sem apresentou valores menores, em escala absoluta, com relação ao esforço normal nas situações NA_5,0 m, NA_10,0 m, NA_15,0 e NA_20,0 m. Isto se deve ao fato de que inicialmente o suporte secundário não é solicitado pelo maciço, ou seja, o suporte primário é o único a ser solicitado. Nesta etapa o esforço normal do suporte secundário foi devido unicamente ao peso próprio. Observa-se também que estes valores aumentaram negativamente (compressão) proporcionalmente o aumento da pressão na interface da membrana.

A Figura 5.10 mostra o momento fletor no suporte secundário, onde pode ser observado as etapas NA_Sem, NA_5,0 m, NA_10,0 m, NA_15,0 m e NA_20,0 m. 


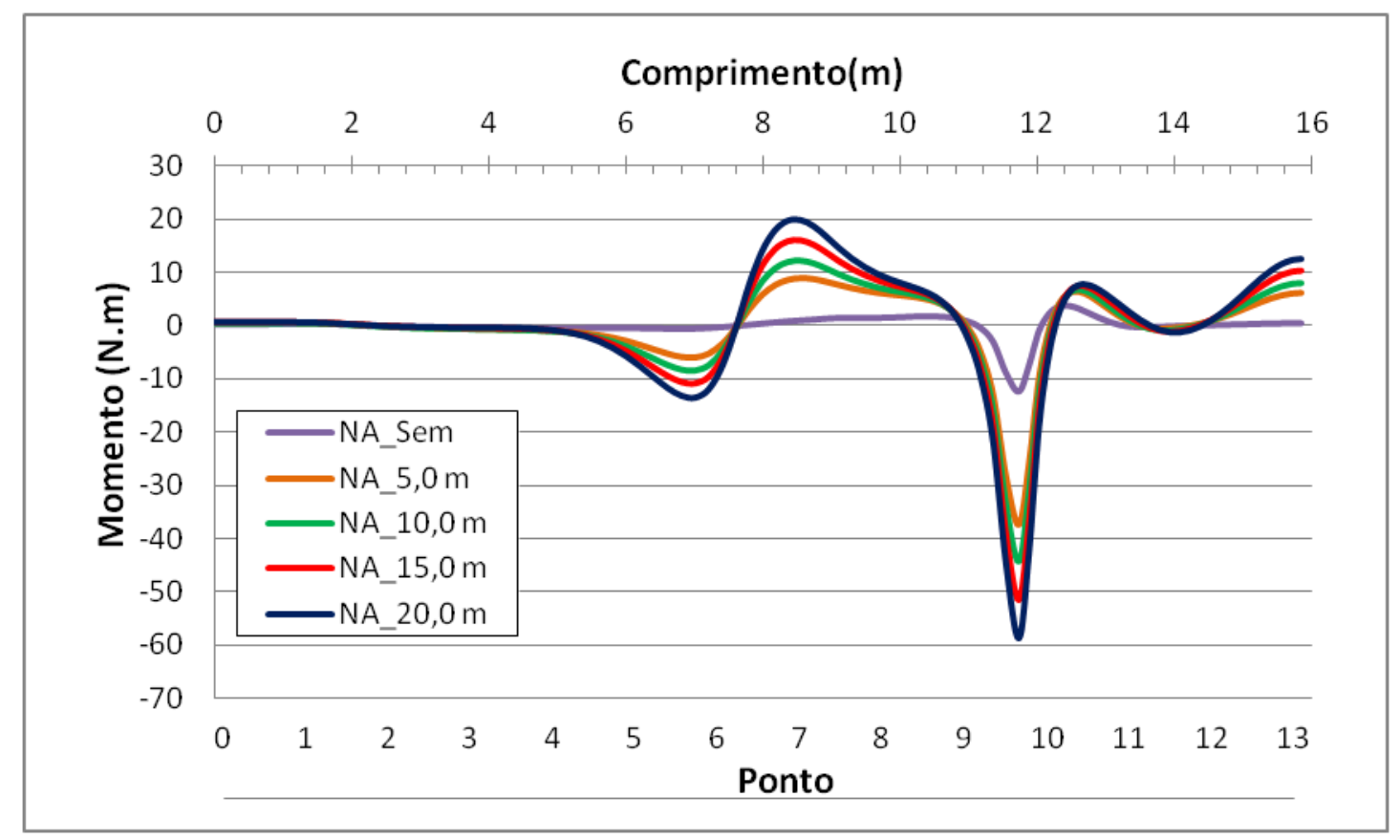

Figura 5.10: Momento fletor na seção do suporte secundário.

Na região em torno do ponto 10 da Figura 5.10 houve uma grande variação do momento fletor em todas as etapas, desta forma, fica evidente a necessidade de armadura nesta região. Observa-se também que na etapa de colocação do suporte secundário (NA_sem) os momentos foram bem próximos de zero, mostrando a pouca solicitação do mesmo como elemento estrutural.

Uma das discussões em relação ao assunto de membrana de impermeabilização em tuneis é o tratamento que se dá ao suporte. A discussão é de que maneira tratar o conjunto (suporte primário + membrana + suporte secundário), muitos acreditam que o mesmo funciona de forma homogênea e outros preferem separar e tratar individualmente cada elemento. Este fato pode ser facilmente explicado com as tensões atuantes em cada elemento, por exemplo, se o conjunto for homogêneo, as tensões vão ser continuas ao longo da espessura. A Figura 5.11 mostra os resultados das tensões de Von Mises no suporte primário (S, Mises) e no suporte secundário (BEAM_STRESS, Mises) em MPa. 

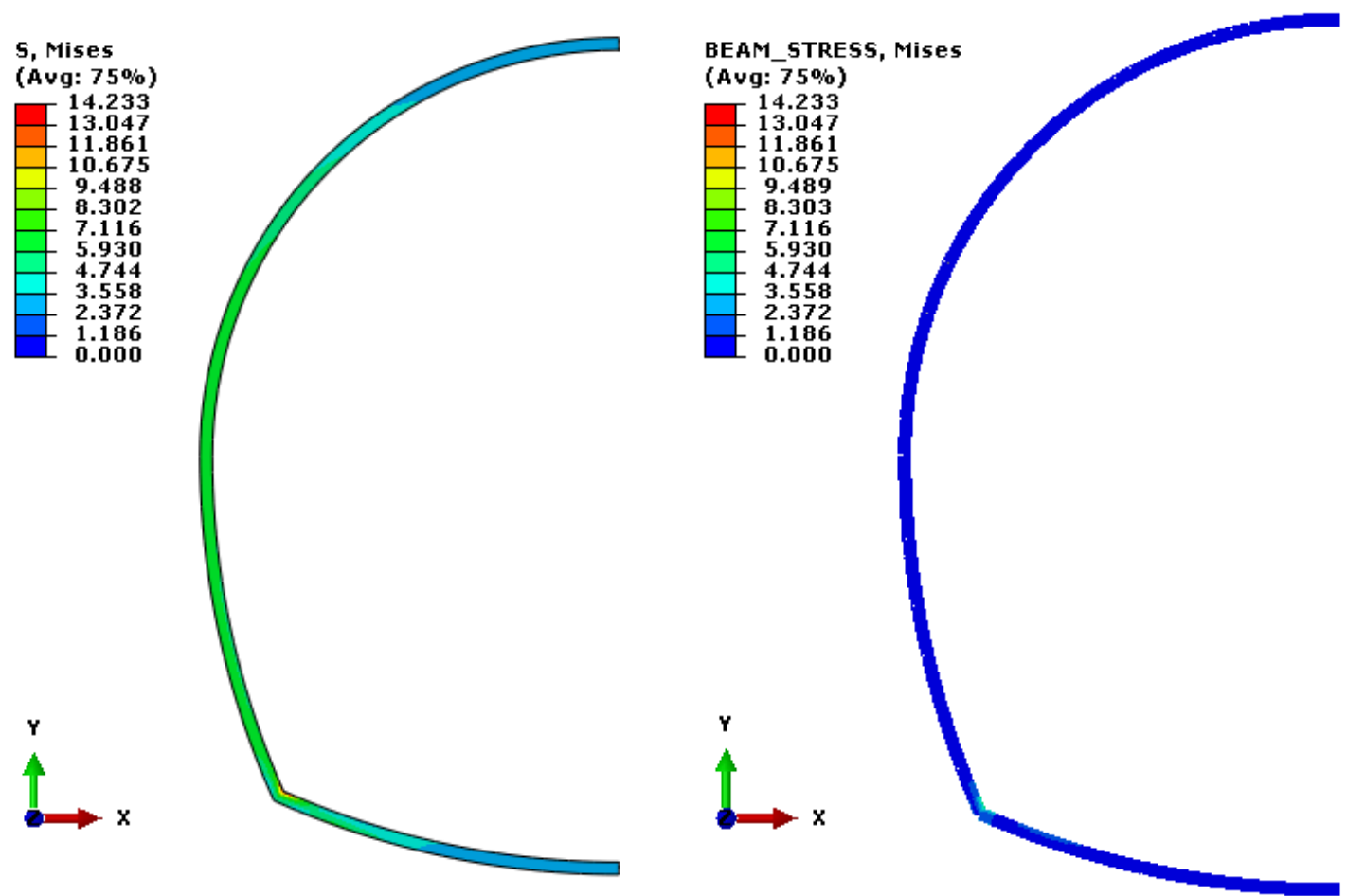

(a) Etapa de suporte secundário
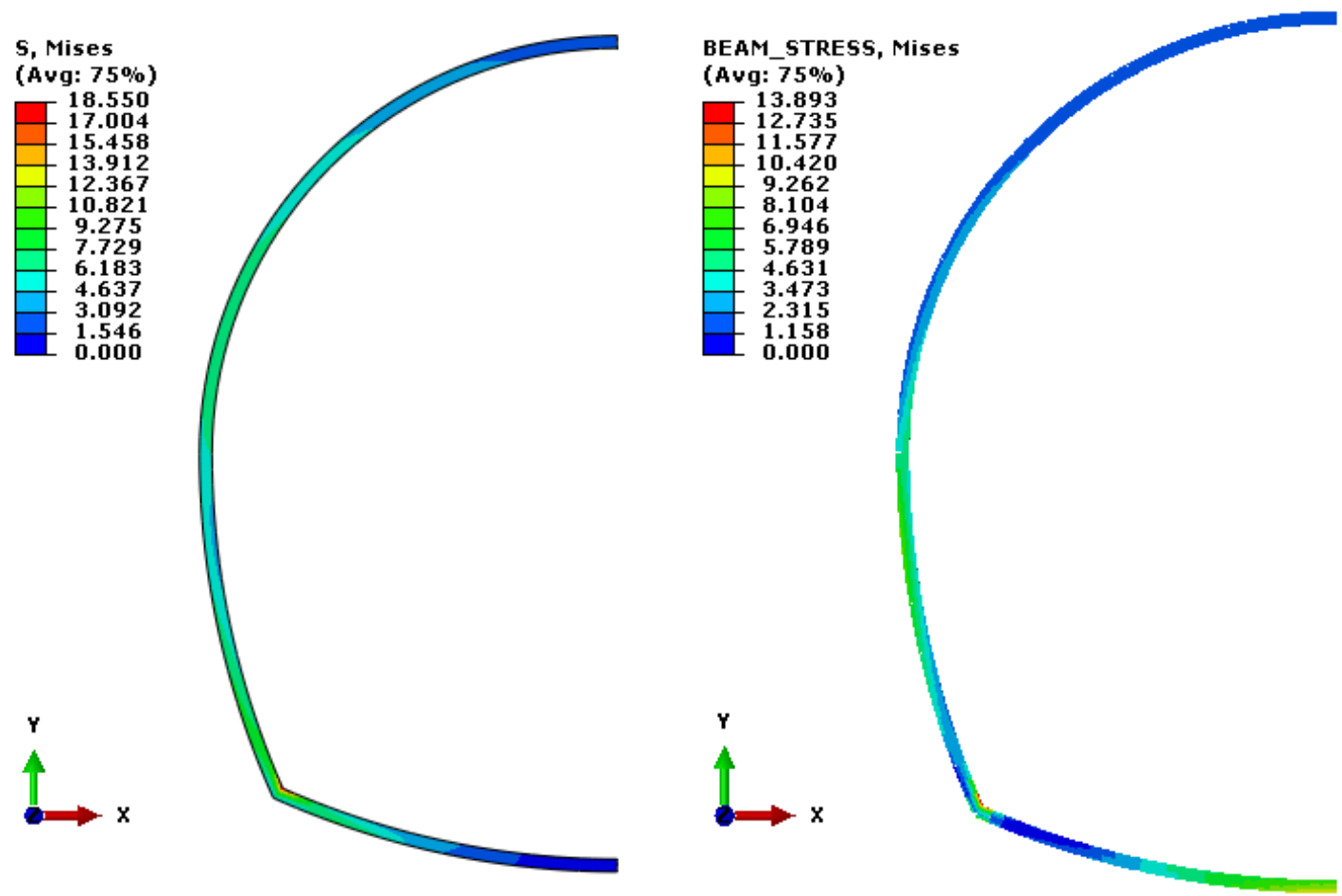

(b) Etapa NA_1 

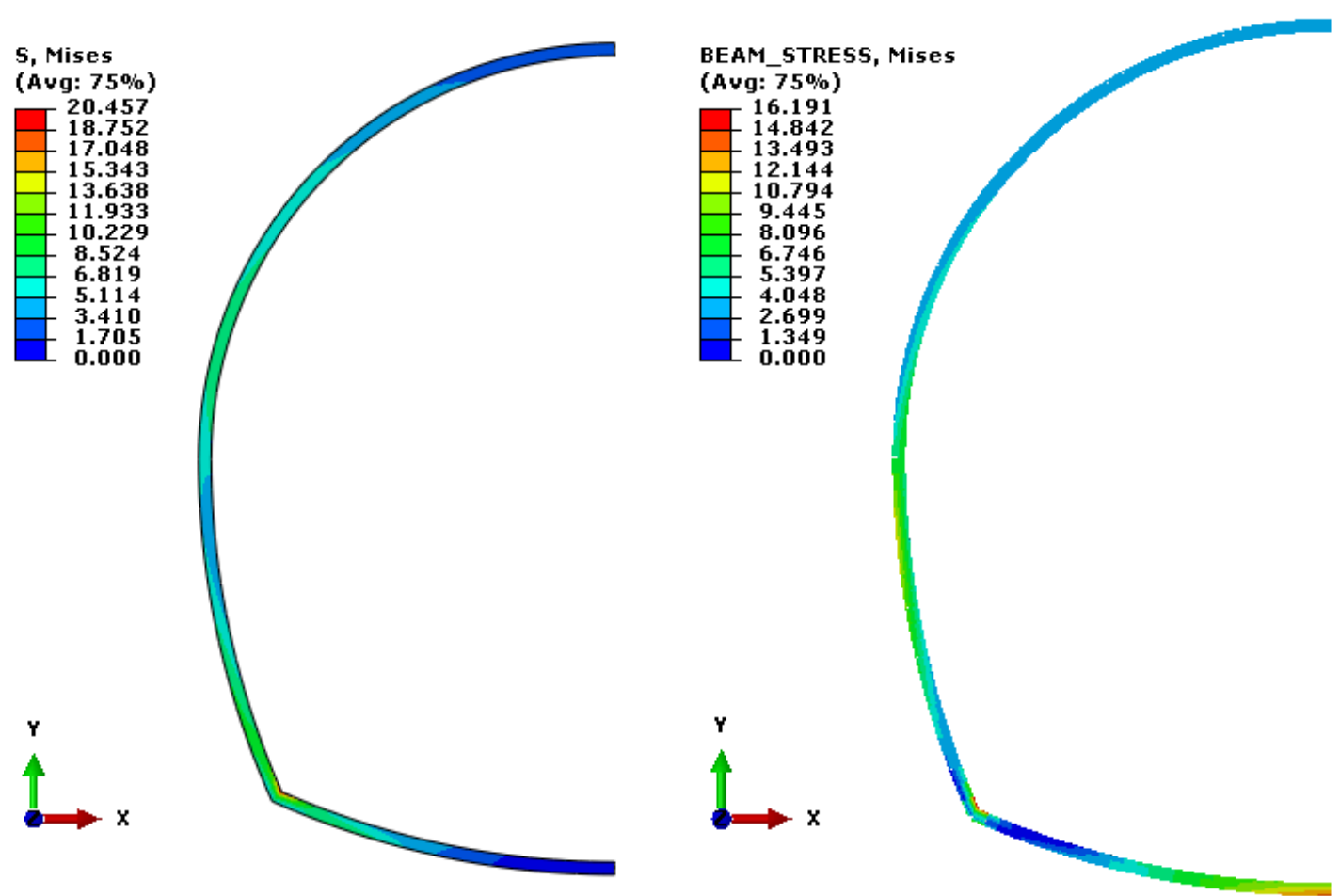

(c) Etapa NA_2
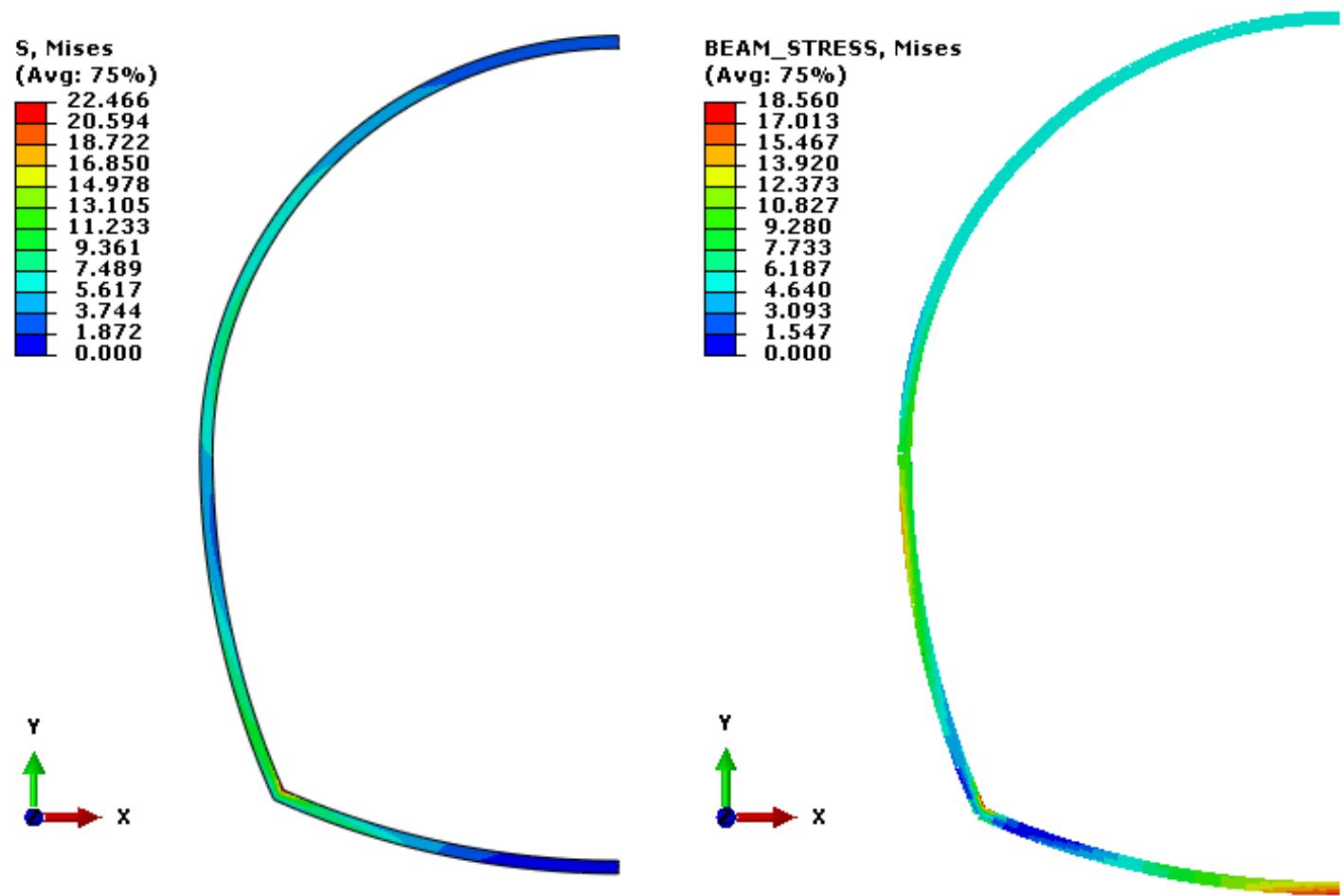

(d) Etapa NA_3 


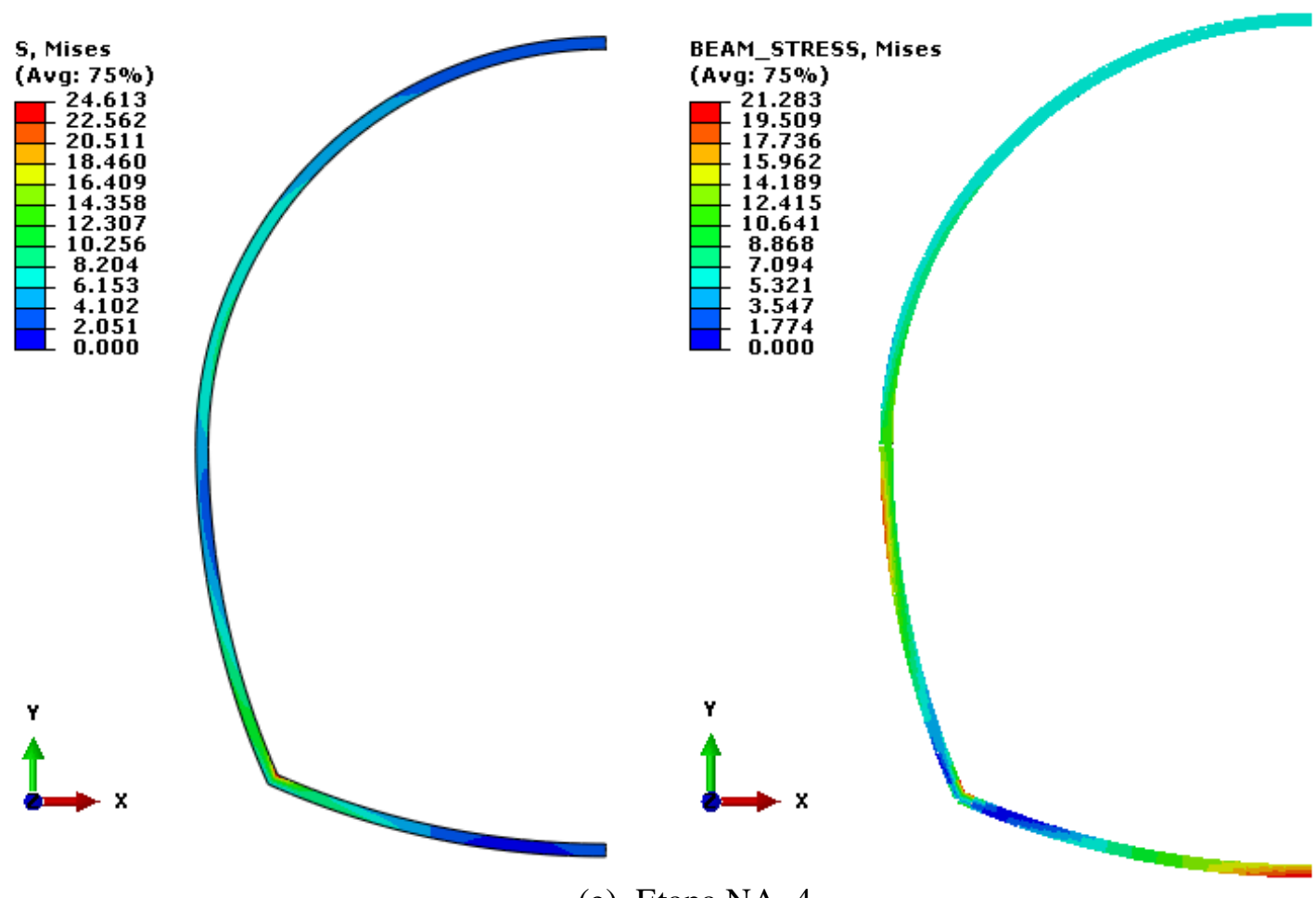

(e) Etapa NA_4

Figura 5.11: Tensões na seção do suporte primário e secundário nas etapas posteriores a escavação.

Observa-se na Figura 5.11 que as tensões de Von Mises do suporte primário e secundário não são continuas, ou seja, os suportes demostram trabalhar separadamente. Este fato derruba a hipótese de conjunto homogêneo e mostra que a membrana realmente tem um papel importante mesmo depois da instalação do suporte secundário. A Figura 5.11 ainda mostra a variação das tensões de Von Mises em cada etapa de simulação, bem como a região com máximas e mínimas tensões. Além disto, é verificado que na etapa de colocação do suporte secundário as tensões estão bem próximas de zero.

Os deslocamentos do suporte secundário é uma das variáveis de grande importância neste tipo de problema. A Figura 5.12 mostra os deslocamentos resultantes (U. Magnitude), horizontais $(\mathrm{U}, \mathrm{U} 1)$ e verticais $(\mathrm{U}, \mathrm{U} 2)$ em mm para o suporte secundário. 

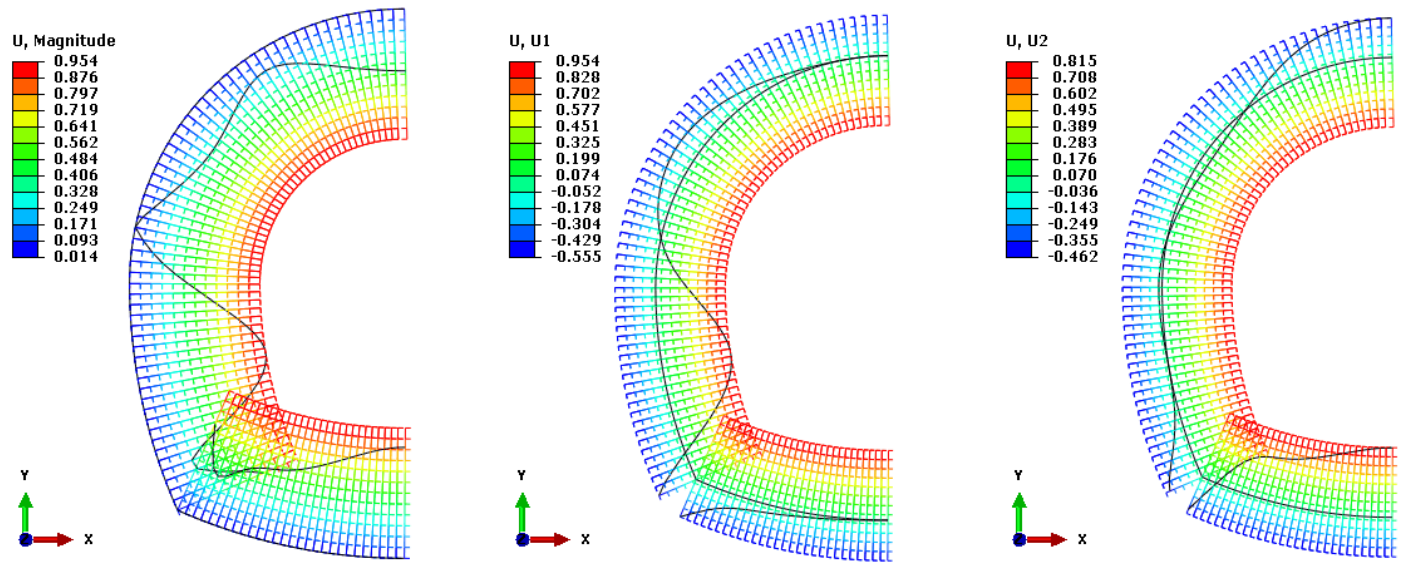

(a) Etapa de suporte secundário
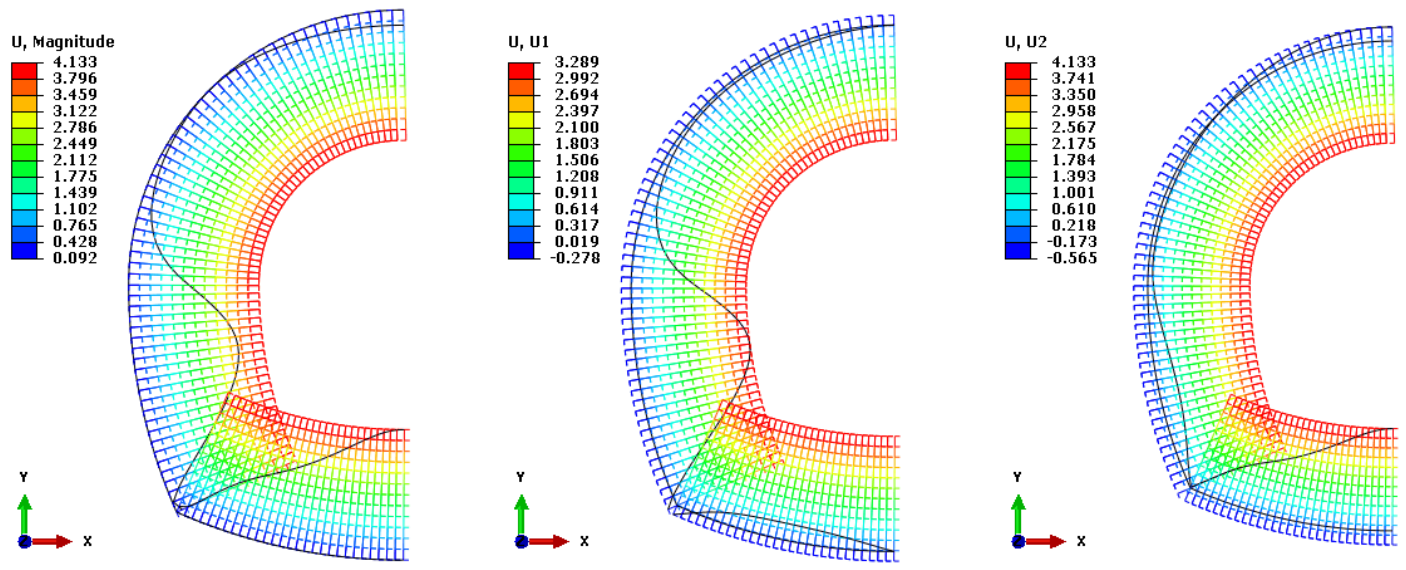

(b) Etapa NA_1
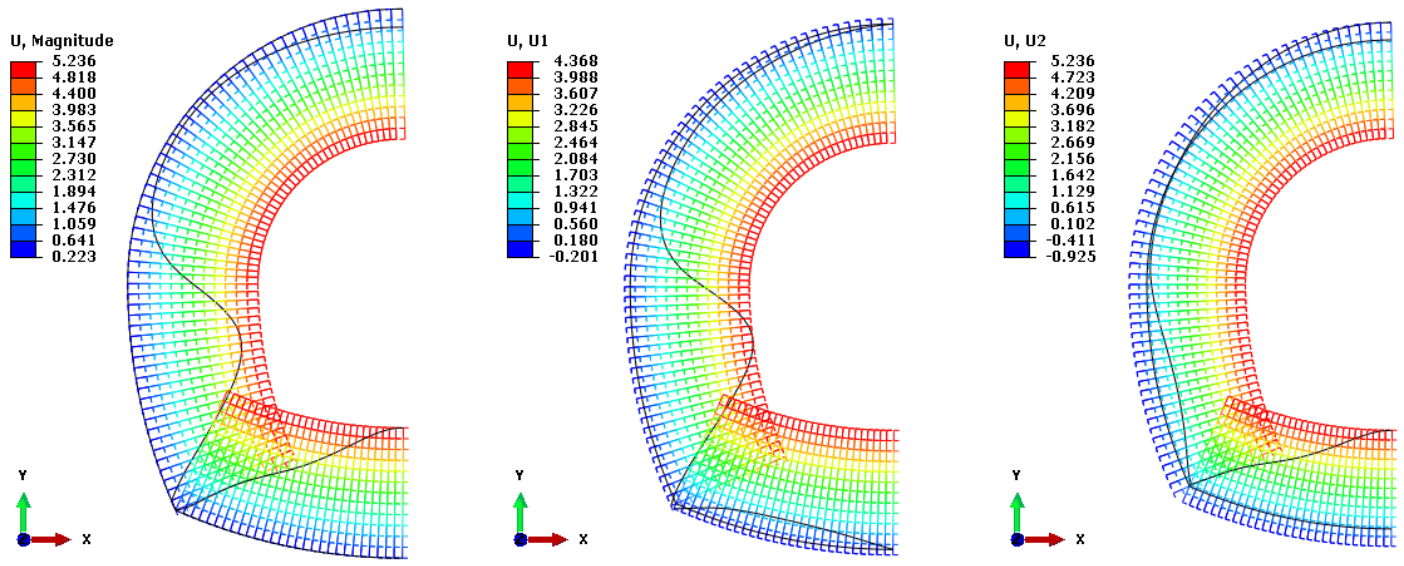

(c) Etapa NA_2 

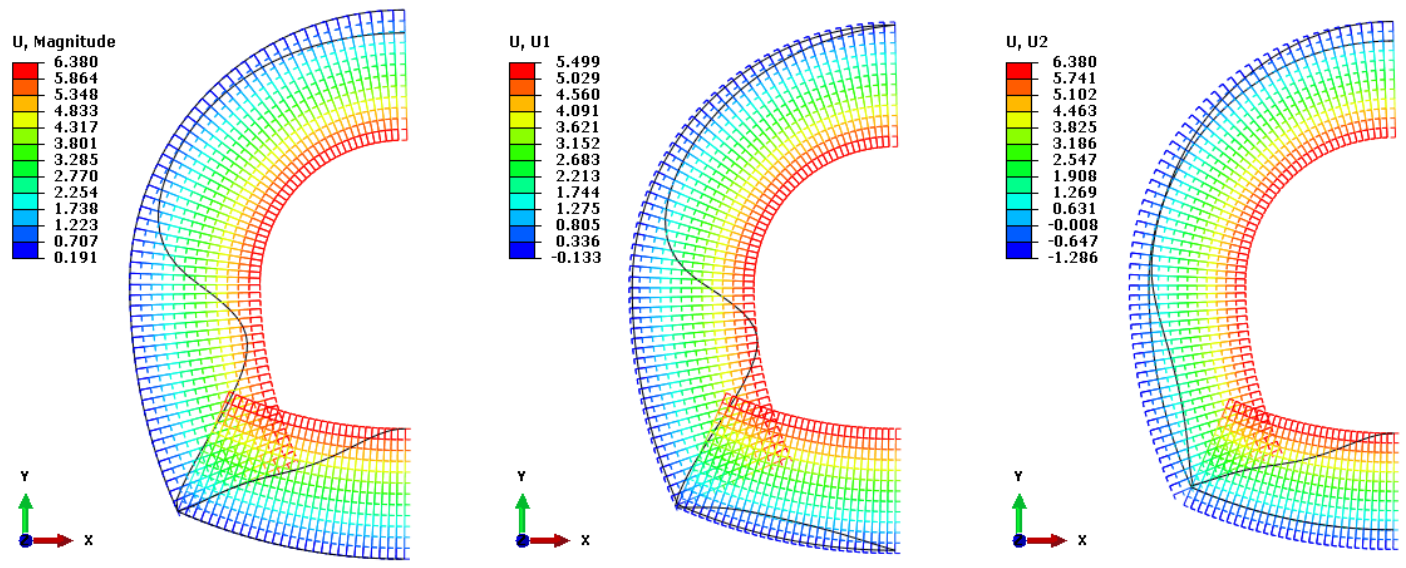

(d) Etapa NA_3
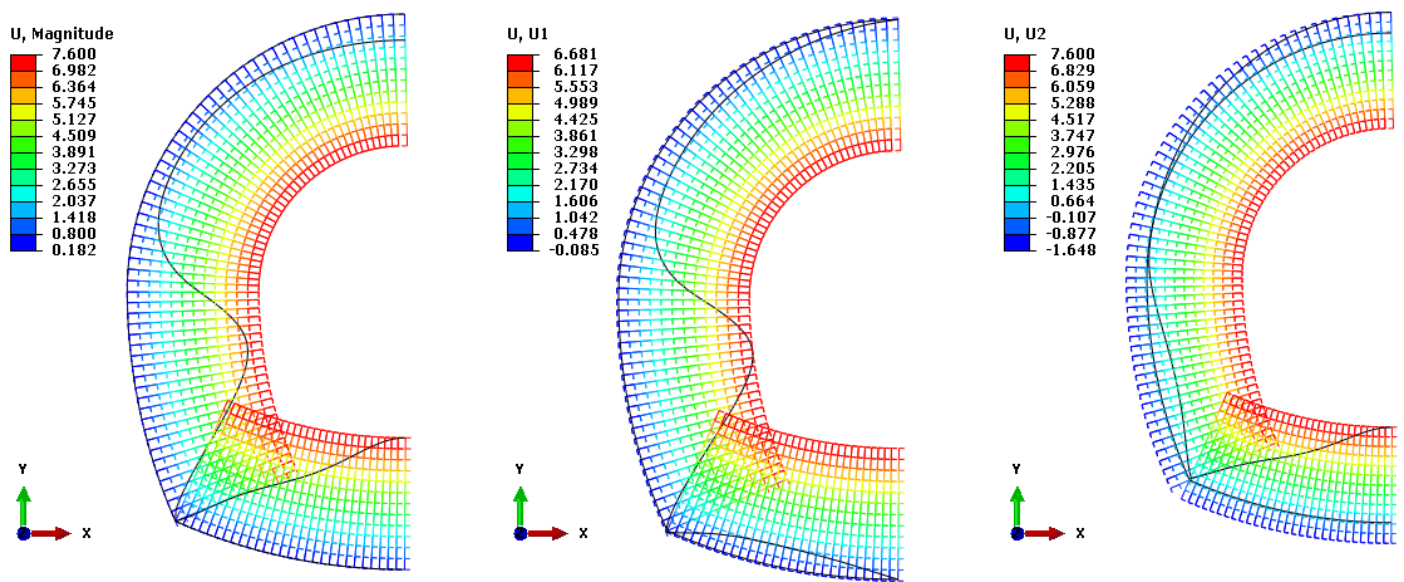

(e) Etapa NA_4

Figura 5.12: Deslocamentos na seção do suporte secundário nas etapas posteriores a etapa de suporte primário.

Observa-se na Figura 5.12 que os maiores deslocamentos ocorreram no arco invertido, ou seja, do ponto 11 ao ponto 13 e os mesmos se deram na direção vertical (sentido positivo). Para os deslocamentos horizontais são observados maiores valores entre os pontos 6 e 9. Devido à condição de simetria, nos pontos 0 e 13 os deslocamento horizontais são nulos e os deslocamentos verticais se apresentam maiores valores absolutos nos dois sentidos do eixo vertical. A Figura 5.13 mostra graficamente os resultados obtidos para os deslocamentos resultantes, ao longo do suporte secundário, em todas as etapas posteriores sua colocação. 


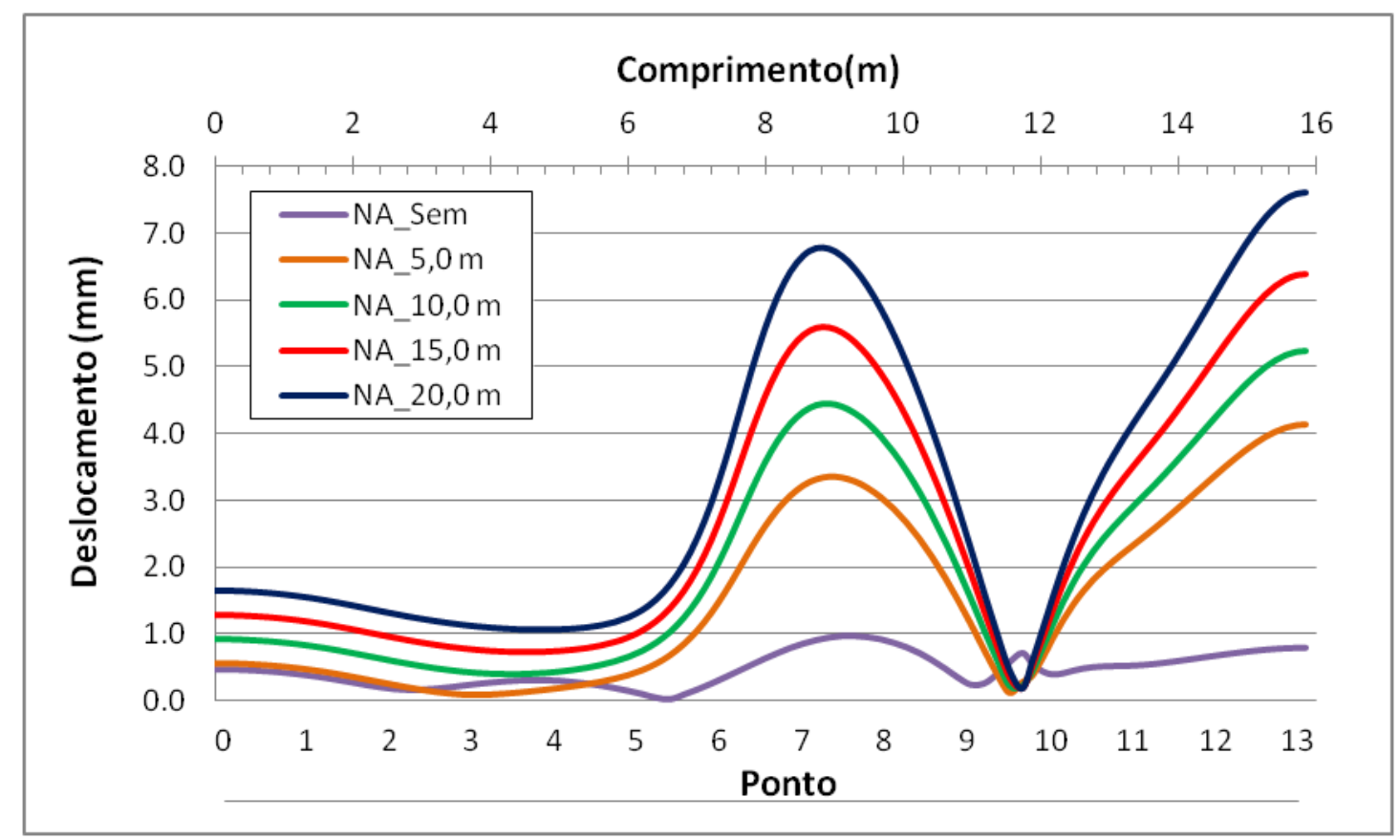

Figura 5.13: Deslocamentos resultantes na seção do suporte secundário.

O deslocamento resultante, Figura 5.13, se apresentou menor para NA_Sem devido unicamente a seu peso próprio e à medida que o nível d'água se elevou houve um aumento do mesmo. Nesta situação a variação dos deslocamentos chegou a quase $200 \%$, quando se compara os deslocamentos ocorrido entre os níveis NA_5,0 e NA_20,0 m.

Para cada interface podem ser observados os deslocamentos geradas nas etapas NA_sem, NA_5,0 m, NA_10,0 m, NA_15,0 m e NA_20,0m. A Figura 5.14 mostra estes deslocamentos para a interface entre o maciço e o suporte primário, entre o suporte primário e a membrana, e entre a membrana e o suporte secundário, bem como os deslocamentos relativos da membrana. 


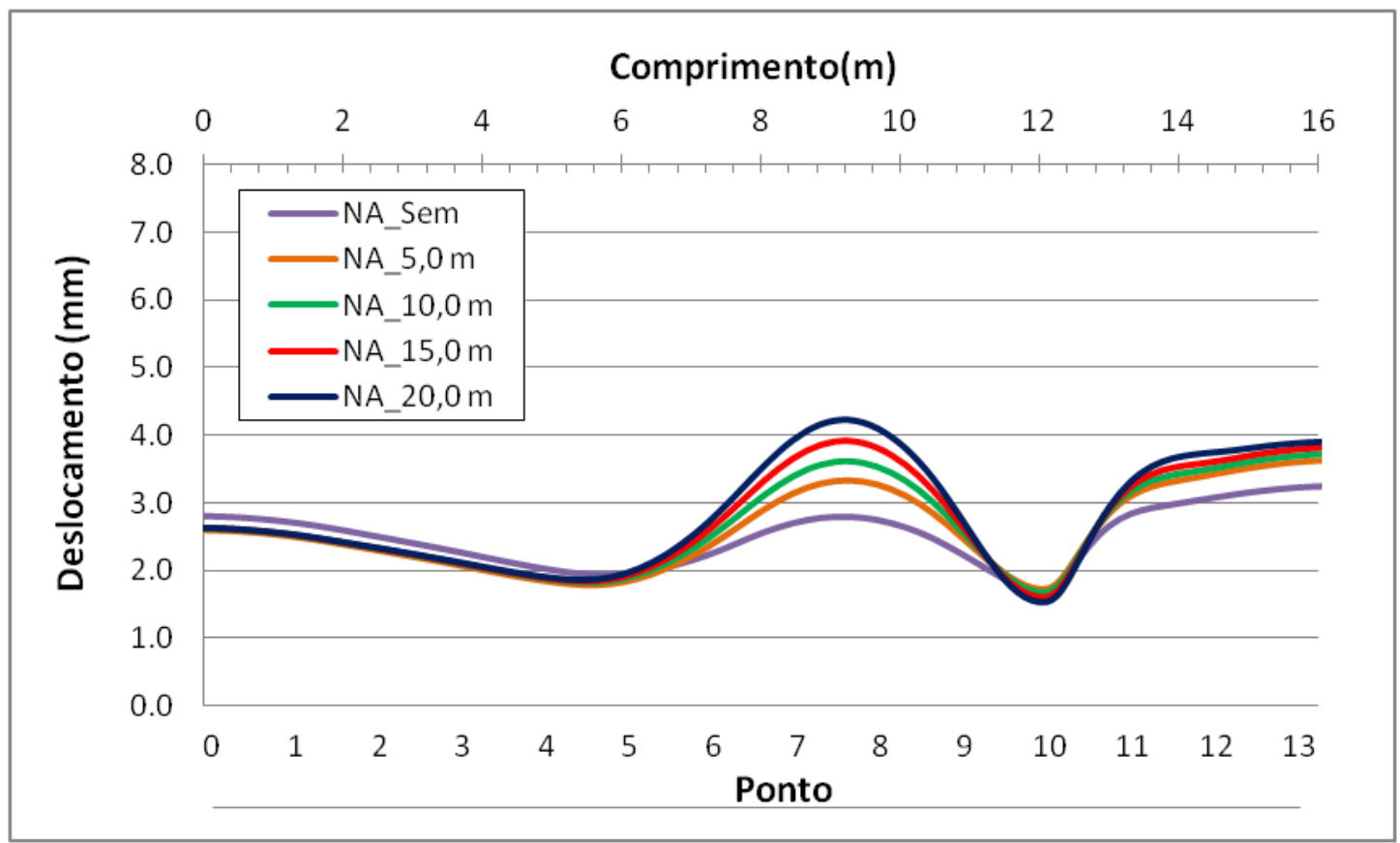

(a) Interface maciço-suporte primário

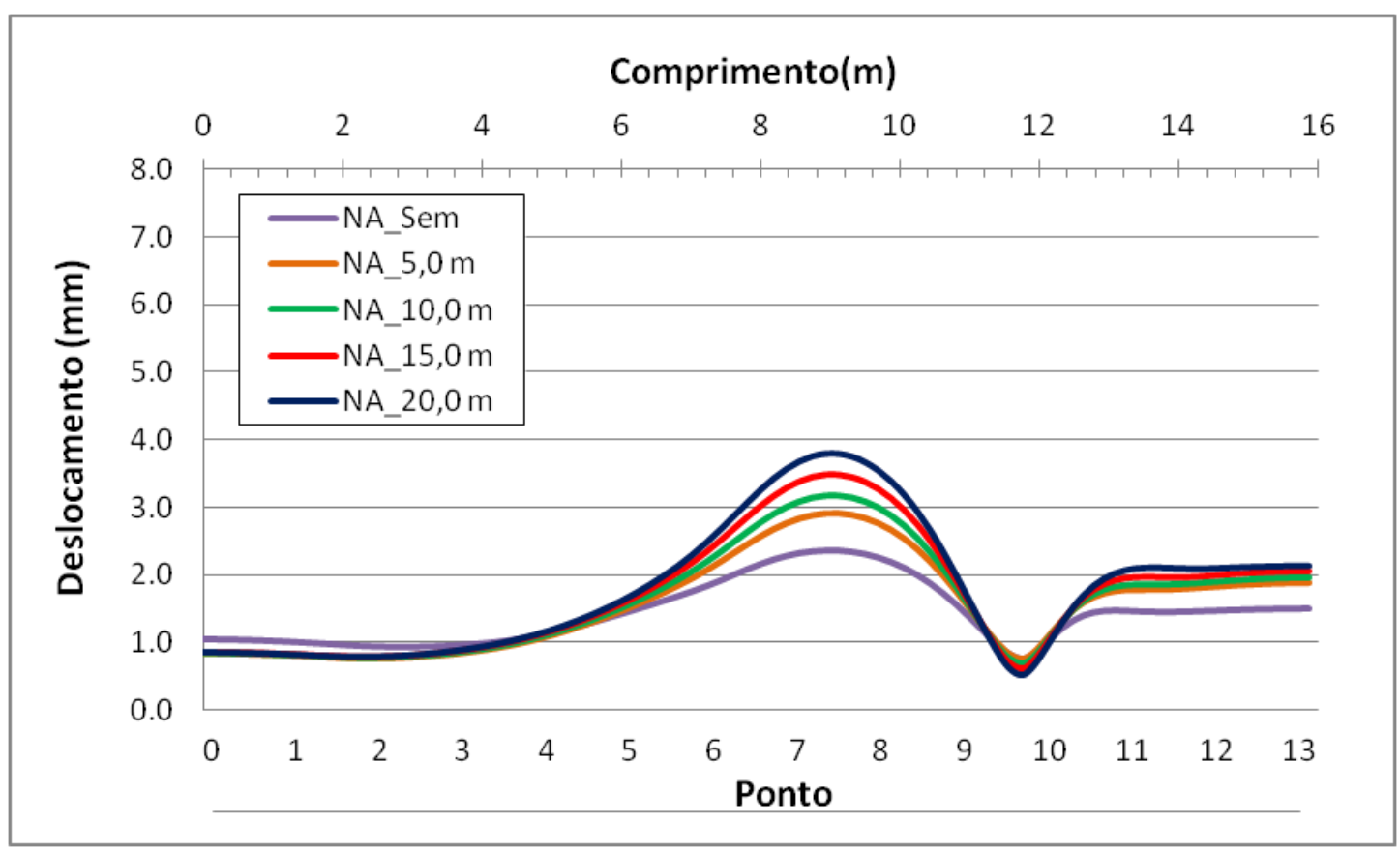

(b) Interface suporte primário-membrana 


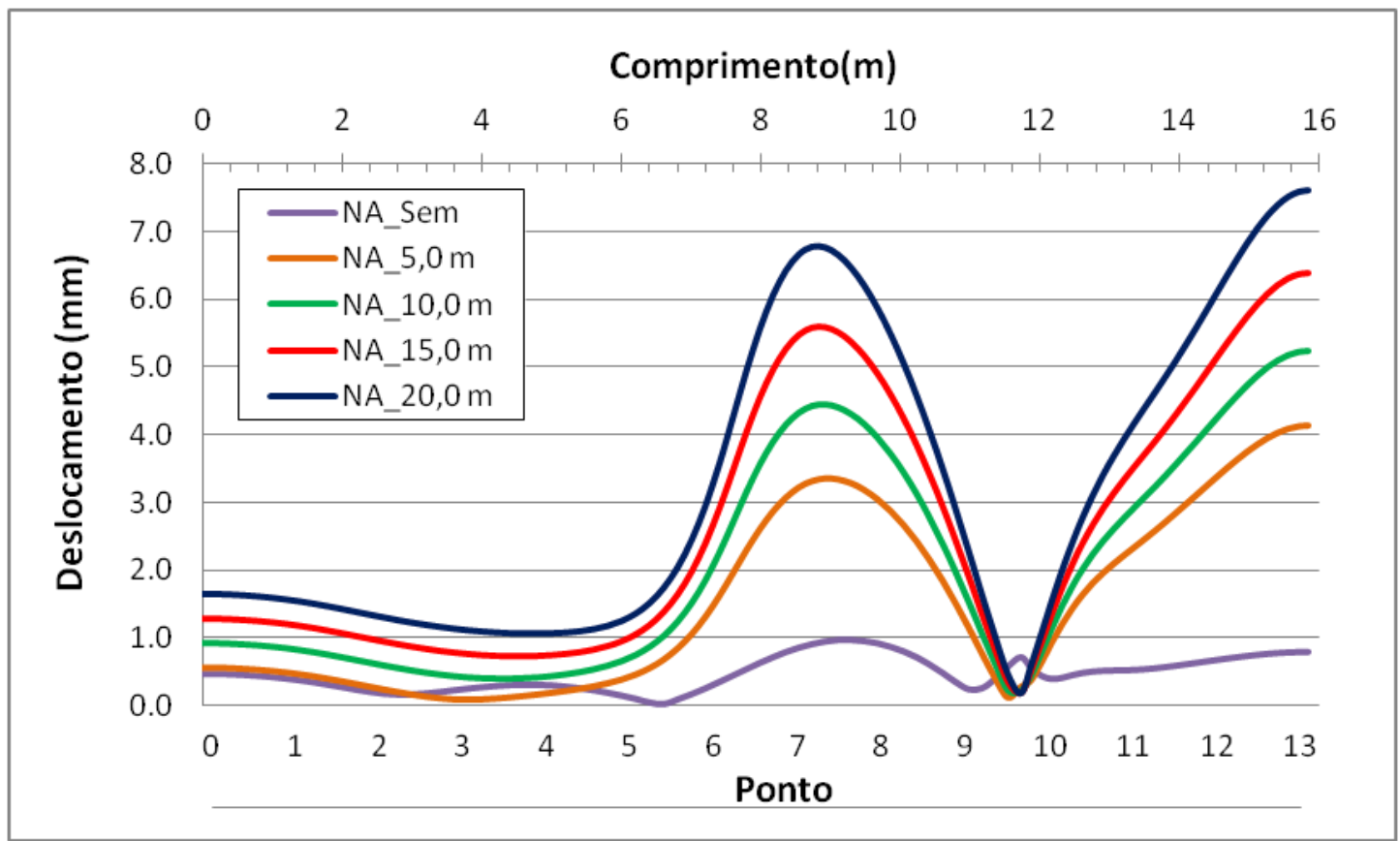

(c) Interface membrana-suporte secundário

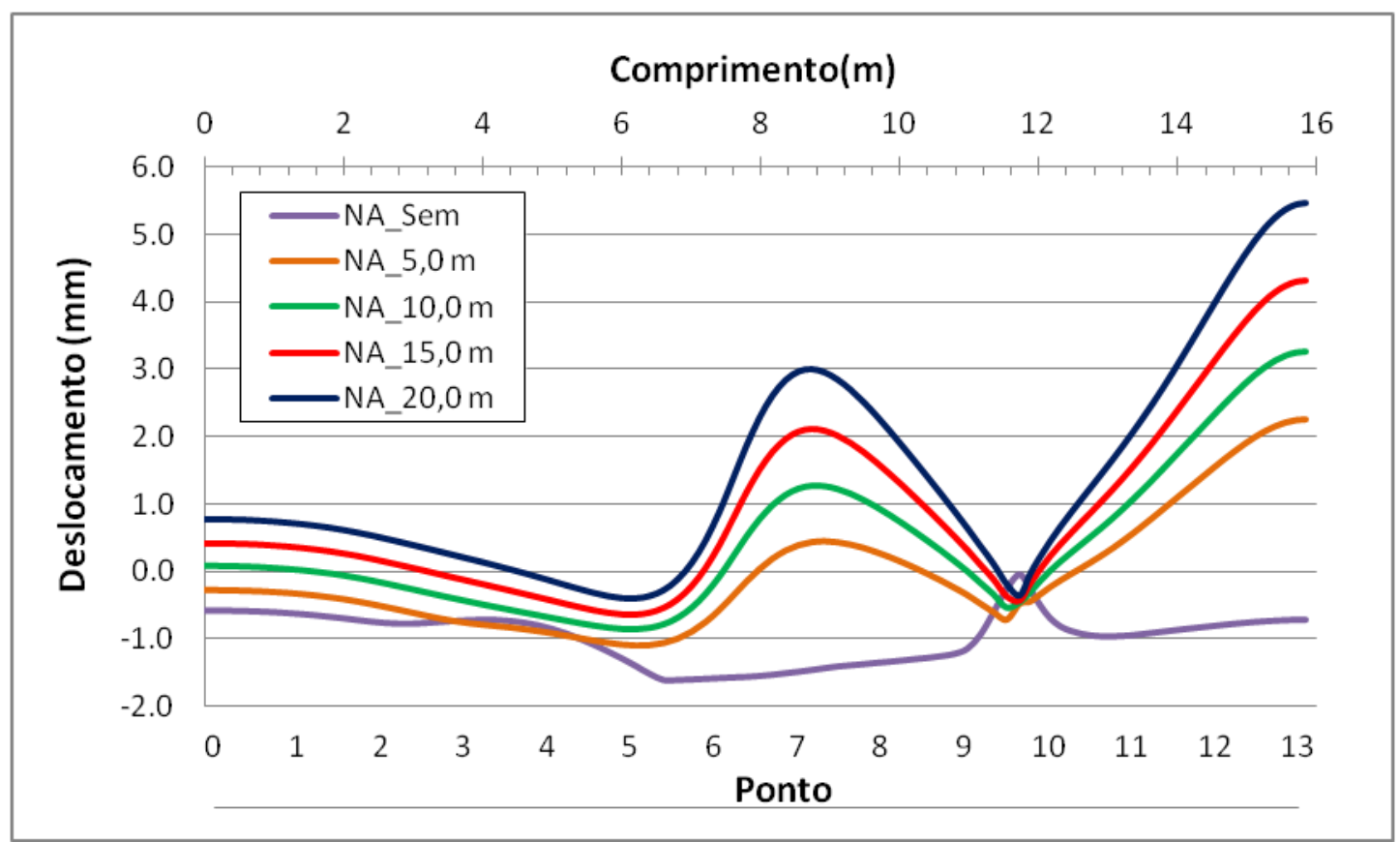

(d) Deslocamento relativo da membrana

Figura 5.14: Deslocamento no contato.

Observa-se na Figura 5.14 que os deslocamentos na interface entre o maciço e o suporte primário são próximos dos deslocamentos observados na interface entre o suporte primário e a membrana. Os deslocamentos relativos na membrana superam o alongamento máximo de cerca de $100 \%$ da espessura. Neste caso os resultados podem ser facilmente corrigidos para limitar este deslocamento relativo com escolha mais adequada da forma da 
seção. Como mencionado antes, foi escolhida uma combinação de parâmetros e geometria de modo a exacerbar a solicitação sobre a membrana.

A seguir são mostrados os resultados de plastificação do maciço, os mesmo servindo apenas como critério de verificação. Para a plasticidade são obtidos os resultados de deformações plásticas e o fator de plasticidade que mostra o quanto o maciço está da plastificação. A Figura 5.15 mostra os resultados para as deformações plásticas equivalentes (PEEQ), deformações plásticas horizontais (PE, PE11) e deformações plásticas verticais (PE, PE22).
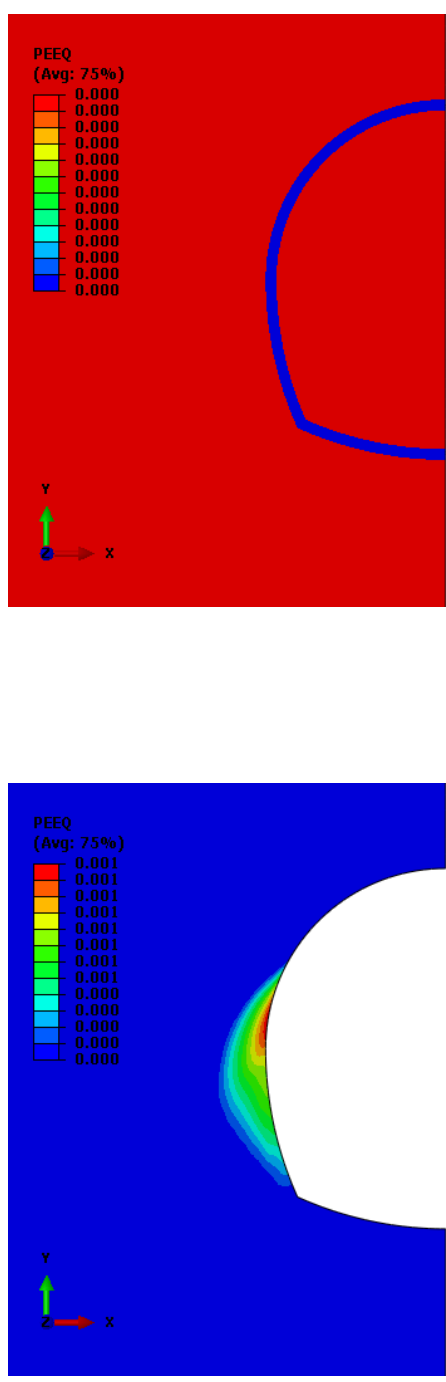

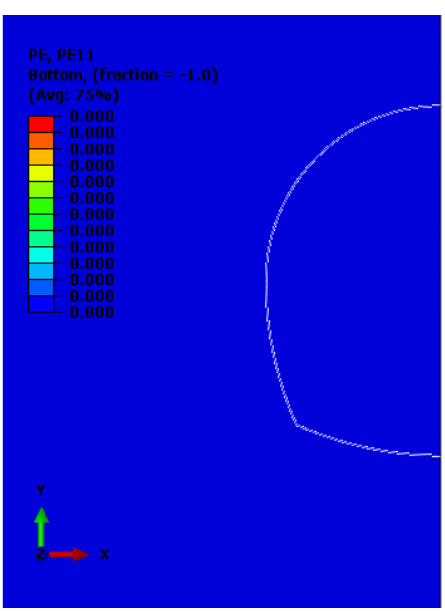

(a) Etapa geostática

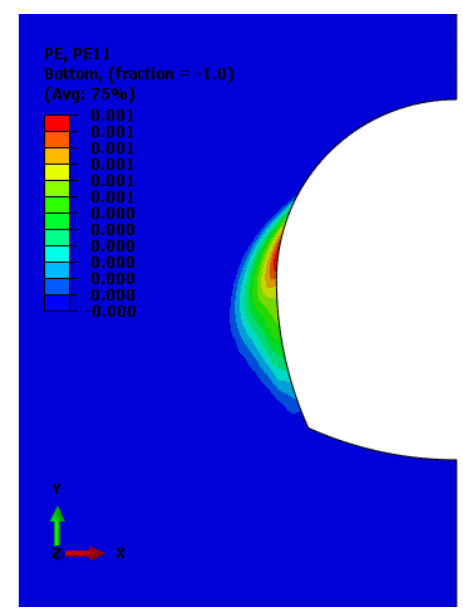

(b) Etapa de escavação
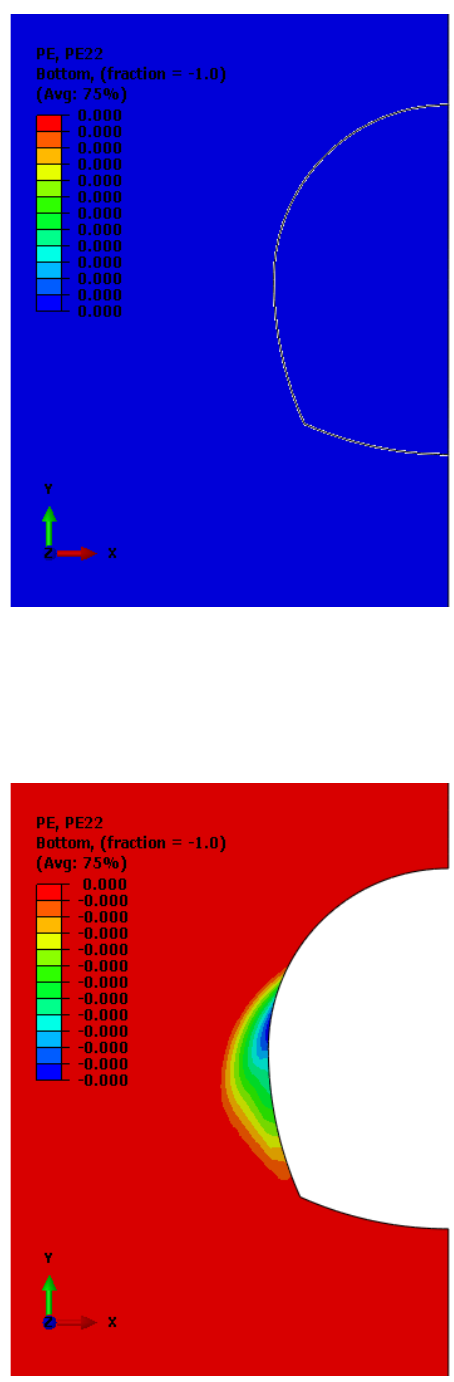

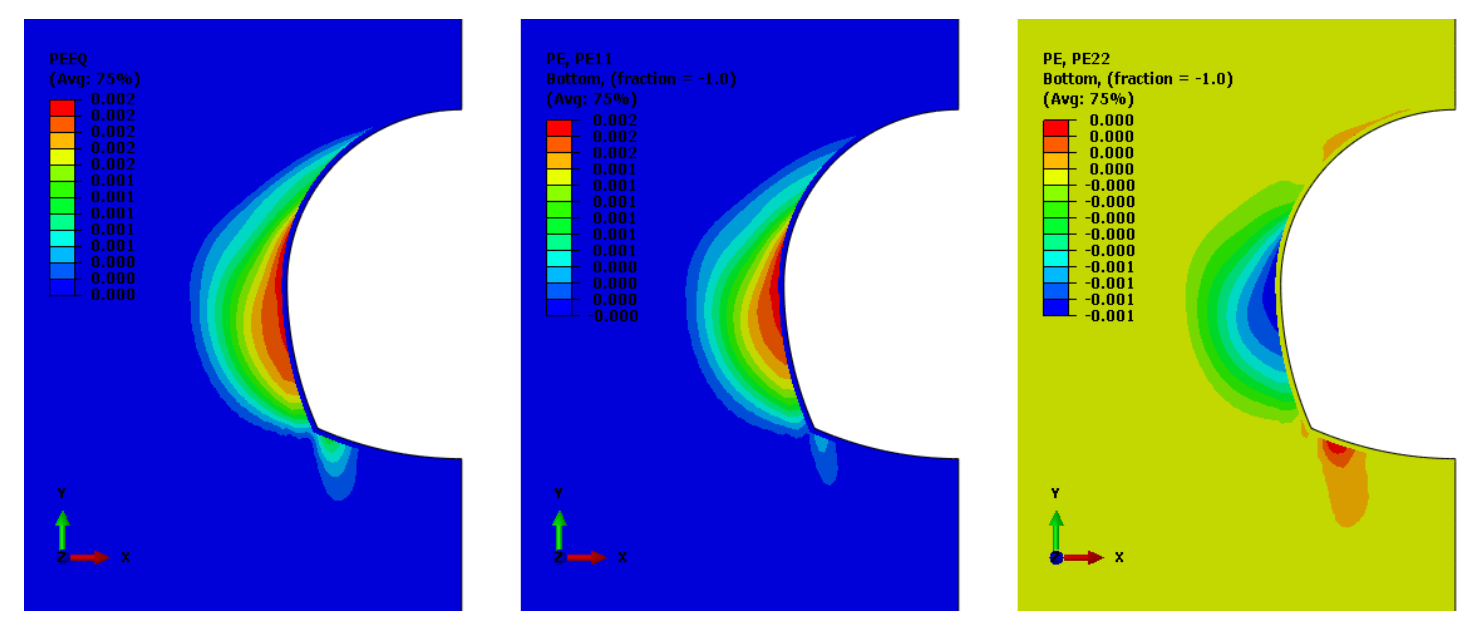

(c) Etapa de suporte primário
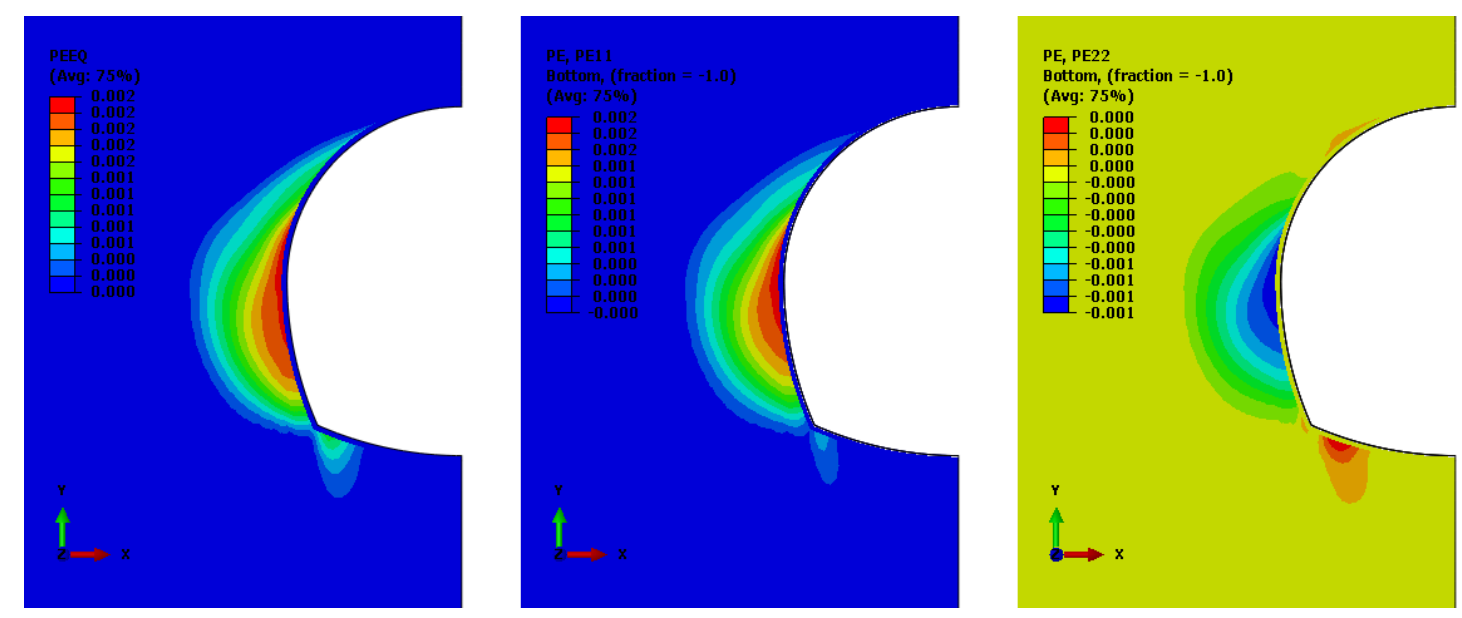

(d) Etapa de suporte secundário
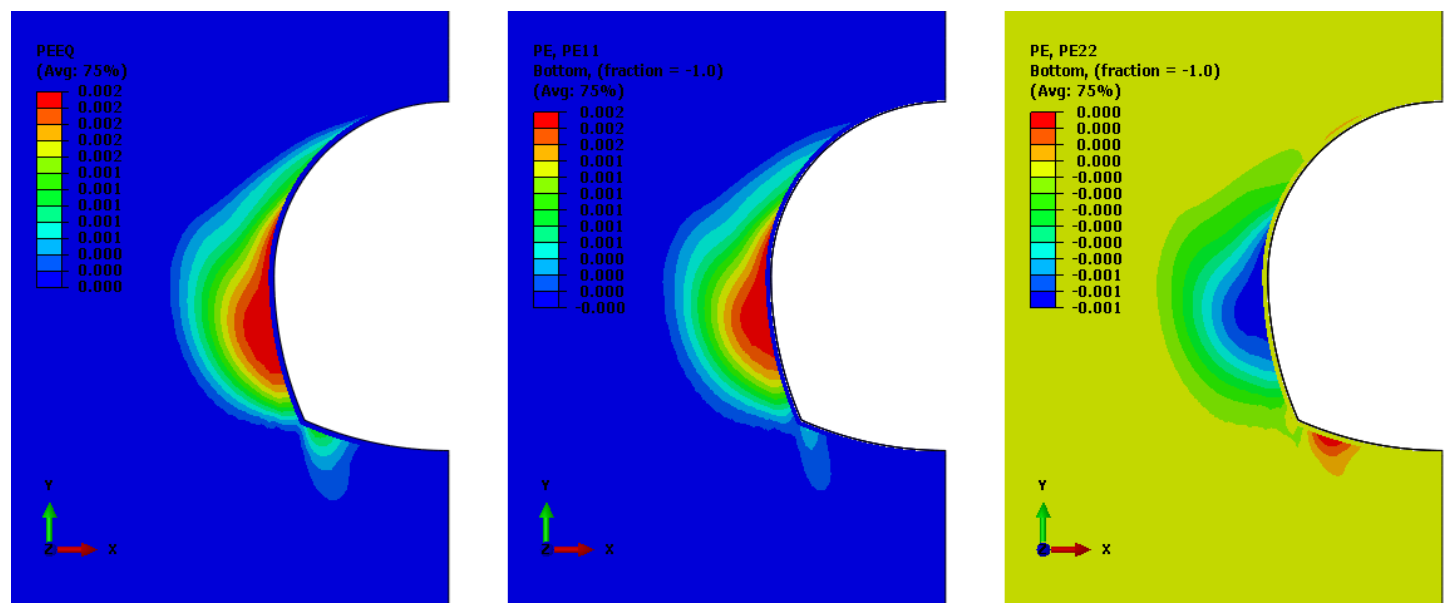

(e) Etapa NA_1 

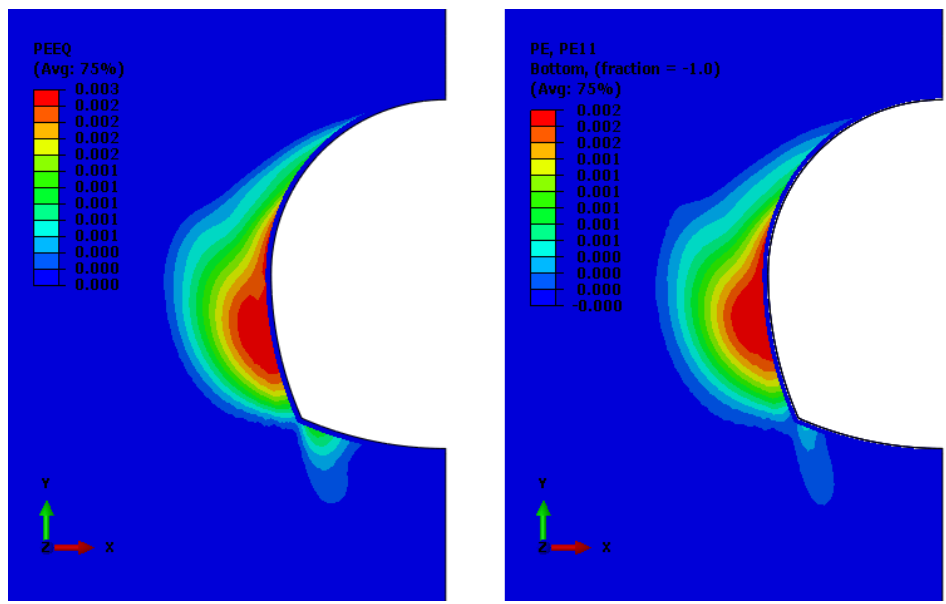

(f) Etapa NA_2
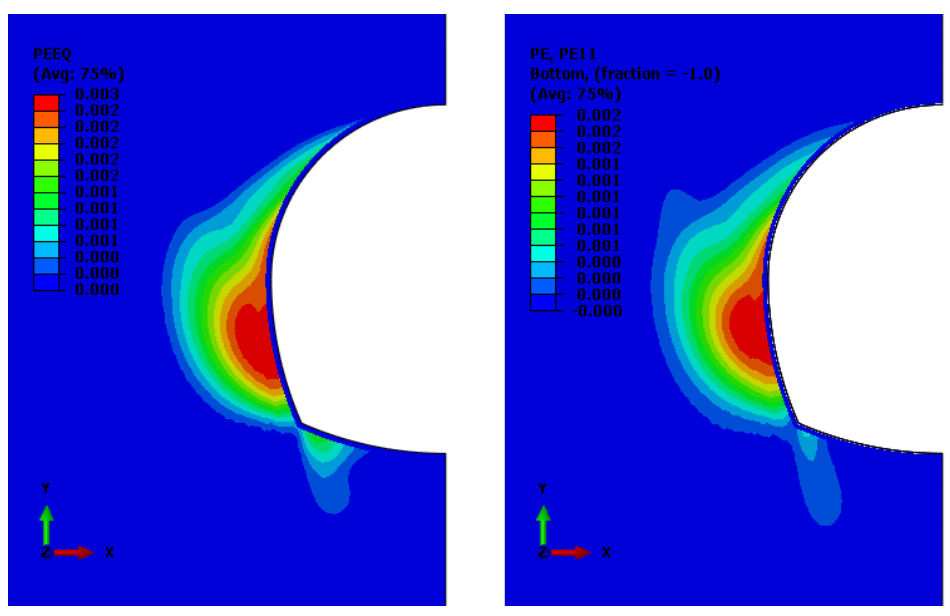

(g) Etapa NA_3
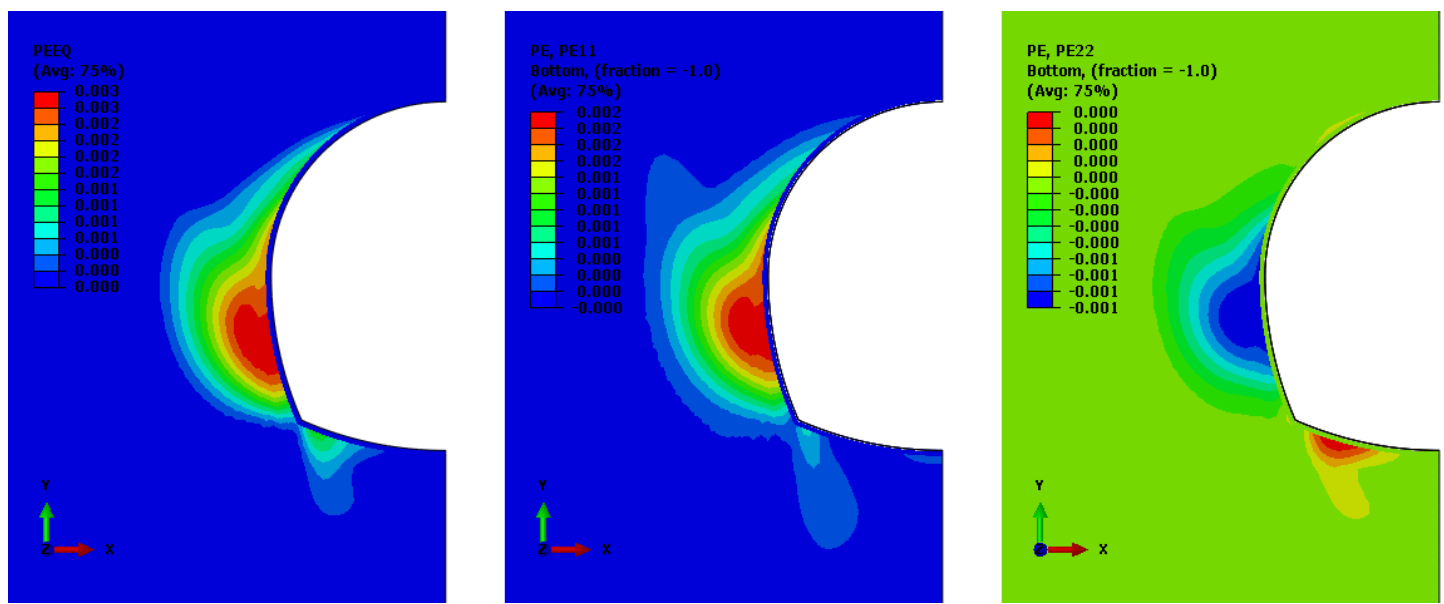

(h) Etapa NA_4
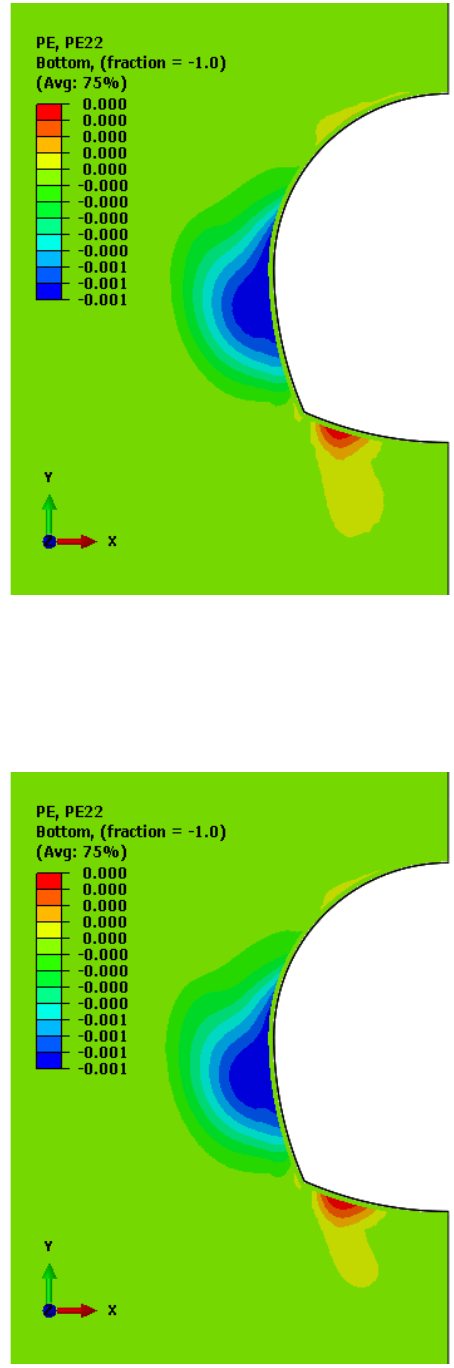

Figura 5.15: Plasticidade em cada etapa.

Observa-se na Figura 5.15 que as deformações plásticas são nulas na etapa geostática e que na etapa de escavação elas começam a aparecer. Até a etapa NA_4 é observado um 
aumento nas deformações plásticas, mas as mesmas não passam de 0,003 (ou 0,3\%) na direção horizontal e de 0,001 (ou $0,1 \%$ ) na direção vertical.

A Figura 5.16 mostra os resultados do fator de plastificação (AC YIELD) para as diferentes etapas simuladas. Para maior entendimento dos resultados deve-se ler os valores da legenda menores que 1 para regiões não plastificadas e maiores que 1 para as regiões plastificadas.
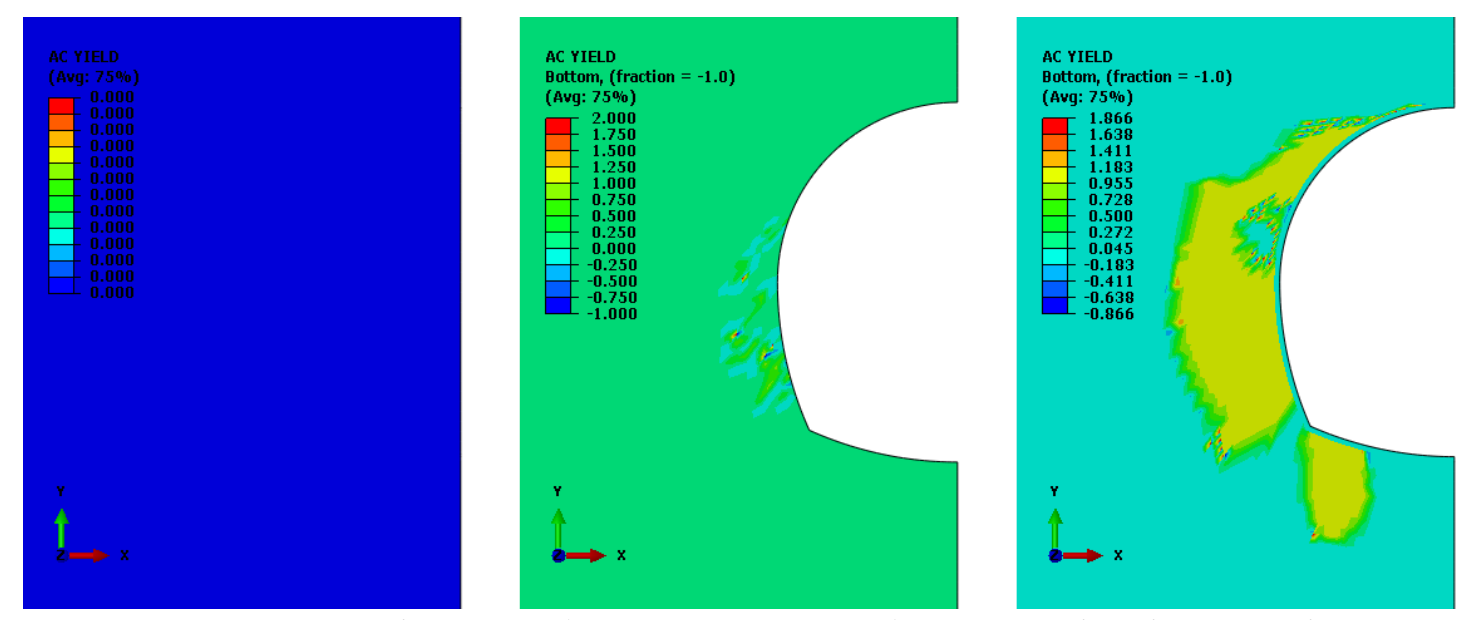

(a) Etapa geostática, etapa de escavação e etapa de suporte primário, respectivamente.
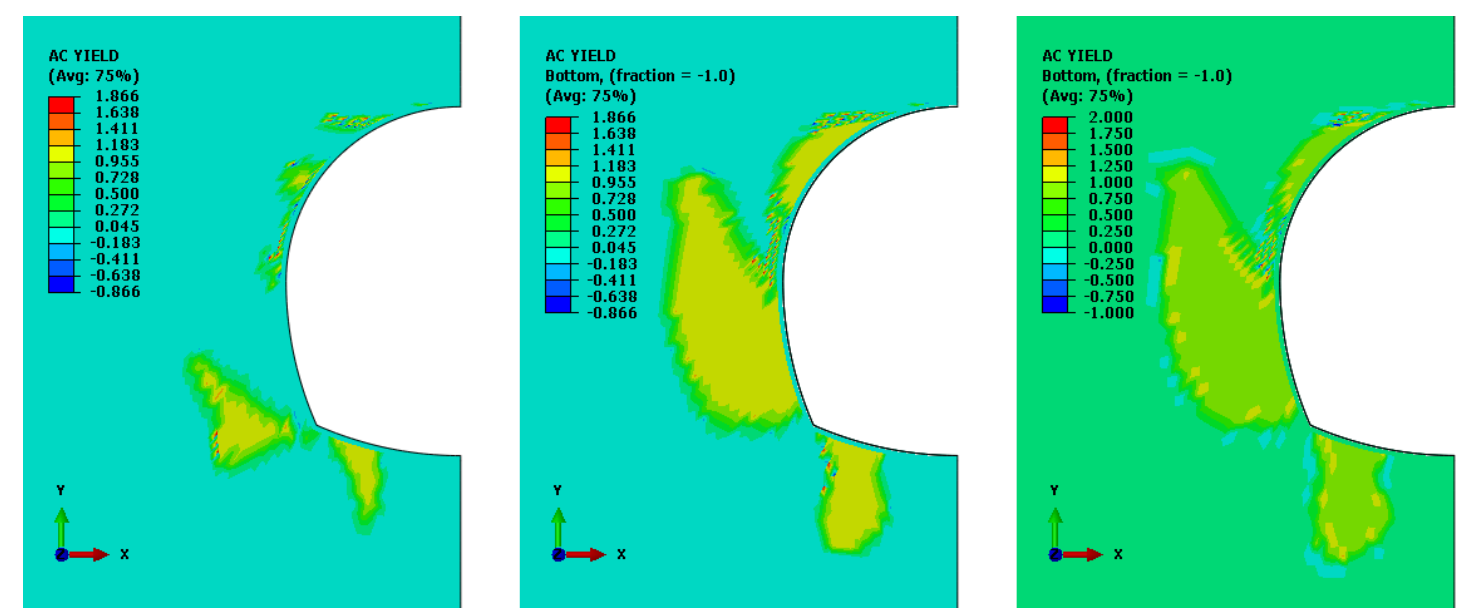

(b) Etapa de suporte secundário, etapa NA_1 e etapa NA_2, respectivamente. 


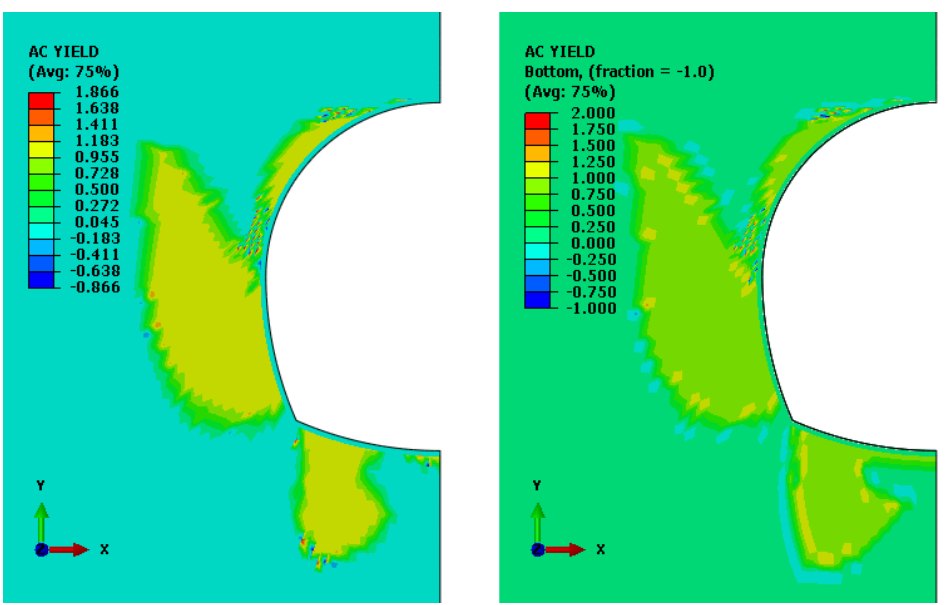

(c) Etapa NA_3 e etapa NA_4, respectivamente. Figura 5.16: Fator de plastificação.

Observa-se na Figura 5.16 que há um aumento progressivo na região plastificada e que esta região está localizada próxima ao suporte do túnel. De fato, esta plastificação não é decorrente de um possível aumento de carregamento no maciço, mas sim do aumento das deformações do suporte. Quando o suporte se deforma, por exemplo, com o aumento da pressão na interface, o maciço se deforma junto e pode provocar este aumento nas deformações plásticas do maciço. 


\section{CAPITULO 6 - SIMULAÇÃO DE FLUÊNCIA EM EVAPORITOS}

A modelagem de diversos tipos de materiais e simulação de seu comportamento é uma prática que vem se tornando cada vez mais comum. A simulação numérica, mesmo tendo aparecido há algum tempo, vem crescendo devido ao aumento de recursos que estão sendo incorporadas aos pacotes de "software" de simulação. Um destes é o Abaqus ${ }^{\circledR}$, programa de elemento finitos utilizado em todas as simulações deste trabalho.

O Abaqus ${ }^{\circledR}$ é um programa que, do ponto de vista geotécnico, possibilita a simulação mecânica, de fluxo e térmica (quando se deseja aplicar um gradiente geotérmico, por exemplo) ou ainda acoplar dois ou mais tipos de simulação. O mesmo traz uma gama de modelos constitutivos para simulação de diversos tipos de materiais.

Incialmente o Abaqus ${ }^{\circledR}$ foi voltado para simulação do comportamento de metais. Ao passar do tempo vários recursos e modelos foram adaptados e incluídos para simular os mais diferentes tipos de problemas geotécnicos.

Neste capítulo serão apresentadas algumas leis de fluência presentes no programa. Além disto, diversas simulações serão feitas com base em um destes modelos e em parâmetros obtidos na literatura ou propostos.

\subsection{EQUAÇÕES CONSTITUTIVAS DE FLUÊNCIA DO ABAQUS®}

A equação de fluência adotada pelo Abaqus® ${ }^{\circledR}$ está proposta para simular o comportamento viscoelástico de metais, mas pode ser utilizada para simular o comportamento de uma rocha evaporítica. No Abaqus ${ }^{\circledR}$ o comportamento de fluência, denominado de "creep" pelo programa, pode ser encontrado na forma de duas leis fundamentais: potencial e seno-hiperbólica. Segundo o manual do programa (Abaqus-6.11, 2011), estas leis são usadas para modelar a fluência de um material em um estágio secundário ou permanente. Como visto no Item 2.3.2, a lei potencial pode ser empregada na simulação de um comportamento de fluência no estágio primário ou transiente. Desta forma, surge a ideia de adaptação da equação do Abaqus® para simular o comportamento primário de fluência. 
Outra forma de simular o comportamento de fluência de um material com Abaqus $®$ é utilizando sub-rotinas, seja, para entrar com uma curva deformação x tempo ou para entrar com outro modelo constitutivo, não encontrado no programa.

\subsubsection{LEI POTENCIAL - "POWER-LAW MODEL"}

O modelo "power-law model" do Abaqus ${ }^{\circledR}$ pode ser encontrado em duas versões: "time-hardening" e "strain-hardening". A versão "time-hardening” é mais apropriada quando o estado de tensão permanece essencialmente constante, enquanto que a versão “strain-hardening” é mais recomendada quando o estado de tensões varia durante as análises.

No "power-law model" a taxa de deformação de fluência da versão proposta pelo programa pode ser expressa pela equação:

$$
\dot{\varepsilon}=A \sigma^{n} t^{m}
$$

onde $\dot{\varepsilon}$ é a taxa de deformação; $\sigma$ é a tensão desviadora; $t$ é o tempo total; e $A, n$ e $m$ são constantes definidas em função da temperatura.

Sabe-se ainda que o $\sigma$ é a tensão equivalente de Mises ou a tensão anisotrópica desviadora de Hill, a depender, respectivamente, se o comportamento de "creep" é definido como isotrópico ou como anisotrópico. Por razões físicas, as constantes $A$ e $n$ devem ser positivas.

\section{- Teoria do endurecimento por Tempo Transcorrido ("Time Hardening Theory")}

A Teoria do endurecimento por Tempo Transcorrido é indicada para prever deformações em longos períodos de tempo, nos quais o estado de tensões não varia muito rapidamente neste período e onde taxa de deformação de fluência é obtida diretamente a partir da Equação (6.1), a uma temperatura constante, em função do tempo. Desta forma, aplicandose a condição inicial $\sigma$ igual a uma constante $\sigma_{0}$ ao longo do tempo e resolvendo a equação diferencial, pode-se chegar a Equação (6.2).

$$
\varepsilon=\frac{t^{m+1} \cdot A \sigma_{0}^{n}}{m+1}
$$


Pode-se concluir que o valor de $m$ deve estar entre -1 e 0 para que a deformação no tempo tenha sentido. Isolando o tempo na Equação (6.2) e substituindo o mesmo na equação (6.1) chega-se a Equação (6.3), versão da formulação para a teoria por deformação ("Strain Hardening Theory").

\section{- Teoria do endurecimento por Deformação ("Strain Hardening Theory")}

A versão endurecimento por deformação da lei potencial de fluência deve ser usada quando o estado de tensão varia durante uma análise. Nesta versão a taxa de deformação de fluência é expressa pela formulação:

$$
\dot{\varepsilon}=\left(A \sigma^{n}[(m+1) \varepsilon]^{m}\right)^{\frac{1}{m+1}}
$$

onde $\dot{\varepsilon}$ é a taxa de deformação; $\varepsilon$ é a deformação de fluência; $\sigma$ é a tensão desviadora; e $A$, $n$ e $m$ são constantes definidas em função da temperatura.

Nos casos em que o estado de tensão permanecer constante durante toda a análise e não houver dependência da temperatura, as versões "Time Hardening" e a "Strain Hardening" são equivalentes, Abaqus-6.11 (2011).

\subsubsection{LEI SENO-HIPERBÓLICA - "HYPERBOLIC-SINE LAW MODEL"}

A lei seno-hiperbólico, Equação (6.4), pode simular bem o comportamento secundário de fluência, além de levar em conta o efeito do gradiente de temperatura. Desta forma, a mesma pode ser indicada em situações em que a taxa de deformação está diretamente ligada à temperatura.

$$
\dot{\varepsilon}=A(\sinh B \sigma)^{n} \exp \left(-\frac{Q}{R^{\prime}\left(T-T_{0}\right)}\right),
$$

onde $\dot{\varepsilon}$ é a taxa de deformação; $\sigma$ é a tensão desviadora; $T$ é o valor da temperatura; $T_{0}$ é o valor da temperatura inicial; $Q$ é a energia de ativação; $R^{\prime}$ é a constante universal dos gases; e $A, B$ e $n$ são constantes do material. 
Por se tratar de um modelo que inclui a dependência da temperatura, os parâmetros $A$, $B, n, Q$, e $R^{\prime}$ não podem ser definidos como função da temperatura, Abaqus-6.11 (2011). No entanto, para as leis potenciais do Item 6.1.1 esta estratégia de modificar os parâmetros com a temperatura pode ser a saída para considerar a dependência da taxa de deformação com o efeito da temperatura.

Dependendo da escolha das unidades, para qualquer uma das leis de fluência do Abaqus®, o valor dos parâmetros utilizado não pode sair da faixa estabelecida pelo programa, por exemplo, $A$ não dever ser menor que $10^{-27}$. Caso seja menor que $10^{-27}$, a solução pode deixar de convergir. Neste caso é necessário adotar um novo sistema de unidades de modo a evitar tais dificuldades no cálculo dos incrementos de deformação (Abaqus-6.11, 2011).

\subsection{AJUSTE DE PARÂMETROS PARA FLUÊNCIA}

A Falta de parâmetros e a dificuldade de obtê-los pode torna inviável a utilização de um modelo constitutivo. Outro problema importante é o emprego dos mesmos com parâmetros pouco confiáveis, gerando resultados muito aquém do que seria de fato e levando uma desconfiança na utilização dos mesmos. Como alternativa para essas dificuldades, Cavalcante e Ramos (2010) propuseram uma série de parâmetros ajustados com base em ensaios de fluência em rochas salinas do tipo halita. Os mesmos foram ajustados e podem ser utilizados para as diversas faixas de tensão, nos intervalos usuais da engenharia geotécnica, como serão mostrados a seguir. As simulações feitas com estes parâmetros foram comparadas com alguns resultados, encontrados em literaturas, para poços perfurados em rochas evaporíticas.

\subsubsection{LEI CONSTITUTIVA DE FLUÊNCIA PARA AJUSTE}

Os estudos de fluência para finalidades práticas incluem modelos reológicos, físicos e empíricos, geralmente descrevendo apenas um estágio de comportamento. Inicialmente estes modelos fundamentaram-se no comportamento dos metais que posteriormente foram adaptados para a mecânica das rochas.

A lei empírica potencial é o modelo que, além de simples, pode representar bem o comportamento nos primeiros estágios de fluência. A Equação (6.5), desenvolvida por Lomenick (1969 apud Gravina 1997) e apresentada no Item 2.3.2, utiliza três constantes 
empíricas para o seu melhor ajuste e relaciona a deformação com a tensão, temperatura e tempo.

$$
\varepsilon=K \sigma^{c} t^{b} T^{a}
$$

onde $\varepsilon$ é a deformação transiente de fluência; $\sigma$ é a tensão desviadora; $t$ é o tempo; $T$ é a temperatura; e $K, a, b$ e $c$ são constantes empíricas.

Devido ao comportamento das rochas evaporíticas a lei potencial vem sendo bastante aplicada na fase transiente de fluência. Algumas referências sugerem outras formulações potenciais para descrever o fenômeno, por exemplo, a apresentada no Item 6.1.1. ( "power-law model" do Abaqus®). A modelo "power-law model” do Abaqus ${ }^{\circledR}$ leva em consideração a tensão desviadora $(\sigma)$ e o tempo $(t)$, podendo o mesmo ser utilizado nas versões: "timehardening" e "strain-hardening".

Nas simulações realizadas leva-se em consideração a taxa de deformação de fluência na versão "time-hardening”, visto que nas análises considera-se uma variação muito pequena no estado de tensão (Abaqus-6.11, 2011). Desta forma a equação utilizada para o ajuste é:

$$
\varepsilon=\frac{\left(t^{m+1}\right) \cdot A \sigma_{0}^{n}}{m+1}
$$

onde $\dot{\varepsilon}$ é a taxa de deformação; $\sigma_{0}$ é a tensão desviadora; $t$ é o tempo total; e $A, n$ e $m$ são constantes definidas em função da temperatura.

\subsubsection{DADOS PARA AJUSTE}

Os ensaios de fluência utilizados neste estudo foram realizados por Cella (2003) e correspondem a ensaios triaxiais de fluência em corpos de prova de halita, sob altas pressões e temperaturas. A halita é uma rocha que se caracteriza por ser formada por íons cristalizados num sistema cúbico. Normalmente é incolor ou branca. Quando pura apresenta fratura conchoidal, dureza baixa (aproximadamente 2,5) e densidade moderada (por volta de 2.100 $\mathrm{kg} / \mathrm{m}^{3}$ ). 
Em seus estudos, Cella (2003) obteve as taxas de deformação para o regime estacionário de fluência da halita. Essas taxas, na maioria dos casos, foram retiradas a partir de períodos superiores a 1400 horas, em diferentes ensaios de fluência. Na Tabela 6.1 tem-se o resumo das taxas de deformação obtidas nos ensaios triaxiais de fluência, para diferentes tensões diferenciais e temperatura de $86^{\circ} \mathrm{C}(359 \mathrm{~K})$. Em todos os ensaios Cella (2003) utilizou uma tensão de confinamento de $10 \mathrm{MPa}$. O tempo de extração da fluência estacionaria e as tensões diferenciais de cada um dos ensaios também são apresentadas na Tabela 6.1.

Tabela 6.1: Taxa de deformação para as diferentes tensões diferenciais, Cella (2003).

\begin{tabular}{|c|c|c|c|}
\hline Ensaio & $\begin{array}{c}\text { Taxa de Deformação } \\
\text { (horas }^{-1} \text { ) }\end{array}$ & $\begin{array}{c}\text { Tensão Desviadora } \\
(\mathbf{M P a})\end{array}$ & $\begin{array}{c}\text { Tempo de Extração da } \\
\text { Fluência Estacionária }\end{array}$ \\
\hline $102-06$ & $2,321 \mathrm{E}-07$ & 6 & $>1400$ horas \\
\hline $102-03$ & $8,468 \mathrm{E}-07$ & 8 & $>1600$ horas \\
\hline $102-05$ & $1,801 \mathrm{E}-06$ & 10 & $>700$ horas \\
\hline $102-04$ & $7,911 \mathrm{E}-06$ & 12 & $>1400$ horas \\
\hline $102-07$ & $2,807 \mathrm{E}-05$ & 14 & $>850 h$ até $1400 \mathrm{~h}$ \\
\hline $102-02$ & $7,749 \mathrm{E}-05$ & $16-17$ & $>22 \mathrm{~h}$ \\
\hline $102-01$ & $1,000 \mathrm{E}-03$ & 20 & \\
\hline
\end{tabular}

Para o ajuste da função de fluência do Abaqus® ${ }^{\circledR}$ são utilizados os dados dos ensaios de Cella (2003) nos diferentes níveis de tensões. O objetivo é estimar os parâmetros da Equação (6.2), de modo que a mesma possa representar a curva de deformação para diferentes níveis de tensões diferenciais.

\subsubsection{MÉTODO DE AJUSTE}

Na estimativa dos parâmetros (ajuste das curvas de fluência) da equação do Abaqus® é utilizado o Solver, ferramenta do programa Microsoft Office Excel@. Esse recurso faz parte de um conjunto de programas, algumas vezes chamado de ferramentas de análise hipotética, e tem como uma de suas funções o ajuste de um ou alguns parâmetros de uma equação a partir de uma série de dados. Com o "solver", um valor ou uma sequência de valores, referências de células, nomes, funções ou operadores em uma célula podem ser encontrados de maneira rápida e interativa. Pode-se ainda aplicar algumas restrições às células ajustáveis, à célula de destino ou a outras células direta ou indiretamente relacionadas à célula de destino, restringindo assim os valores que afetam a formulação a ser ajustada.

No processo de ajuste procura-se minorar uma função de erro que é definida como o somatório dos erros absolutos, diferença absoluta entre o valor de deformação do ensaio $y_{i} \mathrm{e}$ 
o valor estimado no ajuste $\bar{y}_{i}$, de maneira a se obter o melhor ajuste para os parâmetros da equação. A expressão para este erro pode ser dada pela Equação (6.6).

$$
E_{\text {erro }}=\sum_{i=1}^{n}\left|y_{i}-\overline{y_{i}}\right|
$$

\subsubsection{APRESENTAÇÃO DOS RESULTADOS DO AJUSTE}

Na determinação dos parâmetros de fluência da equação do Abaqus®, as deformações obtidas para os diferentes ensaios, o tempo e a tensão desviadora são dados de entrada. $\mathrm{O}$ resultado que retorna do ajuste são os parâmetros $A, m$ e $n$ para a equação de fluência do Abaqus®. A Figura 6.1 mostra as curvas ajustadas para os diferentes níveis de tensões. Estes ajustes retornaram como parâmetros $A=1,862 \cdot 10^{-31}, m=-0,21$ e $n=6,69$ para a tensão $\tilde{\sigma}$ em $\mathrm{kPa}$ e $t$ em horas.

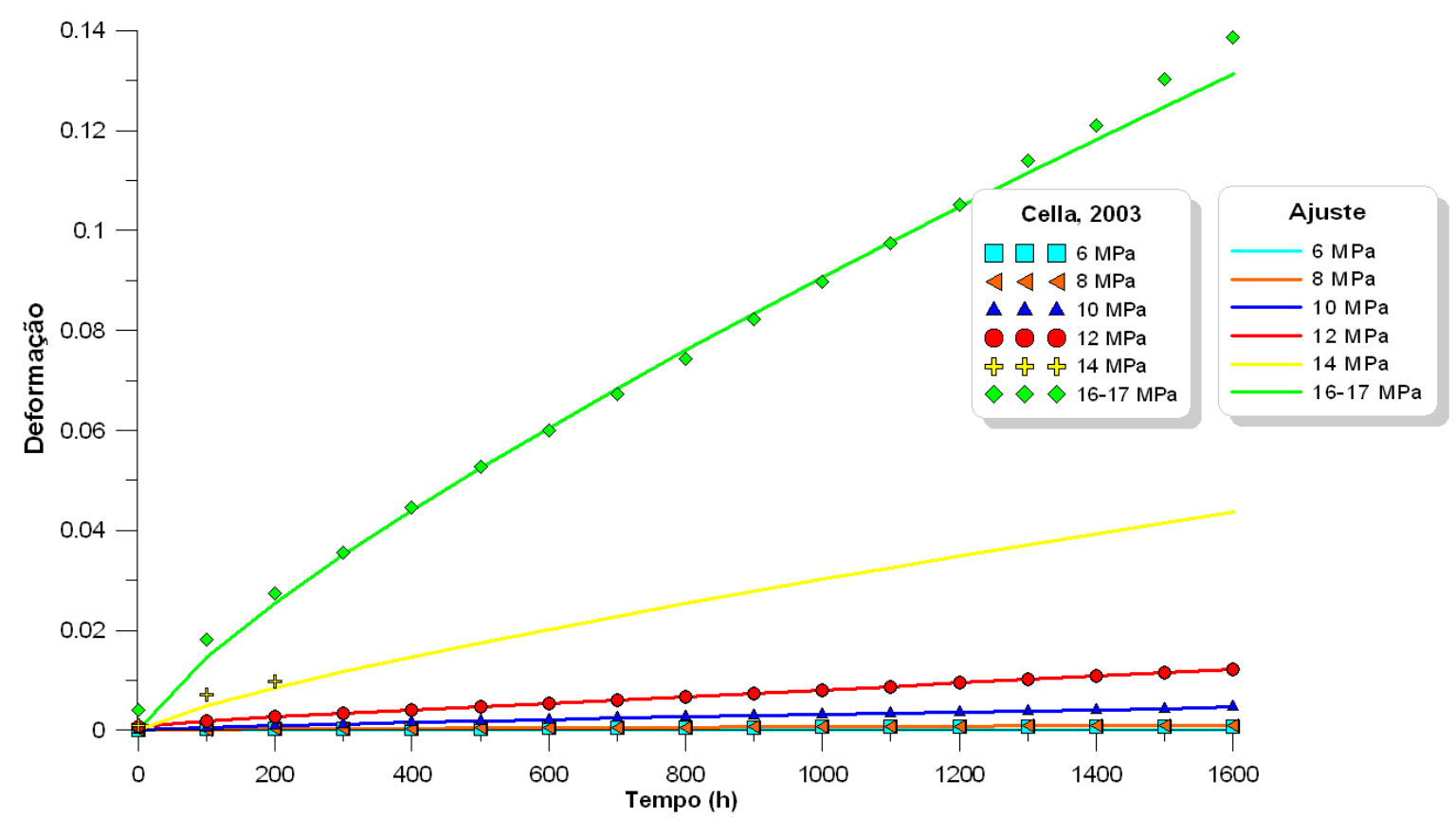

Figura 6.1: Ajuste da deformação ao longo do tempo para os diferentes níveis de tensões desviadora.

Observa-se que há uma boa aproximação da equação com os dados do ensaio. Nessa situação, com os parâmetros obtidos, observam-se erros muito pequenos da ordem de menos de $0.5 \%$. Alguns autores também fizeram ajustes de parâmetros para equações semelhantes a do Abaqus ${ }^{\circledR}$. Starfield e Mcclain (1973), por exemplo, fizeram ajustes para o modelo 
potencial (Equação (6.5)) com base em ensaios uniaxiais de fluência em rochas evaporíticas e obtiveram a Equação (6.7).

$$
\varepsilon=1,3 \cdot 10^{-37} \sigma^{3} t^{0,3} T^{9,5},
$$

sendo $\sigma$ em psi, $t$ em horas, $T$ em Kelvin e $\varepsilon$ adimensional.

Hansen e Mellegard (1980) também fizeram ajuste para a Equação (6.5) e obtiveram a Equação (6.8).

$$
\varepsilon=2,21 \cdot 10^{-40} \sigma^{3,28} t^{0,45} T^{11,45},
$$

sendo $\sigma$ em $\mathrm{kPa}, t$ em horas, $T$ em graus Kelvin e $\varepsilon$ adimensional.

Transformando as Equações (6.7) e (6.8) numa expressão semelhante à do Abaqus® e admitindo $\sigma$ em kPa, $t$ em horas, chega-se aos parâmetros da Tabela 6.2.

Tabela 6.2: Parâmetros para a equação do Abaqus®.

\begin{tabular}{|c|c|c|c|}
\hline Parâmetros & Starfield e Mcclain (1973) & Hansen e Mellegard (1980) & Ajustado \\
\hline $\boldsymbol{A}$ & $2,233 \mathrm{E}-16$ & $1,792 \mathrm{E}-11$ & $1,862 \mathrm{E}-32$ \\
\hline $\boldsymbol{n}$ & 3,00 & 3,28 & 6,69 \\
\hline $\boldsymbol{m}$ & $-0,70$ & $-0,55$ & $-0,21$ \\
\hline
\end{tabular}

A Figura 6.2 apresenta uma comparação entres os parâmetros ajustados e os obtidos na literatura com o ensaio de 16-17 MPa de Cella (2003). 


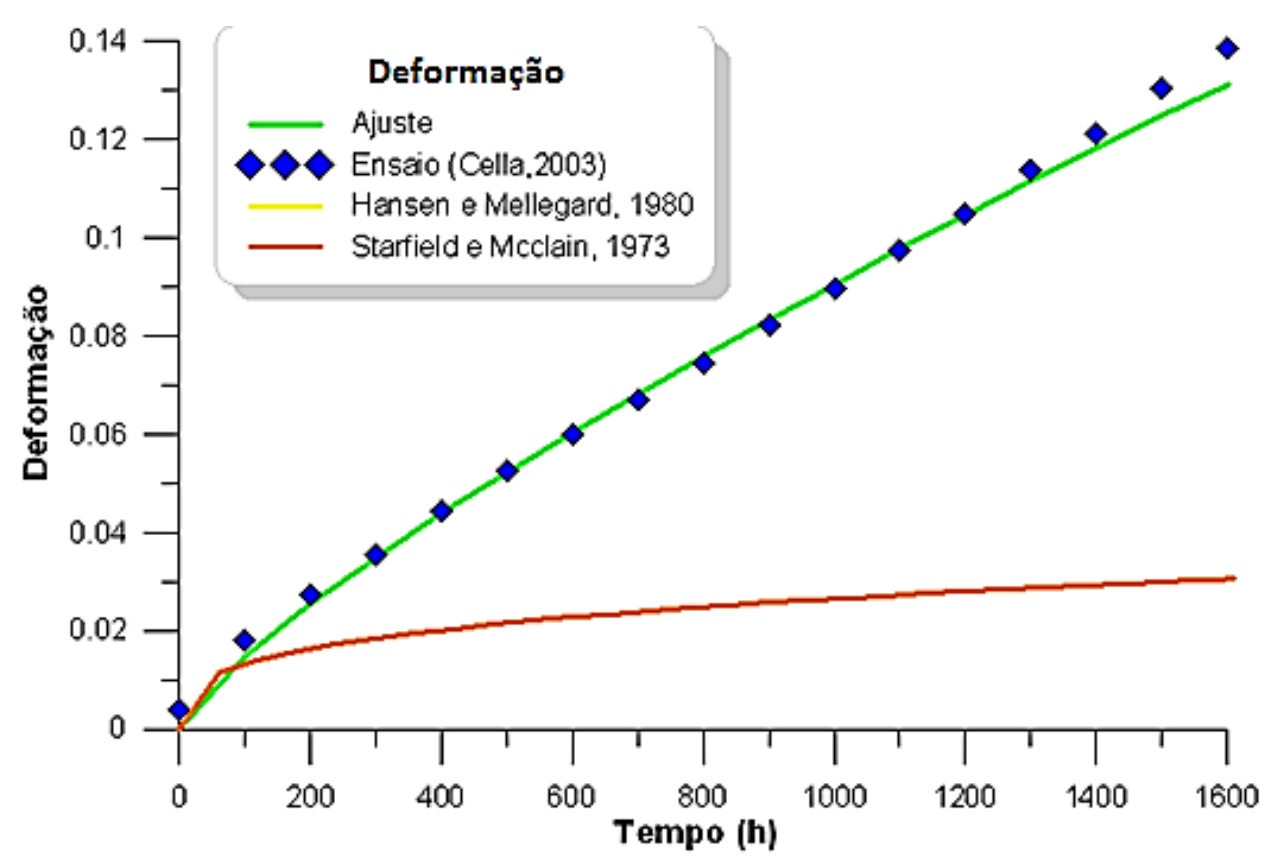

Figura 6.2: Comparação com outros parâmetros.

Observa-se na Figura 6.2 uma discrepância muito grande entre os dados do ensaio e o ajuste com os parâmetros de Starfield e Mcclain (1973), ou seja, não existe uma boa relação com a fluência da halita. Para os parâmetros de Hansen e Mellegard (1980) a discrepância é ainda maior e as deformações são dezenas de vezes maiores que as do ensaio, por isto não é visto o resultado. Observa-se ainda que, para os parâmetros ajustados, o erro é muito pequeno e a curva, neste caso, é a que melhor representa o comportamento de fluência da halita.

Atualmente existe uma tendência em se adotar o modelo de Mecanismo Duplo de Deformação. É um modelo que representa bem o comportamento secundário de fluência e por ser um modelo linear o ajuste dos parâmetros é muito mais simples. O modelo físico de Duplo Mecanismo de Deformação, Item 2.3.1, considera o "dislocation glide" e "mecanismo indefinido" como mecanismo de deformação. Costa et al. (2005) apresentaram uma solução para a equação para uma temperatura de $86^{\circ} \mathrm{C}$. Nesta situação Costa et al. (2005) propuseram a Equação (6.9).

$$
\varepsilon=1,88 \cdot 10^{-6} \cdot\left(\frac{\sigma_{e f}}{10}\right)^{n}
$$

para uma tensão de referencia $\sigma_{0}=9,91 \mathrm{MPa}$, onde: 
- $n=3,36$ para $\sigma_{e f}<\sigma_{0}$ (tensão desviadora efetiva menor que a tensão de referência);

- $n=7,55$ para $\sigma_{e f} \geq \sigma_{0}$ (tensão desviadora efetiva maior ou igual à tensão de referência).

A Figura 6.3 apresenta uma comparação com os dados do ensaio de Cella (2003) e as curvas dos modelos ajustado de Costa et al. (2005).

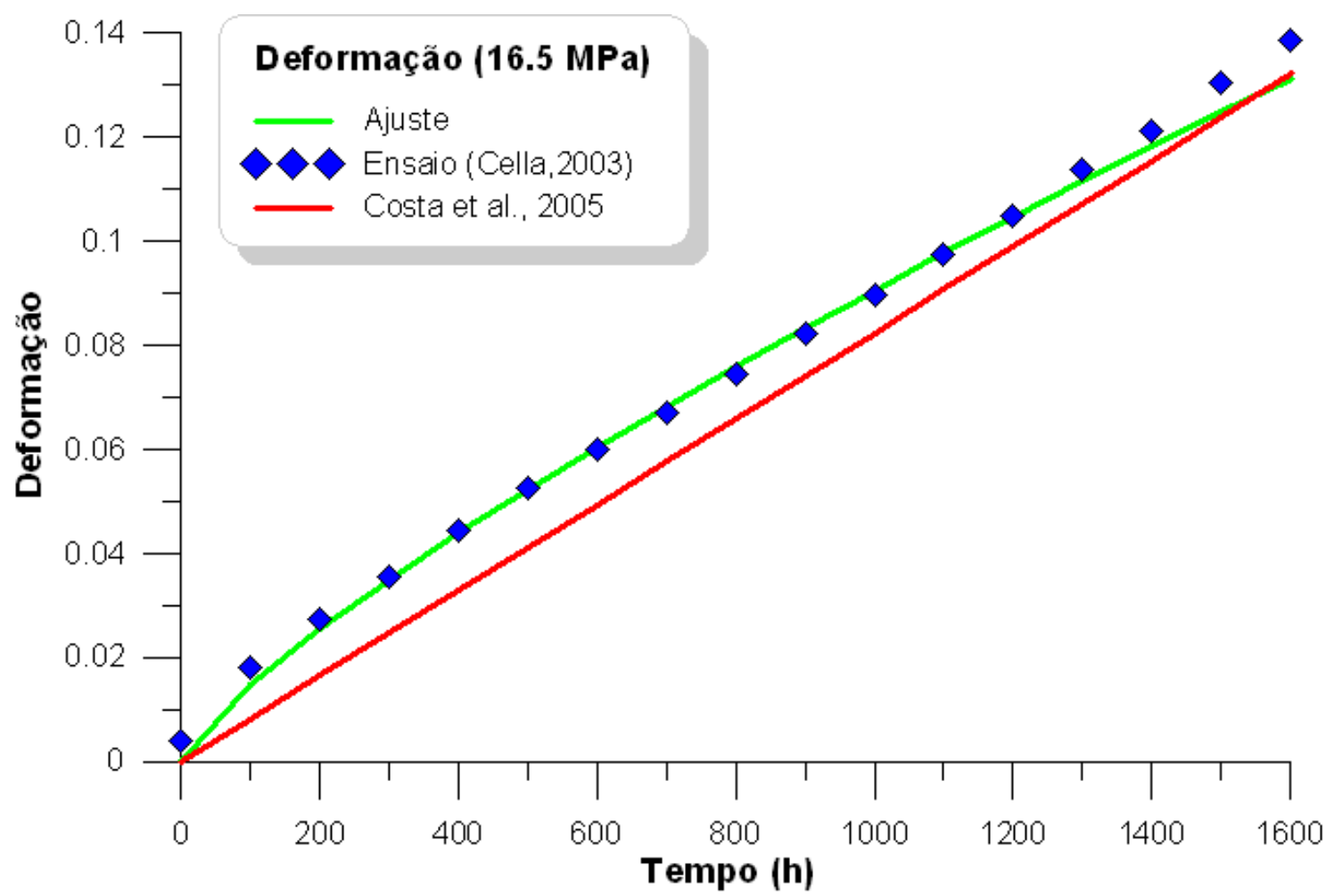

Figura 6.3: Comparação com o modelo de Costa et al. (2005)).

Observa-se na Figura 6.3 que o modelo de Costa et al. (2005) apresentou deformações com discrepâncias próximas de $1 \%$, fato já comprovado pelo referido autor. Mesmo sendo funções de leis diferentes, as curvas mostram uma boa relação com a fluência.

De fato os parâmetros ajustados demonstraram boa relação com as deformações de fluência, nos diferentes níveis de tensão, para os ensaios de Cella (2003). Para fins de engenharia, os erros entre as deformações são aceitáveis. O mais importante é deixar claro que:

1. Os parâmetros ajustados são validos apenas para a halita;

2. A halita deve estar a $86^{\circ} \mathrm{C}$, ou próximo;

3. As tensões diferenciais não devem se afastar muitos das tensões utilizadas para ajuste; 
4. Para o ajuste, os parâmetros levam em consideração um tempo de fluência de 1600 horas, ou seja, a fluência no estágio secundário pode estar sendo levada em consideração (desta forma, é recomendado utilizar os parâmetros neste intervalo de tempo);

5. Os parâmetros não são válidos quando se quer obter apenas a fluência no estagio primário (para tanto existem modelos e parâmetros mais apropriados na literatura).

\subsection{MODELAGEM NUMÉRICA DE UM POÇO}

A modelagem numérica da perfuração do poço de petróleo foi realizada a partir das características da Bacia de Campos (Brasil). Segundo Costa et al. (2005), a Bacia de Campos é caracterizada por uma espessa camada de evaporito localizada abaixo de uma camada de rocha dura e a cerca de $1400 \mathrm{~m}$ de profundidade. Para as simulações realizadas é admitido um cenário (semelhante ao de Costa et al., 2005) com uma espessa camada de halita pura, a ser perfurado no intervalo de $4000.0 \mathrm{~m}$ a $4014.4 \mathrm{~m}$ abaixo do nível do mar. Nesta intervalo as temperaturas estão próximas de $86^{\circ} \mathrm{C}$, o que permite o uso dos parâmetros ajustados. Essa situação adotou uma modelagem axissimétrica e pode ser melhor entendida a partir da Figura 6.4 que ilustra o perfil geológico utilizado na análise.

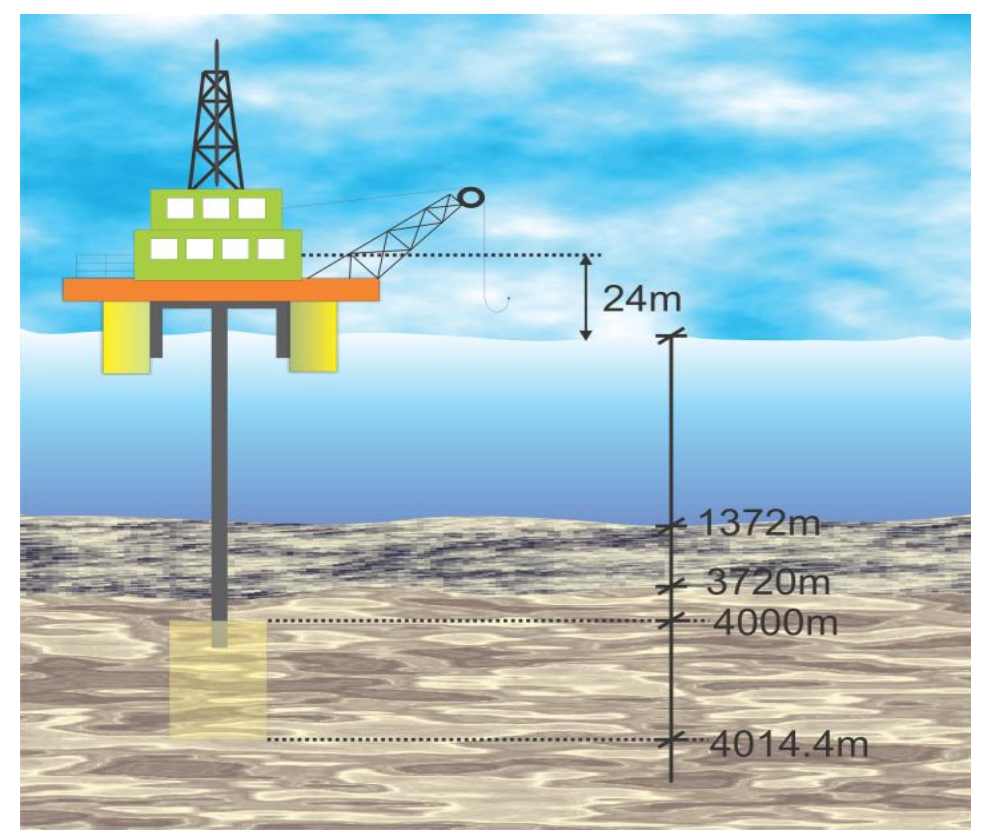

Figura 6.4: Perfil geológico analisado, fora de escala. 
Observa-se que para a situação em análise, o equipamento de perfuração está localizado $24 \mathrm{~m}$ acima do nível do mar e que entre a halita e o mar existe uma camada de rocha com $2348 \mathrm{~m}$ de espessura.

O cálculo da tensão de confinamento levou em consideração o peso do fluido (lama de perfuração) de $12,6 \mathrm{kN} / \mathrm{m}^{3}$. Para as tensões in situ foi idealizado o material com características isotrópicas, ou seja, as tensões são iguais em todas as direções $\left(\sigma_{x}=\sigma_{y}=\sigma_{z}\right)$. Além disso, o módulo de elasticidade $E$ é constante em todo camada do material, ou seja, o meio é homogêneo.

Os pesos específicos adotados para os diferentes materiais foram escolhidos com base em dados da literatura, utilizados por Botelho (2008) e Costa et al. (2005). O Cálculo das tensões até a profundidade de estudo, $4000 \mathrm{~m}$ abaixo do nível do mar, é mostrado na Tabela 6.3 .

Tabela 6.3: Cálculo das tensões até $4000 \mathrm{~m}$ abaixo do novel do mar.

\begin{tabular}{|c|c|c|c|}
\hline Tipo de material & Peso Específico $(\mathbf{k N} / \mathbf{m 3})$ & Profundidade $(\mathbf{m})$ & Tensão $(\mathbf{k P a})$ \\
\hline Lâmina de água & 10,18 & 0 a 1372 & 13966,96 \\
\hline Rochas Duras & 22,56 & 1372 a 3520 & 48458,88 \\
\hline Estrato de sal & 21,6 & 3520 a 4000 & 10368,00 \\
\hline \multirow{2}{*}{} & \multicolumn{2}{|c|}{ Total de $\sigma_{y}$ na profundidade de estudo } & $\mathbf{7 2 7 9 3 , 8 4}$ \\
\cline { 2 - 4 }
\end{tabular}

As simulações são feitas tanto para um modelo axissimétrico, como para um modelo plano de deformação e levam em consideração um poço com diâmetro de $0,36 \mathrm{~m}$, aproximadamente 14". Essa consideração, em ambos os casos, resume o estudo de caso a um problema semelhante ao de Costa et al. (2005) e pode servir como parâmetro para a verificação da coerência de resultados.

O modelo do Abaqus ${ }^{\circledR}$, Equação (6.2), não tem como variável a temperatura e dessa forma não é necessário o uso de um gradiente geotérmico, o que leva a uma simplificação do modelo. Por se tratar de uma região com temperaturas próximas a $86^{\circ} \mathrm{C}$, Costa et al. (2005), os parâmetros podem mostrar resultados satisfatórios.

Os parâmetros elásticos utilizados nas modelagens foram extraídos de Poiate et al. (2006) e tem como valor para o módulo de elasticidade e coeficiente de Poisson: $E=20,7 \mathrm{GPa}$ e $v=0,36$, respectivamente. Esses valores foram obtidos a partir de estudos relacionados ao comportamento mecânico do sal da mina Taquari-Vassouras no Nordeste Brasileiro. 
O comportamento de fluência da halita, simulado no Abaqus® pelo modelo "powerlaw model" na versão "time hardening", é obtido com base nos parâmetros ajustados e o objetivo das simulações numéricas é de investigação, na zona evaporítica, da taxa de fechamento do poço

\subsubsection{MODELO AXISSIMÉTRICO DO POÇO}

O modelo axissimétrico corresponde a um plano de $7.2 \mathrm{~m}$ x $14.4 \mathrm{~m}$ como mostra a Figura 6.5. Nessa situação considera-se apoio do primeiro gênero na parte inferior, de modo a impedir os deslocamentos na direção vertical. Na Figura 6.5 ainda é possível observar o eixo de revolução na lateral esquerda e os apoios do primeiro gênero impedido os deslocamentos na horizontal, o que caracteriza o modelo.

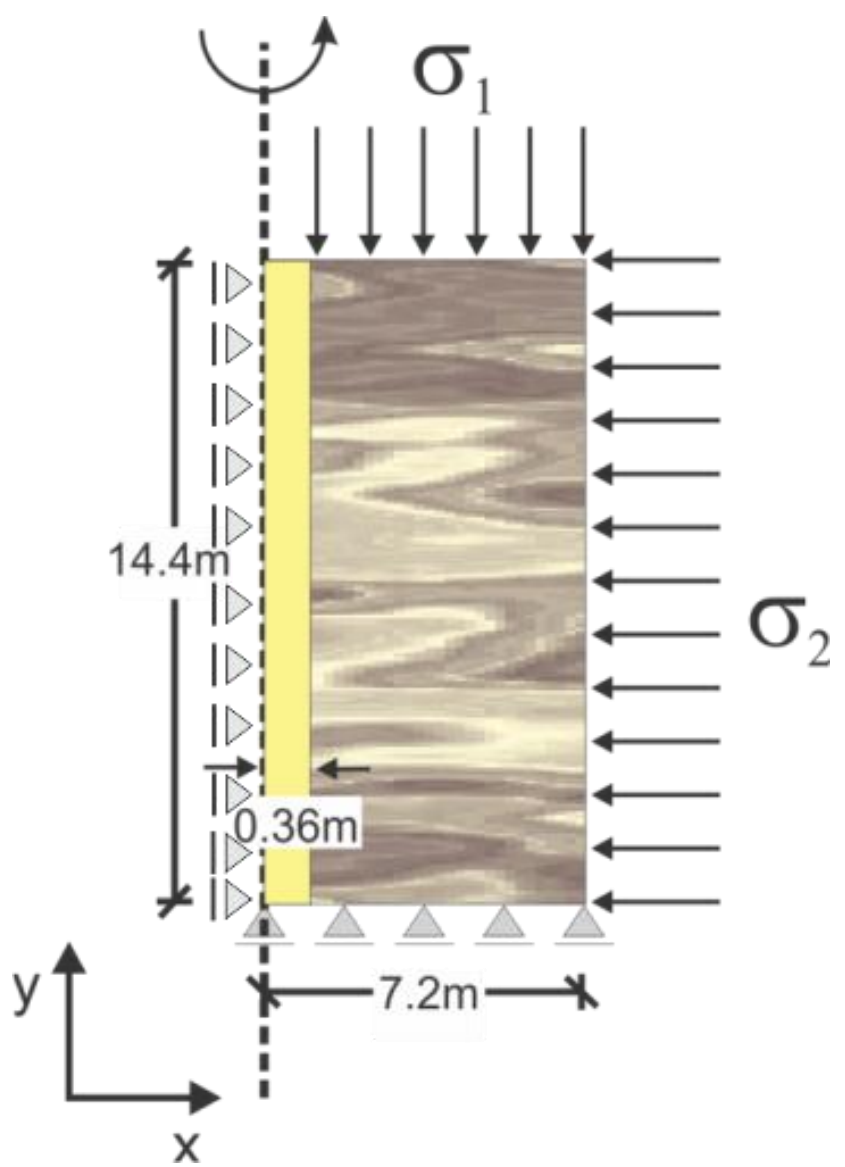

Figura 6.5: Modelo axissimétrico do poço.

Por ser considerado um meio isotrópico tem-se que $\sigma_{1}=\sigma_{2}$. Estas tensões, calculadas anteriormente, vão sofrer variação com a profundidade no modelo utilizado. Ou seja, as tensões verticais tendem a aumentar o que leva a um aumento das tensões horizontais. Para tanto é usado o carregamento gravitacional, do Abaqus®, no modelo em análise. 
A simulação do modelo Axissimétrico é dividida em 31 "steps" que corresponde a cada etapa da simulação. Na primeira etapa (step) é feito o uso da função geostática do Abaqus®; nessa etapa é simulado um equilíbrio entre o estado de tensão e a força externa. $\mathrm{Na}$ segunda e em todas demais etapas "pares" (etapa 2, etapa 4, etapa 6,...), é feita a escavação; nestas etapas são simuladas a resposta elástica e a introdução das tensões geradas pelo peso do fluido de perfuração. A terceira e as demais etapas "ímpares" (etapa 3, etapa 5, etapa $7, \ldots$ ) correspondem à fase de fluência da halita. Nestas etapas são considerados tempos de resposta de 6 minutos até a escavação do próximo lance. For fim, na última (etapa 31) o tempo considerado é 200 horas para a simulação da fluência a médio prazo.

\subsubsection{MODELO PLANO DE DEFORMAÇÃO DO POÇO}

O modelo plano de deformação corresponde a um plano de $7,2 \mathrm{~m} \mathrm{x} \mathrm{7,2} \mathrm{m,} \mathrm{como}$ mostra a Figura 6.6. Na parte inferior e lateral esquerda são considerados apoios do primeiro gênero de modo a impedir os deslocamentos na direção horizontal e vertical, respectivamente. Na superfície do modelo e na lateral direita são admitidas as tensões efetivas de compressão nas direções 1 e 2 . Tensões estas calculadas para uma profundidade de $4020 \mathrm{~m}$ abaixo do nível do mar e que corresponde a 73,23 MPa.

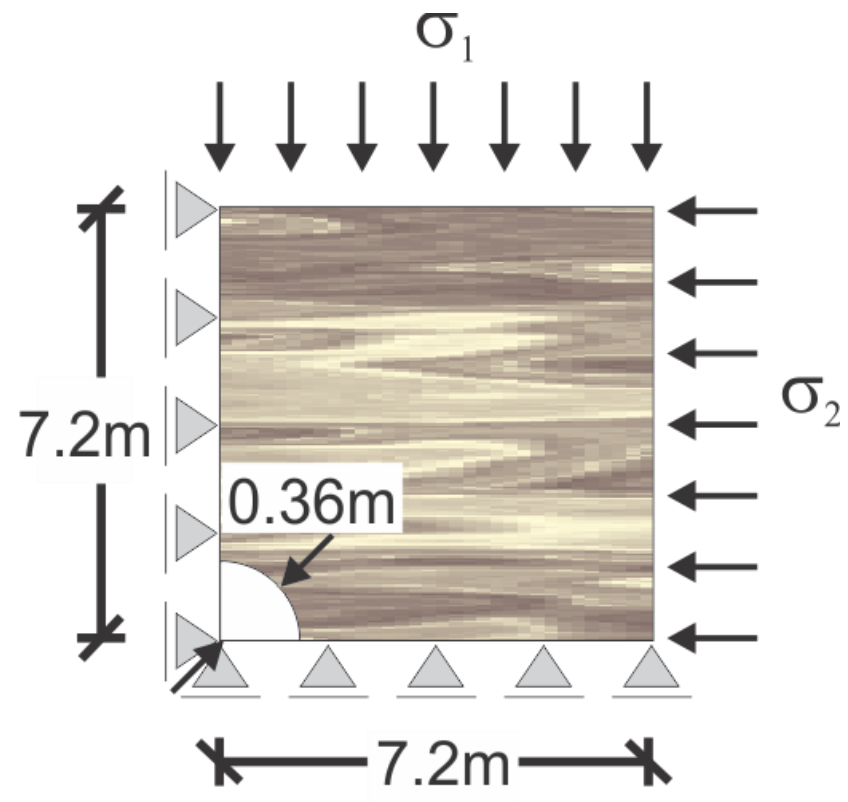

Figura 6.6: Modelo plano de deformação do poço.

Por ser considerado um meio isotrópico tem-se que $\sigma_{1}=\sigma_{2}=72,23 \mathrm{MPa}$. Esta situação não necessita de um carregamento gravitacional, pois são analisadas as deformações em uma dada profundidade. 
A simulação do modelo Axissimétrico é dividida em 3 "steps" que correspondem a cada etapa da simulação. Na primeira etapa (step) é feito o uso da função geostático do Abaqus®; na segunda é feita a simulação da resposta elástica devido à escavação e a introdução das tensões geradas pelo peso do fluido de perfuração. Na terceira é feita a simulação da fluência da halita em um período de 500 horas.

\subsubsection{RESULTADOS DA SIMULAÇÃO DO POÇO}

Os resultados da simulação axissimétrica foram obtidos em 6 diferentes profundidades, variando de $4007.5 \mathrm{~m}$ a $4012.5 \mathrm{~m}$ abaixo do nível do mar. Os resultados apresentados na Figura 6.7 são correspondentes ao fechamento radial do poço ao longo do período analisado. Segundo Costa et al. (2005), o fechamento aceitável para este poço, considerando as irregularidades da escavação, é de 1.75" (22 mm).

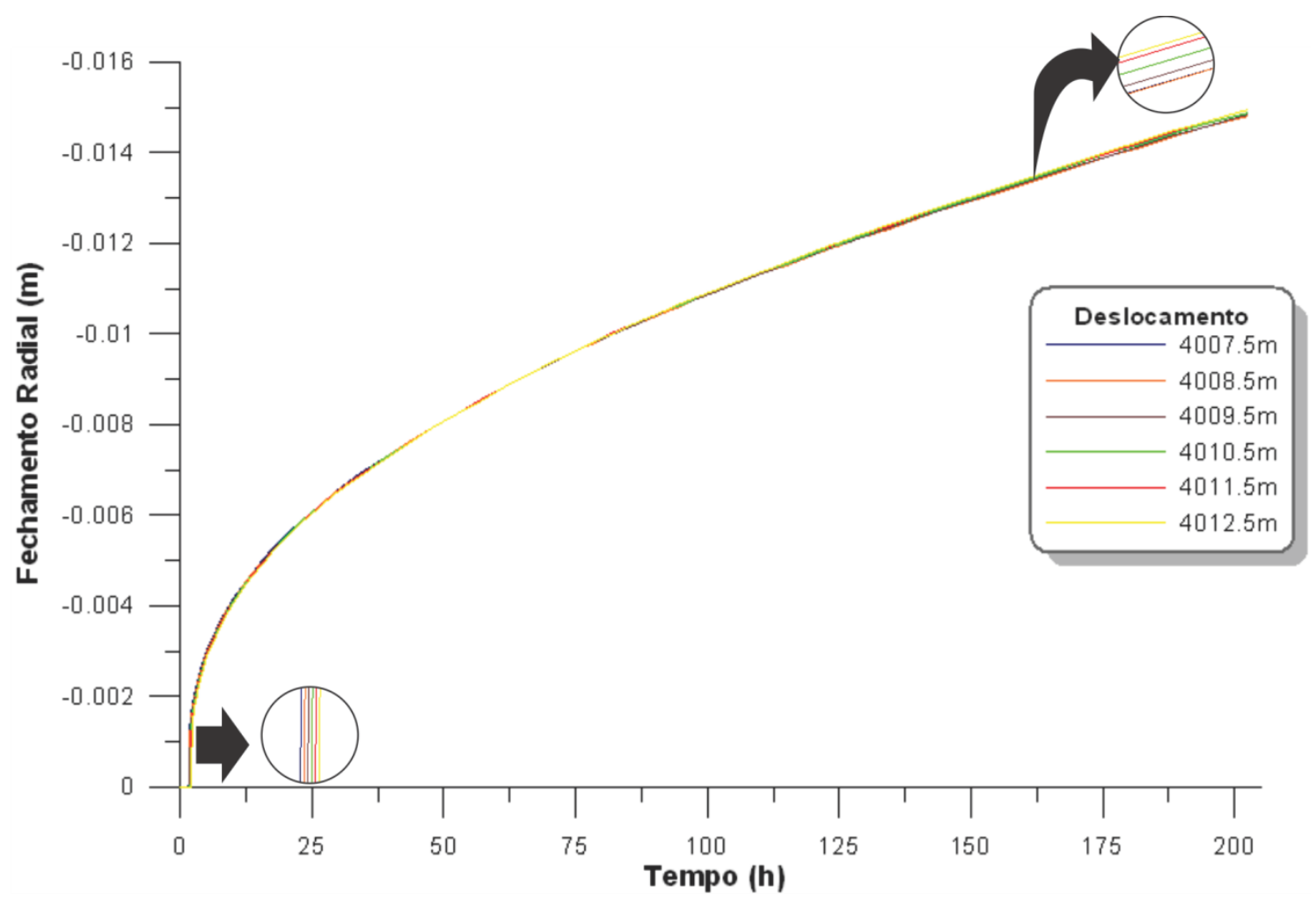

Figura 6.7: Curva de fechamento do poço para 6 diferentes profundidades

Observa-se que até 200 horas do inicio da escavação não houve deslocamentos suficientes para atingir o limite aceitável. Dessa forma é possível realizar a descida do revestimento sem quaisquer danos. Na Figura 6.7 ainda é observada quase que uma sobreposição entre as curvas de fechamento. Isso se deve a pequena variação de profundidades, separadas a cada metro. Inicialmente, próximo do tempo zero, observa-se uma 
separação horizontal entre as curvas, o que corresponde aos diferentes níveis de escavação. Cada nível, ou profundidade, começando em um tempo diferente, à medida que o poço é perfurado. Após certo tempo do início da fluência é observado um aumento mais considerável para as regiões mais profundas. Isso se deve ao fato de que as tensões em profundidades mais elevadas são maiores que em profundidades menores.

Para a simulação de deformação plana, a uma profundidade de 4020 m abaixo do nível do mar, são mostrados os deslocamentos ao longo de 500 horas após a perfuração. A Figura 6.8 mostra o resultado da simulação comparado com os resultados obtidos por Costa et al. (2005).

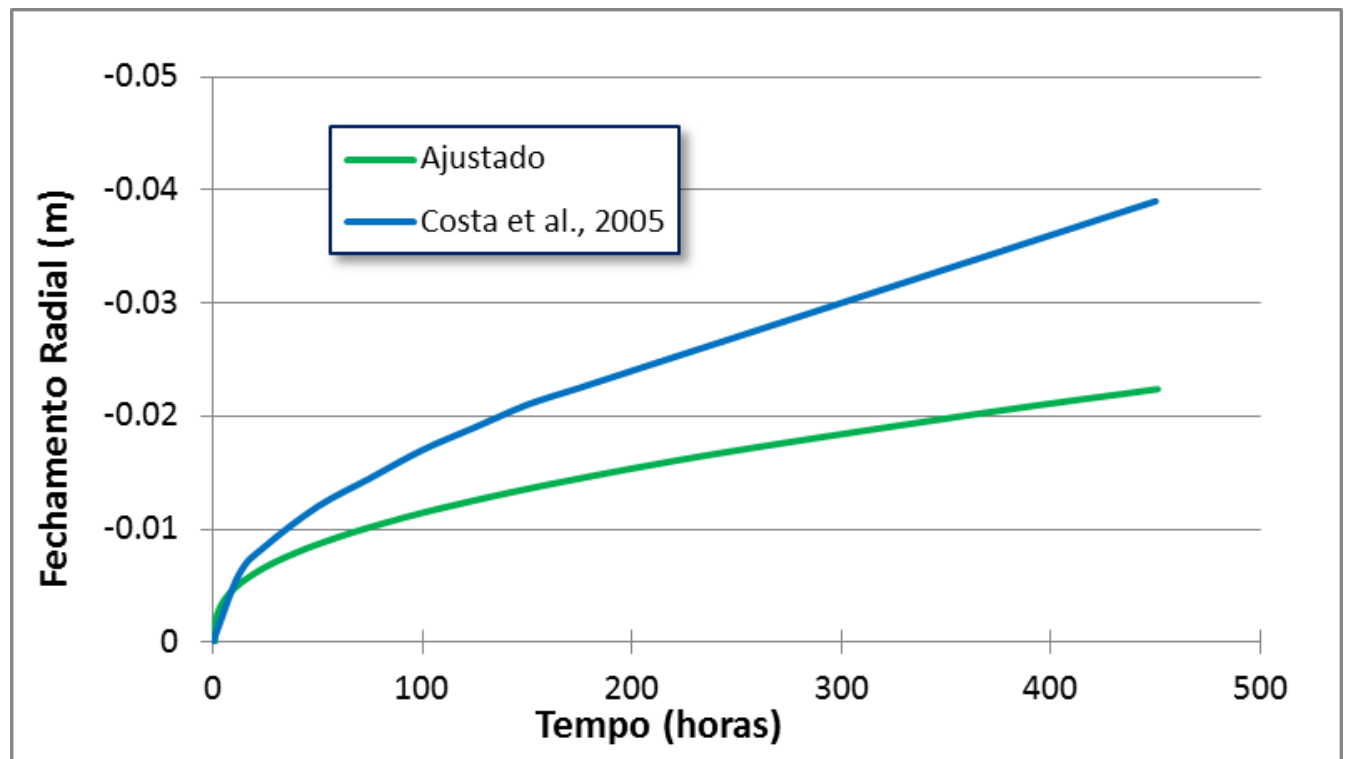

Figura 6.8: Curva de fechamento do poço, profundidade de $4020 \mathrm{~m}$ abaixo do nível do mar.

Observa-se uma relação entre as curvas de fechamento para o caso analisado. Vale ressaltar que não houve uma reprodução fiel do modelo de Costa et al. (2005), isto se deve às considerações adotadas para os diferentes modelos. 


\section{CAPITULO 7 - CONSIDERAÇÃo DA FLUÊNCIA PRIMÁriA E SECUNDÁRIA NA SIMULAÇÃO DE EVAPORITOS}

A dificuldade de obtenção de um modelo de fluência capaz descrever os três estágios de fluência (primário, secundário e terciário) tem gerado muitas discussões acerca do assunto. Geralmente os modelos constitutivos encontrados na literatura servem apenas para descrever um dos estágios de fluência e os que podem simular mais de um, às vezes podem levar a resultados distantes da realidade. Além disto, dificuldade em não se conseguir parâmetros para os mesmos, ou a dificuldade em ajustá-los, torna estes modelos inviáveis para utilização em materiais geotécnicos.

Neste capítulo será abordada uma nova metodologia de simulação de fluência, onde se levará em conta o estágio primário e secundário. A metodologia parte da lei potencial de fluência do Abaqus®, Equação (6.1). A partir desta equação e dos recursos do programa será simulado o comportamento típico de um evaporito: deformação elástica instantânea, fluência no estágio primário e fluência no estágio secundário, ou seja:

$$
\varepsilon=\varepsilon_{e}+\varepsilon_{f_{1}}+\varepsilon_{f_{2}}
$$

onde $\varepsilon_{e}$ é a deformação elástica, que em um caso uniaxial pode ser dada pela equação de Hooke (Equação (2.10)); $\varepsilon_{f_{1}}$ é a fluência primaria ou transiente; e $\varepsilon_{f_{2}}$ é a fluência secundaria.

A etapa de fluência terciária ou acelerada não será avaliada no presente trabalho (Item 2.2), desta forma a análise será voltada nestas três fases:

1. Primeira Fase: voltada a avaliação da deformação instantânea, independente do tempo, ligada diretamente ao comportamento elástico do material;

2. Segunda Fase: voltada a fluência primaria ou transiente, onde a taxa de deformação diminui com o tempo até se atingir um valor constante;

3. Terceira Fase: voltada a fluência secundária, caracterizada por um aumento de deformação a uma taxa de deforma constante.

A Figura 7.1 mostra o comportamento típico de uma rocha evaporítica para as três fases descritas anteriormente. 


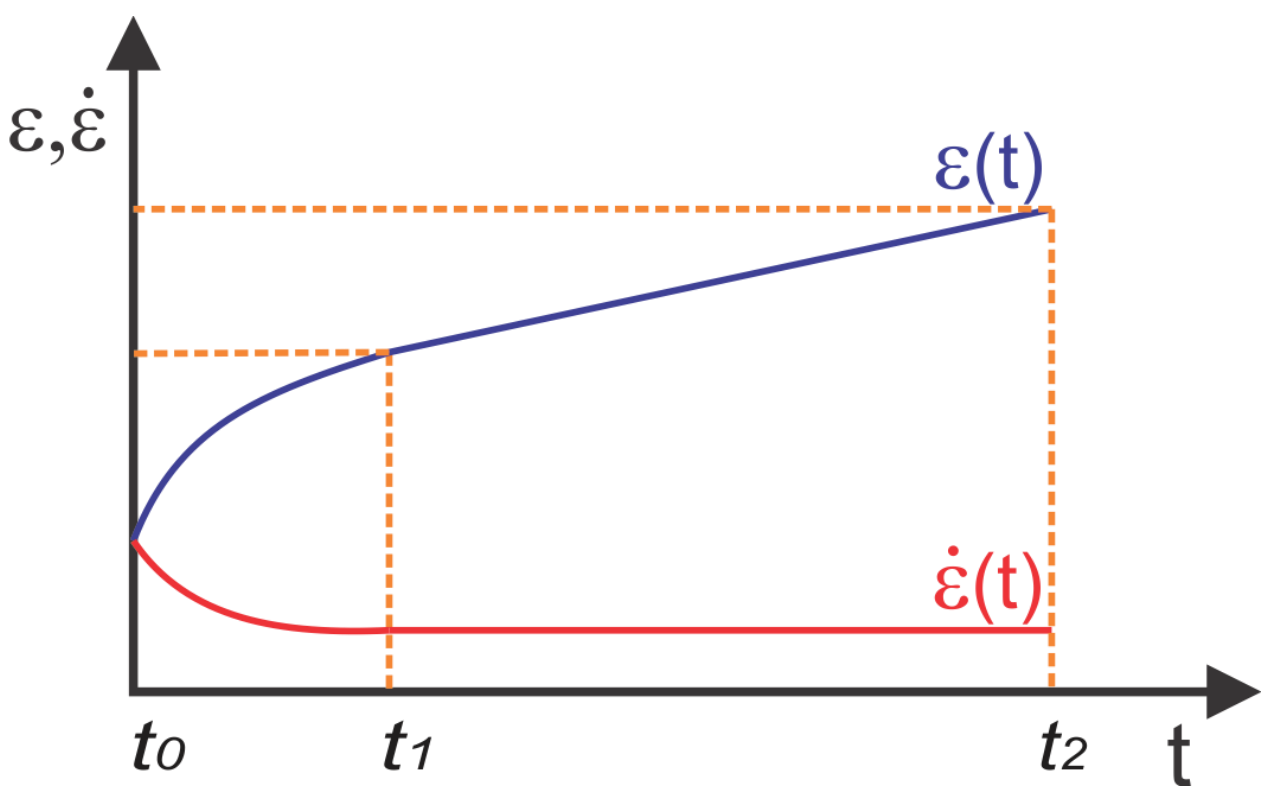

Figura 7.1:Comportamento primário e secundário de fluência.

Numa lei constitutiva potencial de fluência as deformações estão diretamente relacionadas com o tempo por uma função exponencial. A lei de fluência do Abaqus®, Equação (6.1), é um exemplo e pode representar o comportamento primário de fluência. A fluência segundaria por outro lado tem as deformações diretamente proporcionais ao tempo, ou seja, a taxa de deformação é constante em todo estágio. Observando a Equação (6.1) é possível visualizar que, para $m$ igual a zero, a taxa de deformação passa a ser constante, Equação (7.2).

$$
\dot{\varepsilon}=A \sigma^{n}
$$

Tem-se então uma lei deformação versus tempo linear, remetendo ao comportamento de fluência secundária. Dessa forma, o comportamento primária de fluência é descrito quando $m$ é menor que zero e comportamento secundário de fluência é descrito quando $m$ é igual à zero.

\subsection{PARÂMETROS ELÁSTICOS DE EVAPORITOS}

Os parâmetros elásticos utilizados para obtenção das deformações instantânea são facilmente encontrados na literatura. A Tabela 7.1 mostra alguns destes parâmetros para quatro tipos de rochas evaporíticas, obtidos com base em amostras da mina TaquariVassouras (Costa, 1995 apud Cella, 2003). 
Tabela 7.1: Propriedade elástica de evaporitos (Costa, 1995 apud Cella, 2003).

\begin{tabular}{|c|c|c|}
\hline Material & $\boldsymbol{E}(\mathbf{G P a})$ & $\boldsymbol{v}$ \\
\hline Silvinita & 15,7 & 0,33 \\
\hline Halita & 20,4 & 0,36 \\
\hline Carnalita & 4,20 & 0,36 \\
\hline Taquidrita & 4,92 & 0,33 \\
\hline
\end{tabular}

\subsection{PARÂMETROS PARA A FLUÊNCIA PRIMÁRIA E SECUNDÁRIA DO ABAQUS®}

Algumas leis constitutivas de fluência vêm sendo consagradas para a determinação do comportamento viscoelástico de evaporitos. A fluência primária dos evaporitos, por exemplo, vem sendo descrita pela lei potencial de Lomenick apud Gravina (1997), apresentada no Item 2.3.2. Muitos autores, como Starfield e Mcclain (1973), Hansen e Mellegard (1980), e Costa (1984) utilizaram a equação potencial de Lomenick para descrever a fluência primária e os mesmos propuseram alguns parâmetros para esta equação, alguns deles mostrados no Item 6.2.4.

Por outro lado a fluência secundária vem sendo descrita, por autores como Cella (2003) e Costa et al. (2005), pela lei de duplo mecanismo de deformação (Item 2.3.1). Esta é uma lei já consagrada e amplamente utilizada na avaliação de fluência em evaporitos.

\subsubsection{PARÂMETROS PARA A FLUÊNCIA PRIMÁRIA}

Para obtenção dos parâmetros primários da equação de fluência do Abaqus ${ }^{\circledR}$, a partir da equação potencial de Lomenick, integrou-se a Equação (6.1) para que as deformações fossem obtidas em função do tempo. Igualando-se o resultado a Equação (6.5) chega-se:

$$
\begin{gathered}
A=K \cdot b \cdot T^{a}, \\
n=c, \\
m=b-1,
\end{gathered}
$$

Costa (1984), em ensaios de fluência uniaxial e de fluência confinada ou triaxial, obteve alguns parâmetros para a equação potencial de Lomenick. Os ensaios foram realizados em rochas evaporíticas, como taquidrita, silvinita, halita e carnalita em diferentes temperaturas $\left(23,33,43^{\circ} \mathrm{C}\right)$. Os ensaios triaxiais foram necessários nas amostras de rochas 
com pouca competência, no caso a taquidrita. A Tabela 7.2 mostra os resultados obtidos que podem ser usados na falta de parâmetros mais confiáveis.

Tabela 7.2: Parâmetros obtidos por Costa (1984) para a equação potencial de Lomenick.

\begin{tabular}{|c|c|c|c|c|c|c|c|c|}
\hline \multirow{2}{*}{ Rochas } & \multicolumn{4}{|c|}{$\varepsilon=\varepsilon_{0}$} & \multicolumn{4}{|c|}{$\varepsilon=\frac{1}{3} \varepsilon_{0}$} \\
\hline & $\mathbf{K}$ & c & b & $\mathbf{a}$ & K & c & b & $\mathbf{a}$ \\
\hline Halita & $1,02 \times 10^{-14}$ & 2,22 & 0,209 & 4,68 & $2,85 \times 10^{-14}$ & 1,99 & 0,101 & 4,78 \\
\hline Silvinita & 0,132 & 1,08 & 0,359 & 0 & 0,234 & 1,19 & 0,254 & 0 \\
\hline Taquidrita & $1,57 \times 10^{-4}$ & 0,388 & 0,218 & 1,58 & 1,82 & 0,527 & 0,155 & 0,053 \\
\hline $\begin{array}{c}\text { Carnalita } \\
\mathrm{FPH}^{2}\end{array}$ & 0,0936 & 1,54 & 0,222 & 0,0085 & & & & \\
\hline $\begin{array}{c}\text { Carnalita } \\
\text { FMH }^{3}\end{array}$ & $2,94 \times 10^{-8}$ & 1,50 & 0,186 & 2,65 & $1,07 \times 10^{-4}$ & 1,51 & 0,114 & 1,33 \\
\hline $\begin{array}{c}\text { Carnalita } \\
\mathrm{GPH}^{4}\end{array}$ & $4,09 \times 10^{-6}$ & 1,37 & 0,177 & 1,84 & $6,71 \times 10^{-11}$ & 1,51 & 0,116 & 3,82 \\
\hline $\begin{array}{c}\text { Carnalita } \\
\text { GMH }^{5} \\
\end{array}$ & 0,070 & 1,68 & 0,176 & 0 & 0,153 & 1,65 & 0,103 & 0 \\
\hline
\end{tabular}

$\mathrm{Na}$ Tabela 7.2, $\varepsilon_{0}$ é a deformação sofridas na fase de carregamento, ou seja, os parâmetros foram ajustados para duas situações: a primeira considerando que toda deformação sofrida na etapa de carregamento é elástica e a segunda considerando que apenas $1 / 3$ é elástica.

\subsubsection{PARÂMETROS PARA A FLUÊNCIA SECUNDÁRIA}

Os parâmetros para equação de fluência secundária do Abaqus® são obtidos a partir da equação de duplo mecanismo de deformação. Neste caso as taxas de deformação das Equações (2.4) são igualadas às da Equação (7.2). Desta forma, tem-se:

$$
\begin{gathered}
A=\frac{\dot{\varepsilon}_{0}}{\sigma_{0}^{n}} \exp \left(\frac{Q}{R^{\prime} T_{0}}-\frac{Q}{R^{\prime} T}\right), \\
n=n \\
m=0
\end{gathered}
$$

onde; $\varepsilon_{0}$ é a taxa de deformação de referência para a fluência no estado permanente; $\sigma_{0}$ é a tensão desviadora de referência; $Q$ é energia de ativação; $R$ 'é a constante universal dos gases;

\footnotetext{
${ }^{2}$ Carnalita fina com pouca halita.

${ }^{3}$ Carnalita fina com muita halita.

${ }^{4}$ Carnalita grosseira com pouca halita.

${ }^{5}$ Carnalita grosseira com muita halita.
} 
$T_{0}$ é temperatura de referência $(\mathrm{K}) ; T$ é temperatura absoluta; e $n$ é um valor dependente do nível de tensão aplicada $\left(\mathrm{n}_{1}: \sigma_{e f} \leq \sigma_{0}\right.$ e $\left.\mathrm{n}_{2}: \sigma_{e f}>\sigma_{0}\right)$.

Na falta de dados, os parâmetros apresentados na Tabela 7.3 podem ser utilizados e trazer resultados satisfatórios. Os parâmetros foram obtidos e, calibrados através de estudos de retroanálise (Costa, 1995 apud Cella, 2003) feitos a partir de medições da deformação interna em escavações executadas em painel de lavras experimental.

Tabela 7.3: Parâmetros de fluência estacionária de evaporitos obtidos por retroanálise de medidas de convergência em abertura experimental da Mina Taquari-Vassouras, Sergipe (Costa, 1995 apud Cella,

\begin{tabular}{|c|c|c|c|c|}
\hline \multicolumn{7}{|c|}{$2003)}$. \\
\hline Material & $\sigma_{0}(\mathbf{M P a})$ & $\varepsilon_{0}(\mathbf{a n o - 1})$ & $\mathbf{n}_{\mathbf{1}}$ & $\mathbf{n}_{\mathbf{2}}$ \\
\hline Silvinita & 10 & 0,0016 & 3 & 5,8 \\
\hline Halita & 10 & 0,0016 & 3 & 5,8 \\
\hline Carnalita & 8 & 0,0072 & 3 & 5,8 \\
\hline Taquidrita & 10 & 0,22 & 3 & 3,0 \\
\hline
\end{tabular}

\subsection{VALIDAÇÃO DA METODOLOGIA A PARTIR DE ENSAIOS FLUÊNCIAS}

A validação da metodologia foi realizada a partir de um ensaio de fluência de Costa $e t$ al. (2005) em uma amostra de halita. Num ensaio de fluência, uma tensão desviadora é aplicada sobre um corpo de prova e a mesma é mantida constante durante todo ensaio.

Para a simulação foi considerado um corpo de prova submetido a uma tensão confinante, gerada uma pressão constante de água, e uma tensão desviadora, como mostra a Figura 7.2. 


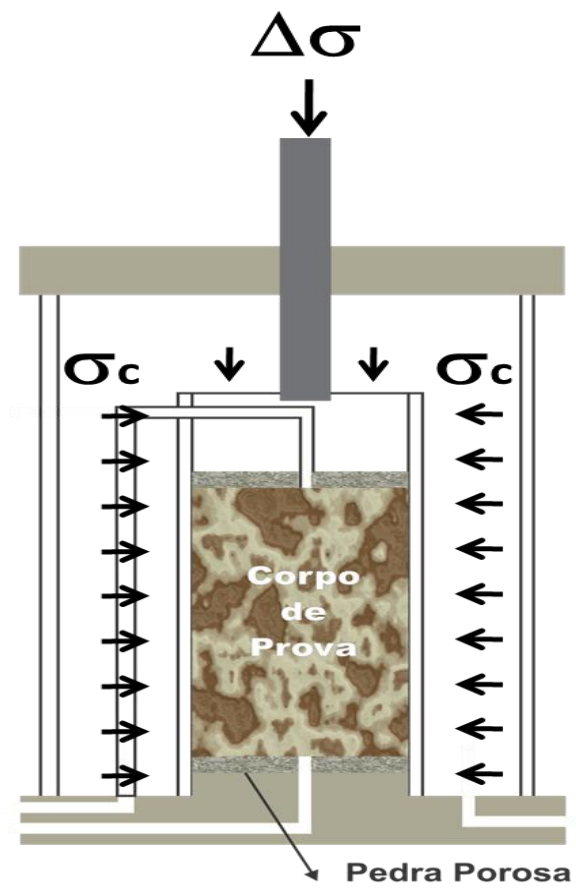

Figura 7.2: Ensaio de fluência

Observa-se que $\Delta \sigma$ e $\sigma_{c}$ representam respectivamente a tensão desviadora e a tensão confinante e que o somatório das duas é equivalente a tensão axial $\sigma_{1}$ aplicada no ensaio, ver Figura 7.3. Para a simulação foi utilizado um modelo axissimétrico que corresponde a $1 / 4$ do modelo de um corpo de prova de 101,6 mm de diâmetro e $185 \mathrm{~mm}$ de altura (Figura 7.3).

\subsubsection{CARACTERÍSTICAS DA SIMULAÇÃO}

Todas as simulações realizadas neste capitulo estão divididas em três Etapas: a primeira para obtenção das deformações elásticas instantâneas, a segunda para obtenção das deformações durante o estagio primário de fluência e a terceira para obtenção das deformações durante o estágio secundário de fluência.

Para a variação das propriedades de fluência durante as etapas de simulação, utilizouse o comando *FIELD, do Abaqus ${ }^{\circledR}$. O comando permite associar uma variável dependente a uma lei constitutiva e à medida que a variável dependente é modificada, os valores de parâmetros associado a ela passam a ser considerados na lei constitutiva. Esta variável pode ser associada ao tempo, deslocamento, temperatura, etapas da simulação, entre outros. Neste caso a mesma foi associada à etapa, ou seja, para etapa de fluência primaria os parâmetros são uns e para a etapa de fluência secundária os parâmetros são outros. 
- $\quad$ Etapa Elástica

Inicialmente é simulada a resposta elástica devido à introdução da tensão desviadora, ou seja, o acréscimo de tensão vertical do ensaio fluência. Nesta etapa as deformações geradas não dependem do tempo, o que torna necessária a colocação de um tempo de simulação muito pequeno para que o mesmo não interfira nos resultados.

- $\quad$ Etapa de Fluência Primária

Para a simulação da fluência primária utilizou-se um tempo de 200 horas. Este tempo foi considerado por se conhecer o tempo aproximado para o término da fluência secundária, Costa et al. (2005). No caso de não se conhecer este tempo, o Item 7.4 traz uma proposta para obtenção do mesmo.

- $\quad$ Etapa de Fluência Secundária

A simulação da fluência secundária se iniciou após o fim da fluência primária e durou até o tempo de 1600 horas do início da simulação, ou seja, foram utilizadas 1400 horas na simulação desta etapa.

$\mathrm{Na}$ segunda e terceira etapa os resultados foram somados com os resultados da etapa anterior, o que garante a continuidade da simulação.

\subsubsection{PROPRIEDADES DO MATERIAL}

A halita é uma rocha salina e assim como as demais possuem uma propriedade de se deformar ao longo do tempo, mesmo em condições de temperatura e tensão constantes. Com base na metodologia proposta, a halita precisaria das propriedades elásticas e das propriedades de fluência para os estágios primário e secundário.

- Parâmetros Elásticos

Os parâmetros elásticos para a halita utilizados na simulação são os mesmo apresentados na Tabela 7.1, ou seja:

$$
\begin{aligned}
& E=20,7 \mathrm{GPa}, \\
& v=0,36 .
\end{aligned}
$$


- Parâmetros de Fluência Primária

Os parâmetros de fluência primária para a equação do Abaqus®, utilizados nas simulações, foram tirados de Costa (1984), Starfield e Mcclain (1973), e Hansen e Mellegard (1980). A partir das Equações (7.3), (7.4) e (7.5), obtêm-se os valores de $A, n, m$ mostrados na Tabela 7.4.

Tabela 7.4: Parâmetros para a equação do Abaqus ${ }^{\circledR}$ para fluência primária.

\begin{tabular}{|c|c|c|c|c|}
\hline & Costa, $1984^{6}$ & $\begin{array}{c}\text { Costa, } 1984 \\
(1 / 3)^{7}\end{array}$ & $\begin{array}{c}\text { Starfield e Mcclain, } \\
1973\end{array}$ & $\begin{array}{c}\text { Hansen e Mellegard, } \\
1980\end{array}$ \\
\hline$A$ & $1,9346 \mathrm{E}-06$ & $4,7045 \mathrm{E}-06$ & $2,23 \mathrm{E}-07$ & $1,24 \mathrm{E}-01$ \\
\hline$n$ & 2,22 & 1,99 & 3 & 3,28 \\
\hline$m$ & $-0,791$ & -0,899 & $-0,7$ & $-0,55$ \\
\hline
\end{tabular}

Os valores dos parâmetros mostrados na Tabela 7.4 estão ajustados para valores de tensão em MPa e tempo em horas. Os valores ajustado no Item 6.2 não serão avaliados, visto que, os parâmetros foram ajustados com base nas fluências primária e secundária, ou seja, os valores podem não estar diretamente associado à fluência primária.

- Parâmetros de Fluência Secundária

Os parâmetros de fluência secundária para a equação do Abaqus® foram obtidos a partir das Equações (7.6), (7.7) e (7.8) com base nos parâmetros de Costa et al. (2005), mostrados no Item 6.2.4, Equação (6.9). Desta forma, a Tabela 7.5 mostra os valores obtidos para equação do Abaqus® considerando-se a tensão em MPa e tempo em horas.

Tabela 7.5: Parâmetros para a equação do Abaqus® para fluência secundária.

\begin{tabular}{|c|c|}
\hline \multicolumn{2}{|c|}{ Costa et al. (2005) } \\
\hline $\boldsymbol{A}$ & $5,29856 \mathrm{E}-14$ \\
\hline $\boldsymbol{n}$ & 7.55 \\
\hline $\boldsymbol{m}$ & 0 \\
\hline
\end{tabular}

Como a tensão desviadora no ensaio de Costa et al. (2005) foi de aproximadamente 14.1 MPa, maior que as tensões de referência, o valor de $n$ adotado foi 7,55 (ver Item 6.2.4). elásticas.

${ }^{6}$ Parâmetros ajustados considerando que $100 \%$ das deformações sofridas na etapa de carregamento são

${ }^{7}$ Parâmetros ajustados considerando que $1 / 3$ das deformações sofridas na etapa de carregamento são elásticas. 


\subsubsection{CONDIÇÕES DE CONTORNO}

A Figura 7.3 é uma representação das condições de contorno às quais o corpo de prova está submetido. Observa-se que na parte inferior e lateral esquerda foram considerados apoios do primeiro gênero, impedindo os deslocamentos verticais e horizontais, respectivamente. $\mathrm{Na}$ lateral direita foi aplicada uma tensão $\sigma_{3}=\sigma_{c}$, equivalente à tensão confinante. Já na superfície do modelo verifica-se uma tensão axial $\sigma_{1}=\sigma_{3}+\Delta \sigma$ que é corresponde à tensão confinante mais o acréscimo, tensão desviadora.

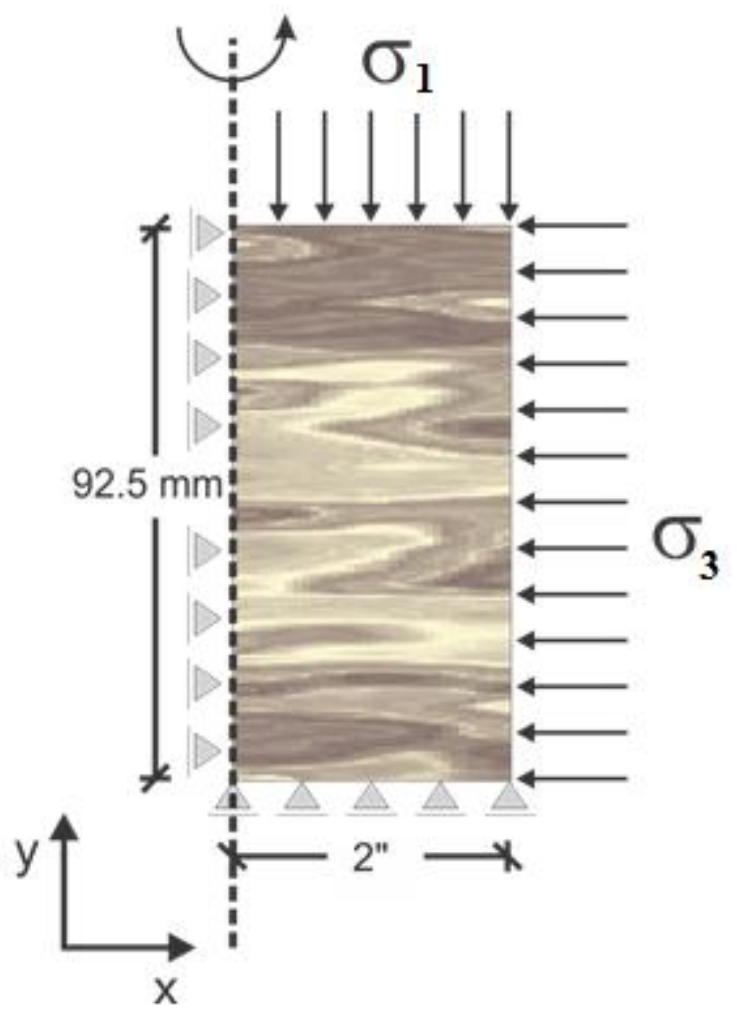

Figura 7.3: Condições de contorno do ensaio de fluência.

\subsubsection{MALHA DO MODELO}

A malha utilizada na simulação foi gerada com 1150 elementos do tipo CAX4, onde C é referente ao meio contínuo em análises de tensão/deslocamento, $\mathrm{AX}$ se refere ao tipo axissimétrico e 4 ao número de nós de cada elemento. 


\subsubsection{RESULTADOS E DISCUSSÕES}

Costa et al. (2005) apresentaram resultados de simulações com base em ensaios de fluência em um corpo de prova de halita. As simulações foram feitas com base na lei constitutiva de duplo mecanismo de deformação, apresentada no Item 6.2.4. Por se tratar de uma lei para fluência secundária, a taxa de deformação é constante ao longo do tempo, quando temperatura e tensão desviadora não variam. Este fato pode gerar erros maiores que admissíveis e levar a valores bem distantes da realidade. Na simulação de Costa et al. (2005), por exemplo, resultaram erros de até $20 \%$ quando comparadas com um ensaio de fluência. A Figura 7.4 mostra a comparação da simulação realizada (em azul) e o ensaio axial de fluência (em verde) realizado pelo autor acima referenciado.

Utilizando os mesmos parâmetros de Costa et al. (2005) para obtenção dos parâmetros de fluência do Abaqus ${ }^{\circledR}$ e simulando a fluência com base apenas no comportamento secundário, chegou-se a resultados muito semelhantes (rosa) aos dos referidos autores. Esta simulação foi uma exceção, pois só utilizou duas etapas de simulação: uma para a resposta elástica e a outra para a fluência secundaria, esta última utilizando apenas os parâmetros do Item 7.2.2.

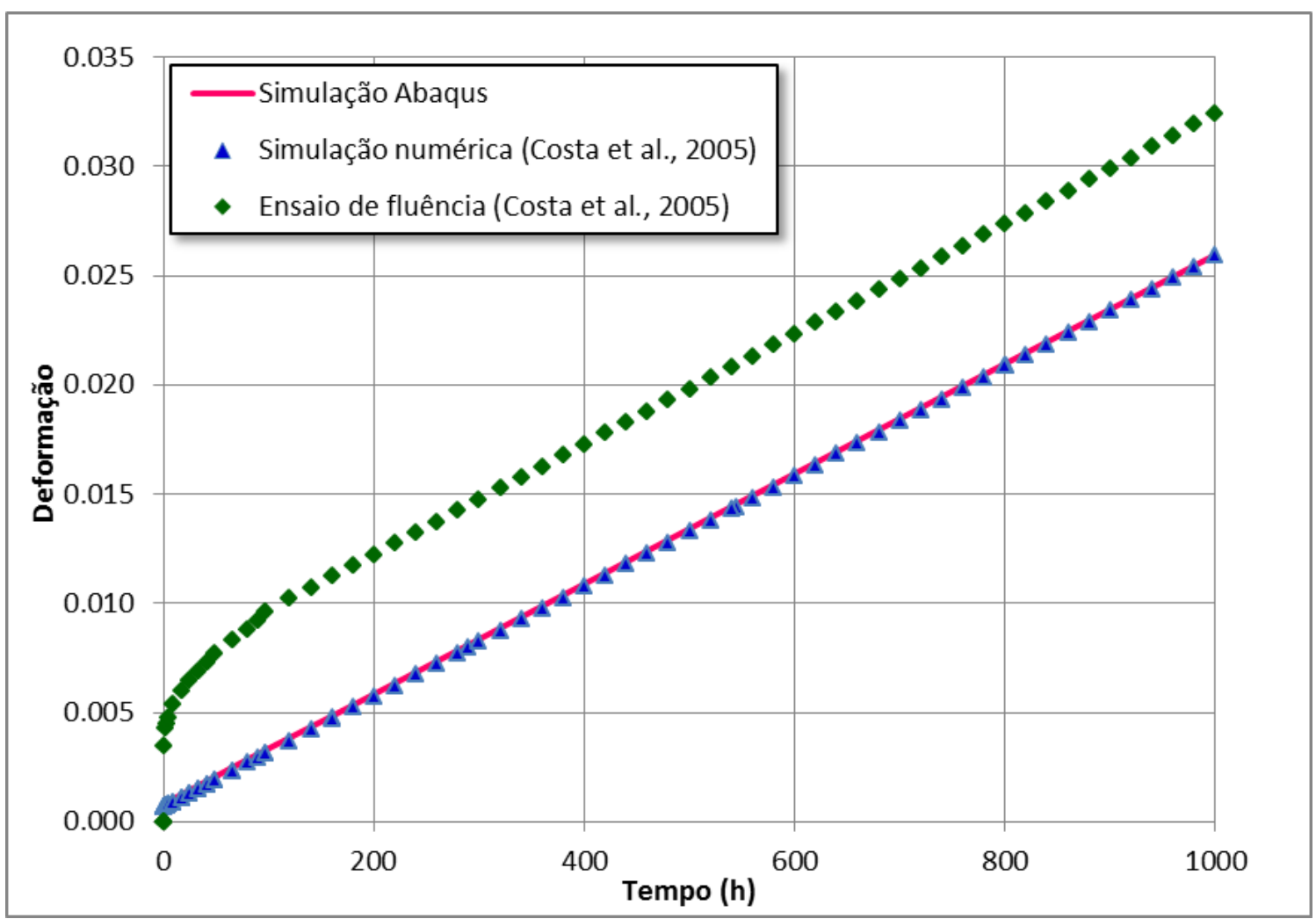

Figura 7.4:Comparação dos resultados da simulação numérica e ensaio de fluência de Costa et al. (2005) com os resultados da simulação pelo Abaqus®. 
Como se vê na Figura 7.4, tanto a deformação elástica, quanto a deformação de fluência apresentaram valores bem próximos, quando se comparam a simulação numérica feita por Costa et al. (2005) (em azul) e simulação do Abaqus ${ }^{\circledR}$ (em rosa). Este fato valida a utilização do Abaqus ${ }^{\circledR}$ para a simulação de fluência em maciços de evaporitos.

Os próximos resultados foram obtidos a partir de simulação em que foram consideradas as três etapas: elástica, fluência primária e fluência secundária. Os procedimentos e características da simulação obedeceram rigorosamente ao descrito no início deste capítulo.

A Figura 7.5 mostra o resultado da simulação numérica com os parâmetros de Starfield e Mcclain (1973), Hansen e Mellegard (1980), Costa (1984) para fluência primária e os parâmetros de Costa et al. (2005) para fluência secundária. Os mesmos são comparados com o resultado obtido no ensaio de Costa et al. (2005).

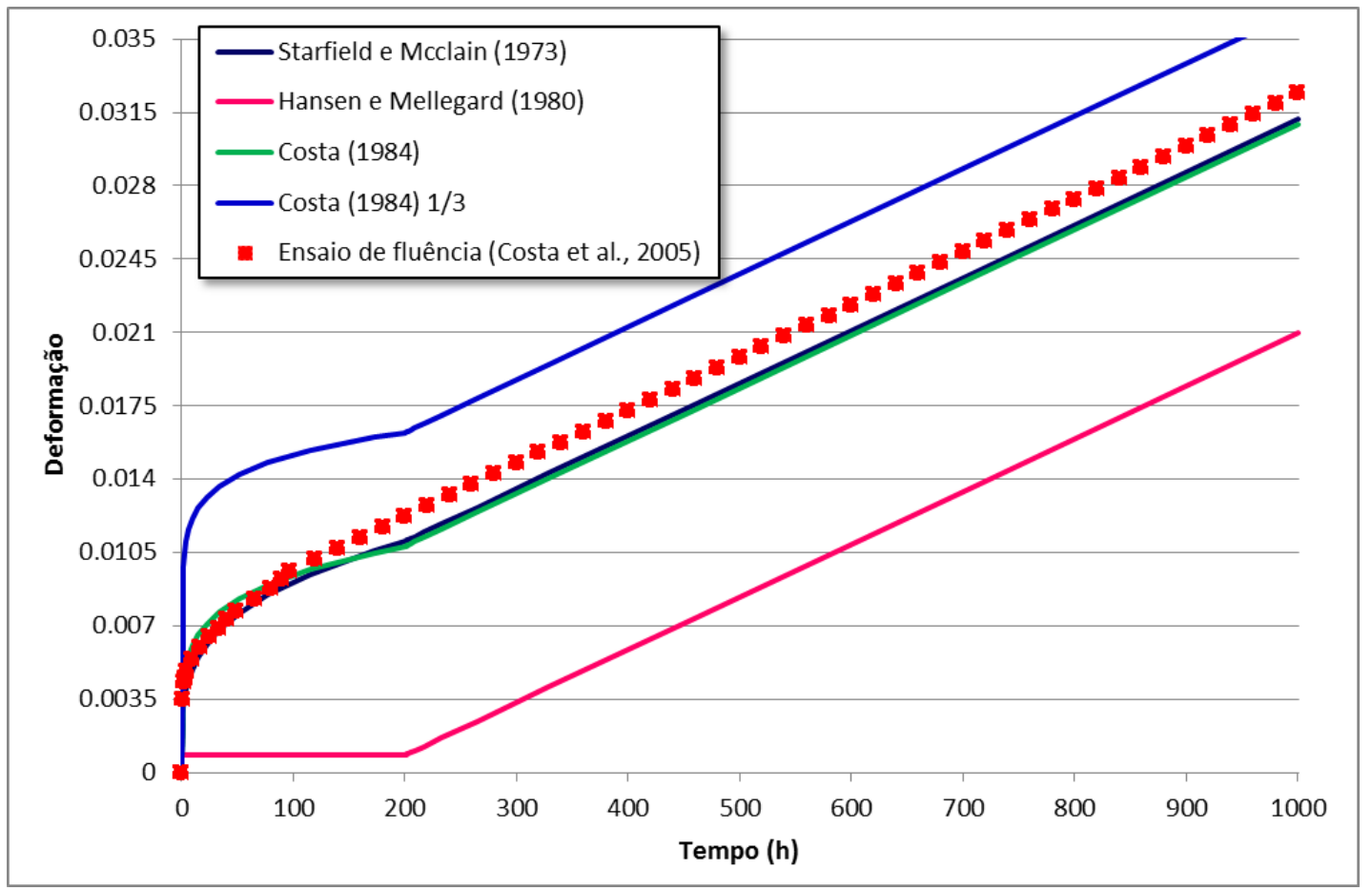

Figura 7.5: Resultados da simulação numérica com os parâmetros de Starfield e Mcclain (1973), Hansen e Mellegard (1980), e Costa (1984) em comparação com os resultados de Costa et al. (2005).

Na legenda da Figura 7.5 a utilização de 1/3 após Costa (1984) está associada à consideração de que 1/3 das deformações iniciais são elásticas, ver Tabela 7.4, e a curva laranja está associada à deformação axial do ensaio de fluência de Costa et al. (2005). Nota-se que o erro de Starfield e Mcclain (1973) e Costa (1984), quando comparado ao resultado deformação axial, é praticamente nulo. Já o erro de Costa (1984) 1/3 foi de 0,3\% e Hansen e 
Mellegard (1980) foi de 1,2\%, em comparação com os resultados do ensaio. Vale ressaltar que em todas as simulações os parâmetros de fluência secundária foram os de Costa et al. (2005), apresentados no Item 7.2.2

Como se observa na Figura 7.5, a transição entre as deformações da fluência primária e secundária não foram contínuas. Isto levou ao surgimento de uma equação para o tempo em função da taxa de deformação, que será apresentada no Item 7.4.

\subsection{EQUAÇÃO PARA OBTENÇÃO DO TEMPO DE INÍCIO DA FLUÊNCIA SECUNDÁRIA}

Muitos autores como Gravina (1997) e Cella (2003), têm mostrado que a fluência primária se manifesta nos primeiros dias e muitas vezes nas primeiras horas. $\mathrm{Na}$ realidade pouco se sabe sobre quando termina a fluência primária e se inicia a fluência secundária, o que se tem comprovado é que esta transição tem relação com o nível de tensão desviadora, temperatura e as propriedades geológicas da rocha evaporítica. Com base nestas incertezas e de posse das Equações (6.1) e (7.2), propõe-se a Equação (7.9).

A Equação (7.9) é uma relação entre tempo e tensão desviadora, obtida quando se iguala a taxa de deformação da Equação (6.1) com a taxa de deformação da Equação (7.2). A ideia de igualar as duas equações parte do principio de que no fim da fluência primária, início da fluência secundária, as taxas de deformação são iguais para os dois estágios.

$$
t^{m_{1}}=\frac{A_{2} \cdot \sigma^{n_{2}-n_{1}}}{A_{1}} \Rightarrow t=\left(\frac{A_{2} \cdot \sigma^{n_{2}-n_{1}}}{A_{1}}\right)^{-m_{1}},
$$

Onde $A_{l}, n_{1}, m_{1}$ são parâmetros da equação de fluência primária, Equação (7.2), e $A_{2}$, e $n_{2}$ são parâmetros de fluência secundária, Equação (6.1).

Aplicando-se os parâmetros de fluência do Item 7.2.1, parâmetros de Starfield e Mcclain (1973), e 7.2.2, Costa et al. (2005), na Equação (7.9), chega-se à curva tempo x tensão desviadora. A Figura 7.6. mostra a curva, tempo x tensão desviadora, para obtenção do início da fluência secundária ou término da fluência primária. 


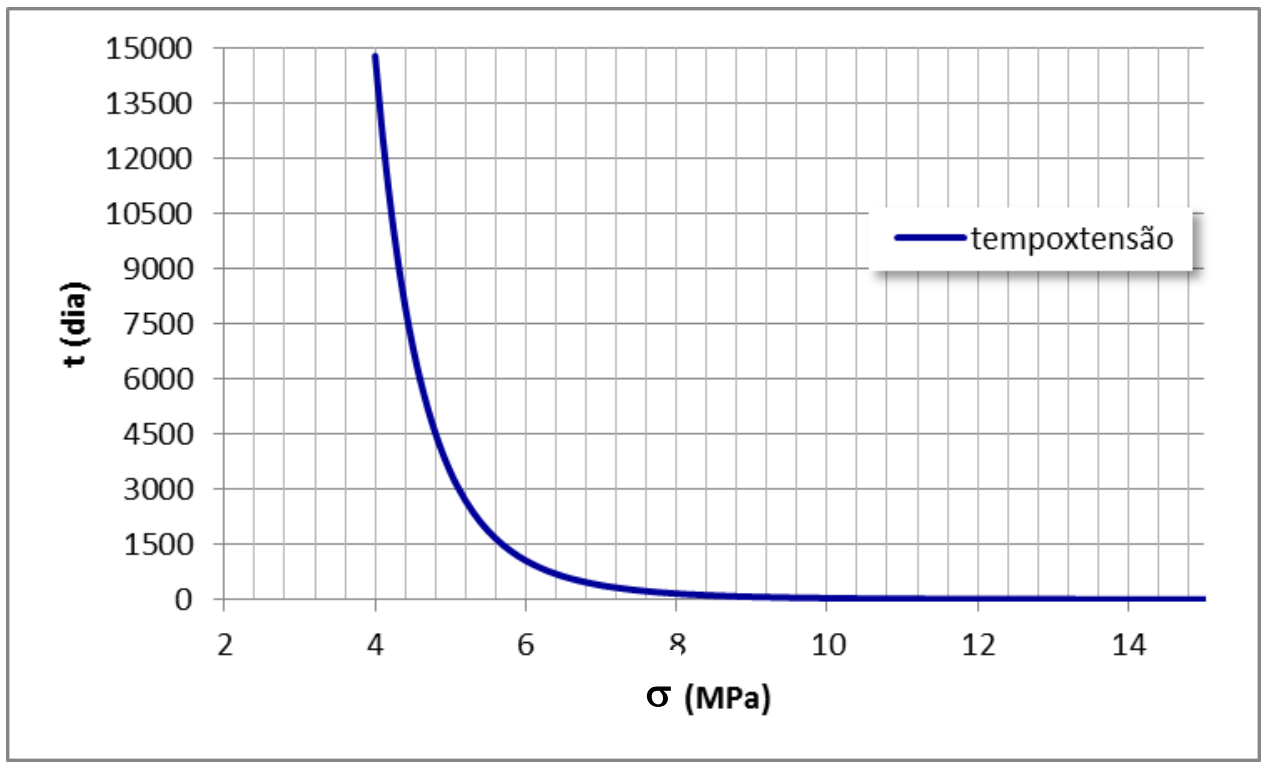

Figura 7.6:Curva tempo x tensão para obtenção do tempo limite da fluência primária, início da fluência secundária.

A Figura 7.6 mostra que a partir de um determinado nível de tensão o tempo de início da fluência secundária tende a zero, ou seja, para níveis de tensão desviadora muito altos as deformações iniciais tendem a se confundir com as deformações elásticas instantâneas, o que de fato é comprovado nos ensaios de fluência em rochas evaporíticas. Costa (1984), por exemplo, considerou em alguns ensaios de fluência que 2/3 das deformações iniciais estavam relacionados à fluência primária, ou seja, apenas $1 / 3$ destas era devido à elasticidade instantânea.

Observa-se ainda na Figura 7.6 que, em níveis de tensões desviadora muito baixos o tempo de deformação tende ao infinito. A prática vem demonstrando que a níveis baixos de tensão a fluência primária se confunde com a fluência secundaria devido ao comportamento suave de deformação com o tempo. Nesta situação a lei constitutiva de fluência que traz melhores resultados é a de duplo mecanismo de deformação, Item 2.3.1. Caso não se disponha de dados para a obtenção do nível da tensão desviadora em que, abaixo dele, a fluência primária irá se confundir com a fluência secundária, fica proposta a tensão de referência $\sigma_{0}$ para a mesma. A tensão de referência, mostrada no Item 2.3.1, é o nível de tensão de transição entre o mecanismo de "dislocation glide" e o "mecanismo indefinido". Esta consideração vem trazendo bons resultados, explicada pelo fato de que a níveis de tensões baixas a taxa de deformação varia pouco. 


\subsection{SIMULAÇÃO DE FLUÊNCIA UTILIZANDO A EQUAÇÃO TEMPO X TAXA DE DEFORMAÇÃO}

O modelo utilizado na simulação de fluência a seguir foi o mesmo utilizado no Item 7.3, ou seja, um modelo de um corpo de prova de halita com diâmetro de 101,6 mm e altura de $185 \mathrm{~mm}$. Além disto, a malha e as condições de contorno são as mesmas. Neste caso foram simulados o comportamento da halita em diversos níveis de carregamento: $6,8,10,12$, 14, 16-17 MPa, tensões estas correspondentes aos acréscimos axiais de tensão em um modelo com $10 \mathrm{MPa}$ de tensão confinante. Os resultados foram comparados com ensaios de fluência realizados por Cella (2003) e as simulações levaram em consideração as três fases descritas neste capítulo: elástica, fluência primária e fluência secundária.

Em todas as simulações foi levado em consideração o tempo de início da fluência secundária, conforme descrito no Item 7.4. Apenas nos casos em que a tensão desviadora foi menor que a tensão de referência não se utilizou a Equação (7.9), como colocado no Item 7.4. Como a rocha é halita e os parâmetros de fluência secundária são obtidos a partir de Costa et al. (2005), o valor para a tensão de referência é $\sigma_{0}=9,91 \mathrm{MPa}$ (Item 6.2.4).

Como propriedades para a halita tem-se, além dos parâmetros elásticos e de fluência primária, a necessidade de calibração dos parâmetros de fluência secundária para as tensões maiores e menores que a tensão de referência. Desta forma, tem-se:

- Parâmetros Elásticos

Os parâmetros elásticos para a halita utilizados na simulação são os mesmos apresentados na Tabela 7.1, ou seja:

$$
\begin{aligned}
& E=20,4 \mathrm{GPa}, \\
& v=0,36
\end{aligned}
$$

- Parâmetros de Fluência Primária

Os parâmetros de fluência primária escolhidos foram de Starfield e Mcclain (1973) devido à boa aproximação apresentada no Item 7.3, ou seja:

$$
A=2,23 \mathrm{E}-07 \text {; }
$$


$n=3,0$;

$m=-0,7$.

Observação: ajustados para valores de tensão em MPa e tempo em horas.

- Parâmetros de Fluência Secundária

Os parâmetros de fluência secundária para a equação do Abaqus® foram obtidos a partir das Equações (7.6), (7.7) e (7.8) com base nos parâmetros de Costa et al. (2005), mostrados no Item 2.3.1. A Tabela 7.6 mostra os resultados obtidos para fluência secundária para tensões diferenciais $\sigma_{e f}$ maiores ou iguais à tensão de referência $\sigma_{0}$ e para tensões diferenciais $\sigma_{e f}$ menores que a tensão de referência $\sigma_{0}$. Os resultados são para valores de tensão em MPa e tempo em horas.

Tabela 7.6: Parâmetros de fluência secundária, Costa et al. (2005).

\begin{tabular}{|c|c|c|}
\cline { 2 - 3 } \multicolumn{1}{c|}{} & $\sigma_{e f} \geq \sigma_{0}$ & $\sigma_{e f}<\sigma_{0}$ \\
\hline $\boldsymbol{A}$ & $5,29856 \mathrm{E}-14$ & $8,21 \mathrm{E}-10$ \\
\hline $\boldsymbol{n}$ & 7,55 & 3,36 \\
\hline $\boldsymbol{m}$ & 0 & 0 \\
\hline
\end{tabular}

A Figura 7.7 apresenta a deformação ao longo do tempo para as tensões de 12, 14, 16 $17 \mathrm{MPa}$, onde pode ser observado que os resultados da simulação se apresentam de forma satisfatória, com erros relativos de $42 \%, 26 \%$ e $2 \%$ respectivamente.

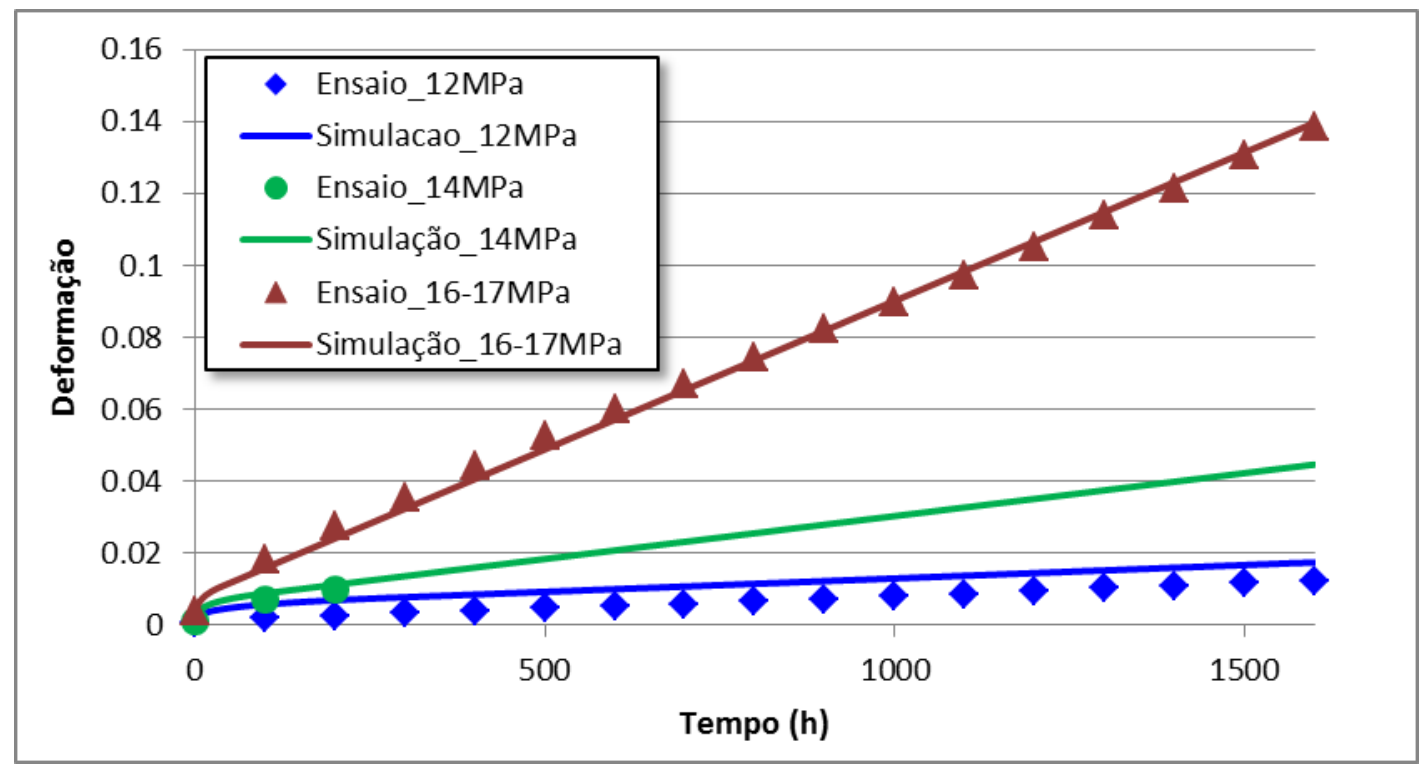

Figura 7.7:Deformações ao longo do tempo para as tensões de 12, 14, 16-17 MPa. 
O ensaio 16-17 MPa foi assim chamado, pois durante o ensaio houve uma variação nos nível de tensão. Desta forma, viu-se a necessidade de variar a tensão desviadora durante a simulação (Simulação 16-17 MPa).

No gráfico da Figura 7.7 ainda é possível observar os comportamentos primário e secundário de fluência, onde para uma tensão de $12 \mathrm{MPa}$ tem-se um tempo de início da fluência secundária de aproximadamente 280 h, seguindo de 103 h e 43 h para as tensões de 14 e $16 \mathrm{MPa}$, respectivamente. Esses valores para o tempo foram obtidos através da Equação (7.9), referenciada no Item 7.4.

Na Figura 7.8 tem-se a deformação ao longo do tempo para as tensões de 6, 8 e 10 $\mathrm{MPa}$. Os resultados das simulações para as tensões de 6 e $8 \mathrm{MPa}$ apresentaram uma pequena variação; isto se deve aos baixos níveis de deformação inicial e à etapa de pré-carregamento do corpo de prova. Nesta etapa, as deformações a níveis baixos de tensão praticamente não são mensurados pelo equipamento, sendo, portanto, um erro aceitável. Já na simulação esses erros não são computados, em virtude, de a simulação trabalhar com um caso ideal. Com relação aos erros relativos estes se apresentaram $23,7 \%, 5,7 \%$ e $0,5 \%$ para as tensões de 6,8 e $10 \mathrm{MPa}$, respectivamente.

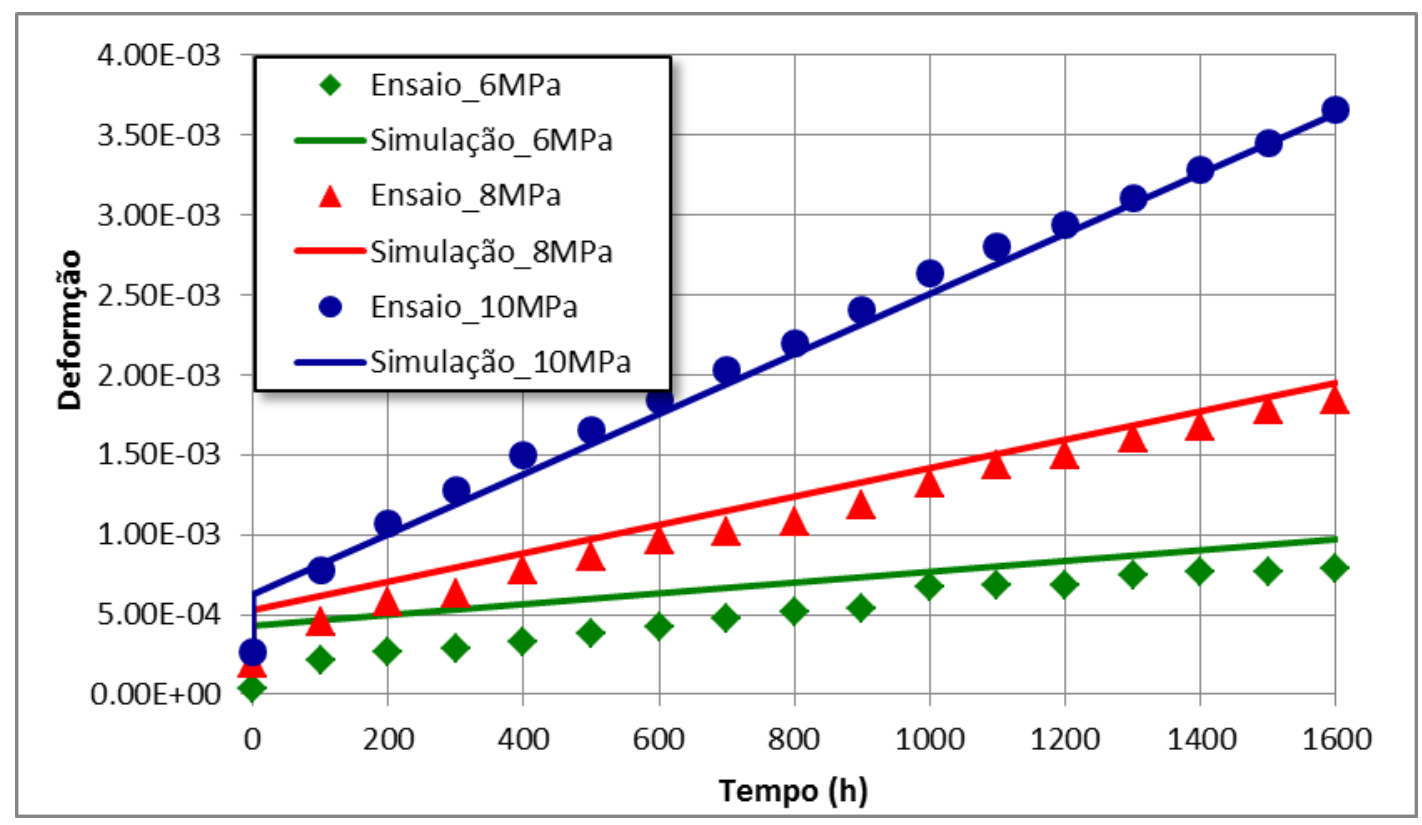

Figura 7.8: Deformações ao longo do tempo para as tensões de 6, 8 e $10 \mathrm{MPa}$.

Segundo Costa (1984), o fato de não se ter resultados precisos pode ser explicado pela geometria do corpo de prova (índice de esbeltez), efeito da pré-compressão hidrostática, 
litologia (identificação nem sempre determinística), entre outros. Estes são fatores que podem influenciar nos resultados ou no comportamento dos corpos de prova.

Mesmo não sendo possível identificar o inicio da fluência secundária observa-se que a relação apresentada no Item 7.4 pode trazer bons resultados. Por não se conhecer uma relação que indique a mudança de comportamento, a mesma pode ser utilizada e a depender dos parâmetros usados, levar a resultados bem mais confiáveis.

\subsection{SIMULAÇÃO DE UMA GALERIA ESCAVADA EM MACIÇO EVAPORÍTICO}

A escavação de galerias em maciços de evaporitos sempre traz uma série de preocupações. No Brasil, a mina Taquari-Vassouras, no nordeste brasileiro, é um destes exemplos. A atividade exploratória da mina, assim como em todas, sempre preocupa devido à possível instabilidade provocada. Numa mina em evaporitos, além da preocupação gerada durante a escavação e a exploração, as deformações muitas vezes não cessam devido ao comportamento de fluência, típico destas rochas.

As deformações provocadas pela característica viscoelástica deste tipo de rocha sedimentar pode levar o fechamento, colapso e até mesmo a perda total de uma galeria. $\mathrm{O}$ mesmo fato é observado em túneis, poços ou em qualquer outro tipo de seção escavada nestes tipos de rochas. Em geral, as deformações são reversíveis quando a fluência está em seu estágio primário ou desacelerado. Nos estágios secundário e terciário, o mesmo não acontece, ou seja, as deformações são irreversíveis mesmo quando o estado de tensão retorna à sua configuração inicial.

A configuração triaxial de tensão torna os modelos analíticos complicados e muitas vezes inviáveis na obtenção do estado de fluência em uma galeria. Por outro lado, os modelos numéricos vêm tornado a simulação deste problema cada vez mais simples. O fato vem sendo observado com o surgimento de diferentes programas de elementos finitos e com os diversos recursos, que os mesmos oferecem para simular os mais diferentes problemas de engenharia.

Costa (1984), utilizando recursos da época, simulou algumas galerias escavadas em maciços de evaporitos. As simulações daquele autor tomou como base a equação empírica potencial (Equação (6.5)) e levou em conta as caracteristicas geologicas na região da mina Taquari-Vassoura. Como o estudo partiu de varias hipóteses e considerações, os resultados podem não ser satisfatórios quando comparados com os resultados obtidos com a metodologia 
de simulação empregada neste capítulo. Além disto, apenas a fluência primária foi simulada pelo autor, diferente do presente trabalho que simula a fluência em seu estágio primário e secundário.

\subsubsection{SEÇÃO ANALISADA}

Como Costa (1984) apresentou diferentes geometrias nas análises realizadas, opta-se em simular uma seção do tipo retangular de 7,2 x 2,7 m. Vale ressaltar que a seção escolhida pode não existir de fato, mas as dimensões e a seção transversal correspodem no mínimo a uma aproximação da realidade.

A seção é escolhida a partir de um conjunto de galerias subterrâneas projetadas para a mina Taquari-Vassoras, Costa (1984). A Figura 7.9 mostra a galeria subterrânea (a) e a seção transversa (b) considerada.

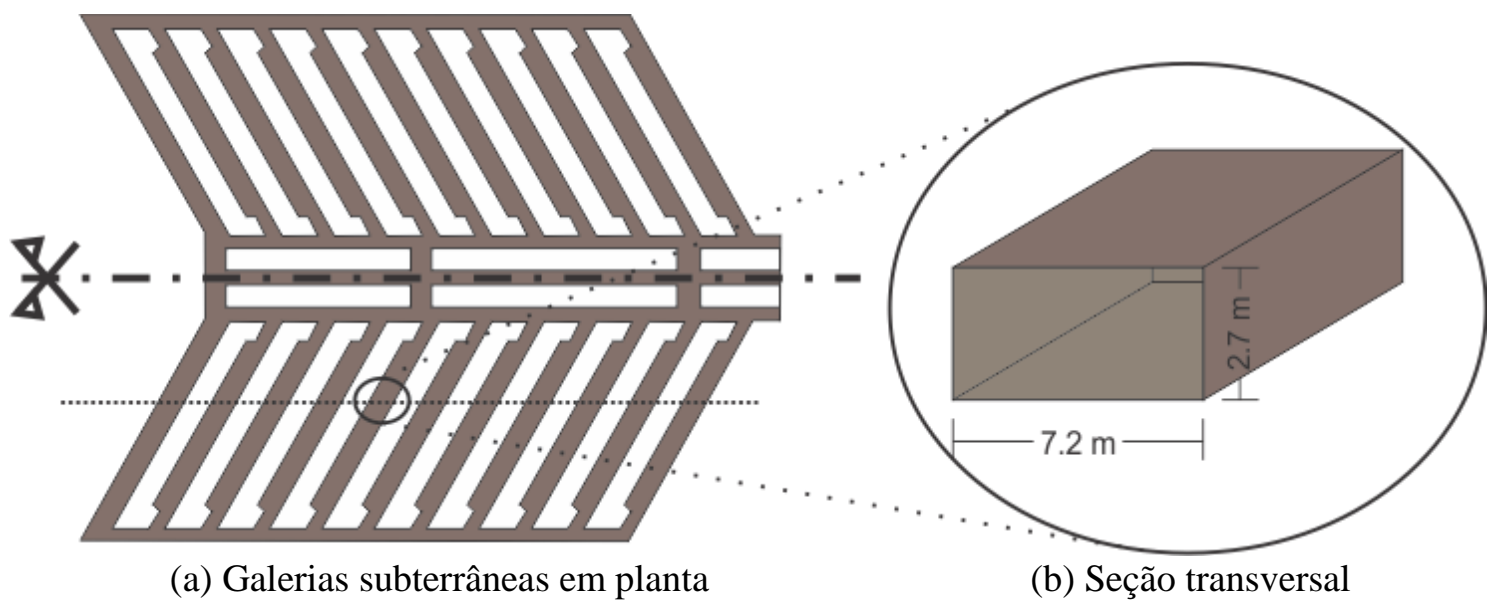

Figura 7.9: Galeria subterrânea da mina Taquari-Vassoura.

Observa-se na Figura 7.9 a simetria em relação ao eixo longitudinal do conjunto de galerias, Costa (1984).

\subsubsection{MODELO SIMULADO}

$\mathrm{Na}$ simulação, procura-se analisar o comportamento de fluência de um maciço de evaporito com a variação das tensões diferenciais na galeria. Para simular esta variação, a tensão vertical, Equação (7.10), sofre variações com o aumento da profundidade $h$. 


$$
\sigma=h \cdot \gamma
$$

onde $h$ é a profundidade da galeria e $\gamma$ é o peso especifico do maciço evaporítico.

Neste estudo são simulados 10 casos diferentes de estado de tensão, ou seja, 10 profundidades diferentes para a galeria. Inicialmente é simulada uma galeria a $100 \mathrm{~m}$ de profundidade, no segundo caso a galeria a $200 \mathrm{~m}$ até o último caso com profundidade de 1000 m. Em cada nova simulação a profundidade é aumentada em $100 \mathrm{~m}$, totalizando 10 simulações quando a profundidade atinge $1000 \mathrm{~m}$.

O modelo simulado corresponde a um quarto da seção apresentada no Item 7.6.1, isto devido à simetria observada. A Figura 7.10 apresenta o modelo utilizado na simulação; observa-se em (a) a seção da galeria e em (b) o modelo com 1/4 de simetria. Foram desprezados possíveis efeitos de ação de uma galeria sobre a outra, ou seja, que os pilares são de grande dimensão. É uma aproximação.

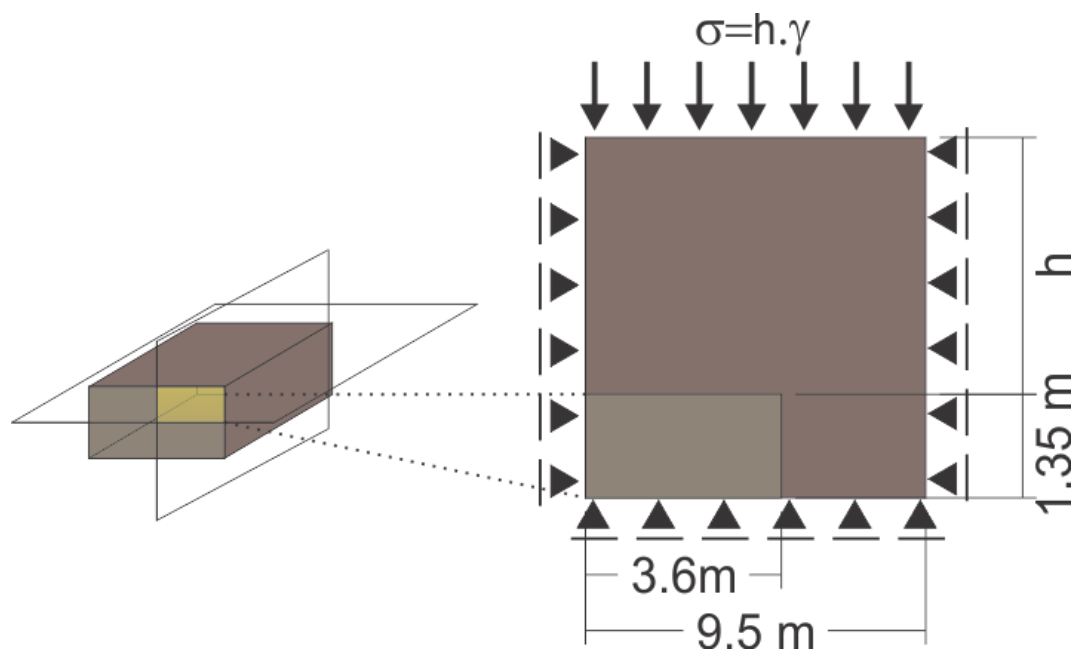

(a) Seção da galeria

(b) Modelo $1 / 4$ de simetria

Figura 7.10: Seção da galeria para a simulação.

Todas as simulações utilizaram 4 etapas: Geostática, Elástica, Fluência Primaria e Fluência Secundária; maiores detalhes podem ser vistos no Item 7.2. Os procedimentos descritos no Item 7.2 são os mesmos utilizados neste Item, ou seja, as etapas e considerações são as mesmas. 


\subsubsection{MALHA DO MODELO}

O modelo simulado considera deformação plana, caso ideal em duas dimensões. Desta forma, utiliza-se em todas as simulações uma malha gerada com 5600 elementos bidimensionais, estruturados quadráticos. São utilizados elementos infinitos do tipo CPE4, elementos contínuos, plano de deformação com 4 nós. A Figura 7.11 mostra a malha utilizada e o eixo de referência adotado em todas as simulações.

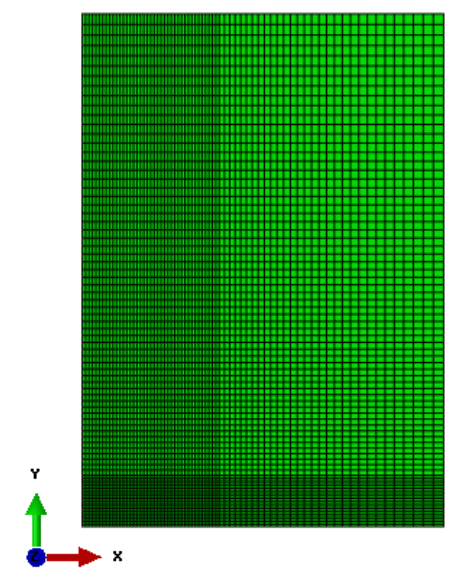

Figura 7.11: Malha do modelo, galeria.

\subsubsection{PROPRIEDADES DO MODELO}

Como hipótese simplificadora, é considerado que o material é homogêneo, ou seja, as propriedades elásticas utilizadas são as mesmas em todo modelo. Por se considerar um maciço de halita, as propriedades elásticas e de fluência são as mesmas apresentadas no Item 7.5. O peso especifico $\gamma$ utilizado para o cálculo das tensões é de $21 \mathrm{kN} / \mathrm{m}^{3}$, Poiate et al. (2006).

\subsubsection{AUTOMATIZAÇÃO DAS SIMULAÇÕES}

Nas simulações dos 10 casos propostos, observa-se a necessidade da alteração dos parâmetros antes e durante as simulações, Item 7.2. Devido ao fato de estes parâmetros estarem atrelados às tensões aplicadas, há a necessidade de modificá-los para dois casos: tensões desviadoras menores que a tensão de referência $\left(\sigma_{e f}<\sigma_{0}\right)$ e tensões desviadoras 
maiores ou iguais à tensão de referência $\left(\sigma_{e f} \geq \sigma_{0}\right)$. Além disto, o tempo para início da fluência secundária deve ser incorporado à simulação, conforme Equação (7.9).

Visando a automatizar todo o processo, utiliza-se o programa computacional Isight@. O Isight ${ }^{\circledR}$ é um programa que permite agrupar diversos programas, otimizar resultados, incorporar parâmetros novos, fazer múltiplas análises (“Loop”), entre outas possibilidades. Esta alternativa possibilita simular todas as situações e incorporar a elas a tensão vertical, o tempo de início da fluência secundária e os parâmetros de fluência do estágio primário e secundário.

A Figura 7.12 mostra o fluxo do programa utilizado para adição de parâmetros, simulação e obtenção de resultados.

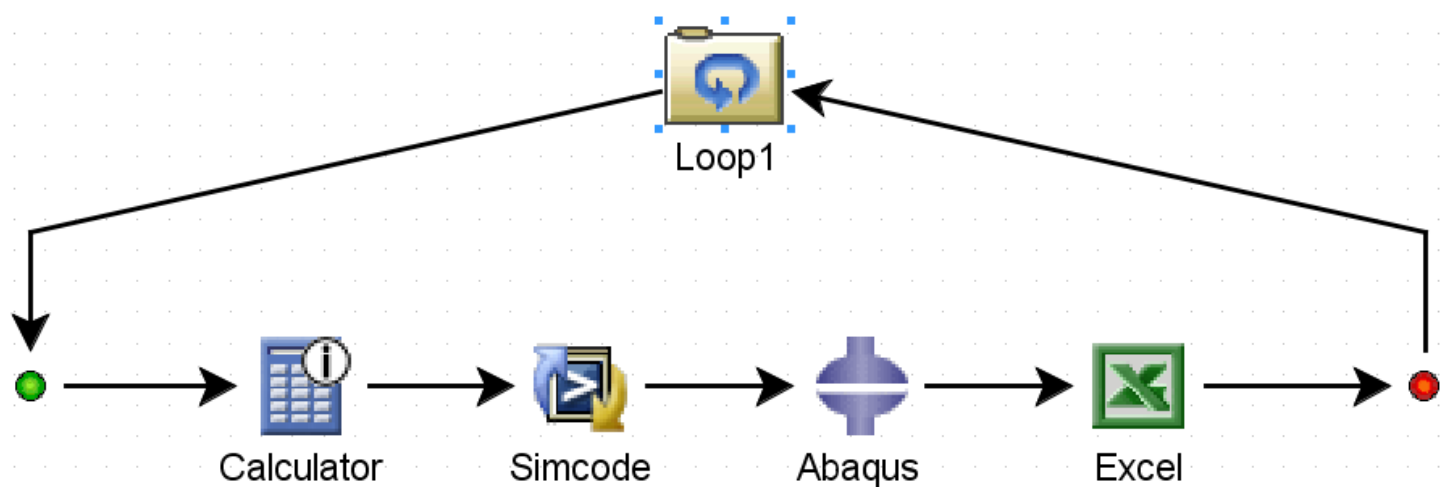

Figura 7.12: Automatização do processo.

Incialmente a profundidade $h$ é atualizada no "Loop 1 " e em seguida os demais cálculos são realizados e os resultados desejados escritos em um arquivo Excel@, quando termina uma etapa (“loop”). A seguir, todo processo é descrito detalhadamente:

\section{LOOP1}

Atualização da profundidade em cada nova etapa ("loop"), a mesma aumentando em incrementos de $100 \mathrm{~m}$. Como a profundidade inicial é de $100 \mathrm{~m}$ e o número de incremento é 10, a máxima profundidade é de $1000 \mathrm{~m}$.

\section{CALCULATOR}

Cálculo dos parâmetros a serem utilizados na nova simulação. Inicialmente a tensão vertical $\sigma$ é calculada com base na nova profundidade $h$ e no peso especifico $\gamma$. Em seguida 
os coeficientes da equação do Abaqus®, Equação (6.1), são obtidos a partir desta tensão conforme a condição:

- Para $\sigma_{e f}<\sigma_{0}$

$$
\begin{aligned}
& A_{l}=8,2065 \mathrm{E}-10 ; \\
& n_{1}=3,36 ; \\
& m_{l}=0 ; \\
& \mathrm{e} \\
& A_{2}=8,21 \mathrm{E}-10 ; \\
& n_{2}=3,36 ; \\
& m_{2}=0 . \\
& \quad \bullet \quad P a r a \sigma_{e f} \geq \sigma_{0} \\
& A_{l}=2.23 \mathrm{E}-07 ; \\
& n_{l}=3 ; \\
& m_{1}=-0,7 ; \\
& \mathrm{e} \\
& A_{2}=5,29856 \mathrm{E}-14 ; \\
& n_{2}=7,55 ; \\
& m_{2}=0 .
\end{aligned}
$$

Onde $A_{1}, n_{1}, m_{1}$ são parâmetros do estágio de fluência primária e $A_{2}, n_{2}, m_{2}$ são parâmetros do estágio de fluência secundária.

Além da tensão vertical e dos coeficientes da equação do Abaqus®, o tempo para início da fluência secundária $t_{1}$ também é obtido a partir da Equação (7.9). Para os casos em que as tensões verticais são menores que a tensão de referência $\left(\sigma_{e f}<\sigma_{0}\right)$, o mesmo não é calculado, conforme descrito no Item 7.3. Neste caso apenas é considerado o comportamento secundário, visto, que o comportamento primário é praticamente imperceptível. 
Em todas as simulações o tempo total considerado é de 3 anos, ou seja, $t_{\text {total }}=26280$ horas. Desta forma o tempo para o estágio secundário $t_{2}$ é obtido pela subtração $t_{2}=t_{\text {total }}-t_{1}$.

\section{SIMCODE}

Com os tempos $t_{1}$ e $t_{2}$ calculados é necessário escrevê-los no arquivo de entrada do Abaqus ${ }^{\circledR}$ (“input”), arquivo que contém todas as informações acerca da simulação. A maneira encontrada para sanar tal problema é de reescrever este arquivo a partir de um comando (“Script”) com o SIMCODE, visto que, a ferramenta existente no Isight ${ }^{\circledR}$ do Abaqus ${ }^{\circledR}$ não permite a leitura do tempo das etapas simuladas.

\section{ABAQUS®}

Com o novo arquivo de entrada, modificam-se os parâmetros da equação de fluência do Abaqus®. Além dos parâmetros, a tensão vertical também é atualizada no arquivo de entrada. Nesta etapa também são selecionadas as variáveis de saída.

\section{EXCEL}

Com as variáveis de saída é possível escrevê-las em uma planilha do Excel®. Para tanto, utiliza-se a ferramenta Excel do Isight@ para leitura e gravação dos parâmetros de saída: deslocamentos verticais e horizontais nos pontos centrais da borda superior e lateral do perímetro interno de escavação, respectivamente.

\subsubsection{RESULTADOS E DISCUSSÕES}

A fluência em maciços de evaporitos pode-se tornar um problema irreversível, visto que, as deformações não são recuperáveis. Este comportamento viscoelástico tende a se agravar quando as tensões diferenciais, temperatura e o tempo aumentam. Muitos destes problemas podem ser observados a curto, a médio ou a longo prazos, a depender da rocha evaporítica e das variáveis dependentes deste comportamento.

A seguir são mostrados os resultados obtidos com as simulações, descritas neste item, para as profundidades $h$ 100, 200, 400, 500, 600, 700, 800, 900 e $1000 \mathrm{~m}$. Os valores adotados para as profundidades permitem obter tensões diferenciais da ordem de 2,1 a 21 $\mathrm{MPa}$, tensões que a curto e a médio prazo podem gerar deformações irreversíveis em maciços de halita. Alguns autores, como Starfield e Mcclain (1973), Costa (1984) e Cella (2003), 
estudaram o comportamento de fluência em halitas, neste intervalo de tensão, para ajustar parâmetros de alguns modelos constitutivos de fluência. Por se utilizar estes parâmetros e pelo fato de não se ter maiores conhecimentos sobre a fluência em longo prazo, optou-se por este intervalo.

Os resultados apresentados da Figura 7.13 à Figura 7.16 mostram os deslocamentos horizontais e verticais máximos obtidos no perímetro de escavação. Os pontos para obtenção estão localizados nos pontos centrais da borda lateral e superior, respectivamente, no perímetro escavado. Para melhor entendimento é possível visualizar estes pontos, de maiores deslocamentos horizontal e vertical, da Figura 7.20(c) à Figura 7.29(c).

A Figura 7.13 mostra os deslocamentos horizontais para a profundidade $h$ de 100, 200, 300 e $400 \mathrm{~m}$.

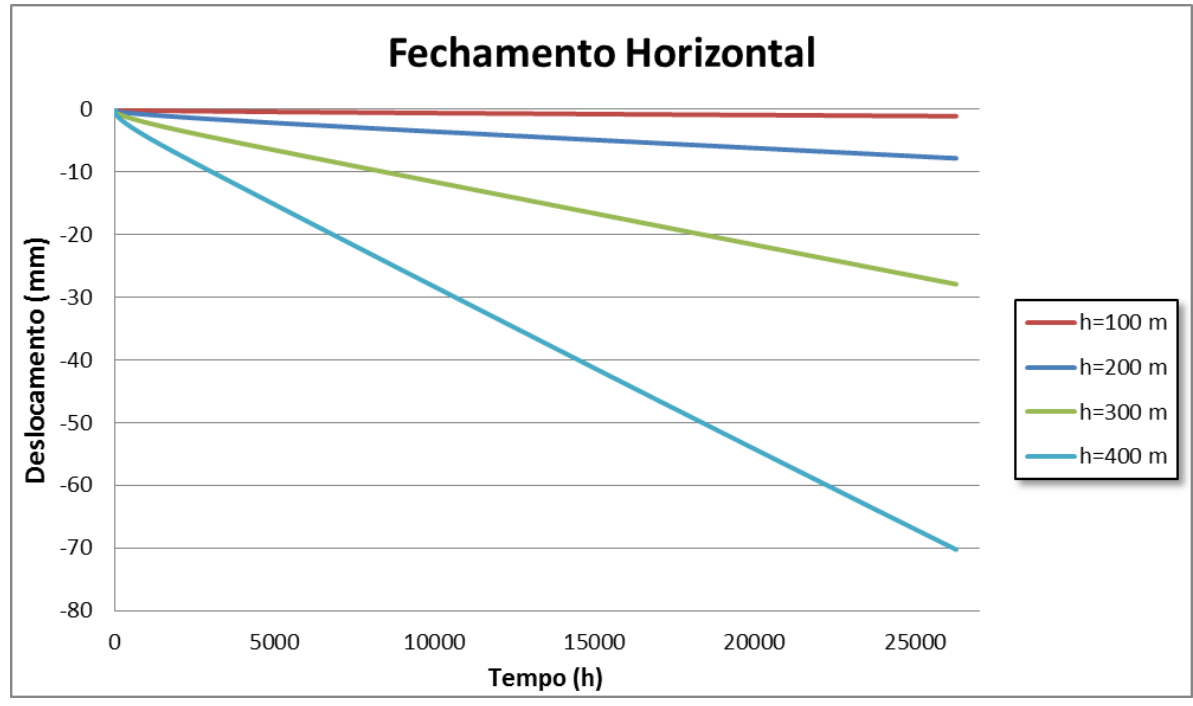

Figura 7.13: Deslocamentos horizontais ao longo do tempo para $h=100,200,300$ e $400 \mathrm{~m}$.

Observa-se na Figura 7.13 que os deslocamentos horizontais, obtidos para as profundidades de 100, 200, 300 e 400 m, têm um comportamento praticamente linear com o tempo. Isto se deve à consideração feita para as tensões desviadoras menores que a tensão de referência $\left(\sigma_{e f}<\sigma_{0}\right)$, ou seja, para quando as tensões desviadoras são menores que 9,91 MPa. Como visto no Item 7.3, a lei de duplo mecanismo de deformação é a que melhor se ajusta ao comportamento e nesta situação o melhor é utilizar apenas esta lei.

A Figura 7.14 mostra os deslocamentos horizontais para a profundidade $h$ de 500,600, $700,800,1000 \mathrm{~m}$. 


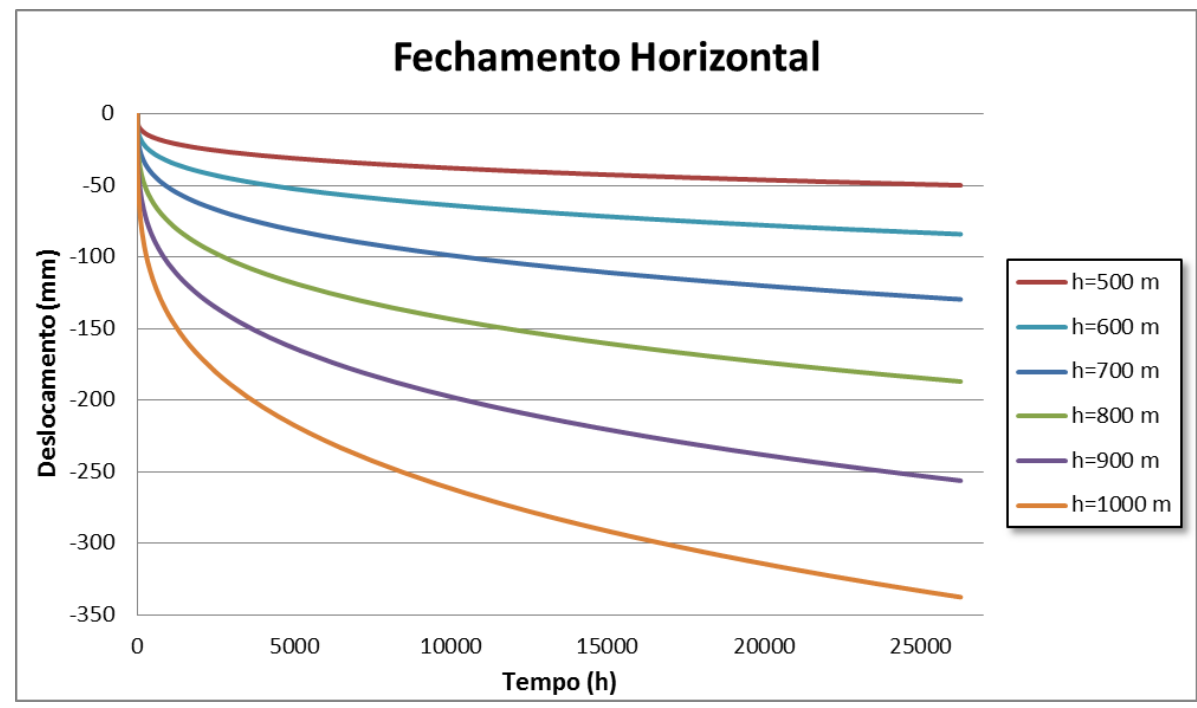

Figura 7.14: Deslocamentos horizontais ao longo do tempo para $h=500,600,700,800,900$ e $1000 \mathrm{~m}$.

Observa-se na Figura 7.14 que os deslocamentos horizontais, obtidos para as profundidades de 500, 600, 700, 800, 900 e 1000 m, têm um comportamento não linear ao longo do tempo. Nestas situações as tensões desviadoras foram maiores que a tensão de referência, ou seja, o comportamento de fluência foi obtido em seu estágio primário e secundário, conforme Item 7.3. No gráfico da Figura 7.14 ainda é possível observar a variação, ocorrida para cada nível de tensão, da taxa de deformação de fluência secundária que tende a aumentar com o tempo. Além disto, a transição entre a fluência primária e secundária ocorreu de maneira suave devido à incorporação da Equação (7.9), equação do tempo de início da fluência secundária.

A Figura 7.15 mostra os deslocamentos verticais para a profundidade $h$ de 100, 200, 300 e $400 \mathrm{~m}$.

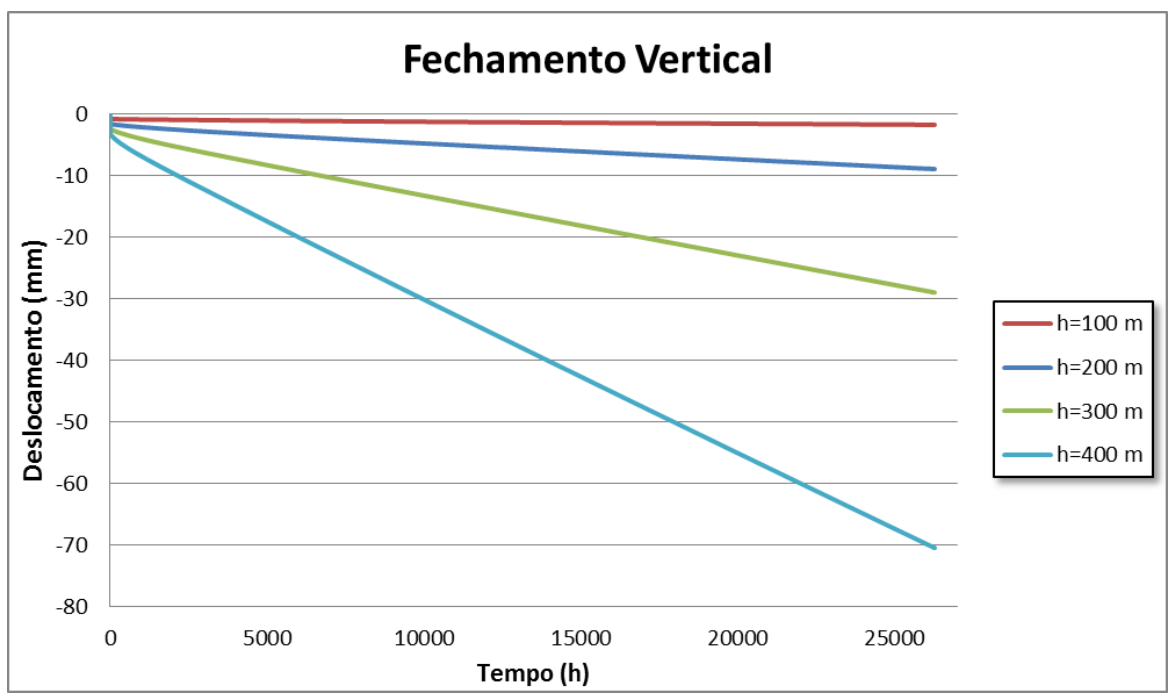

Figura 7.15: Deslocamentos verticais ao longo do tempo para $h=100,200,300$ e $400 \mathrm{~m}$. 
Observa-se na Figura 7.15 que os deslocamentos verticais, obtidos para as profundidades de 100,200, 300 e 400 m, têm um comportamento praticamente linear com o tempo e que a taxa aumenta com o a profundidade.

A Figura 7.16 mostra os deslocamentos verticais para profundidades $h$ de 500, 600, $700,800,1000 \mathrm{~m}$.

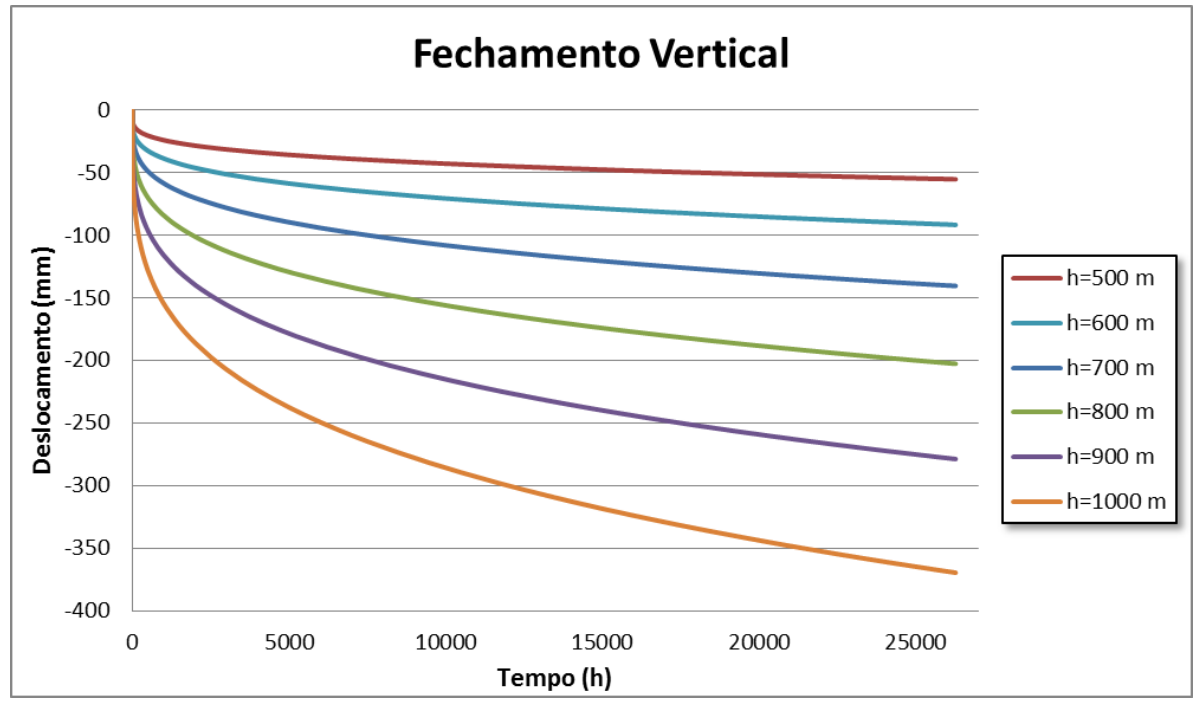

Figura 7.16: Deslocamentos vertical ao longo do tempo para $h=500,600,700,800,900$ e $1000 \mathrm{~m}$.

Observa-se na Figura 7.16 que os deslocamentos verticais, assim como os deslocamentos horizontais obtidos para as profundidades de 500, 600, 700, 800, 900 e 1000 m, apresentam o comportamento não linear ao longo do tempo.

Em todas as situações os deslocamentos máximos foram observados no fechamento vertical. A explicação se dá pela tensão vertical aplicada ao modelo que torna as deformações neste sentido maiores, ou seja, o fato de se considerar apenas tensões verticais leva a uma diminuição das deformações horizontais.

É importante observar que, em todas as situações, existe a possibilidade da perda da galeria devido ao seu fechamento provocado pela fluência do maciço. Desta forma, o ideal é fazer a instalação de um revestimento de sustentação.

Idealizando que o revestimento é suficientemente rígido para suportar o maciço e que os deslocamentos máximos admissíveis são de $22 \mathrm{~mm}$, optou-se em obter o tempo em todas as simulações onde o deslocamento máximo atinge $22 \mathrm{~mm}$. A ideia de extrair o tempo parte do princípio de se considerar um atraso entre a escavação e a colocação do revestimento. É verdade que este tempo é o tempo máximo que o maciço suporta até a colocação do 
revestimento. A Figura 7.17 mostra o tempo obtido em cada simulação para o deslocamento máximo de $22 \mathrm{~mm}$.

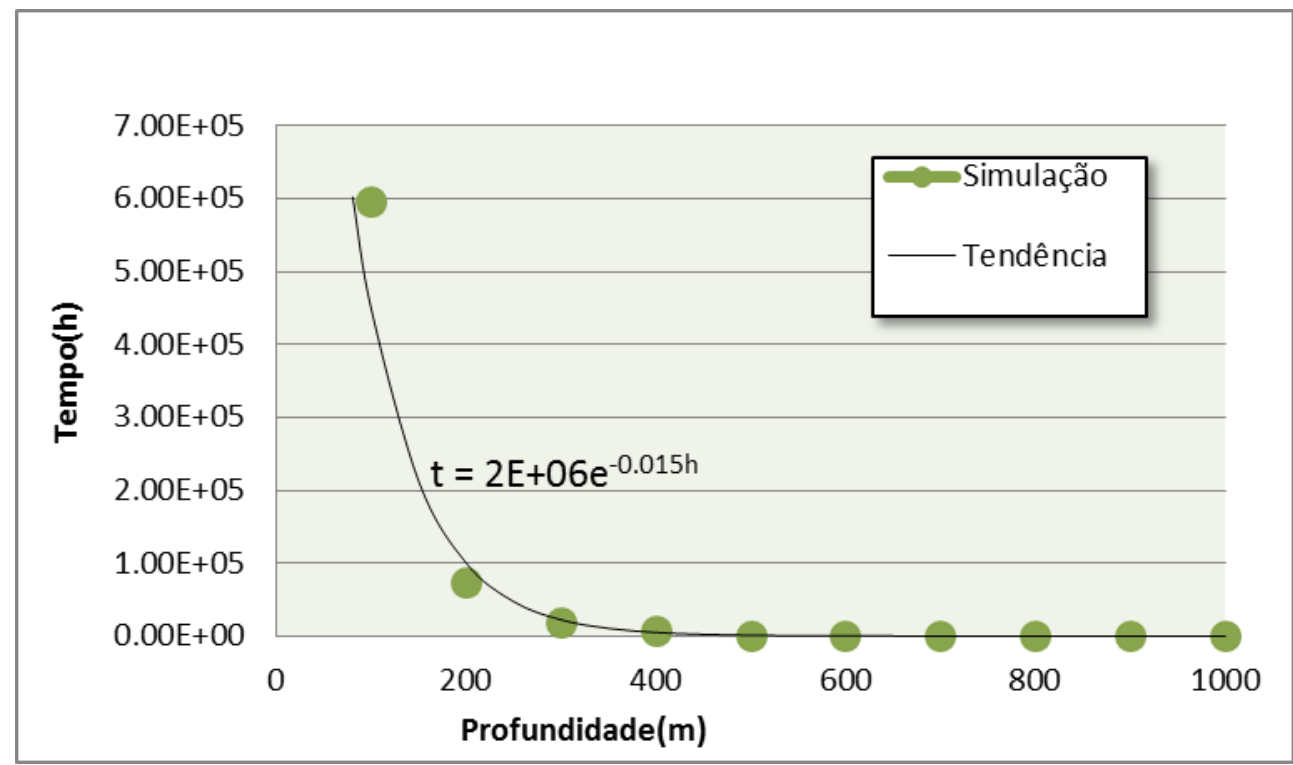

Figura 7.17: Tempo até que os deslocamentos máximos sejam obtidos.

Para as profundidades $h$ de 100 e 200 m o tempo foi obtido a partir de uma estimativa de tendência da curva de deslocamento no tempo. Em todas as situações, os deslocamentos máximos foram observados na vertical e estão mostrados em verde na Figura 7.17. O gráfico da Figura 7.17 tem uma tendência exponencial. A equação mostrada na Figura 7.17, tempo (h) x profundidade $(\mathrm{m})$, pode servir para estimar o tempo máximo para colocação do revestimento de sustentação sem que o deslocamento máximo seja atingido.

Tanto o deslocamento horizontal, quanto para o deslocamento vertical ao término dos 3 anos apresentaram valores maiores para profundidade $h$ de $400 \mathrm{~m}$ em comparação a $h$ de 500 m. A Figura 7.18 apresenta a comparação entre os gráficos deslocamento horizontal versus tempo para $h$ de 400 e $500 \mathrm{~m}$. 


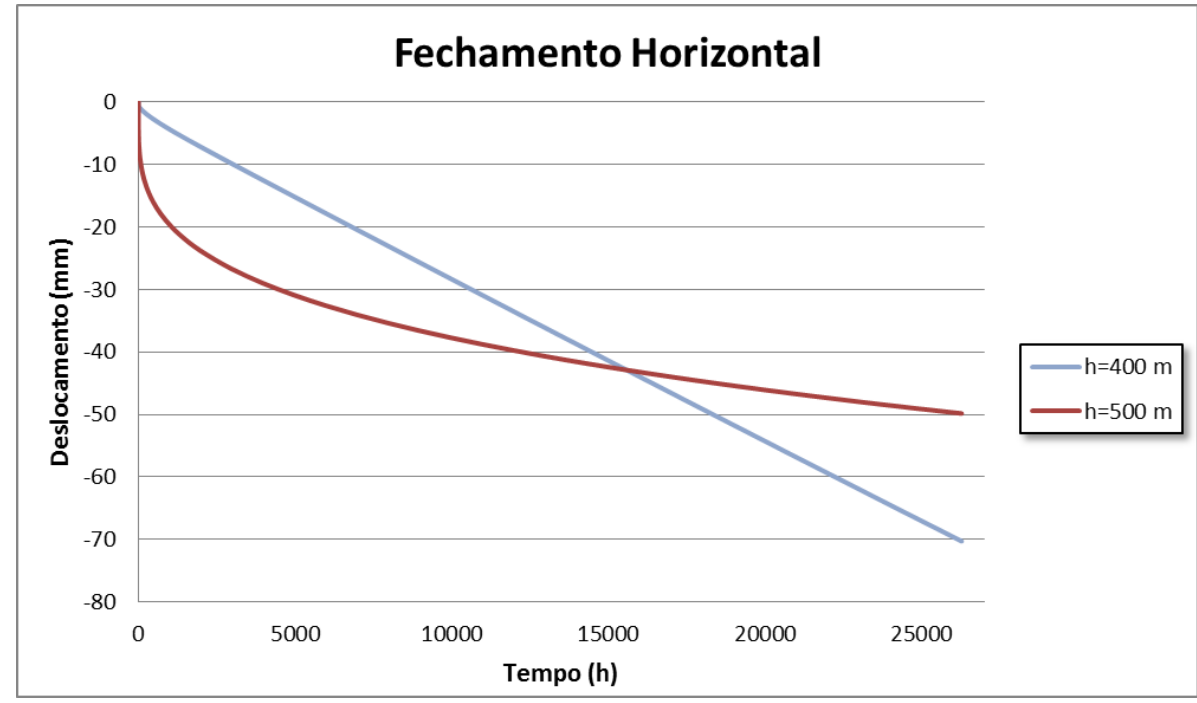

Figura 7.18: Deslocamentos horizontais para $h=400$ e $500 \mathrm{~m}$.

Observa-se na Figura 7.18 que a taxa de deformação para a profundidade $400 \mathrm{~m}$ é maior que a taxa de deformação, da fluência secundária, para a profundidade de $500 \mathrm{~m}$. Isto se deve à simplificação da lei de duplo mecanismo de deformação que considera dois parâmetros $n_{1}$ e $n_{2}$ para as tensões menores que uma tensão de referência e maiores ou iguais a uma tensão de referência, respectivamente. Geralmente o parâmetro $n_{1}$ é menor que $n_{2}$, isto pode provocar uma taxa de deformação maior para $\sigma_{e f}<\sigma_{0}$ e menor para $\sigma_{e f} \geq \sigma_{0}$ quando próximas da tensão de referência, facilmente observado com a Equação (6.9). Na Figura 7.19 este fato também pode ser observado para os deslocamentos verticais ao longo do tempo.

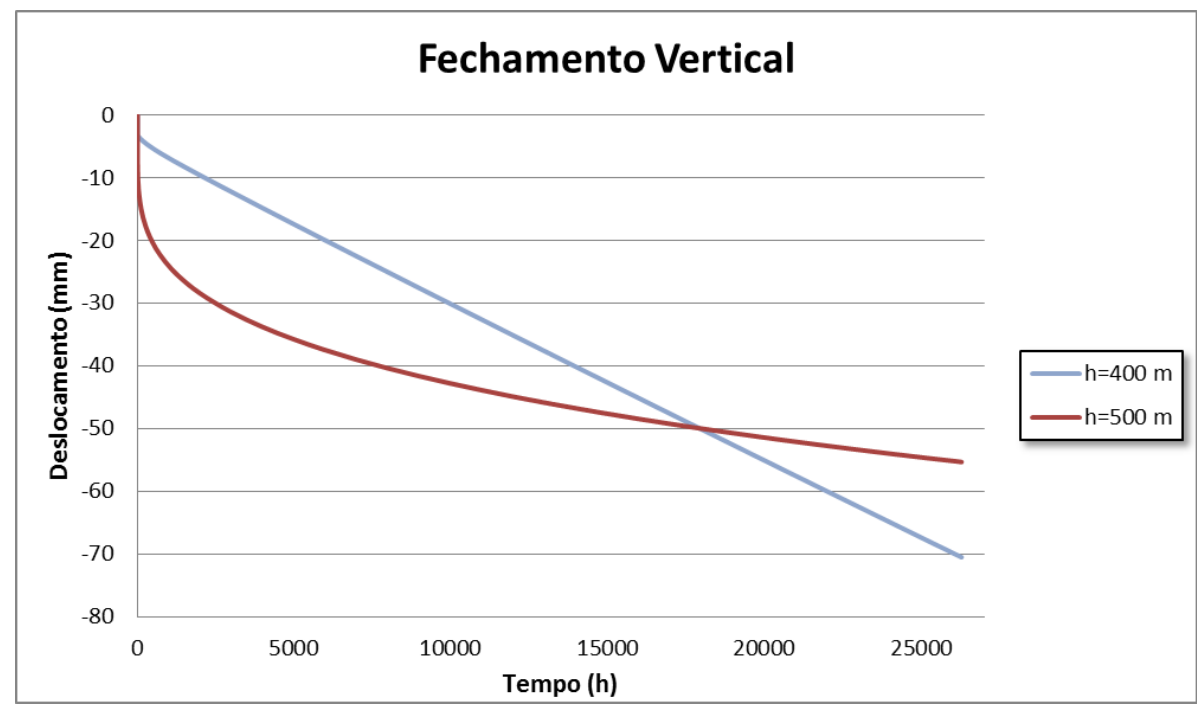

Figura 7.19: Deslocamentos verticais para $h=400$ e $500 \mathrm{~m}$.

Para melhor entendimento são mostrados resultados de deformação, tensão e deslocamento nas 10 diferentes simulações. Os resultados são mostrados da Figura 7.20 a 
Figura 7.29 e os valores são para as máximas deformações principais (a), para as tensões de Von Mises (b) e para os deslocamentos resultantes (c).

A legenda apresentada nos resultados a seguir (Figura 7.20 a Figura 7.29) são para deformações máxima principal, tensão de Von Mises em MPa e deslocamento resultante em $\mathrm{mm}$.
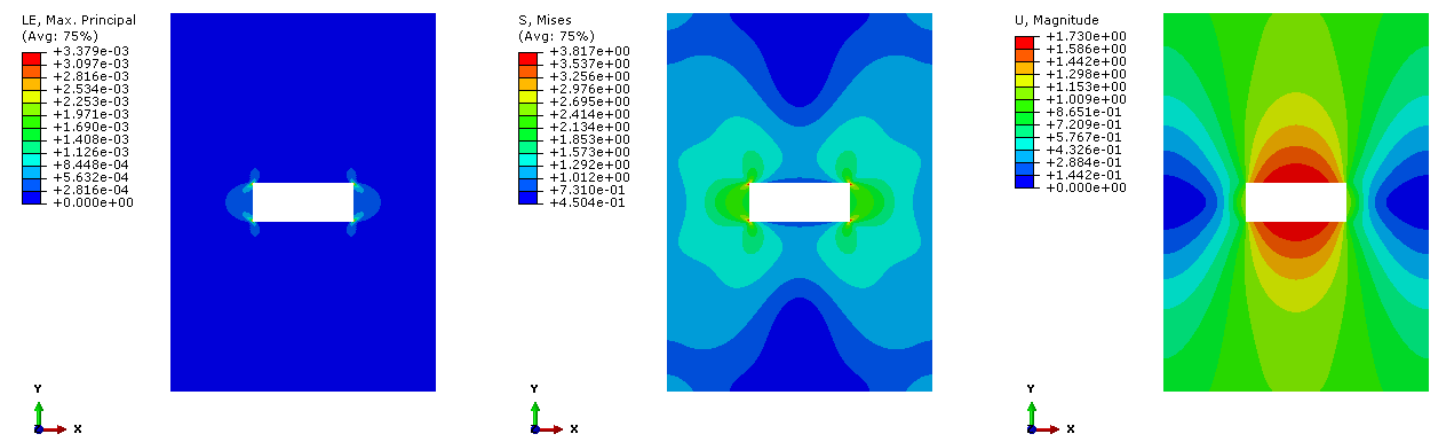

(a) Deformação

(b) Tensão

(c) Deslocamento

Figura 7.20: Resultados no término da simulação para $h=100 \mathrm{~m}$.

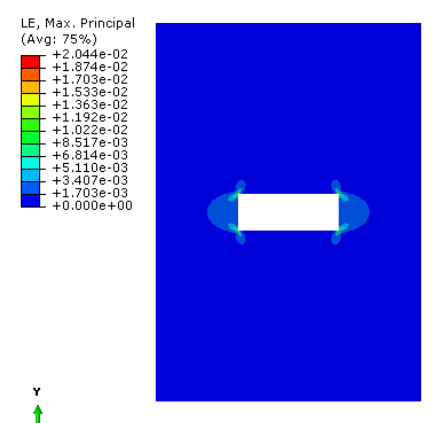

(a) Deformação

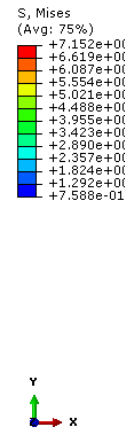

(b) Tensão

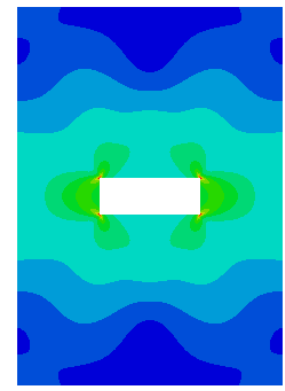

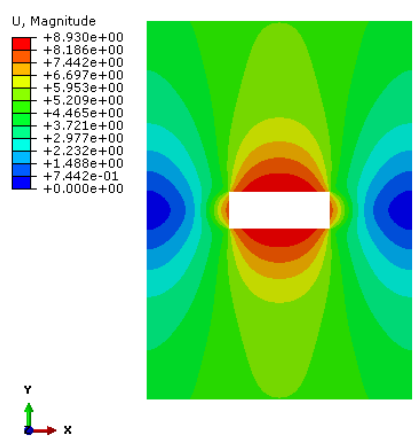

(c) Deslocamento

Figura 7.21: Resultados no término da simulação para $h=200 \mathrm{~m}$.

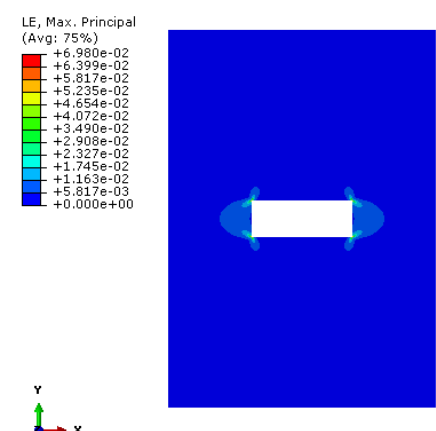

(a) Deformação

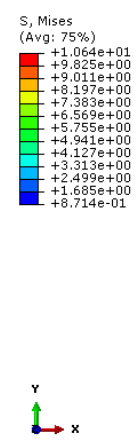

(b) Tensão
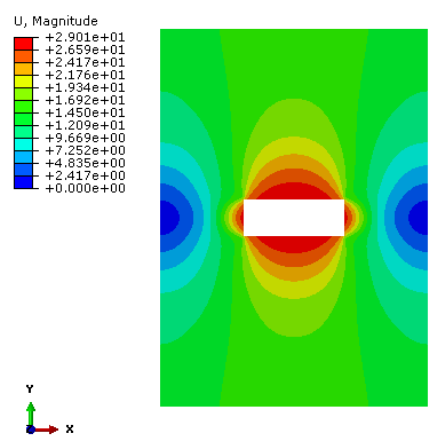

(c) Deslocamento

Figura 7.22: Resultados no término da simulação para $h=300 \mathrm{~m}$. 


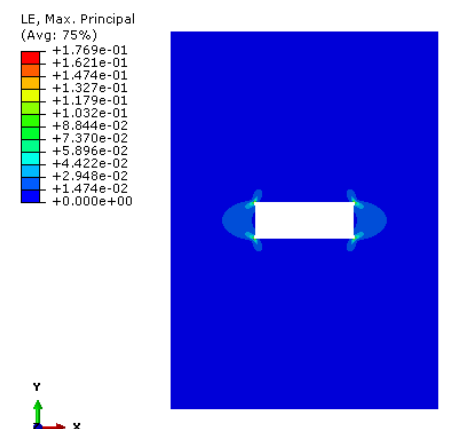

(a) Deformação

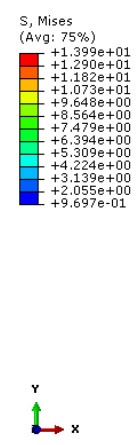

(b) Tensão
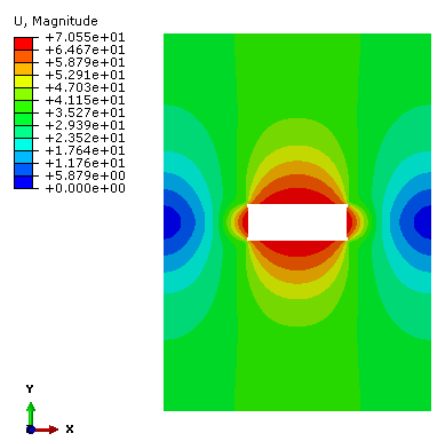

(c) Deslocamento

Figura 7.23: Resultados no término da simulação para $h=400 \mathrm{~m}$.

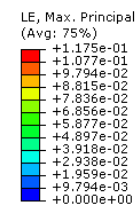

$\stackrel{\uparrow}{\longrightarrow}$

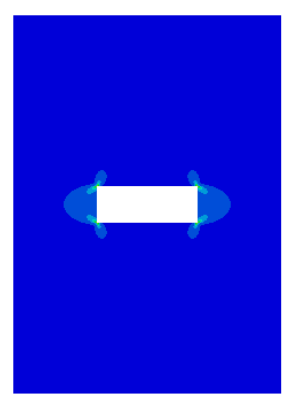

(a) Deformação

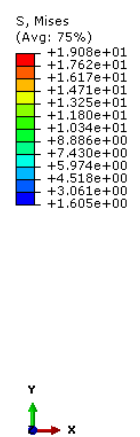

(b) Tensão

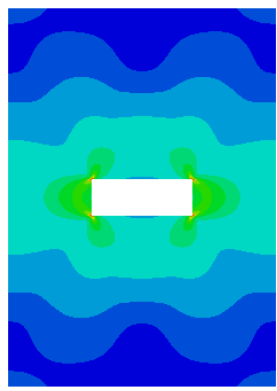

$\stackrel{Y}{\longrightarrow}$

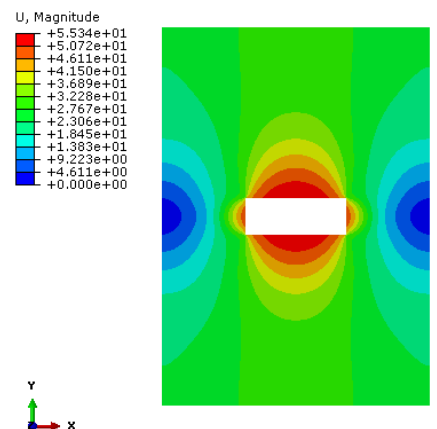

(c) Deslocamento

Figura 7.24: Resultados no término da simulação para $h=500 \mathrm{~m}$.

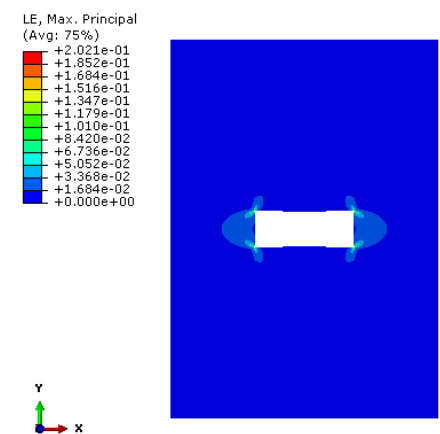

(a) Deformação

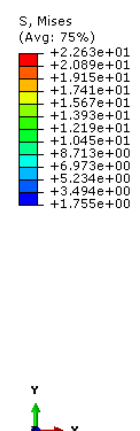

(b) Tensão

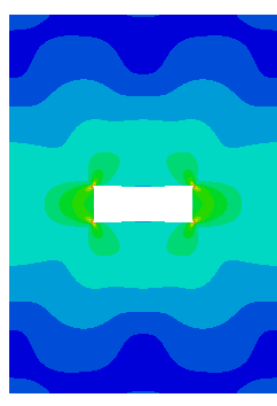

$\stackrel{r}{t}$

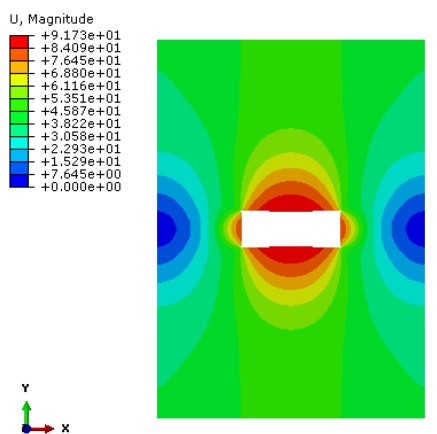

(c) Deslocamento

Figura 7.25: Resultados no término da simulação para $h=600 \mathrm{~m}$.

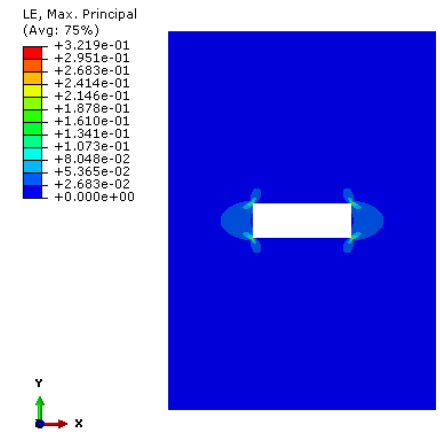

(a) Deformação
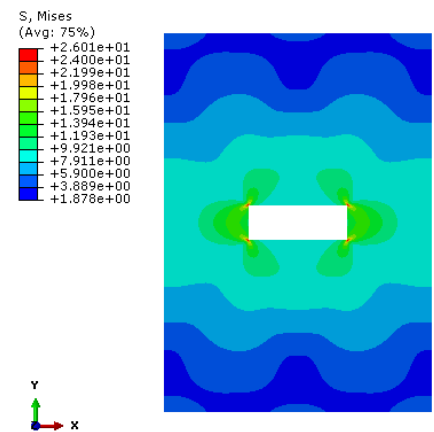

(b) Tensão
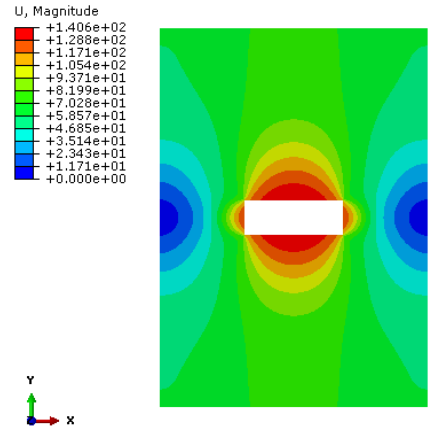

(c) Deslocamento

Figura 7.26: Resultados no término da simulação para $h=700 \mathrm{~m}$. 


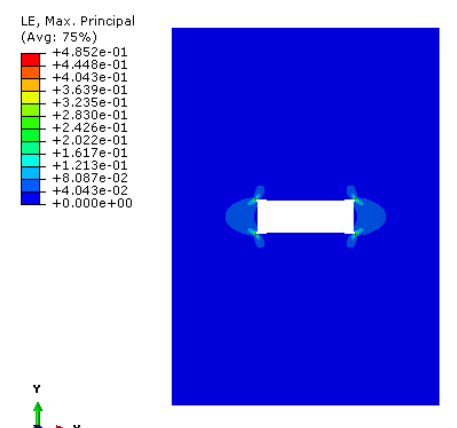

(a) Deformação

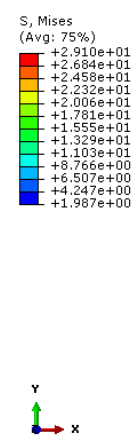

(b) Tensão

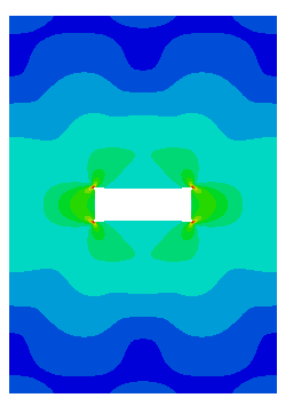

$\stackrel{\leftrightarrow}{\leftrightarrow}$

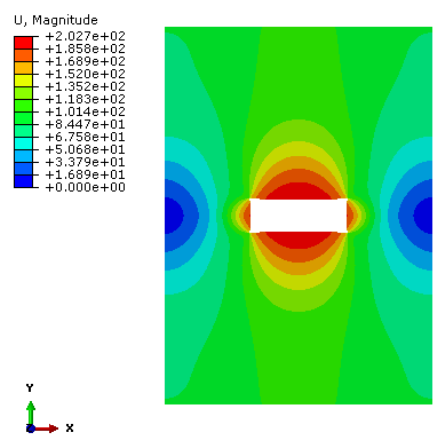

(c) Deslocamento

Figura 7.27: Resultados no término da simulação para $h=800 \mathrm{~m}$.

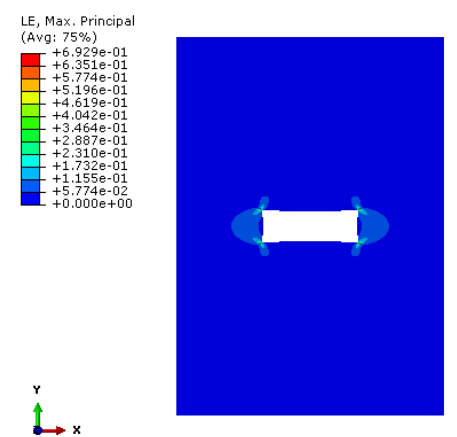

(a) Deformação

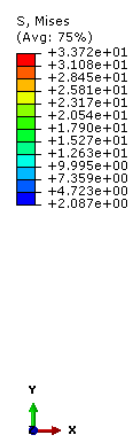

(b) Tensão
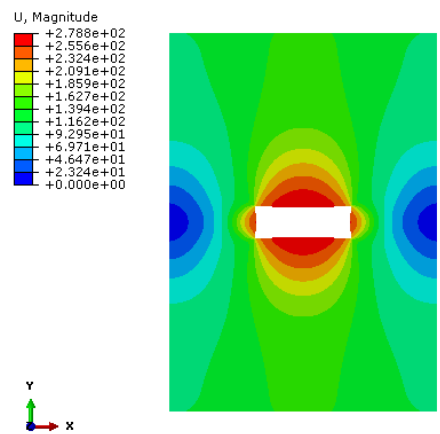

(c) Deslocamento

Figura 7.28: Resultados no término da simulação para $h=900 \mathrm{~m}$.

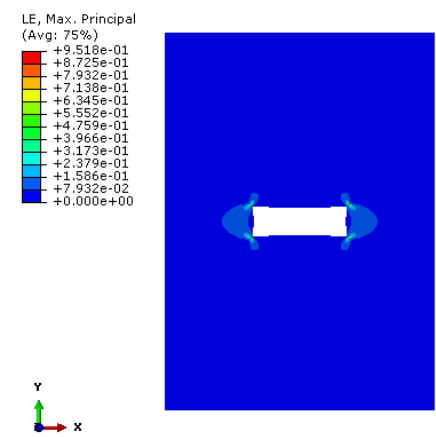

(a) Deformação
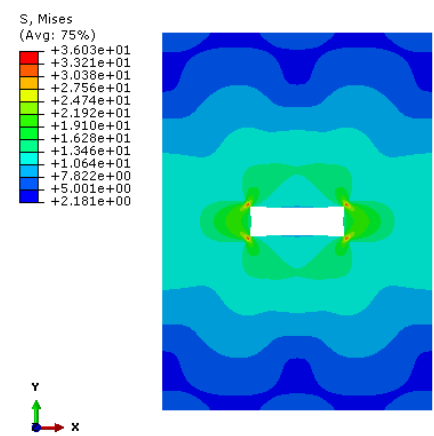

(b) Tensão
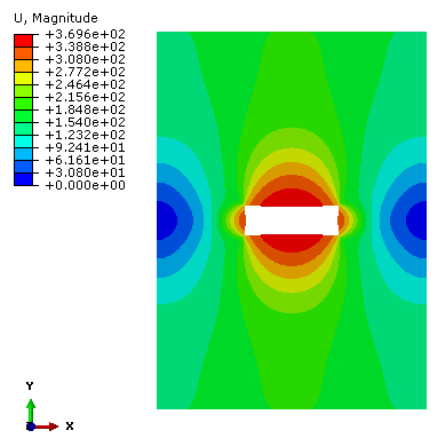

(c) Deslocamento

Figura 7.29: Resultados no término da simulação para $h=1000 \mathrm{~m}$.

Da Figura 7.20 até a Figura 7.29 é apresentada a evolução, com a profundidade, das deformações, tensões e deslocamentos. Observa-se que a região de maiores valores para as deformações e para as tensões se concentrou nos vértices do retângulo escavado. Já os deslocamentos foram maiores no centro de cada aresta do mesmo.

Na Tabela 7.7 tem-se o resumo dos valores máximos obtidos para a deformação principal $\left(\varepsilon_{p}\right)$, tensões de Von Mises $\left(\sigma_{\text {Mises }}\right)$ e deslocamentos $(U)$ nas diferentes etapas da simulação para os diferentes casos simulados. 
Tabela 7.7: Resultados máximos obtidos para deformação, tensão e deslocamento.

\begin{tabular}{|c|c|c|c|c|c|c|c|}
\hline \multirow[b]{2}{*}{$H(\mathrm{~m})$} & \multirow[b]{2}{*}{$\sigma(\mathrm{MPa})$} & \multicolumn{3}{|c|}{ GEOSTÁTICA } & \multicolumn{3}{|c|}{ ELÁSTICA } \\
\hline & & $\varepsilon p$ & $\sigma . M i s e s(\mathrm{MPa})$ & $U(\mathrm{~mm})$ & $\varepsilon p$ & б.Mises(MPa) & $U(\mathrm{~mm})$ \\
\hline 100 & $2,100 \mathrm{E}+00$ & $0,000 \mathrm{E}+00$ & $9,231 \mathrm{E}-01$ & $0,000 \mathrm{E}+00$ & 3,892E-04 & $1,359 \mathrm{E}+01$ & 7,953E-01 \\
\hline 200 & $4,200 \mathrm{E}+00$ & $0,000 \mathrm{E}+00$ & $1,846 \mathrm{E}+00$ & $0,000 \mathrm{E}+00$ & $7,786 \mathrm{E}-04$ & $2,719 \mathrm{E}+01$ & $1,590 \mathrm{E}+00$ \\
\hline 300 & $6,300 \mathrm{E}+00$ & $0,000 \mathrm{E}+00$ & $2,769 \mathrm{E}+00$ & $0,000 \mathrm{E}+00$ & $1,168 \mathrm{E}-03$ & $4,079 \mathrm{E}+01$ & $2,385 \mathrm{E}+00$ \\
\hline 400 & $8,400 \mathrm{E}+00$ & $0,000 \mathrm{E}+00$ & $3,693 \mathrm{E}+00$ & $0,000 \mathrm{E}+00$ & $1,558 \mathrm{E}-03$ & $5,440 \mathrm{E}+01$ & $3,180 \mathrm{E}+00$ \\
\hline 500 & $1,050 \mathrm{E}+01$ & $0,000 \mathrm{E}+00$ & $4,616 \mathrm{E}+00$ & $0,000 \mathrm{E}+00$ & $1,948 \mathrm{E}-03$ & $6,802 \mathrm{E}+01$ & $3,975 \mathrm{E}+00$ \\
\hline 600 & $1,260 \mathrm{E}+01$ & $0,000 \mathrm{E}+00$ & $5,539 \mathrm{E}+00$ & $0,000 \mathrm{E}+00$ & $2,338 \mathrm{E}-03$ & $8,164 \mathrm{E}+01$ & $4,770 \mathrm{E}+00$ \\
\hline 700 & $1,470 \mathrm{E}+01$ & $0,000 \mathrm{E}+00$ & $6,462 \mathrm{E}+00$ & $0,000 \mathrm{E}+00$ & 2,729E-03 & $9,527 \mathrm{E}+01$ & $5,565 \mathrm{E}+00$ \\
\hline 800 & $1,680 \mathrm{E}+01$ & $0,000 \mathrm{E}+00$ & $7,385 \mathrm{E}+00$ & $0,000 \mathrm{E}+00$ & 3,119E-03 & $1,089 \mathrm{E}+02$ & $6,360 \mathrm{E}+00$ \\
\hline 900 & $1,890 \mathrm{E}+01$ & $0,000 \mathrm{E}+00$ & $8,308 \mathrm{E}+00$ & $0,000 \mathrm{E}+00$ & $3,510 \mathrm{E}-03$ & $1,225 \mathrm{E}+02$ & $7,154 \mathrm{E}+00$ \\
\hline \multirow[t]{2}{*}{1000} & $2,100 \mathrm{E}+01$ & $0,000 \mathrm{E}+00$ & $9,231 \mathrm{E}+00$ & $0,000 \mathrm{E}+00$ & $3,901 \mathrm{E}-03$ & $1,362 \mathrm{E}+02$ & $7,949 \mathrm{E}+00$ \\
\hline & & \multicolumn{3}{|c|}{ FLUÊNCIA PRIMÁRIA } & \multicolumn{3}{|c|}{ FLUÊNCIA SECUNDÁRIA } \\
\hline$H(\mathrm{~m})$ & $\sigma(\mathrm{MPa})$ & Ep & O.Mises(MPa) & $U(\mathrm{~mm})$ & $\varepsilon p$ & O.Mises(MPa) & $U(\mathrm{~mm})$ \\
\hline 100 & $2,100 \mathrm{E}+00$ & $*$ & $*$ & $*$ & $3,379 \mathrm{E}-03$ & $3,817 \mathrm{E}+00$ & $1,730 \mathrm{E}+00$ \\
\hline 200 & $4,200 \mathrm{E}+00$ & $*$ & $*$ & $*$ & $2,044 \mathrm{E}-02$ & $7,152 \mathrm{E}+00$ & $8,930 \mathrm{E}+00$ \\
\hline 300 & $6,300 \mathrm{E}+00$ & $*$ & $*$ & $*$ & $6,980 \mathrm{E}-02$ & $1,064 \mathrm{E}+01$ & $2,901 \mathrm{E}+01$ \\
\hline 400 & $8,400 \mathrm{E}+00$ & $*$ & $*$ & $*$ & $1,769 \mathrm{E}-01$ & $1,399 \mathrm{E}+01$ & $7,055 \mathrm{E}+01$ \\
\hline 500 & $1,050 \mathrm{E}+01$ & $9,616 \mathrm{E}-02$ & $1,915 \mathrm{E}+01$ & 4,601E+01 & $1,175 \mathrm{E}-01$ & $1,908 \mathrm{E}+01$ & $5,534 \mathrm{E}+01$ \\
\hline 600 & $1,260 \mathrm{E}+01$ & $1,645 \mathrm{E}-01$ & $2,275 \mathrm{E}+01$ & $7,602 \mathrm{E}+01$ & $2,021 \mathrm{E}-01$ & $2,263 \mathrm{E}+01$ & $9,173 \mathrm{E}+01$ \\
\hline 700 & $1,470 \mathrm{E}+01$ & $2,610 \mathrm{E}-01$ & $2,621 \mathrm{E}+01$ & $1,164 \mathrm{E}+02$ & $3,219 \mathrm{E}-01$ & $2,601 \mathrm{E}+01$ & $1,406 \mathrm{E}+02$ \\
\hline 800 & $1,680 \mathrm{E}+01$ & 3,919E-01 & $2,948 \mathrm{E}+01$ & $1,680 \mathrm{E}+02$ & $4,852 \mathrm{E}-01$ & $2,910 \mathrm{E}+01$ & $2,027 \mathrm{E}+02$ \\
\hline 900 & $1,890 \mathrm{E}+01$ & $5,623 \mathrm{E}-01$ & $3,376 \mathrm{E}+01$ & $2,316 \mathrm{E}+02$ & $6,929 \mathrm{E}-01$ & $3,372 \mathrm{E}+01$ & $2,788 \mathrm{E}+02$ \\
\hline 1000 & $2,100 \mathrm{E}+01$ & $7,726 \mathrm{E}-01$ & $3,678 \mathrm{E}+01$ & $3,074 \mathrm{E}+02$ & $9,518 \mathrm{E}-01$ & $3,603 \mathrm{E}+01$ & $3,696 \mathrm{E}+02$ \\
\hline
\end{tabular}

Na Tabela 7.7 a tensão $\sigma$ é a tensão vertical diretamente proporcional à profundidade $h$, calculada a partir da Equação (7.10). Os valores mostrados são os resultados obtidos ao término de cada etapa: Geostática, Elástica, Fluência Primária e Fluência Secundária. Observa-se ainda que para as profundidades $h$ menores que $400 \mathrm{~m}$ os resultados não foram obtidos para a fluência primária, visto que, neste caso apenas se considerou a fluência secundária. 


\section{CAPITULO 8 - CONCLUSÕES E RECOMENDAÇÕES}

Os resultados mostrados neste trabalho revelam a importância da simulação numérica em problemas de escavações em maciço. Além de um amplo estudo de fluência em maciços de evaporitos, abordando seu comportamento viscoelástico e as equações constitutivas de representação de tal comportamento, fez-se também um estudo paralelo sobre a interação maciço-suporte e sobre a interação das duas camadas de concreto do suporte, com o efeito de uma membrana de impermeabilização. Desta forma, foram cumpridos todos objetivos gerais e específicos deste trabalho apresentados no CAPITULO 1.

No CAPITULO 3 foi feita a validação do Abaqus®. Na realidade o capítulo dedicouse à verificação das técnicas de modelagem a serem adotadas nas demais simulações do trabalho. Neste capítulo dois modelos foram simulados, o primeiro para um caso axissimétrico e o segundo para caso de deformação plana, e os resultados, obtidos para um eixo radial, comparados com a solução consagrada de Kirsch (1890) apud Gomes (2006). Esta comparação mostrou o bom ajuste dos resultados tanto para o modelo plano de deformação como para o modelo axissimétrico, fato que tornou a técnica de simulação válida para utilização nos demais casos deste trabalho.

O CAPITULO 4 apresentou um estudo sobre a importância da interação maciçosuporte em problemas de escavação com colocação de suporte. Neste, além das situações "no slip" e "full slip" (atrito nulo e atrito infinito, respectivamente), um estudo sobre malha e sobre a variação do atrito nesta interação também foi realizado. Os modelos "no slip" e "full slip" simulados foram comparados com a solução de Einstein e Schwartz (1979) e mostraram ser confiáveis, visto que, ocorreram bons ajustes para as tensões (radiais e cisalhantes) no maciço, e para os esforços normais, momentos fletores e deslocamentos (radiais e transversais) no suporte. No estudo da malha foram utilizados quatro tipos de elementos contínuos planos deformados (CPE3, CPE6, CPE4 e CPE8) na modelagem do maciço. Neste caso, os elementos quadráticos, B22 e CPE8, apresentaram os melhores resultados. Para as tensões radiais, os melhores resultados obtidos foram com o elemento CPE4 e para as tensões cisalhantes com o elemento CPE8. No suporte o elemento B22, utilizado em todas as simulações deste capítulo, apresentou resultados satisfatórios para os esforços normais, momentos fletores e deslocamentos (radiais e transversais), diferente do elemento B21 que não apresentou bons resultados para momentos fletores. A variação do atrito entre o suporte e 
o maciço mostrou a coerência existente entre os resultados simulados e a solução de Einstein e Schwartz (1979). Como esperado os resultados numéricos obtidos estiveram dentro da faixa obtida com a solução de Einstein e Schwartz (1979) para os casos extremos de "no slip" e "full slip". Ainda é possível concluir que as tensões no maciço sofrem grande influência do atrito existente com o suporte e que o esforço normal no suporte é a variável que mais sofre variação. O momento fletor e os deslocamentos (radiais e transversais) no suporte, diferente do esforço normal, não demonstraram grande variação.

O CAPÍTULO 5 apresentou uma introdução ao estudo de interação do suporte com a membrana de impermeabilização em túneis. Este capítulo apresentou um caso idealizado de um túnel escavado adotando-se para relaxação um fator de alívio de 0,5 (Panet, 1976) que posteriormente recebeu o suporte primário e o secundário. Para consideração da membrana foram adotados coeficientes de rigidez normal e cisalhante entre o suporte primário e secundário com elementos coesivos, $\mathrm{COH} 2 \mathrm{D} 4$. Os resultados foram obtidos para diferentes níveis de carga hidrostática atuando no maciço, no suporte primário e no suporte secundário, desde o estado inicial. No maciço os resultados numéricos mostraram coerentemente que as tensões e deslocamentos no perímetro escavado aumentaram com escavação e com a instalação do suporte primário devido à relaxação do maciço. Com o aumento do nível d'água o mesmo não foi observado, visto que, o suporte secundário passou a receber o carregamento adicional. Da mesma forma, o suporte primário passou a ter uma grande influência apenas na etapa de sua instalação, devido à relaxação do maciço. No suporte secundário, os esforços normais, momentos fletores e deslocamentos também variaram de forma linear com o aumento do nível d'água. Também foi possível observar que os suportes primário e secundário não podem ser considerados como uma estrutura homogênea, ou seja, um trabalha independente do outro e as tensões não se apresentam idênticas ou contínuas entre eles. Porém, há interação mecânica através da membrana.

O CAPÍTULO 6 apresentou um estudo inicial sobre a simulação de fluência em evaporitos. O comportamento de fluência dos evaporito ao longo do tempo, apesar dos vários modelos constitutivos para sua representação, ainda não possui parâmetros suficientes para as equações apresentadas na literatura. A falta de parâmetros para os diferentes modelos dificulta o avanço nos estudos sobre escavação dos mesmos. Tentando minimizar o problema, este capítulo ressalta o quanto é importante o uso de parâmetros significativos para a determinação da fluência em maciços evaporíticos. O modelo apresentado para fluência no Abaqus®, apesar de não ter como variável a temperatura, mostrou ser bem representativo para fluência 
da halita, mesmo quando associada com os dois estágios iniciais de fluência. Isso permite uma diminuição do erro e uma representação mais fiel deste comportamento com os parâmetros propostos.

O CAPÍTULO 7 utiliza a equação de fluência do Abaqus® para considerar o estágio primário e secundário de fluência em maciços de evaporitos. Neste capítulo foi apresentada uma metodologia para realização deste tipo de simulação, bem como a realização de alguns exemplos utilizando este tipo de metodologia. Com a variação dos parâmetros de fluência da equação do Abaqus® foi possível simular os estágios primário e secundário de fluência de um maciço evaporítico. A falta de conhecimento do tempo para início do estágio secundário de fluência, término do estágio primário, serviu para sugerir uma relação para o cálculo deste tempo. Os resultados apresentados pela simulação do ensaio axissimétrico, apresentaram um bom ajuste com ensaios feitos em laboratório por Cella (2003). Os mesmos foram mais bem ajustados quando se utilizaram os parâmetros de Starfield e Mcclain (1973) (estágio primário) e Costa et al. (2005) (estágio secundário), junto com a equação sugerida para o tempo. Neste capítulo também foram realizadas simulações em uma galeria escavada, em maciço evaporítico, típico da mina Taquari Vassouras (Costa, 1984). Para tanto, foram simulados nove casos com diferentes níveis de tensão, automatizados com o uso do software Isight ${ }^{\circledR}$. O processo de automatização também permitiu o cálculo do tempo para início da fluência secundária. Os resultados apresentados destas simulações demonstram o aumento gradual das deformações, tensões e deslocamentos com o aumento do nível inicial de tensão. Devido à simplificação da lei de duplo mecanismo, observou-se que a taxa de deformação para fluência para a profundidade de $400 \mathrm{~m}$ foi maior, a partir de certo ponto, do que para a profundidade de $500 \mathrm{~m}$. Esta simplificação é diretamente relacionada aos parâmetros $n_{1}, n_{2}$ e a tensão de referência que, como visto, pode provocar este tipo de erro em níveis de tensões próximos a tensão de referência.

Este trabalho serviu como contribuição para o estudo de fluência em evaporitos, bem como para problemas de interação entre suporte e maciço. A utilização da simulação numérica para este tipo de problema foi um fator que possibilitou esse estudo, visto que os modelos teóricos são modelos muito restritivos e que impossibilitam diversas considerações. Como recomendação fica a incorporação de modelos constitutivos, em programas de simulação numérica, com maior fidelidade ao comportamento mecânico dos evaporitos. $\mathrm{Na}$ simulação de fluência, por exemplo, um único modelo capaz de simular os diversos estágios de fluência poderia reduzir a complexidade e o tempo da simulação. Uma alternativa para isto 
é a utilização de sub-rotinas implementadas e incorporadas ao modelo simulado. O estágio de fluência terciário também é um ponto importante e que até o momento há pouca literatura a respeito. Com relação à interação maciço suporte, existe a necessidade de uma formulação teórica capaz de retornar o comportamento para diferentes valores de atritos, bem como ensaios que representem fielmente esta interação. $O$ estudo de membrana de impermeabilização para revestimento de túneis é um problema de interação que a cada momento vem tomando uma importância maior. Atualmente, a falta de dados e literatura a respeito torna seu estudo restrito. Desta forma, fica a recomendação de um aprofundamento neste mérito em vista da importância do mesmo. 


\section{REFERÊNCIAS BIBLIOGRÁFICAS}

ABAQUS-6.11. Abaqus Theory Manual. In: SYSTEMS, D. (Ed.). Documentation, 2011.

BÉREST, P.; KARIMI-JAFARI, M.; BROUARD, B. Transient Creep In Salt Caverns. Conference on Mechanics and Material. Louisiana, USA 2005.

BIENIAWSKI, Z. Rock mechanics design in mining and tunneling. AA Balkema, 1984.

BOTELHO, F. V. C. Análise Numérica do Comportamento Mecânico do Sal em Poços de Petróleo. 2008. (Dissertação de Mestrado). Departamento de Engenharia Civil, Pontifícia Universidade Católica do Rio de Janeiro, Rio de Janeiro.

BOUliAnNE, M.; SIMON, R.; AUBERTIN, M. A Numerical Investigation of the Creep (Viscoplastic) Behaviour of Circular Opening and Pillar in Rocksalt. 57th Canadian Geotechnical Conference and the 5th Joint CGS-IAH Conference: 25-32 p. 2004.

BRANDENBERGER, R.; GARSHOL, K. F.; MELBYE, T. A.; SCHUBERT, P. A. Waterproof cladding construction and method of providing the same. Google Patents, 2004.

BURNS, J. Q.; RICHARD, R. M. Attenuation of Stress for Buried Cylinders. Symposium on Soil-Structure Interaction. Tucson: Ariz: 378-392 p. 1964.

CAVAlCAnte, A. D. S.; RAMOS, V. C. L. Ajuste de Parâmetros para Modelos Viscoelástico de Fluência com Aplicações em Rochas Salinas. Mecánica Computacional. Buenos Aires, Argentina: Asociación Argentina de Mecánica Computacional. XXIX: 88 p. 2010.

CELESTINO, T. B.; RUIZ, A. P. T. Shape of settlement troughs due to tunnelling through different types of soft ground. Felsbau, v. 16,12, p. 118-121, 1998.

CELlA, P. R. C. Desenvolvimento de Execução de Ensaios Triaxiais de Fluência Estacionária em Rochas Salinas sob Altas Pressões e Temperatura. . 2003. (Tese de Doutorado). Escola Politécnica, Universidade de São Paulo, São Paulo.

CHAN, K. S.; BRODSKY, N. S.; FOSSUM, A. F.; BODNER, S. R.; MUNSON, D. E. Damage-induced nonassociated inelastic flow in rock salt. International Journal of Plasticity, v. 10, n. 6, p. 623-642, 1994. ISSN 0749-6419.

CHEN, W.; SALEEB, A. F. Constitutive Equations for Engineering Materials. In: (Ed.). Elasticity and Modeling. Wiley, v.1, 1982.

COSTA, A. Uma Aplicação de Métodos Computacionais e Princípios de Mecânica das Rochas no Projeto e Análise de Escavações Subterrâneas Destinadas à Mineração Subterrânea. 1984. Tese de Doutorado, COPPE/UFRJ, 1984

COSTA, A. M.; POIATE, E.; FALCÃO, J.; COELHO, L. Triaxial creep test in salt applied in drilling through thick salt layers in Campos Basin - Brazil. paper SPE 92629, presented at 
the SPE Drilling Conference, Amsterdam - The Netherlands, February 23-25., p. 14-24, 2005.

CRISTESCU, N. Viscoplastic creep of rocks around horizontal tunnels. International Journal of Rock Mechanics and Mining Sciences, v. 22, n. 6, p. 453-459, 1985. ISSN 0020-7624.

CRISTESCU, N. Viscoplastic creep of rocks around a lined tunnel. International Journal of Plasticity, v. 4, n. 4, p. 393-412, 1988.

CRISTESCU, N.; FOTA, D.; MEDVES, E. Tunnel support analysis incorporating rock creep. International Journal of Rock Mechanics and Mining Sciences, v. 24, n. 6, p. 321-330, 1987.

CURTIS, R.; EVANS, G.; KINSMAN, D. J. J.; SHEARMAN, D. J. Association of Dolomite and Anhydrite in the Recent Sediments of the Persian Gulf. Nature. 1963. 197

DA SILVA, M. A. M.; SCHREIBER, B. C.; DOS SANTOS, C. L. EVAPORITOS COMO RECURSOS MINERAIS. Brazilian Journal of Geophysics, v. 18, n. 0102-261X, p. 3, 2000.

INSTITUTE FOR ROCK MECHANICS AND TUNNELLING. Direct Shear Test Results. Technical University of Graz, Austria. 2008

DREYER, W. The science of rock mechanics. Trans Tech Publications, 1972. ISBN 0878490027.

DUSSEAULT, M. B.; FORDHAM, C. J. Time dependent behaviour of rocks. J.A. Hudson. Pergamon Press, 1994.

DUSSEAULT, M. B.; MAURY, V. B.; SANFILIPPO, F. B.; SANTARELLI, F. J. Drilling Through Salt: Constitutive Behavior and Drilling Strategies. North American Rock Mechanics Symp., 2004. Houston.

DUSSEAULT, M. B.; MRAZ, D. Z.; ROTHENBURG, L. B. The Design of Openings in Saltrocks Using a Multiple Mechanism Viscoplastic Law. 28th US Symp. on Rock Mech, 1987. Balkema, Rotterdam. .

DUSSEAUlT, M. B.; ROTHENBURG, L. B.; MRAZ, D. Z. The Design Of Openings In Saltrock Using A Multiple Mechanism Viscoplastic Law. 28th US Symp. on Rock Mech., 1987. Balkema. Rotterdam.

EINSTEIN, H. H.; SCHWARTZ, C. W. Simplified Analysis for Tunnel Supports. Journal of the Geotechnical Division, v. 105, n. ASCE 14541, p. 499-518, 1979.

ERTIN, E. Spray Applied Waterproofing Membrane, Masterseal® 345, within the Concept of Single Shell Tunnel Linings. International Symposium on: Utilization of underground space in urban areas. Sharm El-Sheikh, Egypt 2006.

FARMER, I. W. Engineering behaviour of rocks. 2nd. London: Chapman and Hall, 1983. 208 ISBN 0412252805. 
GOMES, R. A. M. P. Análise tridimensional de túneis considerando o comportamento dependente do tempo na interação maciço-suporte. 2006. Tese (Doutorado) - Escola de Engenharia de São Carlos, Universidade de São Paulo, São Carlos.

GOODMAN, R. E. Introduction to Rock Mechanics. New York: 1989.

GRAVINA, C. C. Simulação Numérica do Comportamento Mecânico do Sal em Poços de Petróleo. Faculdade de Engenharia Mecânica. 1997. (Dissertação de Mestrado). Universidade Estadual de Campinas

HANSEN, F. D.; MELLEGARD, K. D. Quasi-static strength and deformational characteristics of domal salt from Avery Island, Louisiana. p.Medium: X; Size: Pages: 86. 1980. (ONWI-116 United StatesFri Feb 08 08:34:07 EST 2008NTIS, PC A05/MF A01.ERA06-002877; INS-80-019407; EDB-81-002137English)

JAEGER, J. C.; COOK, N. G. W.; ZIMMERMAN, R. W. Fundamentals of Rock Mechanics. Blackwell, 2007. 475

KIRSCH, G. Die Theorie der Elastizität und die Bedürfnisse der Festigkeitslehre. Zeitschrift des Vereines Deutscher Ingenieure, v. 42, n. 29, p. 797-807, 1898.

LOMENICK, T. F.; BRADSHAW, R. L. Deformation of rock salt in openings mined for the disposal of radioactive wastes. Rock Mechanics and Rock Engineering, v. 1, n. 1, p. 5-29, 1969. ISSN 0723-2632.

MACKAY, F.; INOUE, N.; DA FONTOURA, S.; BOTELHO, F. Analyzing Geomechanical Effects While Drilling Sub Salt Wells Through Numerical Modeling 2008.

MUNSON, D.; DEVRIES, K. Development and validation of a predictive technology for creep closure of underground rooms in salt. 1991.

PANET, M. Stability analysis of a tunnel driven in a rock mass in taking account of the post- failure beha vior. 1976.

PANET, M. Time dependent deformations in underground works. Fourth I.S.R.M. Congress, 1979. Rotterdam. Monteux. A. A. Balkema and the Swiss Society for Soil and Rock Mechanics. p.279-289.

PANET, M.; GUENOT, A. Analysis of convergence behind the face of a tunnel. 1982. p.197204.

PECK, R. B. Advantages and limitations of the observational method in applied soil mechanics. Geotechniques, v. 19, n. 2, p. 171-187, 1969. ISSN 0016-8505.

PECK, R. B.; HENDRON, A.; MOHRAZ, B. State of the Art of Soft-Ground Tunneling. First Rapid Excavation and Tunneling Conference, 1972. Americam Institute of Mining, Metallugical, and Petroleum Engineers. p.259-286.

PEHOVAZ-ALVAREZ, H. I. Estudo de mecanismos de deformação lenta da gipsita bandada da Chapada do Araripe em ensaios de fluência monitorados por emissão acústica. 2009. (Doutorado). Departamento de Geotecnia, Escola de Engenharia de São Carlos (USP), São Carlos-SP. 
POIATE, J., E.; COSTA, A. M.; FALCÃO. Well Design Thick Evaporite Layers in Santos Basin - Brazil. ADC/SPE Drilling Conference. Miami, Florida 2006.

SCHWARTZ, C. W.; EINSTEIN, H. H. Improved design of tunnel supports: Simplified analysis for ground structure interaction in tunneling. Massachussets Institute of Technology. Boston: sn. 1: 427 p. 1980.

SENSENY, P. E. Review of Constitutive Laws Used to Describe the Creep of Salt. 1983

SERAFIM, J. L.; PEREIRA, J. P. Consideration of the geomechanical classification of Bieniawski. Proc. Int. Symp. on Enginneering Geology and Underground Constructions, 1983. p.1133-1144.

ŠÍMA，J.; KRČMÁŘ， O.; MATZNER， R.; DVOŘÁK，J.; CHÁMA， L. APPLIED WATERPROOFING MEMBRANE MASTERSEAL 345-SUCCESSFUL ALTERNATIVE SOLUTION. Tunel v. 2/2011, p. 9, 2011.

STARFIELD, A. M.; MCCLAIN, W. C. PROJECT SALT VAULT: A CASE STUDY IN ROCK MECHANICS. Rock Mock. Min. Sci. \& Geomcrh, v. Vol. 10, p. 641-657., 1973.

THOMAS, A.; PICKETT, A. P. The design of composite shell linings. Sixth International Symposium on Sprayed Concrete, 2011. Tromsø-Norway. Norwegian Concrete Association.

WARREN, J. Evaporite sedimentology. Old Tappan, NJ (USA); Prentice Hall Inc., 1989.

YU, C.-W. Creep Characteristics of Soft Rock And Modelling of Creep in Tunnel. 1998. 190 (Doctor of Philosophy). Department of Civil and Environmental Engineering, University of Bradford 


\section{APÊNDICE A - ESTUDO PRELIMINAR NA MODELAGEM MACIÇO/SUPORTE}

Os estudos preliminares, realizados com o Abaqus®, possibilitaram a escolha dos elementos e das considerações para a interação maciço-suporte. Além de permitir a análise de problemas em condições associadas com estados planos de deformação e de tensão, estados axissimétricos, o Abaqus ${ }^{\circledR}$ possibilita a consideração tridimensional de equilíbrio que se estabelecem nas estruturas geotécnicas reais. Desta forma, levou-se em consideração o efeito do contato maciço-suporte em três dimensões, para verificações das simplificações de um modelo bidimensional.

\section{A.1 EFEITO DO ATRITO NA INTERAÇÃO MACIÇO/SUPORTE}

Uma das fases do estudo preliminar da interação maciço-suporte em túneis foi a verificação do contato entre a superfície escavada (maciço) e a superfície do suporte. Em escavações de maciços pouco competentes sabe-se que é necessária à colocação de suporte e que o mesmo deve ter uma resistência alta, capaz de suportar as tensões hidrostáticas e as tensões de sobrecarga. Para tanto o suporte é instalado de forma que o maciço adira à superfície do mesmo, passando a receber a maior parte das tensões. Em condições de isotropia de tensões, o atrito não desempenha papel importante. Em condições de tensões iniciais anisotrópicas, diferentes níveis de cisalhamento entre maciço e suporte mostram a importância do atrito.

\section{A.1.1 ANÁLISE EM DUAS DIMENSÕES}

A análise em duas dimensões tomou como referência um modelo plano de deformação, onde se verificou o efeito de um acréscimo de tensão $\Delta \sigma=83,3$ Pa na superfície. Tanto a geometria quanto os parâmetros utilizados não têm associação com nenhum caso específico. A simulação utilizou apenas um "step", onde se verificou o efeito do acréscimo de tensão no suporte do túnel. A geometria do modelo é apresentada na Figura A.1, onde $D=18$ m e corresponde ao diâmetro do túnel. Como condições de contorno foi assumido apoio de primeiro gênero, travando os deslocamentos na horizontal, nas bordas laterais do modelo, e na vertical, na base do mesmo (Figura A.1). 


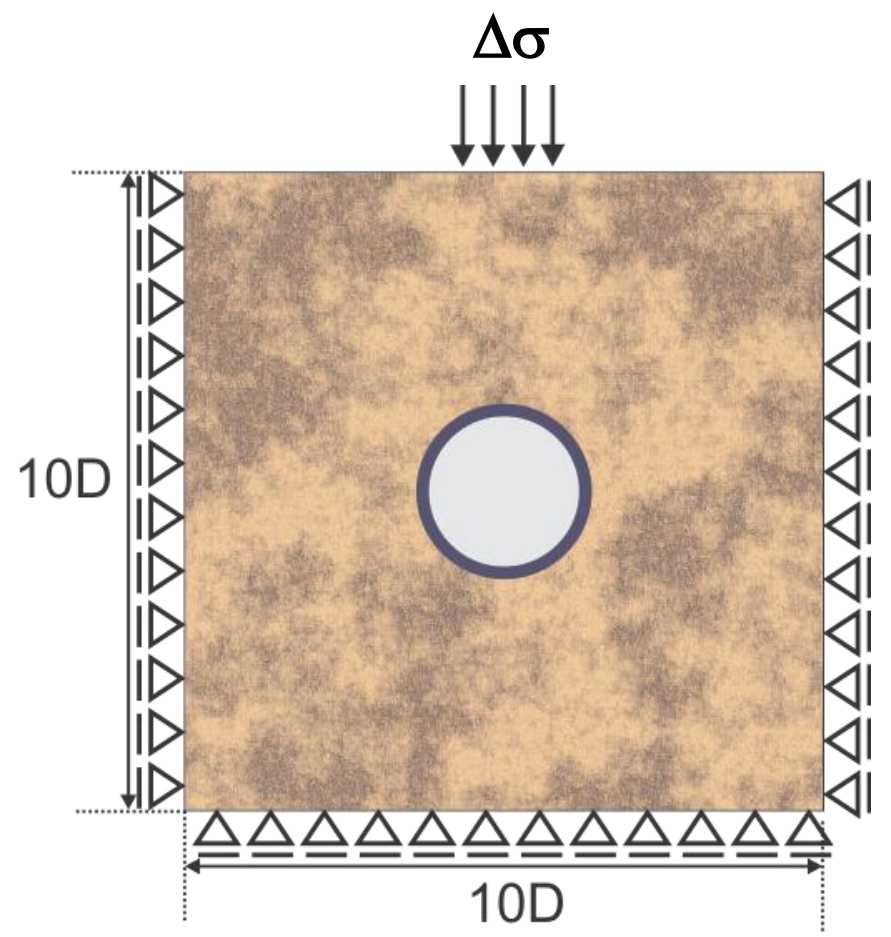

Figura A.1: Modelo plano de deformação para análise do atrito.

O modelo de elementos finitos foi gerado com 3109 elementos biaxiais do tipo CPE4 (elementos contínuos com 4 nós, plano de deformação) e 40 elementos uniaxiais do tipo B21 (elemento viga linear com 2 nós), conforme mostra a Figura A.2 (manual do Abaqus 6.11, 2011).

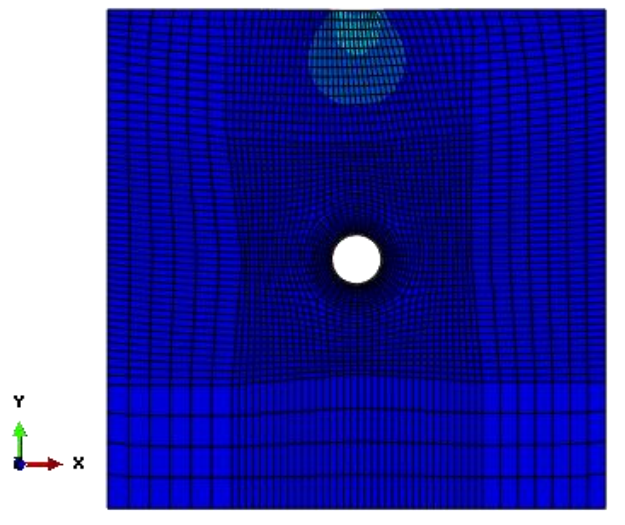

(a) Elementos planos de deformação

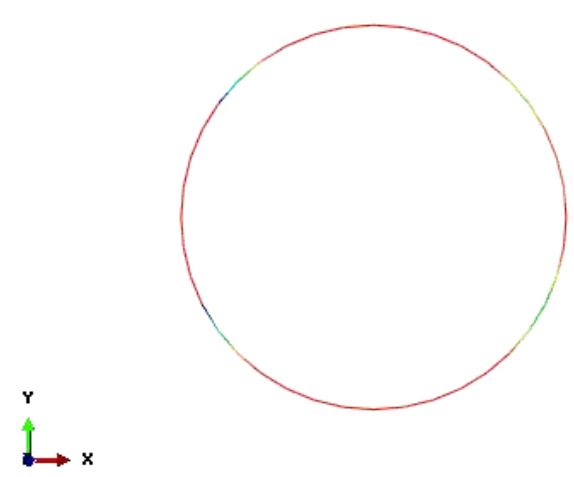

(b) Elementos viga

Figura A.2: Malha do modelo.

Para as propriedades do modelo, é importante salientar que foi utilizado material elástico para o maciço e para o suporte. Como hipótese simplificadora, foi considerado que o material é isotrópico, ou seja, as propriedades elásticas utilizadas são as mesmas nas duas direções, tanto para maciço quanto para o suporte. A Tabela A.1 resume as propriedades 
elásticas adotadas para os dois tipos de materiais utilizados, onde é observado que o módulo de elasticidade do suporte é bem maior que o do Maciço:

Tabela A.1: Propriedades dos materiais.

\begin{tabular}{|c|c|c|}
\cline { 2 - 3 } \multicolumn{1}{c|}{} & Módulo de Elasticidade $(\boldsymbol{E})$ & Poisson $(\boldsymbol{v})$ \\
\hline Maciço & $5,80 \mathrm{kPa}$ & 0,3 \\
\hline Suporte & $30,45 \mathrm{GPa}$ & 0,3 \\
\hline
\end{tabular}

O efeito do atrito com o acréscimo de tensão na superfície foi verificado para o contato maciço-suporte, com adoção de diversos valores para o mesmo. Os valores para o atrito variou de 0,01 a 0,60, analisando neste intervalo sete valores diferentes para o mesmo. A Figura A.3 mostra os resultados obtidos para os diversos valores de atrito, modelo em estudo.

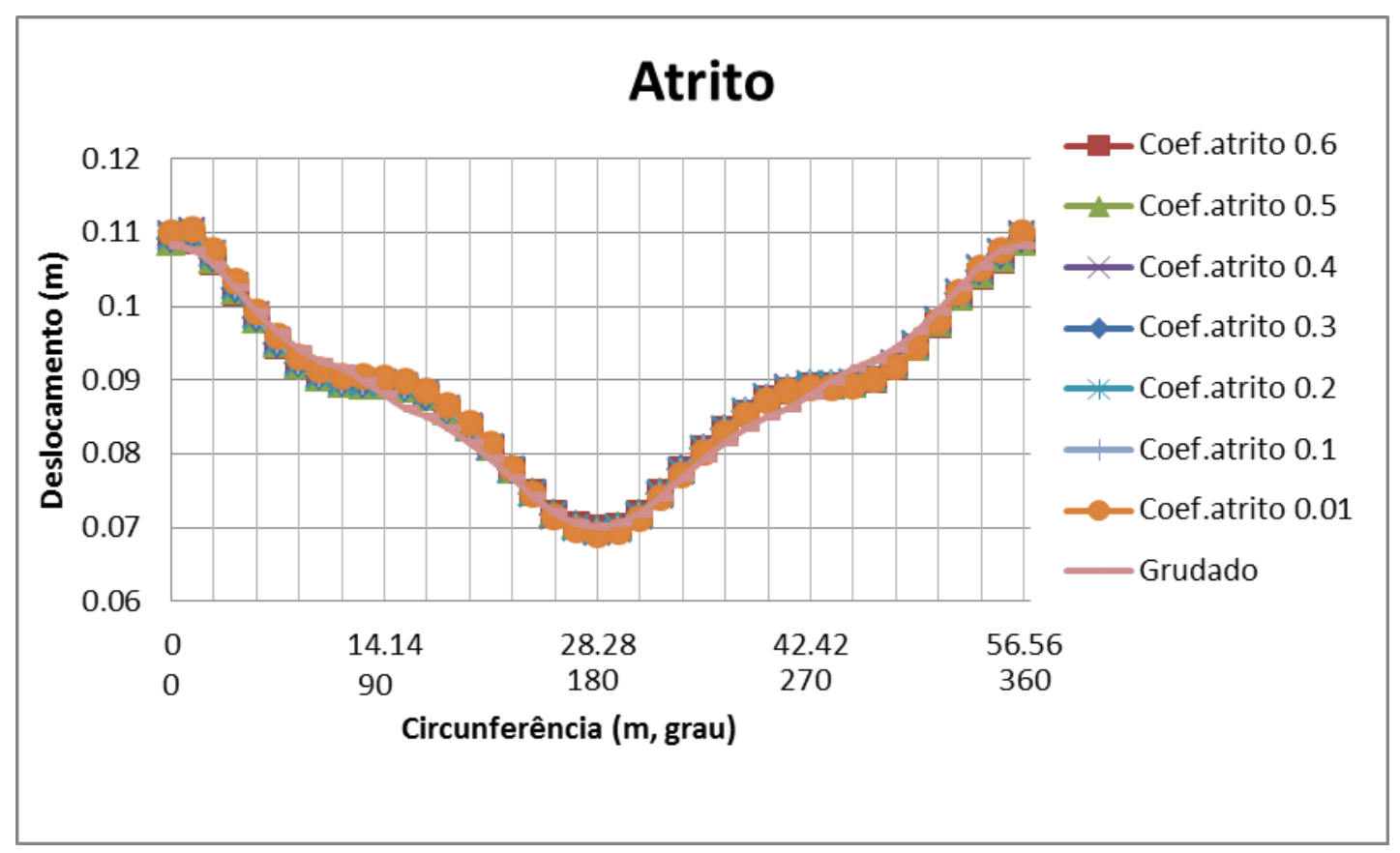

Figura A.3: Deslocamentos ao longo da superfície do suporte para diferentes coeficientes de atrito, 2D.

Neste gráfico é possível observar os deslocamentos verticais, em metros, no suporte. Os deslocamentos observados são em torno do suporte, partindo do topo da circunferência no sentido anti-horário. O gráfico ainda mostra o resultado do suporte grudado ao maciço, ou em condição de atrito infinito. Como se vê há uma pequena variação nos deslocamentos, ou quase nenhuma, o que torna o atrito dispensável para esta situação. Por ser um modelo simétrico é possível perceber a simetria dos resultados, o que valida de certa forma a simulação. 


\section{A.1.2 ANÁLISE EM TRÊS DIMENSÕES}

A análise em três dimensões tomou como referência um domínio cúbico, onde se verificou o efeito de um acréscimo de tensão $\Delta \sigma=83,3$ Pa numa faixa na superfície. Da mesma forma que no caso de duas dimensões, a geometria e os parâmetros utilizados não tem associação com nenhum caso específico. Além disto, a simulação também utilizou um "step", onde se verificou o efeito do acréscimo de tensão no suporte do túnel. A geometria do modelo é apresentada na Figura A.4, onde $D=18 \mathrm{~m}$ e corresponde ao diâmetro do túnel. Como condições de contorno foi assumido apoio de primeiro gênero, travando os deslocamentos na horizontal, tanto na face como nas laterais do modelo, e na vertical, na base do mesmo (Figura A.4).

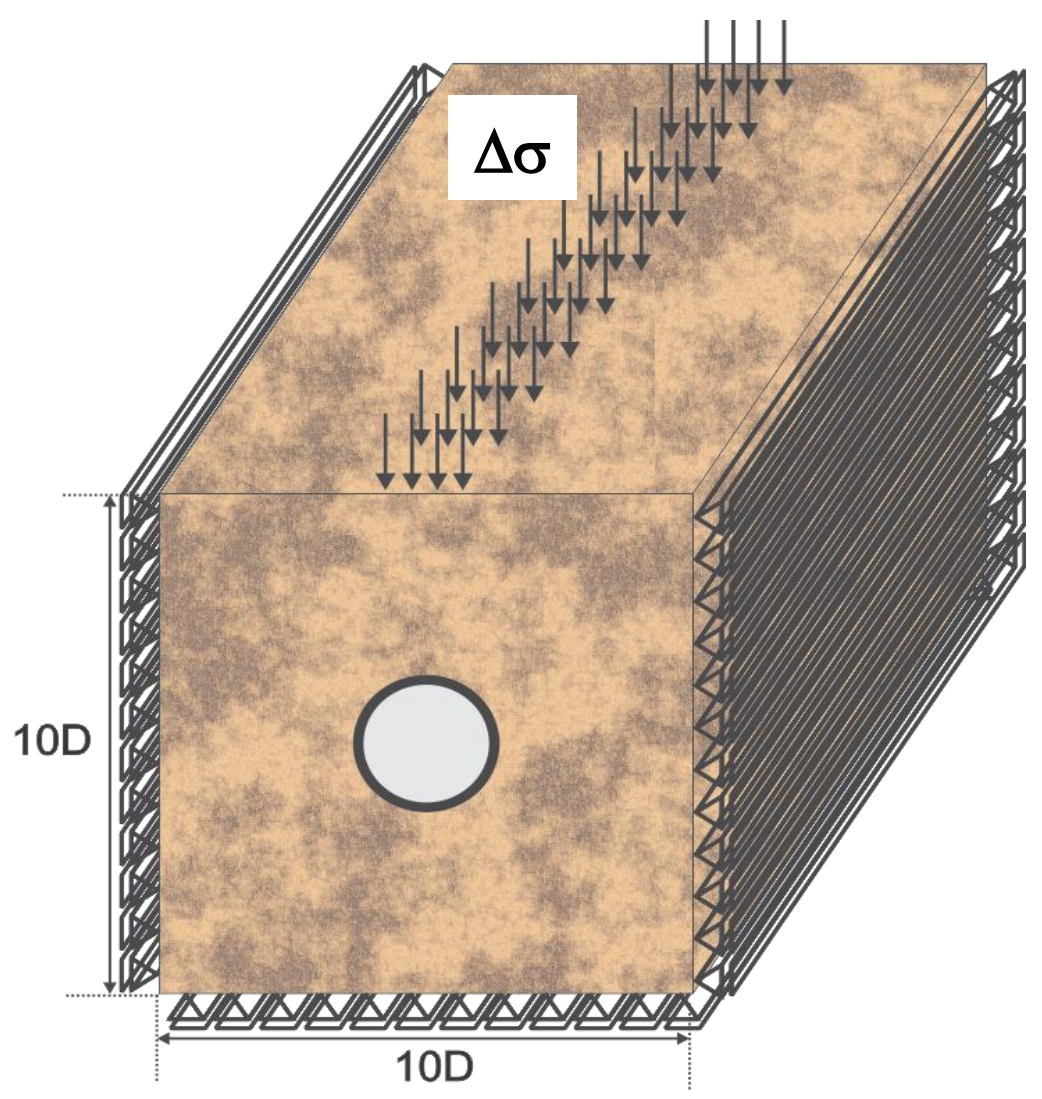

Figura A.4: Modelo cúbico para análise do atrito.

Observa-se que o modelo em três dimensões é uma extrapolação do modelo apresentado no Item A.1.1. Nesta situação o modelo de elementos finitos foi gerado com 24534 elementos sólido do tipo C3D10 (elementos contínuos tetraédrico com 10 nós) e 640 elementos de casca do tipo S4R (elemento "shell" com 4 nós), conforme mostra a Figura A.5 (manual do Abaqus 6.11, 2011). 


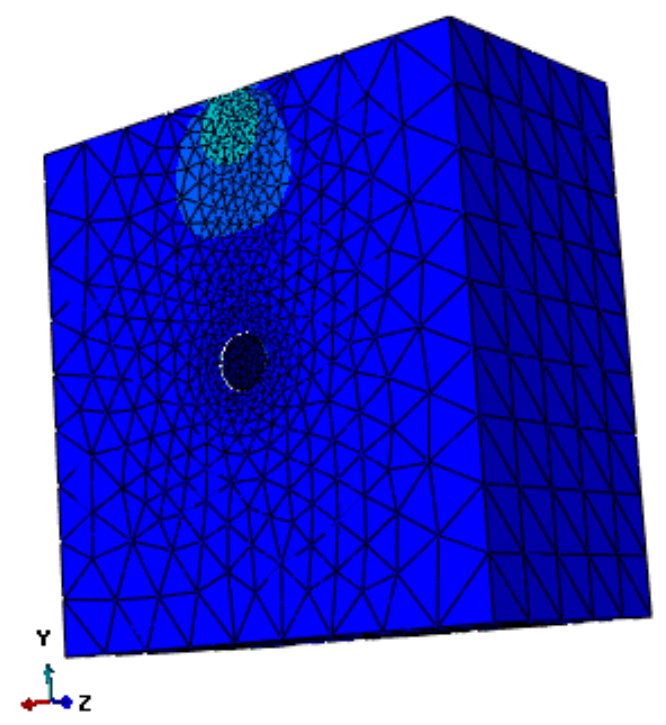

(a)

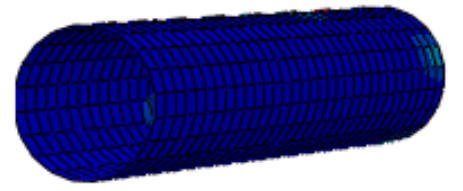

(b)

Figura A.5: Malha do modelo; (a) elementos sólidos, (b) elementos de casca.

Como no modelo plano de deformação, as propriedades consideradas levam em conta o maciço e suporte perfeitamente elástico. Além disto, foi considerado que o material é homogêneo e o meio é isotrópico. A Tabela A.1 resume as propriedades elásticas, também adotadas para este modelo, para o maciço e para o suporte.

Para esta situação foi verificado o efeito do atrito, caso em três dimensões, devido ao um acréscimo de tensão na superfície. Assim como no modelo plano de deformação (Item A.1.1), foi verificado o contato maciço-suporte com e sem atrito. Nesta situação, os resultados obtidos foram comparados com os resultados do Item A.1.1 para uma condição de atrito igual a 0,01 e para o caso do suporte aderido ao maciço. Por ser considerado um caso isotrópico, o atrito utilizado foi o mesmo para todas as direções do modelo. A Figura A.6 mostra os resultados obtidos para os diversos valores de atrito e a comparação com o modelo do Item A.1.1. 


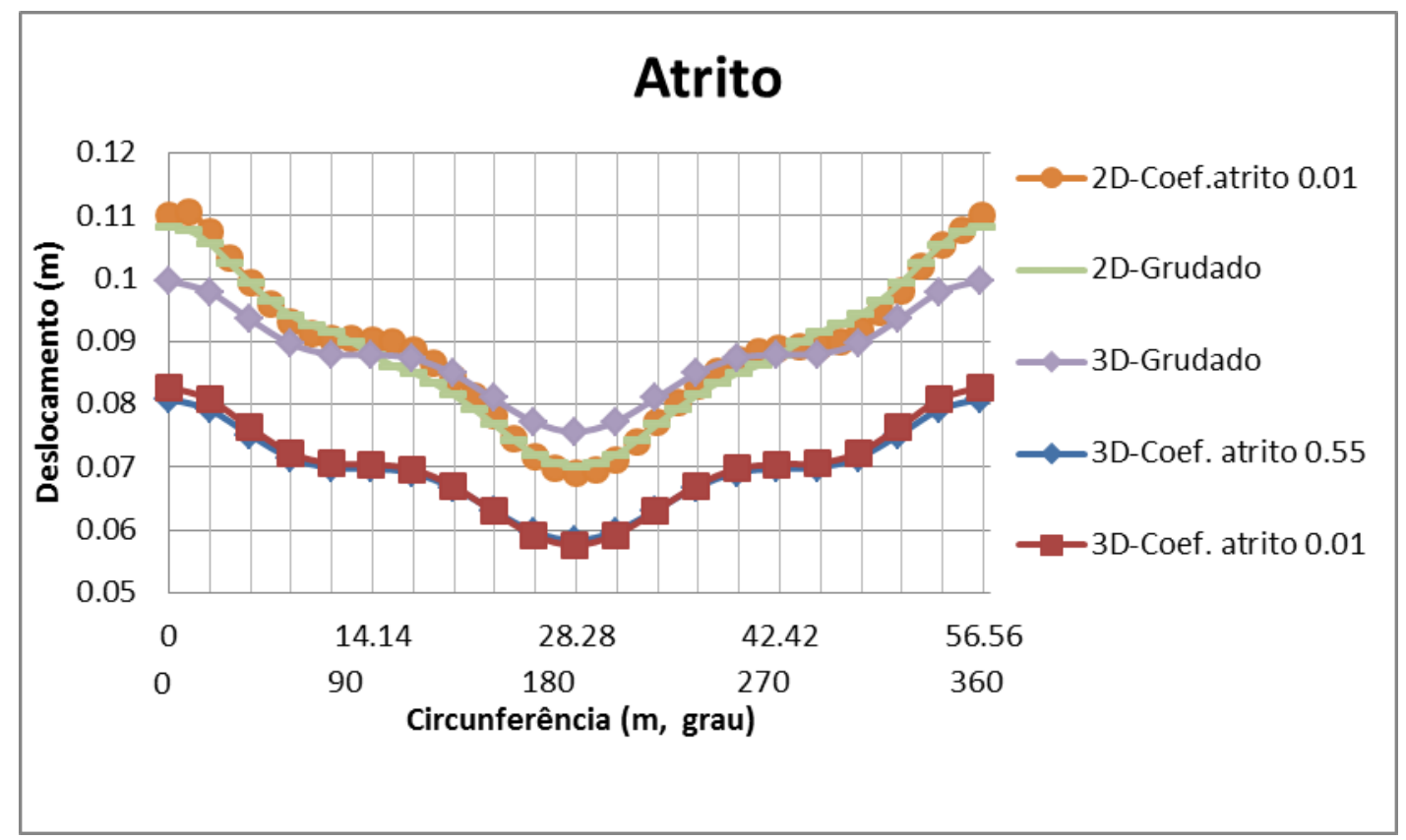

Figura A.6: Deslocamentos ao longo da superfície do suporte para diferentes atritos, 2D e 3D.

Neste gráfico é possível visualizar os deslocamentos verticais, em metros, no suporte. Os deslocamentos observados são em torno do suporte, partindo do topo da circunferência no sentido anti-horário. O gráfico ainda mostra o resultado do suporte grudado ao maciço para os modelos em duas e três dimensões. Estes dois casos são modelados de forma diferente, mas mostram resultados próximos dos obtidos no modelo plano de deformação (Item A.1.1). No primeiro caso duas geometrias são geradas e ligadas posteriormente. No segundo caso a casca é gerada na superfície escavada do túnel, ou seja, há apenas uma geometria. Para a situação que foi utilizado atrito, os deslocamentos não foram tão próximos. Nesta situação verifica-se que há uma ligação dos deslocamentos com o contato utilizado. Como é observado os deslocamentos verticais são menores com atrito, ou seja, nesta situação existe a possibilidade de favorecimento do subdimensionamento do suporte. De fato a consideração do atrito pode ser desprezível, visto que, a aderência do suporte ao maciço é bem considerável e por se tratar de modelo estático, o mesmo pode ser desprezível.

\section{A.2 ESCOLHA DO ELEMENTO FINITO PARA O SUPORTE}

Numa simulação em elementos finitos a escolha dos elementos é um processo importante na modelagem, visto que, os mesmos devem representar as condições da situação analisada. Em um túnel com estrutura de suporte é evidente a importância do mesmo e o mau dimensionamento pode gerar problemas irreversíveis. Para tanto se dá a importância do 
estudo de um elemento que possa representar o comportamento esperado de um suporte em um túnel.

O estudo foi realizado para um modelo em três dimensões com elementos tipo C3D10 para o maciço e dois tipos de elementos para o suporte. Para tanto se utilizaram elementos de cascas e elementos sólidos, elementos que podem ser diferenciados pelas as dimensões predominantes. Nos elementos sólidos as três dimensões são fundamentais para a simulação tensão/deslocamento de uma estrutura, já nos elementos de casca há apenas duas dimensões características. O comportamento do suporte, no primeiro momento foi verificado com elementos tipo S4R, caso de casca, e no segundo momento com C3D8R, caso de sólido (manual do Abaqus 6.11, 2011).

\section{A.2.1 MODELO GERAL}

O modelo em estudo é caso em que se acrescenta um carregamento $\Delta \sigma$ na superfície. A análise em três dimensões tomou como referência um domínio cúbico, onde se verificou o efeito deste acréscimo, $\Delta \sigma=83,3 \mathrm{~Pa}$, numa pequena área na superfície. Neste modelo a geometria e os parâmetros utilizados não têm associação com nenhum caso específico, mas as considerações e parâmetros adotados têm uma boa relação com um caso real. Para a simulação foi utilizado um "step", onde se verificou o efeito do acréscimo de tensão no suporte do túnel. A geometria do modelo é apresentada na Figura A.7, onde $D=18 \mathrm{~m}$ e corresponde ao diâmetro do túnel. Como condições de contorno foi assumido apoio de primeiro gênero, travando os deslocamentos na horizontal, tanto nas faces como nas laterais do modelo, e na vertical, na base do mesmo. A espessura do suporte " $t_{w}$ " foi adotada de maneira grosseira, mas, como foi dito, o modelo não representa nenhum caso real. Logicamente para um $t_{w}$ como este é evidente a inviabilidade econômica para a construção de qualquer túnel. 


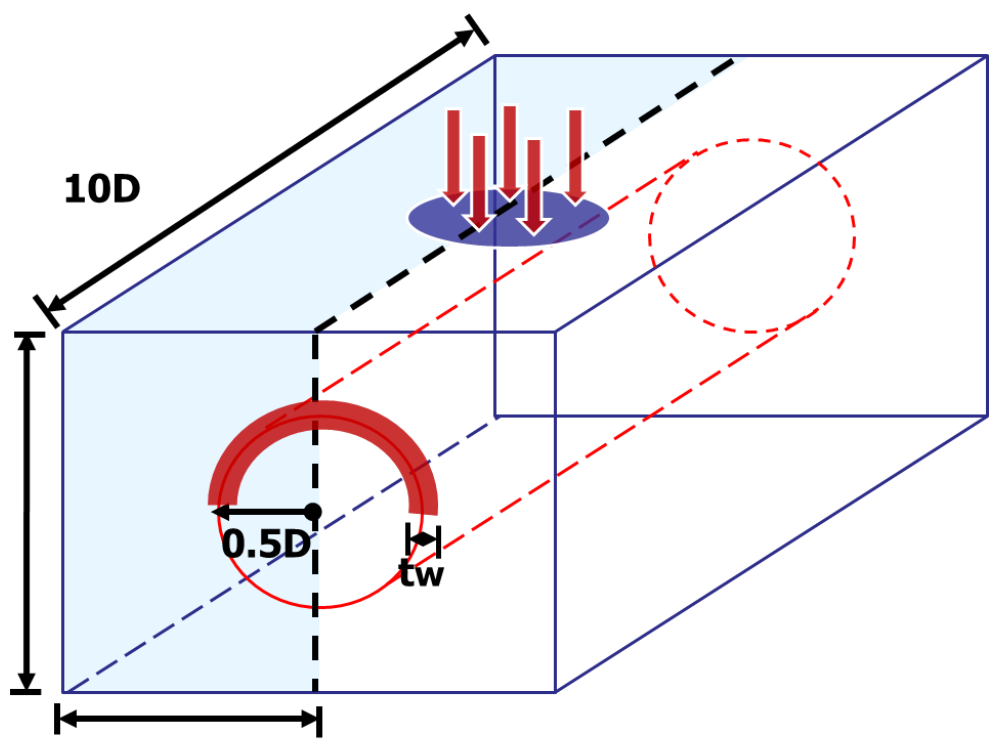

5D

Figura A.7: Geometria do modelo para análise dos elementos de suporte de um túnel.

Os parâmetros elásticos utilizados na simulação são mostrados na Tabela A.1, ou seja, a simulação considera o maciço e o suporte perfeitamente elástico.

\section{A.2.2 SUPORTE COM ELEMENTOS DE CASCA}

Elementos de casca são elementos em que uma das dimensões (espessura) é significativamente menor do que as outras. Estes tipos de elementos, normalmente, define a geometria de uma superfície e apresentam graus de liberdades para deslocamentos e rotações. Existem diversos tipos de elementos de cascas, um deles é o S4R e será utilizado nesta vericação. O elemento S4R é quadilateral, tensão/deslocamento, de 4 nós com integração reduzida e formulado para grandes deslocamentos (Figura A.8).

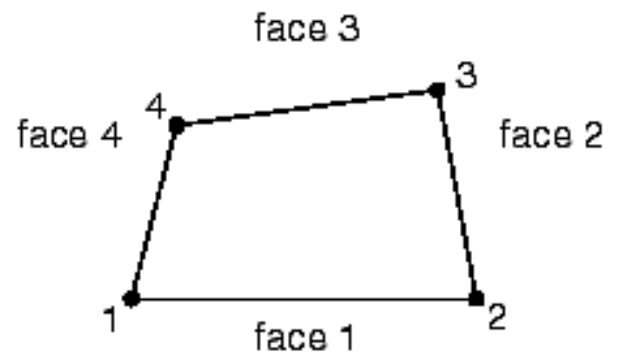

Figura A.8: Elemento casca com 4 nós.

$\mathrm{Na}$ construção da malha de elementos finitos, para o modelo com este tipo de elemento, foram utilizados 50781 elementos do tipo C3D10, onde C é referente ao meio contínuo em análises de tensão/deslocamento, 3D se refere ao espaço e 10 ao número de nós 
de cada elemento. Para o suporte foram utilizados 608 elementos do tipo S4R, onde S é referente à "shell", 4 é o número de nós de cada elemento e R é referente à integração reduzida, opcional (manual do Abaqus-6.11, 2011). Na Figura A.10 (a) e na Figura A.11(a) podem ser observados os tipos de elementos utilizados no modelo com suporte representado por elementos tipo casca.

\section{A.2.3 SUPORTE COM ELEMENTOS SÓLIDOS}

Elementos sólidos são utilizados para modelos em que as três dimensões têm uma significativa importância na relação tensão/deslocamento. Estes tipos de elementos, normalmente, definem uma geometria sólida como paralelepípedos e tetraedros e podem apresentam graus de liberdades para deslocamentos e rotações. Existem diversos tipos de elementos de sólidos, um deles é o C3D8R e será utilizado nesta verificação, na modelagem do suporte. O elemento C3D8R é "brick” de 8 nós com integração reduzida e formulado para análise de deformações nas três dimenções (Figura A.9).

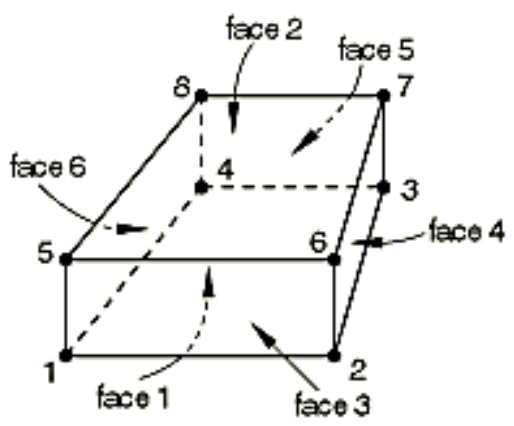

Figura A.9: Elemento sólido com 8 nós.

$\mathrm{Na}$ construção da malha de elementos finitos, para o modelo com este tipo de elemento, foram utilizados 43682 elementos do tipo C3D10, onde: C é referente ao meio contínuo em análises de tensão/deslocamento, 3D se refere ao espaço e 10 ao número de nós de cada elemento. Para o suporte foram utilizados 3040 elementos do tipo C3D8R, onde C é referente ao meio contínuo em análises de tensão/deslocamento, 3D se refere ao espaço, 8 ao número de nós de cada elemento e $\mathrm{R}$ é referente à integração reduzida, opcional. Na Figura A.10 (b) e na Figura A.11 (b) podem ser observados os tipos de elementos utilizados no modelo com suporte representado por elementos tipo sólido. 


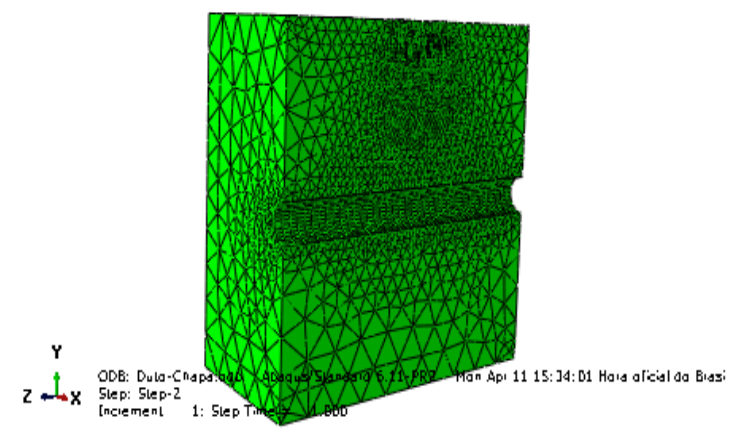

(a)

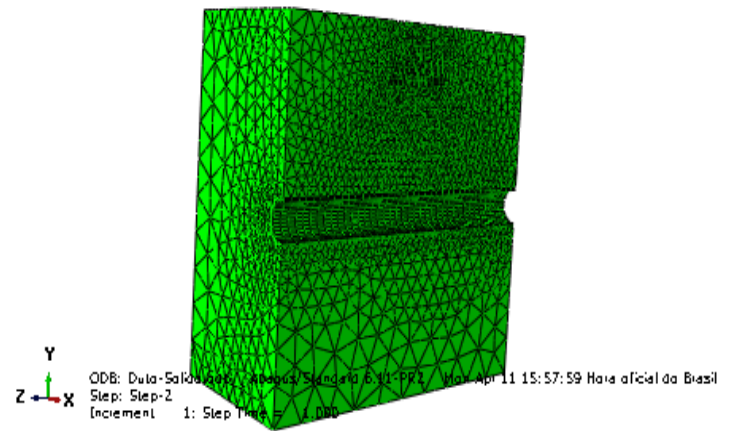

(b)

Figura A.10: Malha para o maciço - (a) utilizando elementos de casca, (b) utilizando elementos sólidos.

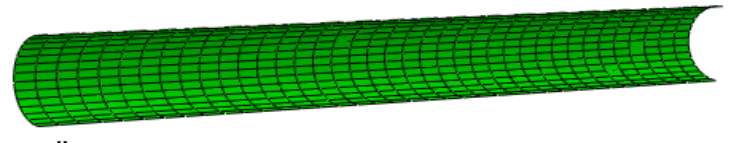

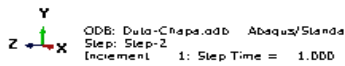

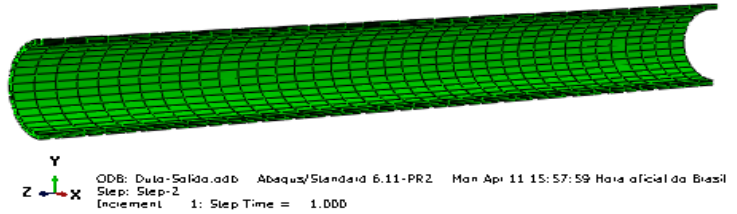

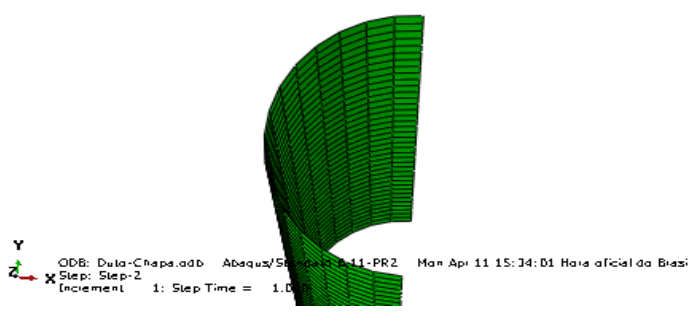

(a)

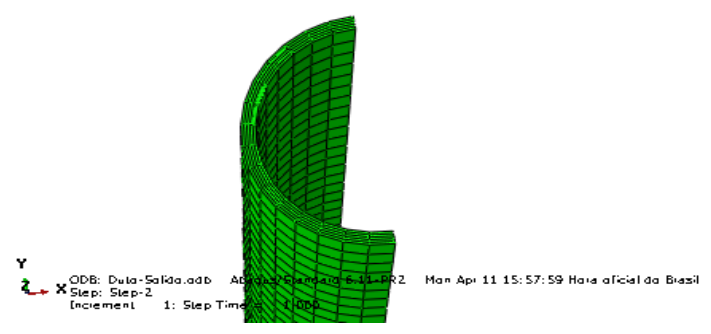

(b)

Figura A.11: Malha do suporte - (a) utilizando elementos de casca, (b) utilizando elementos sólidos.

\section{A.2.4 RESULTADOS}

Os resultados obtidos nas duas simulações foram comparados e serão mostrados no próximo item. Observa-se que existiu pouca diferença entres a malhas, os números de elementos das malhas foram próximos, e as condições de contorno e carregamento foram as mesmas. Desta forma, a variação do resultado não deve ser levada em conta. A Figura A.12 mostra os resultados para as duas situações, no caso são mostradas a variação das tensões de Von Mises. 

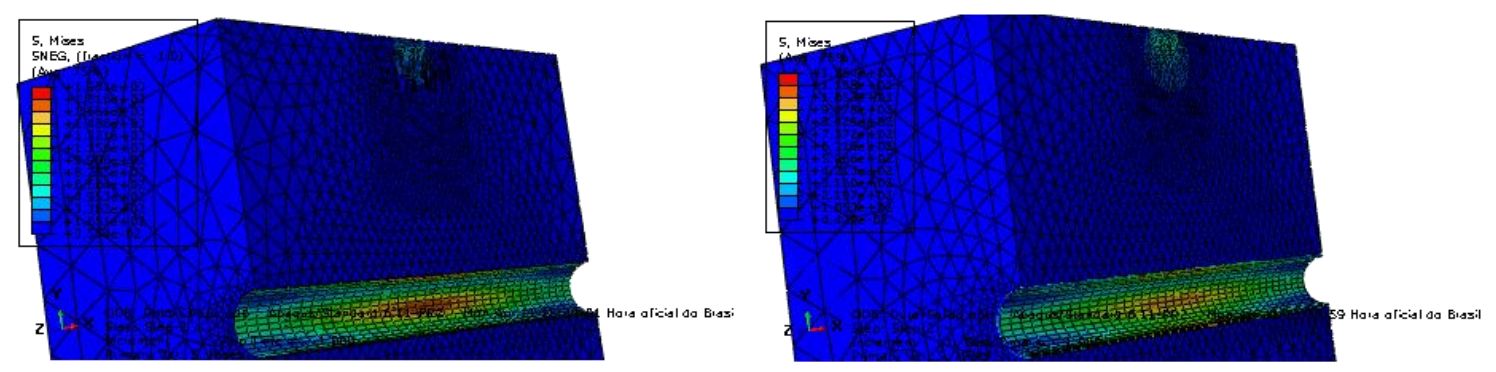

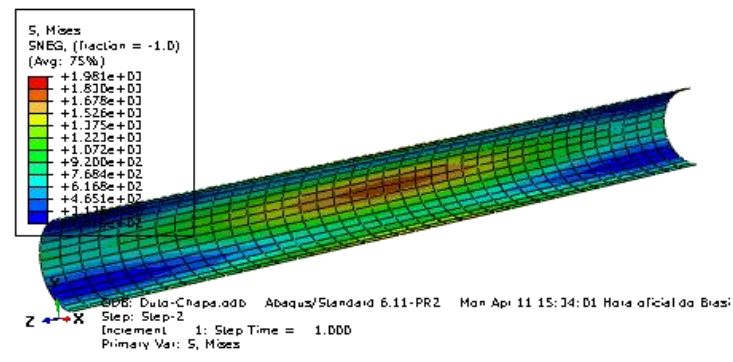

(a)

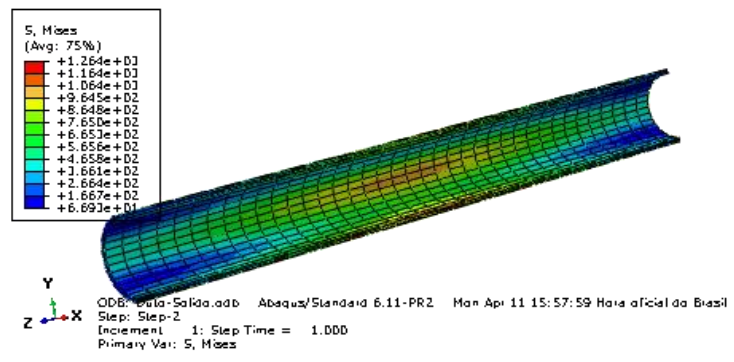

(b)

Figura A.12: Tensões de Von Mises - (a) utilizando elementos de casca, (b) utilizando elementos sólidos.

Com vista às figuras acima, percebe-se que as tensões estão concentradas próximo à superfície (onde o carregamento foi aplicado) e na parede do suporte. Mesmo com uma boa aproximação entre os dois resultados, observa-se que no suporte com elemento de casca as tensões que chagam são maiores que no caso de suporte com elemento de sólido. Como se vê os elementos sólidos recebem menos carregamento, ou seja, boa parte pode não ser percebida. Este fato pode ser causado por um mau refinamento na espessura ou pelo o próprio elemento não ser o mais apropriado para a situação. Dessa forma os resultados podem fugir daqueles esperados para o caso em análise.

Com base nos resultados obtidos pelos modelos numéricos, foram plotados alguns gráficos de comparação. Primeiramente foi plotado o gráfico de comparação das tensões verticais ao longo da profundidade, Figura A.13, desde a superfície até a base do modelo. Os resultados foram tirados de um eixo de referencia vertical que passa pelo centro de aplicação do carregamento. 


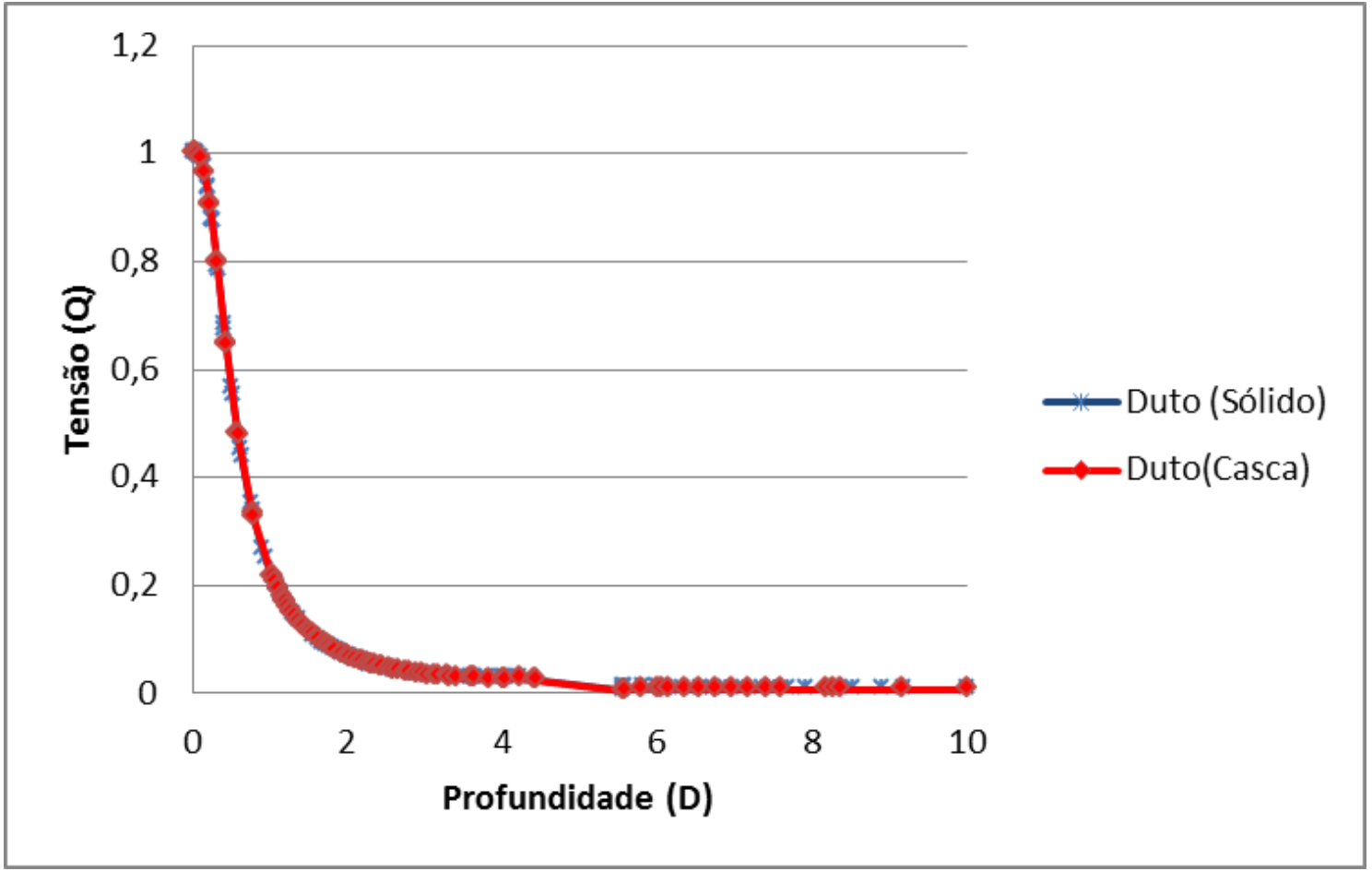

Figura A.13: Verificação das tensões atuantes no maciço.

Observa-se que as tensões para os dois modelos apresentaram o mesmo comportamento e que as mesmas foram, se não iguais, muito próximas. Desta forma os dois modelos podem ser validados quanto às condições de contorno e carregamento.

A comparação das duas simulações numéricas servirá para entender o comportamento de cada elemento de suporte analisado. É evidente que existe uma variedade de elementos que podem ser estudados para esta situação, mas todos os outros podem ser entendidos como variações destes elementos. Para saber o quanto a escolha do elemento afeta os resultados, serão mostrados a seguir a comparação entre os deslocamentos ocorridos no suporte em cada caso. A Figura A.14 mostra o eixo que foi considerado para obtenção destes resultados, eixo $\mathrm{Z}$ na superfície do suporte. 


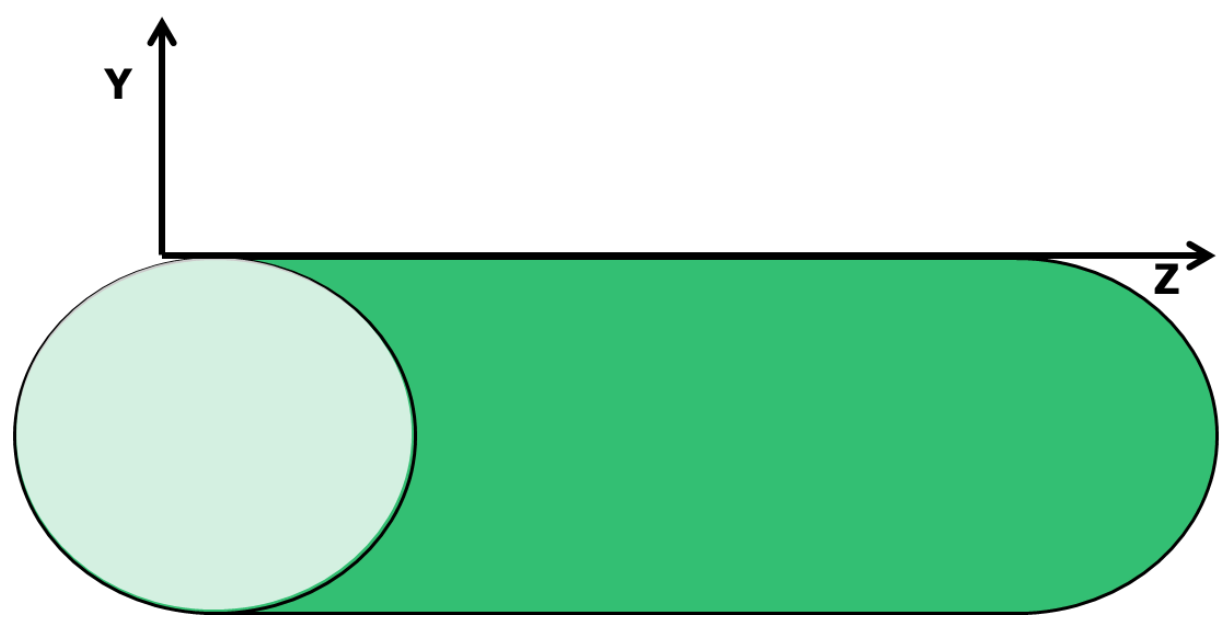

Figura A.14: Eixos de referências para utilizados na interpretação dos resultados.

A figura acima mostra dois eixos, $\mathrm{Y}$ e Z, que foram considerados para a obtenção dos deslocamentos ao longo da superfície do suporte, Figura A.15. O eixo Z representa a direção desta superfície e o eixo Y o sentido dos deslocamentos observados.

O gráfico a seguir, Figura A.15, mostra a comparação dos deslocamentos obtidos nas duas simulações. Para tanto, os deslocamento e o afastamento ao longo da direção Z foram adimensionalizados pelo diâmetro do túnel.

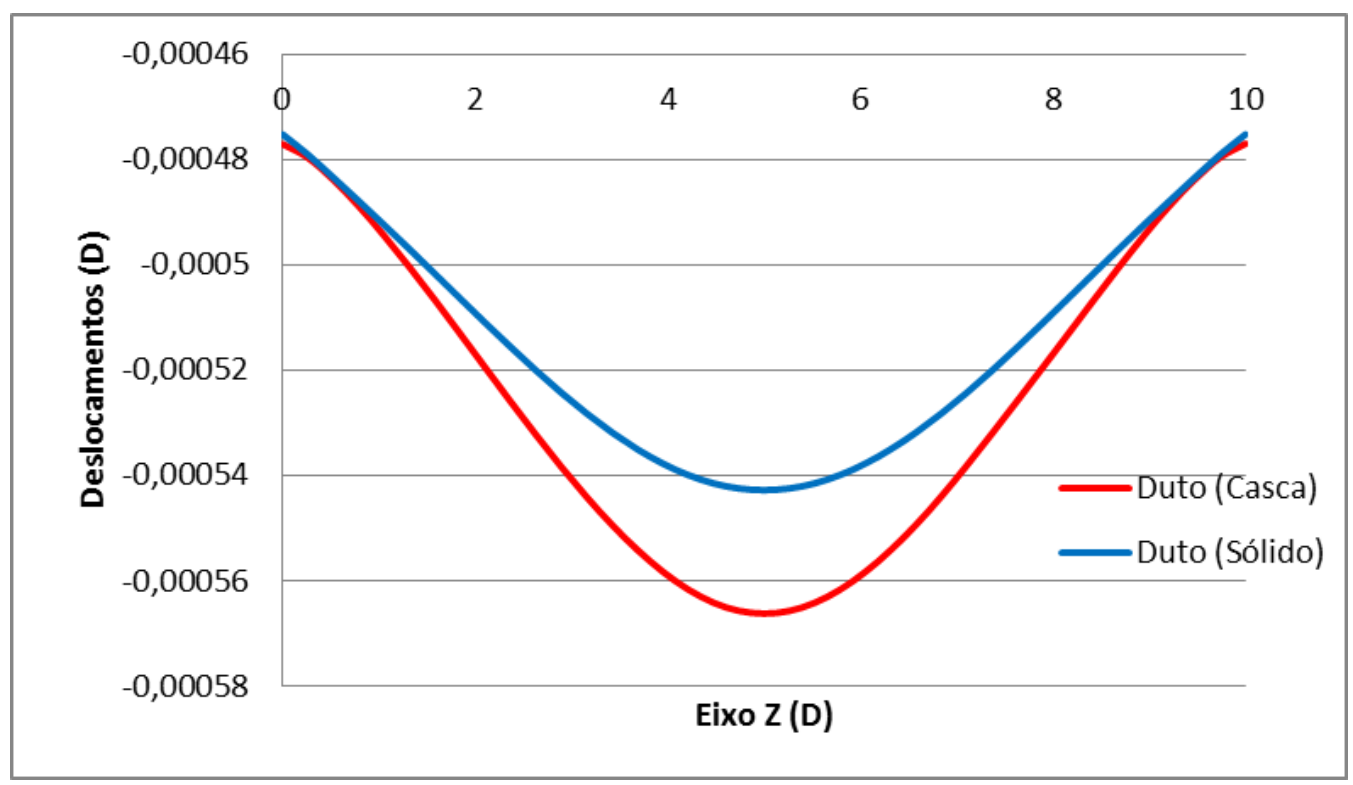

Figura A.15: Deslocamentos ao longo do eixo $\mathrm{Z}$ adimensionalizados pelo diâmetro.

Observa-se que nas duas soluções numéricas os deslocamentos no suporte são maiores na região de aplicação do carregamento. Sabe-se que numa situação real as condições geostáticas, bem como outras variáveis do meio, deveriam ser levadas em consideração. De fato este é um modelo simplificado, em que o foco não é a simulação de um problema real e 
sim a comparação de resultados entre os elementos finitos em estudo. No gráfico acima, ainda é possível observar a variação dos deslocamentos no suporte para os dois modelos. Verificase também que esta variação é maior próximo ao eixo de aplicação do carregamento e menor quando se afastam deste. Por serem deslocamentos muito pequenos, a variação entre as curvas parece ser muito grande e o erro pode ser entendido alto. Se o erro for convertido para uma unidade de média de comprimento, verifica-se que nesta situação é de 0,36 mm ou desprezíveis.

De fato o modelo pode não representar uma situação geral, mas os resultados mostram que existem variações no comportamento quando se utiliza diferentes elementos. Muitos autores sugerem que para suporte é mais adequando utilizar elementos de casca, visto que: a quantidade de elementos diminui, o modelo é simplificado e os problemas com os elementos devido ao refinamento (distorção, volume zero, entre outros) não aparecem. Tudo isso leva a uma diminuição nos custos computacionais, fato mais relevante numa simulação numérica. 